\title{
A STUDY OF CONSTANT VOLTAGE ANEMOMETRY FREQUENCY RESPONSE
}

\author{
A Thesis \\ presented to \\ the Faculty of California Polytechnic State University, \\ San Luis Obispo
}

\author{
In Partial Fulfillment \\ of the Requirements for the Degree \\ Master of Science in Mechanical Engineering
}

by

Alex Douglas Powers

June 2016 
(C) 2016

Alex Douglas Powers

ALL RIGHTS RESERVED 


\section{COMMITTEE MEMBERSHIP}

TITLE:

AUTHOR:

DATE SUBMITTED:

COMMITTEE CHAIR:

COMMITTEE MEMBER:

COMMITTEE MEMBER:
A Study of Constant Voltage Anemometry Frequency Response

Alex Douglas Powers

June 2016
Russell V. Westphal, Ph.D.

Professor of Mechanical Engineering

Christopher C. Pascual, Ph.D.

Professor of Mechanical Engineering

William R. Murray, Ph.D.

Professor of Mechanical Engineering 


\begin{abstract}
A Study of Constant Voltage Anemometry Frequency Response
\end{abstract}

Alex Douglas Powers

The development of the constant voltage anemometer (CVA) for the boundary layer data system (BLDS) has been motivated by a need for the explicit autonomous measurement of velocity fluctuations in the boundary layer. The frequency response of a sensor operated by CVA has been studied analytically and experimentally. The thermal lag of the sensor is quantified by a time constant, $M_{C V A}$. When the time constant is decreased, the half-amplitude cut-off frequency, $f_{C V A}$, is increased, thereby decreasing the amount of attenuation during measurements. In this thesis, three main approaches have been outlined in theory and tested experimentally to determine the feasibility and effectiveness of implementing them with CVA to limit attenuation: operation at higher $V_{w}$, implementation of software compensation, and utilization of smaller diameter sensors. Operation of CVA at higher voltage results in little improvement in frequency response but is accompanied by increased danger of wire burnout. However, sensors do need to be operated at high wire voltages to be more sensitive to velocity fluctuations and less sensitive to temperature fluctuations, without reaching a temperature high enough for wire burnout. Software compensation of the CVA output has been shown not to be useful for measurements with BLDS. The electrical noise present in the CVA measurement system is amplified by the correction algorithm and creates measurements that are not representative of the fluctuations being measured. Decreasing sensor diameter leads to a significant decrease of $M_{C V A}$ and therefore increase of $f_{C V A}$. Under similar operating conditions, a 2.5 micron diameter sensor showed less roll off in the frequency spectra (measured higher turbulence intensities) than a 3.8 micron diameter sensor for tests in both a turbulent jet and in a turbulent boundary layer. Smaller sensors are more fragile and have been shown to have a decrease in sensitivity as compared to larger sensors; however, for some applications, the increase in frequency response may be worth the trade-off with fragility and sensitivity.

Keywords: Hot-wire, constant voltage anemometer, boundary layer, calibration jet apparatus, BLDS, frequency response, transition, turbulence intensity, turbulent jet, anemometry 


\section{ACKNOWLEDGMENTS}

Thank you my God, for giving me grace and peace at all times. All praise, honor, and glory belongs to you and I cannot even take credit for this work I have done because it is you, my father, that has allowed me to complete it. I would not be where I am without constantly focusing on who you are.

Words do not even begin to describe how wonderful my fiancée Sarah is. Thank you for all the love, joy, and support that you give me; I do not deserve you.

Dr. Russ Westphal, you have given me so much advice and knowledge, and it has been an absolute joy to learn from you and spend this year working so closely with you. I am extremely grateful for all the opportunities you have given me and for our time together. Thank you for not only being an advisor, but also a friend.

I would also like to thank Dr. Christopher Pascual and Dr. William Murray for serving on my committee and giving suggestions for this work.

Thank you to Kris Lawrence, Jakob Graf, Jacob Phillips, and Ruben Botello for your help and companionship while working on this project.

Thanks to Don Frame for his selfless efforts and expertise in building CVA I and CVA II.

I would also like to thank Northrop Grumman Corp. for their support of the BLDS

projects and of my thesis. Thank you to Anne Sullivan and Tom Duncan for your support of hot-wire work in conjunction with the BLDS.

Finally, I would like to thank my family and all of my friends for their support and encouragement throughout all of my education. 


\section{TABLE OF CONTENTS}

\section{Page}

LIST OF TABLES viii

LIST OF FIGURES .................................................................................. ix

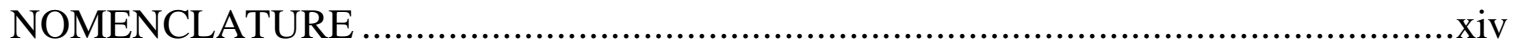

\section{CHAPTER}

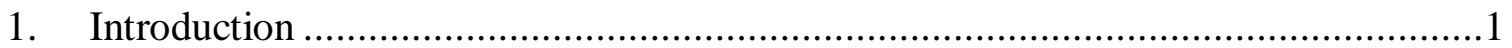

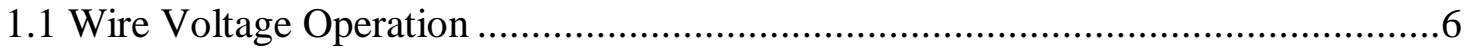

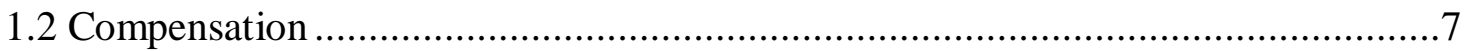

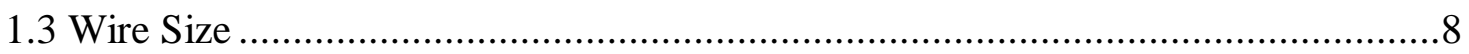

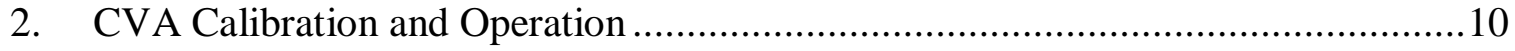

2.1 CVA Systems ................................................................................... 10

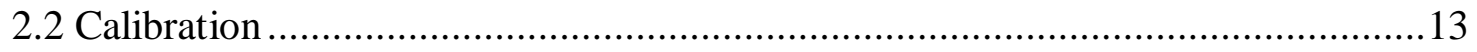

2.3 Turbulent Jet Measurements..................................................................... 17

2.4 Boundary Layer Measurements ...................................................................22

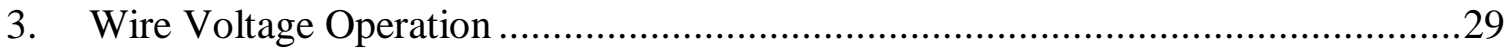

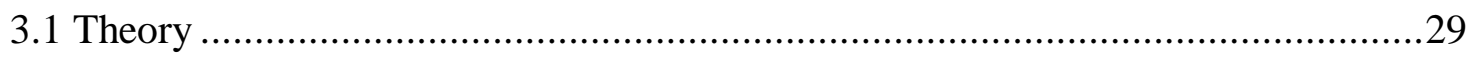

3.2 Turbulent Jet Measurements with $10 \mathrm{~mm}$ Nozzle ............................................32

3.3 Turbulent Jet Measurements with 5 mm Nozzle ..............................................34

3.4 Boundary Layer Measurements .............................................................. 38

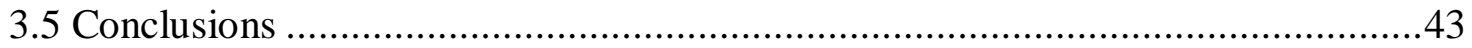

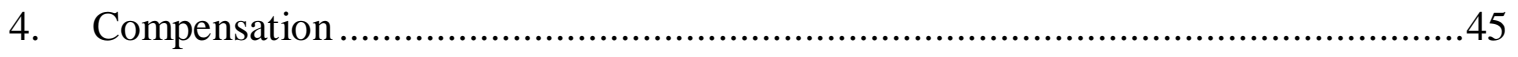

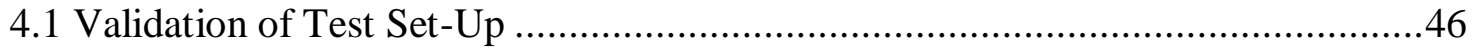


4.2 Software Compensated Turbulent Jet Data .................................................48

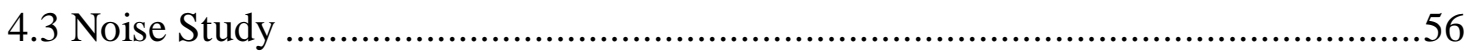

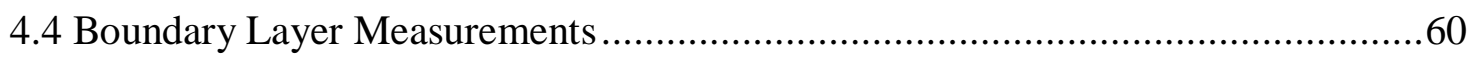

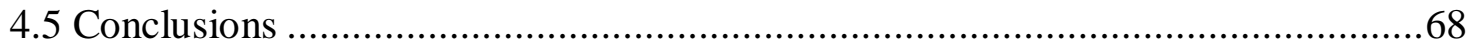

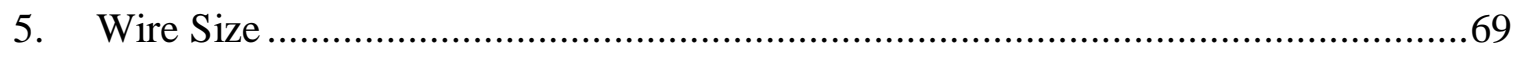

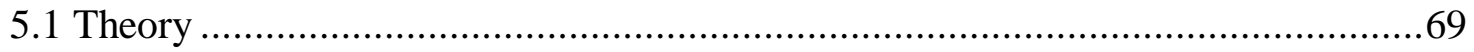

5.2 Turbulent Jet Measurements............................................................... 70

5.3 Boundary Layer Measurements ................................................................ 77

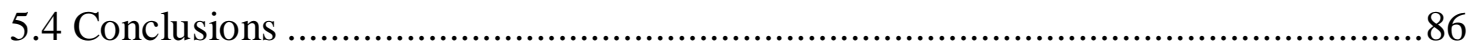

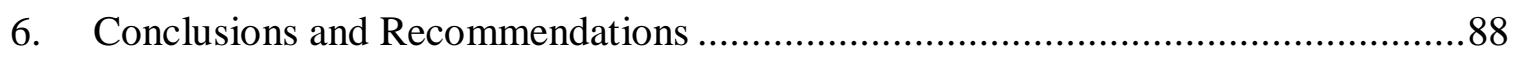

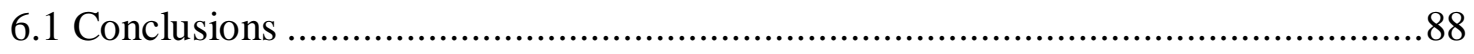

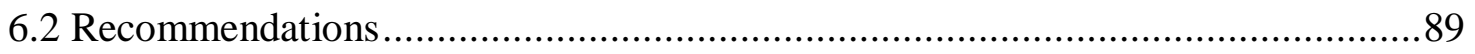

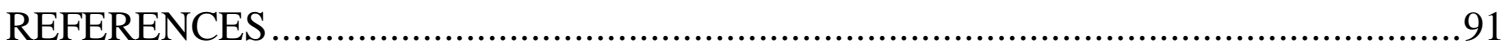

APPENDICES

APPENDIX A. CVA Operating Procedure ...................................................93

APPENDIX B. $\quad$ Updated Jet Apparatus ...........................................................97

APPENDIX C. Labview Front Panels ............................................................ 100

APPENDIX D. Uncertainty Analysis for Boundary Layer Origin ......................... 102

APPENDIX E. $\quad$ Updated Thermal Electrical Model (EES Code) .......................... 103

APPENDIX F. Radiation Heat Transfer Model and Calculations .......................... 107 


\section{LIST OF TABLES}

Table

Page

Table 3.1 Variation in corrected half amplitude cut-off frequency for a TSI 3.8 micron sensor at freestream velocity of $22 \mathrm{~m} / \mathrm{s}$, resulting in OHR $=1.6$

Table 4.1 Comparisons between mean and RMS data measured with a Fluke DVM and data calculated from a time series acquired with the NI DAQ

Table 4.2 Comparison of RMS voltage measurements recorded with the laptop plugged in to AC power or unplugged. 


\section{LIST OF FIGURES}

Figure Page

Figure 1.1 Commercial hot wire probe (TSI 1210-T1.5) and diagram of probe in flow

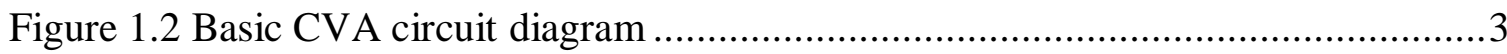

Figure 1.3 Plot of varying frequency sine waves added together to demonstrate

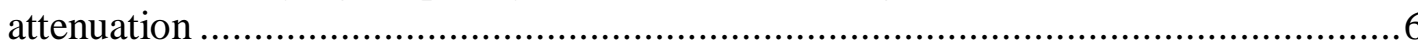

Figure 1.4 Predicted effect of $V_{w}$ on overheat ratio and the half amplitude cut-off

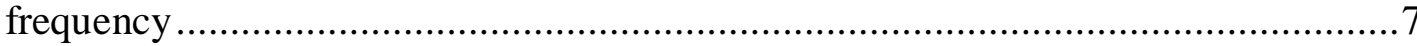

Figure 1.5 Theoretical half amplitude cutoff frequency, $f_{C V A}$, for various sensor diameters

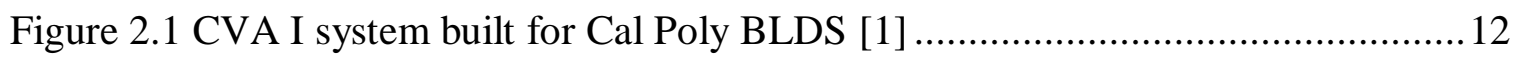

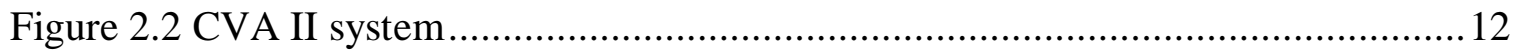

Figure 2.3 Annotated diagram of calibration set-up.................................................. 14

Figure 2.4 Initial CVA calibration compared with Ryan Murphy's calibration ................15

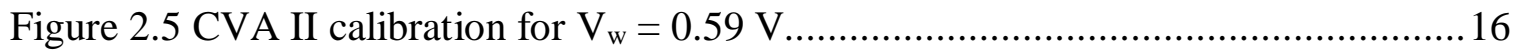

Figure 2.6 Diagram illustrating centerline turbulence measurements .............................18

Figure 2.7 Image used to determine hot wire distance from nozzle outlet ....................... 18

Figure 2.8 Comparison of turbulence intensity results measured on the centerline of the turbulent jet for similar operating conditions ....................................................19

Figure 2.9 Mean local velocities at each point on the centerline of the turbulent jet with curve fit to show the drop off that behaves like the inverse of distance ...........20

Figure 2.10 Turbulence intensities measured in a circular turbulent jet [18] ..................21

Figure 2.11 Analog spectrum analysis of CVA signal for sensor 5 inches away from

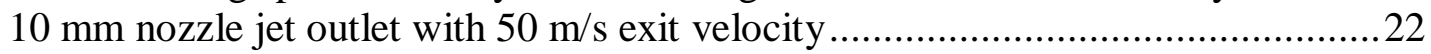

Figure 2.12 Line diagram of boundary layer measurement set up in Cal Poly Wind

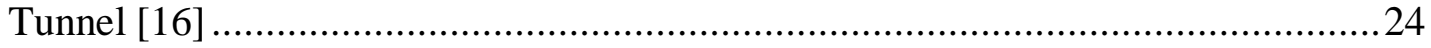

Figure 2.13 Layout of boundary layer measurement set up in Cal Poly Wind Tunnel .....24

Figure 2.14 Digital microscope in position to capture sensor distance from plate .26 
Figure 2.15 Images used to measure starting sensor distance from plate. .26

Figure 2.16 Sample mean velocity profile from initial boundary layer tests with CVA 28

Figure 2.17 Initial boundary layer measurements compared with Li and Klebanoff

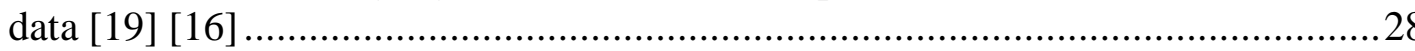

Figure 3.1 Comparison of mean local velocities at each point on the centerline of the turbulent jet with $10 \mathrm{~mm}$ diameter nozzle at $50 \mathrm{~m} / \mathrm{s}$ jet exit velocity

Figure 3.2 Comparison of turbulence intensities at each point on the centerline of the turbulent jet with $10 \mathrm{~mm}$ diameter nozzle at $50 \mathrm{~m} / \mathrm{s}$ jet exit velocity.

Figure 3.3 Comparison of local mean velocities at each point on the centerline of the turbulent jet with $5 \mathrm{~mm}$ diameter nozzle at $50 \mathrm{~m} / \mathrm{s}$ jet exit velocity.....

Figure 3.4 Comparison of turbulence intensities at each point on the centerline of the turbulent jet with $5 \mathrm{~mm}$ diameter nozzle at $50 \mathrm{~m} / \mathrm{s}$ jet exit velocity .36

Figure 3.5 Comparison of local mean velocities at each point on the centerline of the turbulent jet with $5 \mathrm{~mm}$ diameter nozzle at $25 \mathrm{~m} / \mathrm{s}$ jet exit velocity.....

Figure 3.6 Comparison of turbulence intensities at each point on the centerline of the turbulent jet with $5 \mathrm{~mm}$ diameter nozzle at $25 \mathrm{~m} / \mathrm{s}$ jet exit velocity.

Figure 3.7 Sample $\mathrm{I}_{\mathrm{w}}$ calibration for $\mathrm{V}_{\mathrm{w}}=0.48 \mathrm{~V}$ used for boundary layer measurements at $\mathrm{U}=23 \mathrm{~m} / \mathrm{s}$ and $\mathrm{f}_{\mathrm{s}}=2.5 \mathrm{kHz}$

Figure 3.8 Sample $\mathrm{I}_{\mathrm{w}}$ calibration for $\mathrm{V}_{\mathrm{w}}=0.58 \mathrm{~V}$ used for boundary layer measurements at $\mathrm{U}=23 \mathrm{~m} / \mathrm{s}$ and $\mathrm{f}_{\mathrm{s}}=2.5 \mathrm{kHz}$

Figure 3.9 Mean velocities at each point for each $\mathrm{V}_{\mathrm{w}}$ test plotted for boundary layer measurements at $\mathrm{U}=23 \mathrm{~m} / \mathrm{s}$ and $\mathrm{f}_{\mathrm{s}}=2.5 \mathrm{kHz}$

Figure 3.10 Turbulence intensities for each $\mathrm{V}_{\mathrm{w}}$ test for boundary layer measurements at $\mathrm{U}=23 \mathrm{~m} / \mathrm{s}$ and $\mathrm{f}_{\mathrm{s}}=2.5 \mathrm{kHz}$.

Figure 3.11 Frequency spectra for each $\mathrm{V}_{\mathrm{w}}$ test for the closest point to the wall at $\mathrm{U}$ $=23 \mathrm{~m} / \mathrm{s}$ and $\mathrm{f}_{\mathrm{s}}=2.5 \mathrm{kHz}$.

Figure 3.12 Frequency spectra for each $\mathrm{V}_{\mathrm{w}}$ test halfway through the boundary layer at $\mathrm{U}=23 \mathrm{~m} / \mathrm{s}$ and $\mathrm{f}_{\mathrm{s}}=2.5 \mathrm{kHz}$

Figure 3.13 Frequency spectra for each $V_{w}$ test for a freestream point at $U=23 \mathrm{~m} / \mathrm{s}$ and $\mathrm{f}_{\mathrm{s}}=2.5 \mathrm{kHz}$

Figure 4.1 Oscilloscope output for $\mathrm{I}_{\mathrm{w}}$ signal in the centerline of a turbulent jet. 
Figure 4.2 Plot of time series data for $\mathrm{I}_{\mathrm{w}}$ signal in the centerline of a turbulent jet taken with LabVIEW code and NI USB-6009 DAQ......

Figure $4.3 \mathrm{I}_{\mathrm{w}}$ calibration used for $10 \mathrm{~mm}$ nozzle measurements ...............................50

Figure $4.4 \mathrm{I}_{\mathrm{w}}$ calibration used for $5 \mathrm{~mm}$ nozzle measurements ..................................51

Figure 4.5 Comparison between mean local velocity measurements for $10 \mathrm{~mm}$ nozzle and $50 \mathrm{~m} / \mathrm{s}$ jet exit velocity for compensated and uncompensated data

Figure 4.6 Comparison between mean local velocity measurements for $5 \mathrm{~mm}$ nozzle and $50 \mathrm{~m} / \mathrm{s}$ jet exit velocity for compensated and uncompensated data

Figure 4.7 Comparison between turbulence intensity measurements for $10 \mathrm{~mm}$ nozzle and $50 \mathrm{~m} / \mathrm{s}$ jet exit velocity for compensated and uncompensated data

Figure 4.8 Comparison between turbulence intensity measurements for $5 \mathrm{~mm}$ nozzle and $50 \mathrm{~m} / \mathrm{s}$ jet exit velocity for compensated and uncompensated data

Figure 4.9 Comparison of compensated and uncompensated power spectral densities for $\mathrm{x} / \mathrm{D}=0.3$ on the centerline of the turbulent jet for $10 \mathrm{~mm}$ nozzle and $50 \mathrm{~m} / \mathrm{s}$ jet exit velocity

Figure 4.10 Comparison of compensated and uncompensated power spectral densities for $\mathrm{x} / \mathrm{D}=0.4$ on the centerline of the turbulent jet for $5 \mathrm{~mm}$ nozzle and $50 \mathrm{~m} / \mathrm{s}$ jet exit velocity

Figure 4.11 Comparison of compensated and uncompensated power spectral densities for $\mathrm{x} / \mathrm{D}=7.6$ on the centerline of the turbulent jet for $10 \mathrm{~mm}$ nozzle and $50 \mathrm{~m} / \mathrm{s}$ jet exit velocity ......

Figure 4.12 Comparison of compensated and uncompensated power spectral densities for $\mathrm{x} / \mathrm{D}=15.1$ on the centerline of the turbulent jet for $5 \mathrm{~mm}$ nozzle and $50 \mathrm{~m} / \mathrm{s}$ jet exit velocity

Figure 4.13 Comparison of compensated and uncompensated power spectral densities for $\mathrm{x} / \mathrm{D}=12.7$ on the centerline of the turbulent jet for $10 \mathrm{~mm}$ nozzle and $50 \mathrm{~m} / \mathrm{s}$ jet exit velocity

Figure 4.14 Comparison of compensated and uncompensated power spectral densities for $\mathrm{x} / \mathrm{D}=25.3$ on the centerline of the turbulent jet for $5 \mathrm{~mm}$ nozzle and $50 \mathrm{~m} / \mathrm{s}$ jet exit velocity .56

Figure 4.15 Centerline turbulence measurements using a gain of 4 on a $1.24 \mathrm{~V}$ offset signal for a $5 \mathrm{~mm}$ diameter nozzle and $\mathrm{U}=50 \mathrm{~m} / \mathrm{s}$

Figure 4.16 $\mathrm{V}_{\mathrm{s}}$ calibration for $\mathrm{V}_{\mathrm{w}}=0.58 \mathrm{~V}$ used for boundary layer measurements at $\mathrm{U}=23 \mathrm{~m} / \mathrm{s}$ and $\mathrm{f}_{\mathrm{s}}=20 \mathrm{kHz}$ 
Figure 4.17 Mean velocity data at each point measured in the boundary layer for $U$ $=22 \mathrm{~m} / \mathrm{s}, \mathrm{V}_{\mathrm{w}}=0.58 \mathrm{~V}$, and $\mathrm{f}_{\mathrm{s}}=20 \mathrm{kHz}$

Figure 4.18 Turbulence intensities at each point measured in the boundary layer for $\mathrm{U}=22 \mathrm{~m} / \mathrm{s}, \mathrm{V}_{\mathrm{w}}=0.58 \mathrm{~V}$, and $\mathrm{f}_{\mathrm{s}}=20 \mathrm{kHz}$.

Figure 4.19 Compensated and uncompensated frequency spectra for a the closest point to the wall for $U=22 \mathrm{~m} / \mathrm{s}, \mathrm{V}_{\mathrm{w}}=0.58 \mathrm{~V}$, and $\mathrm{f}_{\mathrm{s}}=20 \mathrm{kHz}$

Figure 4.20 Compensated and uncompensated frequency spectra for a point midway through the boundary layer for $\mathrm{U}=22 \mathrm{~m} / \mathrm{s}, \mathrm{V}_{\mathrm{w}}=0.58 \mathrm{~V}$, and $\mathrm{f}_{\mathrm{s}}=20 \mathrm{kHz}$.

Figure 4.21 Compensated and uncompensated frequency spectra for a point in the free stream for $U=22 \mathrm{~m} / \mathrm{s}, V_{w}=0.58 \mathrm{~V}$, and $\mathrm{f}_{\mathrm{s}}=20 \mathrm{kHz}$.

Figure 4.22 Mean velocity data at each point measured in the boundary layer for $\mathrm{U}$ $=22 \mathrm{~m} / \mathrm{s}, \mathrm{V}_{\mathrm{w}}=0.58 \mathrm{~V}$, and $\mathrm{f}_{\mathrm{s}}=2.5 \mathrm{kHz}$

Figure 4.23 Turbulence intensities at each point measured in the boundary layer for $\mathrm{U}=22 \mathrm{~m} / \mathrm{s}, \mathrm{V}_{\mathrm{w}}=0.58 \mathrm{~V}$, and $\mathrm{f}_{\mathrm{s}}=2.5 \mathrm{kHz}$

Figure 4.24 Compensated and uncompensated frequency spectra for a the closest point to the wall for $U=22 \mathrm{~m} / \mathrm{s}, \mathrm{V}_{\mathrm{w}}=0.58 \mathrm{~V}$, and $\mathrm{f}_{\mathrm{s}}=2.5 \mathrm{kHz}$

Figure 4.25 Compensated and uncompensated frequency spectra for a point midway through the boundary layer for $\mathrm{U}=22 \mathrm{~m} / \mathrm{s}, \mathrm{V}_{\mathrm{w}}=0.58 \mathrm{~V}$, and $\mathrm{f}_{\mathrm{s}}=2.5 \mathrm{kHz}$

Figure 4.26 Compensated and uncompensated frequency spectra for a point in the free stream for $U=22 \mathrm{~m} / \mathrm{s}, V_{\mathrm{w}}=0.58 \mathrm{~V}$, and $\mathrm{f}_{\mathrm{s}}=2.5 \mathrm{kHz}$.

Figure 5.1 Theoretical half amplitude cutoff frequency, $f_{C V A}$, for various sensor diameters

Figure 5.2 Custom 2.5 micron diameter probe type 55 Dantec Dynamics 15497 hot wire sensor .70

Figure 5.3 Test set-up for calibration and centerline measurements with filter box .71

Figure 5.4 Sample $I_{w}$ calibration for 2.5 micron Dantec sensor operated at $V_{w}=0.52$ $\mathrm{V}$

Figure 5.5 Mean local velocities at each point on the centerline of the turbulent jet for $10 \mathrm{~mm}$ nozzle and $50 \mathrm{~m} / \mathrm{s}$ jet exit velocity

Figure 5.6 Turbulence intensities at each point on the centerline of the turbulent jet for $10 \mathrm{~mm}$ nozzle and $50 \mathrm{~m} / \mathrm{s}$ jet exit velocity

Figure 5.7 Turbulence intensity measurements for each sensor for a $10 \mathrm{~mm}$ diameter nozzle and $50 \mathrm{~m} / \mathrm{s}$ jet exit velocity .... 
Figure 5.8 Power spectral densities plotted for each sensor at $x / D=7.5$ for a $10 \mathrm{~mm}$ diameter nozzle and $50 \mathrm{~m} / \mathrm{s}$ jet exit velocity

Figure 5.9 Power spectral densities plotted for each sensor at $x / D=12.7$ for a 10 $\mathrm{mm}$ diameter nozzle and $50 \mathrm{~m} / \mathrm{s}$ jet exit velocity . 75

Figure 5.10 Compensated and uncompensated turbulence intensity measurements for a $10 \mathrm{~mm}$ diameter nozzle and $50 \mathrm{~m} / \mathrm{s}$ jet exit velocity for the $2.5 \mathrm{micron}$ diameter wire

Figure 5.11 Wind tunnel $V_{s}$ calibration used for the 3.8 micron TSI sensor measurements operated at $\mathrm{V}_{\mathrm{w}}=0.58 \mathrm{~V}$

Figure 5.12 Wind tunnel $V_{s}$ calibration used for the 2.5 micron Dantec sensor measurements operated at $\mathrm{V}_{\mathrm{w}}=0.52 \mathrm{~V}$

Figure 5.13 Mean velocity data for each sensor measured in the boundary layer at each point for $U=34 \mathrm{~m} / \mathrm{s}$

Figure 5.14 Mean velocity data for each sensor measured in the boundary layer at each point for $U=45 \mathrm{~m} / \mathrm{s}$.

Figure 5.15 Turbulence intensities for each sensor measured in the boundary layer at each point for $U=34 \mathrm{~m} / \mathrm{s}$

Figure 5.16 Turbulence intensities for each sensor measured in the boundary layer at each point for $U=45 \mathrm{~m} / \mathrm{s}$

Figure 5.17 Power spectra for each sensor for $34 \mathrm{~m} / \mathrm{s}$ freestream velocity test at closest point to the wall

Figure 5.18 Power spectra for each sensor for $45 \mathrm{~m} / \mathrm{s}$ freestream velocity test at closest point to the wall....

Figure 5.19 Power spectra for each sensor for $34 \mathrm{~m} / \mathrm{s}$ freestream velocity test at point midway through the boundary layer

Figure 5.20 Power spectra for each sensor for $45 \mathrm{~m} / \mathrm{s}$ freestream velocity test at point midway through the boundary layer

Figure 5.21 Power spectra for each sensor for $34 \mathrm{~m} / \mathrm{s}$ freestream velocity test at freestream point

Figure 5.22 Power spectra for each sensor for $45 \mathrm{~m} / \mathrm{s}$ freestream velocity test at freestream point 


\section{NOMENCLATURE}

$$
\begin{aligned}
& A=\text { Power law offset coefficient } \\
& a_{w}=O H R-1 \\
& B=\text { Power law multiplying factor } \\
& c_{w}=\text { Specific heat capacity for tungsten wire, } 140 \mathrm{~J} / \mathrm{kg}-\mathrm{K} \text { in prediction } \\
& \text { model } \\
& C p=\text { Pressure Coefficient } \\
& D=\text { Hot-wire probe wire diameter, } \mu \mathrm{m} \\
& E=\text { Mean voltage output from HWA, V } \\
& E_{w}=\text { Elastic modulus of tungsten wire, } 400 \mathrm{GPa} \\
& e=\text { Instantaneous HWA output voltage, } \mathrm{V} \\
& f=\text { Friction factor } \\
& g=\text { Gravitational constant, } 9.81 \mathrm{~m} / \mathrm{s}^{2}, 32.2 \mathrm{ft} / \mathrm{s}^{2} \\
& G=\text { Feedback amplifier gain for CTA } \\
& H=\text { Amplitude ratio } \\
& h=\text { Heat transfer convection coefficient, } \mathrm{W} /\left(\mathrm{m}^{2} \mathrm{~K}\right) \\
& I_{T}=\text { Total feedback current in CVA circuit analysis } \\
& I_{w}=\text { CVA output proportional to current, } \mathrm{V} \\
& \Delta I_{w}=\text { CVA output difference between actual temperature and reference, } \mathrm{V} \\
& I_{w, \text { Corrected }}=\text { Corrected CVA output calibration data, } \mathrm{V} \\
& k=\text { Exponent for inverted calibration curve power law } \\
& k_{f, \infty}=\text { Thermal conductivity of air at film or fluid temperature, W/m-K } \\
& k_{L}=\text { Loss coefficient } \\
& L=\text { Hot-wire probe wire length, } 1.27 \mathrm{~mm} \text { for 1210-T1.5 } \\
& L_{C}=\text { Adjustable inductor for cable inductance compensation, } \mathrm{H} \\
& L M=\text { Time constant correction factor to account for lead resistance effects } \\
& M=\text { Time constant for HWA system (CCA, CTA, or CVA), ms } \\
& M_{n}=\text { Mach number } \\
& N=\text { Number of data points for mean square error calculation }
\end{aligned}
$$




$$
\begin{aligned}
& N u=\frac{h D}{k_{f}} \quad \text { (Nusselt number) } \\
& n=\text { Power law exponent } \\
& O H R=\text { Traditional overheat ratio, ratio of hot to cold probe resistance } \\
& P_{T}=\text { Total pressure, } \text { in }_{2} \mathrm{O} \\
& P_{s}=\text { Fan static pressure, } \mathrm{inH}_{2} \mathrm{O} \\
& \Delta P=\text { Plenum pressure difference, } \mathrm{inH}_{2} \mathrm{O} \\
& q=\text { Dynamic pressure, } \mathrm{inH}_{2} \mathrm{O} \\
& R_{0}=\text { Probe resistance at } 20^{\circ} \mathrm{C} \text { reference temperature, } \Omega \\
& R_{l}=\text { HWA fixed circuit resistor, } 5000 \Omega \text { in CVA prediction model } \\
& R_{2}=\text { HWA fixed circuit resistor, } 50 \Omega \text { in CVA prediction model } \\
& R_{3}=\text { Adjustable resistor for balancing bridge circuit, } \Omega \\
& R_{a, b}=\text { Resistance of hot-wire probe at conditions } a \text { and } b \\
& R_{b o x}=\text { Resistance of internal circuitry of CVA system, } \Omega \\
& R_{\text {cable }}=\text { Resistance of probe BNC cable, } \Omega \\
& R_{D V M}=\text { Probe resistance at ambient temperature measured by DVM, } \Omega \\
& R e=\frac{\rho_{f} U D}{\mu_{f}} \quad \text { (Reynolds number) } \\
& R_{F}=\text { CVA circuit resistor, } 1000 \Omega \text { in prediction model } \\
& R_{\text {int }}=\text { Resistance inside hot-wire probe, before actual wire sensor, } \Omega \\
& R_{L}=\text { Resistance of probe cable in anemometer circuit, } \Omega \\
& R_{s} \quad=\quad \text { Adjustable resistor to vary source current, } \Omega \\
& R_{\text {support }}=\text { Resistance of probe support stem, } \Omega \\
& R_{T}=\text { Total feedback resistance in CVA circuit analysis, } \Omega \\
& R_{w}=\text { Resistance (hot) of hot-wire probe at operating temperature, } \Omega \\
& R_{\infty}=\text { Resistance (cold) of hot-wire probe at ambient temperature, } \Omega \\
& P=\text { Offset coefficient for inverted calibration curve power law } \\
& Q=\text { Multiplier coefficient for inverted calibration curve power law } \\
& S_{T \infty}=\text { Freestream temperature sensitivity coefficient } \\
& S_{u}=\text { Velocity sensitivity coefficient } \\
& T_{a, b}=\text { Temperatures at different conditions } a \text { and } b,{ }^{\circ} \mathrm{C} \\
& T_{f}=\text { Film temperature, }{ }^{\circ} \mathrm{C}
\end{aligned}
$$




$$
\begin{aligned}
T_{w} & =\text { Hot-wire sensor operating temperature, }{ }^{\circ} \mathrm{C} \\
T_{\infty} & =\text { Ambient fluid temperature, }{ }^{\circ} \mathrm{C} \\
U & =\text { Freestream velocity, } \mathrm{m} / \mathrm{s} \\
u & =\text { Instantaneous velocity, } \mathrm{m} / \mathrm{s} \\
V_{1} & =\text { Voltage source powering HWA circuit, } \mathrm{V} \\
V_{o} & =\text { Op-amp output from prototype CVA system, } V_{o}=V_{s} / 2 \\
V_{s} & =\text { Op-amp output voltage for simplified circuit in literature, } \mathrm{V} \\
V_{w} & =\text { Probe wire voltage set-point, } \mathrm{V} \\
z & =\text { Height, feet } \\
\alpha_{0} & =\text { Temperature coefficient of resistance at } 20{ }^{\circ} \mathrm{C} \text { reference, } 0.0042{ }^{\circ} \mathrm{C}^{-1} \\
\beta & =\text { Screen open area ratio } \\
\varepsilon & =\text { Equivalent roughness, feet } \\
\mu_{f, \infty} & =\text { Air viscosity at film or fluid temperature, } \mathrm{N} \text {-s } / \mathrm{m}^{2} \\
\rho_{f \infty} & =\text { Air density at film temperature or fluid temperature, } \mathrm{kg} / \mathrm{m}^{3} \\
\rho_{w} & =\text { Density assumed for platinum plated tungsten wire, } 20,000 \mathrm{~kg} / \mathrm{m}^{3} \\
\theta_{\infty} & =\text { Fluctuating ambient fluid temperature, }{ }^{\circ} \mathrm{C} \\
\gamma & =\text { Specific weight, lb/ft }{ }^{3}
\end{aligned}
$$




\section{Introduction}

When using constant voltage anemometry (CVA) to measure velocity fluctuations in turbulent airflow, it becomes evident that due to the thermal lag of the wire and wide bandwidth of fluctuations encountered in turbulent flows, not all of the fluctuations are always captured. This thesis is focused on exploring various techniques aimed at improving the frequency response of CVA so that less of the signal from a turbulent air flow is attenuated.

Measurement of velocity fluctuations in a boundary layer is a direct method to determine laminar-to-turbulent transition. Neumeister [1] discussed just how big of an effect turbulence has on the aerodynamic drag on an aircraft and how the drag can significantly change depending on the laminar-to-turbulent transition location [2], which makes the prediction and measurement of this location critical to the development of aircraft designed to achieve large regions of laminar flow. Hot-wire anemometry (HWA) is a very effective method for measuring velocity fluctuations. This practice involves submersing a wire sensor typically made of tungsten or platinum with a diameter on the order of microns into a fluid flow for velocity measurements. As the probe is exposed to velocity fluctuations, convection heat transfer occurs, causing a change in probe temperature and therefore resistance. The voltage output for a HWA system is either proportional to the hot-wire probe resistance or the probe current, depending on which parameter is variable in the HWA circuit. A typical hot wire used for measurements in this thesis and a diagram of a hot wire in a flow can be found in Figure 1.1. 

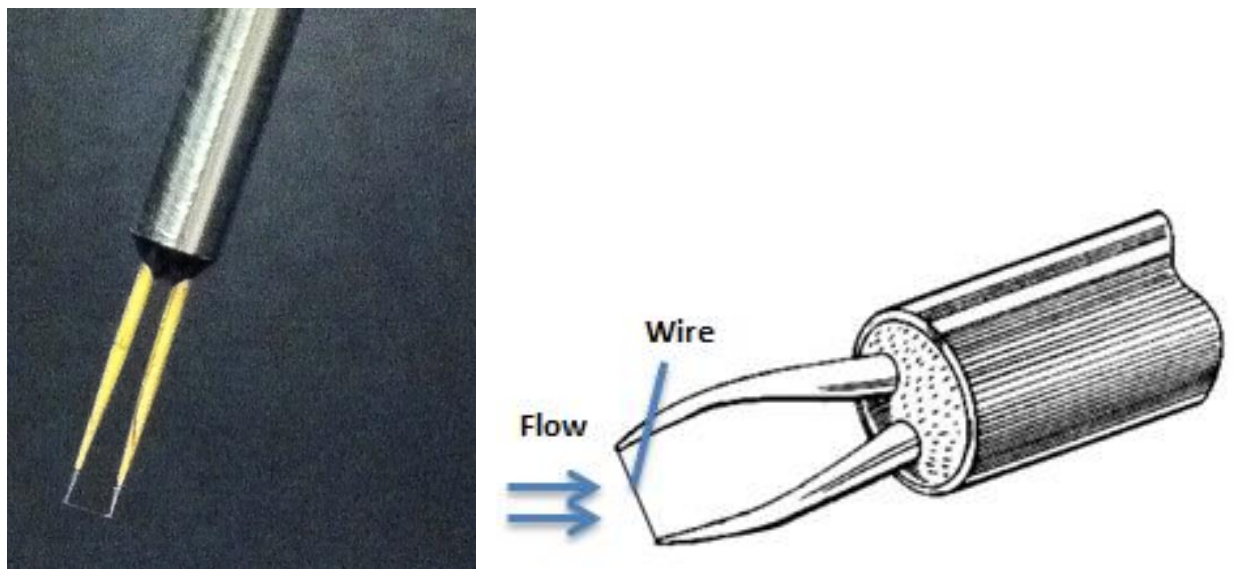

Figure 1.1 Commercial hot wire probe (TSI 1210-T1.5) and diagram of probe in flow

Will Neumeister [1] studied hot wire anemometry and the three common circuit configurations in the interest of implementing hot wire measurements with the Boundary Layer Data System (BLDS) [3]. He concluded that CVA is the best choice due to its simple and low cost circuit components and reasonable frequency response without the need to tune a delicate bridge. Due to the small, self-contained, and autonomous nature of BLDS, complicated bridges and the need for tuning make the constant current and constant temperature circuits unusable, but CVA avoids these. Constant temperature anemometry (CTA) has been used commonly for high frequency applications, but requires the careful tuning of a bridge which would not be possible autonomously in flight using BLDS. CVA provides an improvement in frequency response over constant current anemometry (CCA), while maintaining a balance between ease of operation and performance. The CVA circuit is very simply a voltage follower circuit composed of resistors and an op-amp and is pictured in Figure 1.2. As mentioned above, the primary goal of this thesis is to investigate the effects of various techniques aimed at improving the frequency response of CVA. 


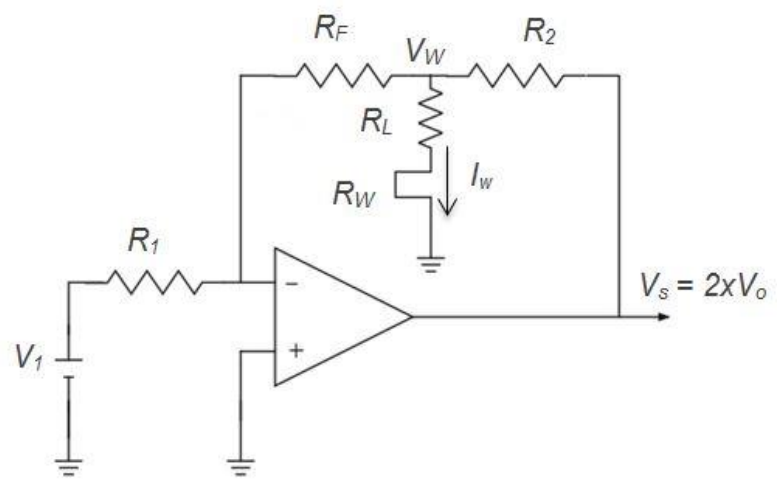

Figure 1.2 Basic CVA circuit diagram

While hot-wire probes have been shown to be capable of measurement of turbulent flow intensities less than $0.1 \%$ due to their low noise and high spatial resolution [4], the hot-wire probe has a heat capacity and cannot respond instantaneously to velocity fluctuations. A finite amount of time is required for heat transfer from the wire to occur and induce a temperature change in response to a flow disturbance. This time period is known as thermal lag and can be quantified by a time constant.

Referencing Hinze's work [5], Neumeister noted that the amplitude ratio $\mathrm{H}$ is the ratio of the attenuated output signal to the full amplitude signal without attenuation and can be represented as a function of frequency, $\omega$, and time constant, $M$ :

$$
H(\omega)=\left(1+\omega^{2} M^{2}\right)^{-1 / 2}
$$

The time constant mentioned above can be calculated for CVA as

$$
M_{C V A}=\frac{a_{w}}{1+2 a_{w}} \frac{\pi}{4} \frac{\rho_{w} c_{w} L D^{2}}{\alpha_{0} R_{0} I_{w}^{2}}
$$

where the variable $a_{w}$ is the ratio of the wire's operating resistance to the cold resistance minus one:

$$
a_{w}=\frac{R_{w}-R_{\infty}}{R_{\infty}}=O H R-1
$$


Comte-Bellot and Sarma [6] showed that equation (1.2) can be written in terms of Reynolds number which is used by Comte-Bellot et. al [7] for calculating $M_{C V A}$.

$$
\begin{gathered}
M_{C V A}=\frac{1+a_{w}}{1+2 a_{w}} \frac{\rho_{w} c_{w} D^{2}}{4 k_{\infty}} \frac{1}{A^{\prime}+B^{\prime}\left(\frac{\rho_{\infty} U D}{\mu_{\infty}}\right)^{1 / 2}} \\
R e_{D}=\frac{\rho_{\infty} U D}{\mu_{\infty}}
\end{gathered}
$$

These equations reveal the influence of $O H R$, wire diameter, and velocity on the time constant. It should be noted that these equations do not take into account the influence of the probe supports and cable, or the lead resistance. These effects are discussed later in this thesis in Chapter 3. Neumeister discussed predictions of $M_{C V A}$ using both equation (1.2) and (1.4) as well using a square wave test to measure the time constant. He showed that the predicted CVA output $I_{w}$ undershoots the true behavior of the sensor by about $10 \%$ for the same $V_{w}$ set-point due to simplifications in the model used for predicting the heat transfer as well as the Collis and Williams [8] correlation being used to determine the convection coefficient. This makes using equation (1.4) to estimate $M_{C V A}$ much more useful than using equation (1.2). Neumeister showed that for a $3.8 \mu \mathrm{m}$ diameter, platinum coated tungsten hot-wire probe at STP conditions and $50 \mathrm{~m} / \mathrm{s}$ velocity operated at $O H R=1.8, M_{C V A}$ is about $0.13 \mathrm{~ms}$ and the half amplitude $(-3 \mathrm{~dB})$ cut-off frequency is about $2200 \mathrm{~Hz}$; however, a study done by Wazzan [9] with the case of the Blasius flat plate boundary layer profile has shown that the fluctuations in a turbulent boundary layer profile can fluctuate up to a frequency of $5,720 \mathrm{~Hz}$ for a freestream velocity of $U_{\infty}=50 \mathrm{~m} / \mathrm{s}$ at a distance $x=1.1$ inches from where the boundary layer begins to form. This situation would present the likelihood of signal attenuation if measurements were being made with CVA. The frequency range, 
or frequency response, of a hot-wire can be thought of as the measureable range of velocity fluctuations or disturbances in a flow. The main drawback with CVA measurements is in the case of unsteady flow where a hot-wire may not be able to capture high frequency fluctuations.

Attenuation occurs when the range of fluctuation frequencies is larger than the frequency range of the hot-wire. Outside of the frequency range of CVA, fluctuations being measured become damped and contaminate the data. This is illustrated in Figure 1.3 where various frequency sine waves are added together and plotted for the "unattenuated" case (representing a signal in which a hot-wire is able to capture all of the signal) and the highest frequency sine wave is removed and the next lowest decreased in the "attenuated" case (representing a case where the frequency range of the hot-wire is smaller than the range of fluctuations). 


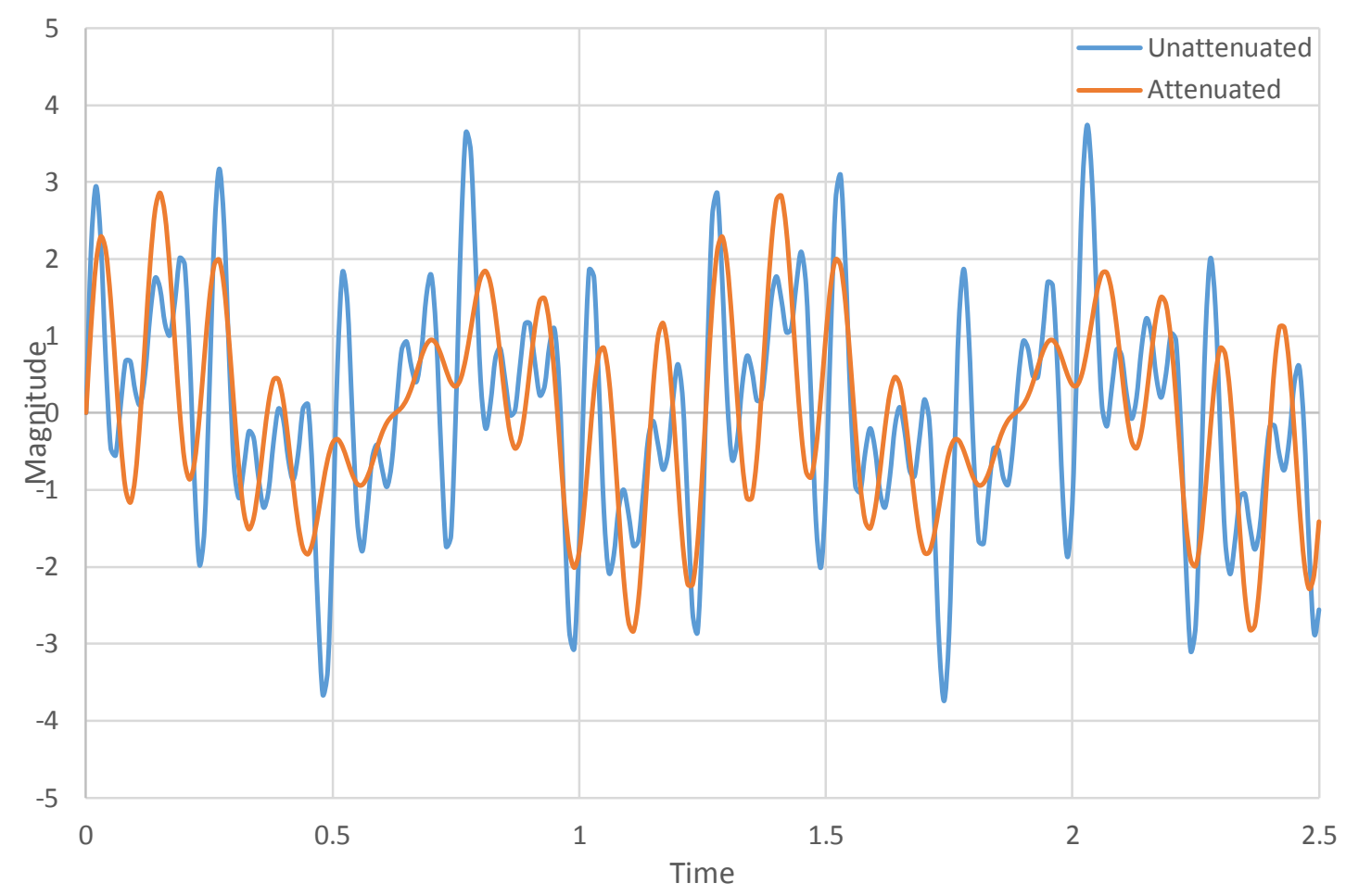

Figure 1.3 Plot of varying frequency sine waves added together to demonstrate attenuation

Based on the literature and background presented above, three approaches have been identified with the potential to improve frequency response and help limit attenuation with CVA measurements. These three main approaches have been outlined in theory and tested experimentally to determine the feasibility and effectiveness of implementing them with CVA to limit attenuation.

\subsection{Wire Voltage Operation}

Operating with a higher $O H R$ (or $a_{w}$ ) decreases $M_{C V A}$ from the $(1+a w) /(1+2 a w)$ ratio in equation (1.4). This approach presents itself as a simple way to improve the frequency response of CVA, and can be easily accomplished by simply operating the wire at a higher voltage. To demonstrate the theoretical effect of the overheat ratio on the 
frequency response, a plot of the half amplitude cut-off frequency, $f_{C V A}$, vs. the wire voltage, $V_{w}$ is shown in Figure 1.4. CVA was operated in the centerline of a turbulent jet and in a boundary layer on a flat plate with the only difference in operating condition being the OHR for direct comparisons between measurements. These results are discussed in Chapter 3.

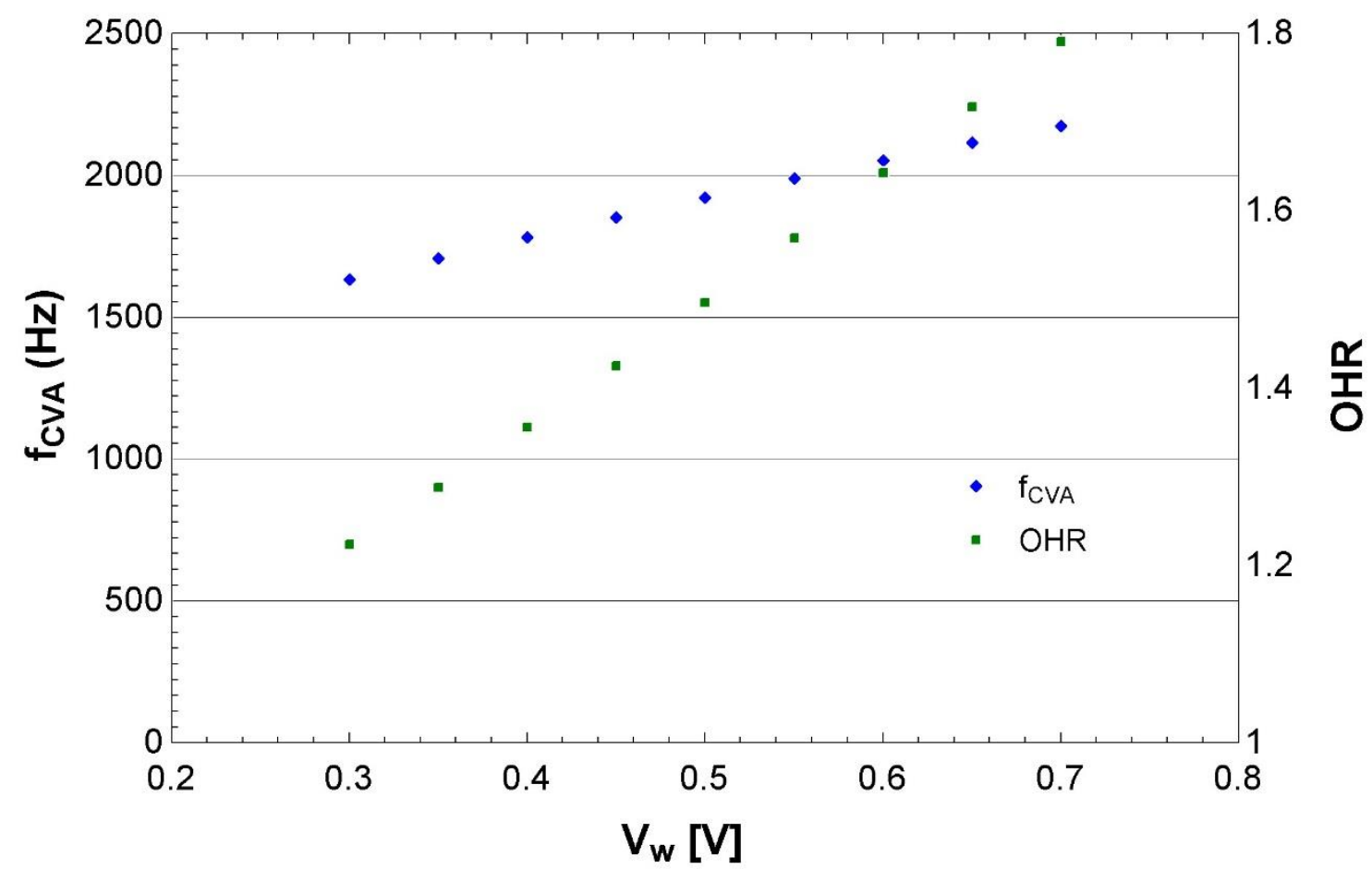

Figure 1.4 Predicted effect of $V_{w}$ on overheat ratio and the half amplitude cut-off frequency

\subsection{Compensation}

In an article detailing constant voltage anemometer practice in supersonic flows, Comte-Bellot and Sarma discuss compensation of the CVA output to effectively improve its frequency response [6]. Compensation is a method by which either an electrical compensation network or an algorithm applied to data are used to selectively amplify fluctuations which were attenuated. This would presumably lead to the lower frequency 
fluctuations staying the same and the higher frequency fluctuations being amplified as compared to the uncompensated data. This has potential to alleviate signal attenuation while still maintaining the autonomous nature of BLDS. This method was applied to data taken with CVA in the centerline of a turbulent jet and a turbulent boundary layer on a flat

plate for direct comparisons between compensated and uncompensated data. This compensation is the second approach discussed in Chapter 4.

\subsection{Wire Size}

Examining (1.4), it is seen that decreasing probe diameter would be a simple way to improve frequency response, because $M_{C V A}$ is roughly proportional to $D^{3 / 2}$. For a visual comparison, a prediction of $f_{C V A}$ vs. wire diameter is shown in Figure 1.5. While smaller probes can be obtained and used, they are more fragile and can be more expensive. A Dantec Dynamics $2.5 \mu \mathrm{m}$ sensor was obtained and tested on the centerline of a turbulent jet and in a turbulent boundary layer on a flat plate for comparisons with the TSI $3.8 \mu \mathrm{m}$ sensor. The advantages, disadvantages, and comparisons are discussed in Chapter 5. 


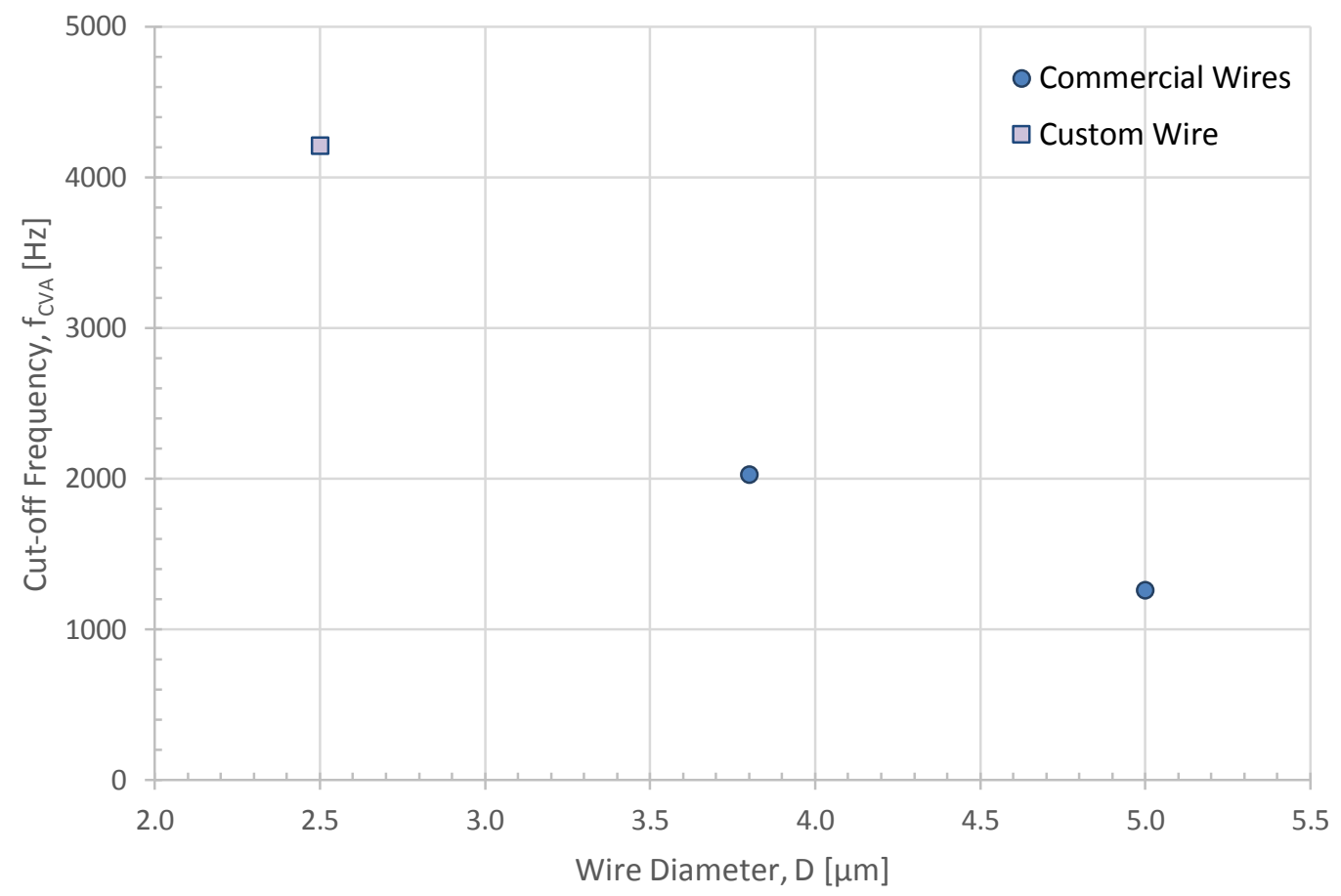

Figure 1.5 Theoretical half amplitude cutoff frequency, $f_{C V A}$, for various sensor diameters

The three main approaches in investigating the frequency response of CVA are operation of the hot wire in increasing the operating resistance of the wire (Chapter 3), compensation of the signal (Chapter 4), and decreasing the size of the hot wire being used (Chapter 5). Each of these is discussed in theory and demonstrated with experimentation in the next three chapters. 


\section{CVA Calibration and Operation}

\subsection{CVA Systems}

In order to proceed with a discussion of CVA measurements and procedures, a discussion of the CVA electronics and their operations should take place. The CVA is a system developed by Sarma in 1990 [10] and the circuit is a simple op amp voltage follower. The circuit design can be seen in Figure 1.2. $V_{w}$ is only dependent upon the values of fixed circuit resistors $R_{1}, R_{2}, R_{F}$, and $R_{L}$, as well as the voltage source $V_{l}$, which is set to a constant value before collecting data. The equation for wire voltage is derived by performing Kirchoff's Current Law (KCL) at the node of the inverting input of the op-amp [11] [12]:

$$
V_{w}=\frac{R_{F}}{R_{1}} V_{1} .
$$

Performing KCL at node $V_{w}$ in an ideal op-amp analysis, the equation for $V_{s}$ is derived as,

$$
V_{s}=\left(1+\frac{R_{2}}{R_{F}}+\frac{R_{2}}{R_{w}+R_{L}}\right) V_{w} .
$$

Equation (2.2) is the generally accepted formula for the CVA output, stated in references [12] and [13]. $R_{L}$ represents any lead resistance used to connect the hot-wire with resistance, $R_{w}$, to the CVA circuit.

For CVA operation, the user only needs to specify the wire voltage, $V_{w}$. As flow is introduced around the sensor, the hot-wire temperature (and therefore resistance) decreases significantly because of the increase in heat transfer coefficient when the main heat transfer mode switches from natural convection to forced convection. By Ohm's law (equation 
(2.3)), when the wire resistance decreases, the op-amp increases the wire current so that the wire voltage remains constant.

$$
V_{w}=I_{w}\left(R_{w}+R_{L}\right) .
$$

$V_{w}$ needs to be set very carefully for the desired operating conditions because wire burnout becomes a concern if the sensor reaches too high of a temperature; however, if the $O H R$ is too low, the hot-wire becomes more sensitive to temperature fluctuations and less sensitive to velocity fluctuations. This is why it is desirable to operate CVA at the highest $V_{w}$ possible while still at a safe temperature; however, this usually requires setting $V_{w}$ with air flow already on which presents the risk of wire burnout if the flow were to go off or too low before $V_{w}$ is decreased. An initial CVA system for the BLDS group was designed and built by Mr. Don Frame, electrical consultant. A photograph of the CVA prototype system called "CVA I" is shown in Figure 2.1. This model was built for stand-alone operation and initial testing of CVA capabilities, before potential implementation of a smaller model on BLDS, and is described in detail by Will Neumeister [1]. Mr. Frame later built a second iteration of his CVA system called "CVA II" which was used for much of the work done in this thesis and can be seen in Figure 2.2. 


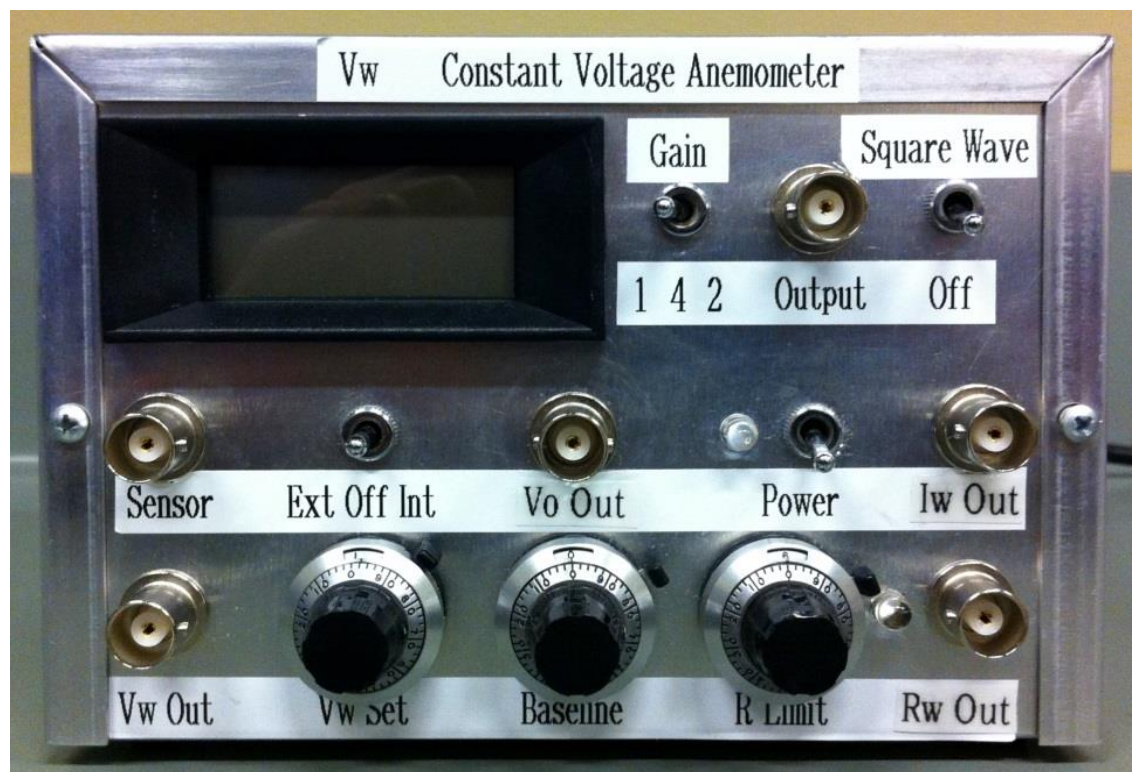

Figure 2.1 CVA I system built for Cal Poly BLDS [1]

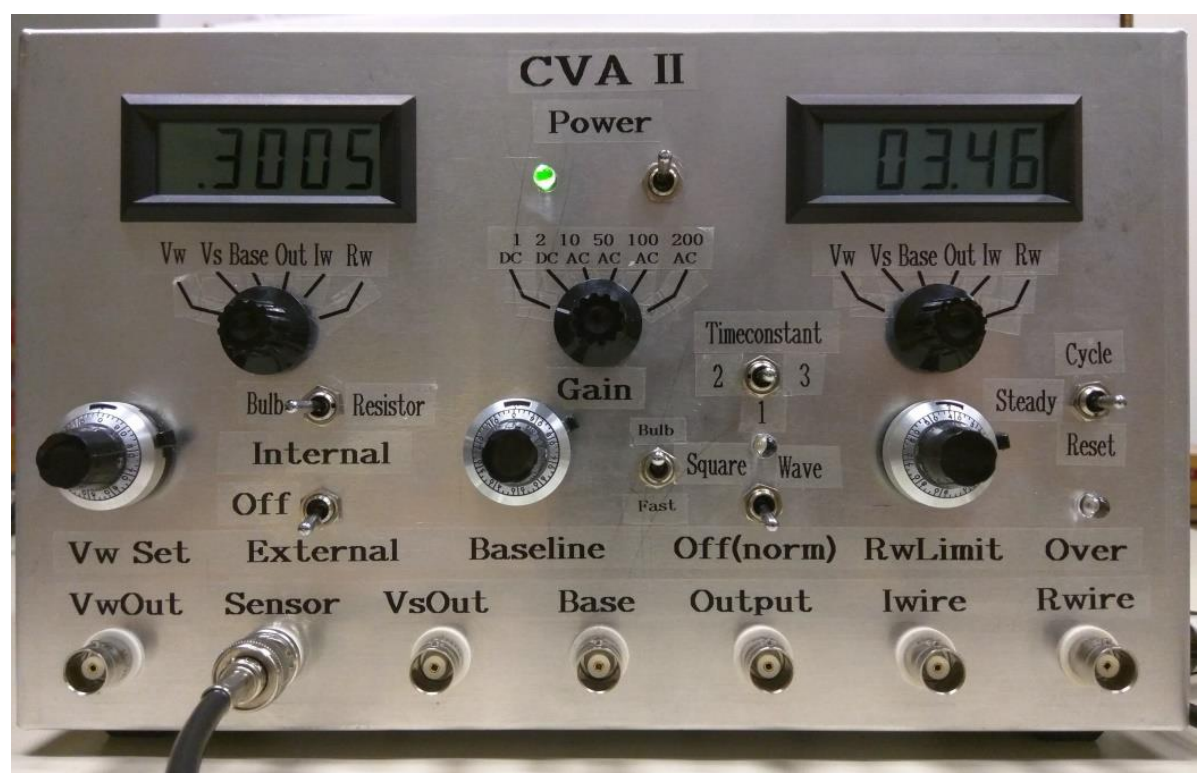

Figure 2.2 CVA II system

CVA II contains all of the functions of CVA I with a few added upgrades and benefits as compared to the original system. The system connects to a hot-wire probe through the Sensor BNC cable jack, and is capable of maintaining 0.1-1.0 V across the wire which is set and adjusted with the $V_{w^{-}}$Set dial and can be monitored on the $V_{w}-O u t$ BNC jack. Either 
the $V_{s}$-Out or $I_{\text {wire }}$ (measured as a voltage proportional to current) BNC output connections may be used as outputs for measuring velocity fluctuations. The $R_{\text {wire }} \mathrm{BNC}$ jack is used to monitor the probe resistance during operation for $O H R$ calculation. "Buck and gain" of the $V_{s}$ - Out signal can be accomplished using the Baseline knob to subtract, or "buck", the signal and the Gain knob to scale, or "gain", the signal. The Base BNC jack is used to monitor the amount of signal being subtracted away when using the Baseline feature. The Output BNC jack is used to monitor an output signal modified by the Baseline and Gain features. All of these outputs can be monitored with a digital voltmeter (DVM) connected to the desired jack or observed on either of the meters at the top of the front panel. A square wave test feature is also included for visual quantitative estimation of the system time constant. One feature unique to this CVA system as compared to previous systems (such as Tao Systems CVA [14]) is a resistance limiter, which engages to help protect the hotwire probe against burnouts. The resistance limit is set higher than the desired maximum operating resistance of the wire, but lower than a wire resistance that would lead to burnout. This is done before operation using the $R_{w}$-Limit knob. If probe heating occurs unexpectedly causing the resistance to exceed the preset threshold, the resistance limit will engage and partially drop the $V_{w}$ set-point in an effort to cool the probe and prevent a burnout. The Timeconstant switch seen on the front panel can be used for hardware compensation and was not used in the experimentation for this thesis. A detailed operating procedure is included in Appendix A.

\subsection{Calibration}

The first step in using CVA to measure air flow is calibration. Using a known variable air flow speed at fixed temperature and static pressure, $V_{s}$ or $I_{w}$ data from the CVA 
can be fitted to the known velocity variation. Initially, a calibration apparatus designed and built by Ryan Murphy [15] was used to provide a uniform, steady, jet flow of known velocity for establishing the relationship between CVA output and air velocity. The entire set-up used to perform the calibration can be seen below in Figure 2.3. Modifications were made to this apparatus to provide a higher probe support for centerline turbulence measurements, and a detail drawing can be found in Appendix B.

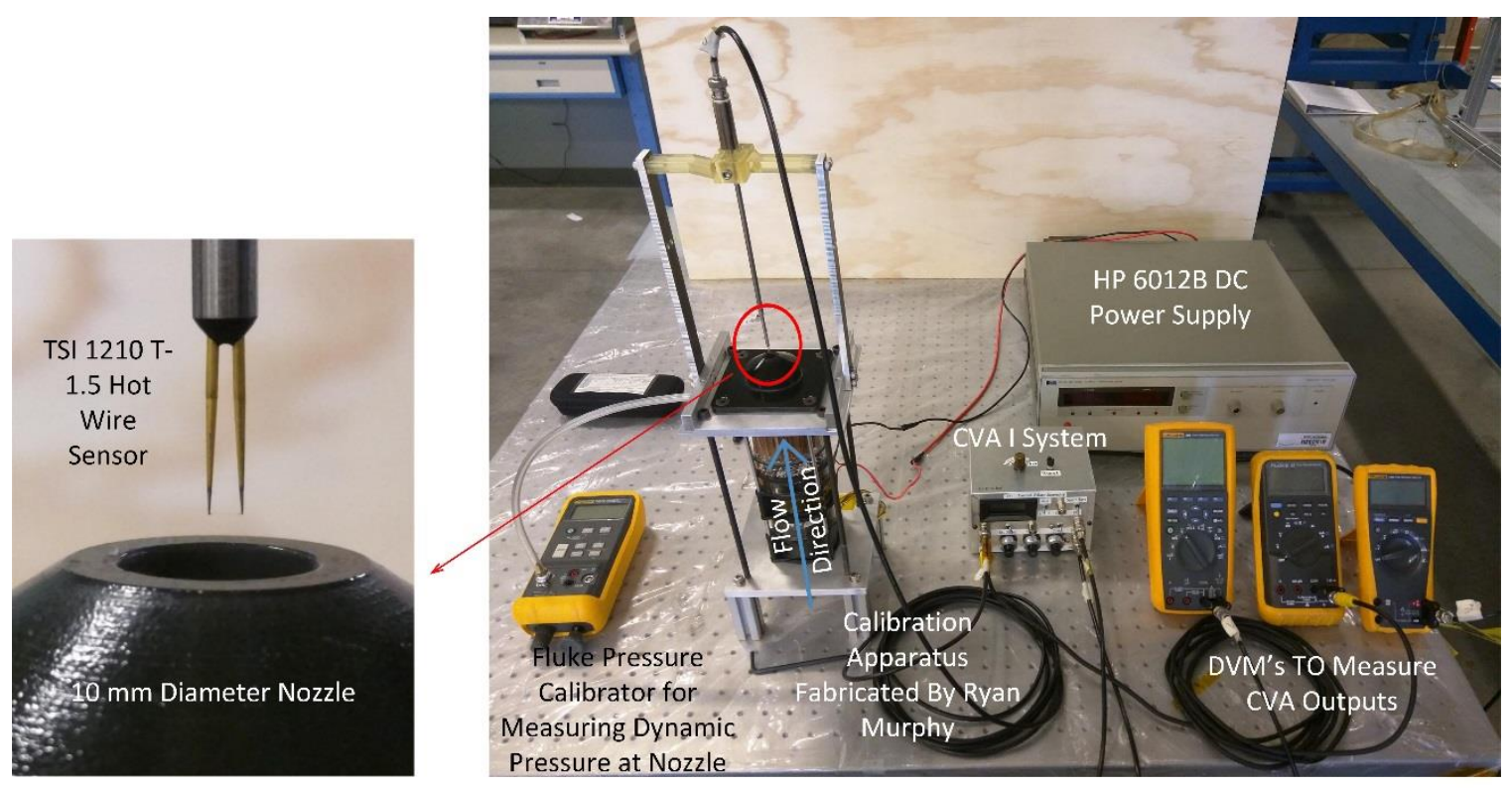

Figure 2.3 Annotated diagram of calibration set-up

A platinum-coated tungsten hot wire probe with a diameter of 3.8 microns, an active wire length of $1.27 \mathrm{~mm}$, and nominal $6 \mathrm{ohm}$ resistance at $20^{\circ} \mathrm{C}$ room temperature (TSI 1210T1.5) was used for most of the experimentation in this thesis. However, a 2.5 micron Dantec Dynamics sensor was used in Chapter 5 for comparisons with a smaller wire diameter. In order to ensure that results were reasonable before moving on, the hot wires were initially operated with CVA I and calibrated over a $15-50 \mathrm{~m} / \mathrm{s}$ velocity range at a wire voltage of $0.69 \mathrm{~V}$ for direct comparisons with Murphy's initial calibrations [15] and 
they were later calibrated using CVA II. Sample results for these calibrations, where the calibration jet velocity $U$ is plotted as a function of the wire current output, $I_{w}$, can be found in Figures 2.4 and 2.5.

While the comparison to Murphy's calibration points in Figure 2.4 matches up very well, a different probe and slightly different flow temperature and ambient pressure can cause a difference in outputs, resulting in calibration curves that are not exactly alike. Hot wire probes of the same model can vary slightly in resistance and consequently, the necessary $V_{w}$ set point and outputs can vary. It should be noted that for lower local velocities the change in the circuit output is much higher for a given change in air velocity because higher temperature probes are at a higher temperature and resistance and are therefore more sensitive to velocity fluctuations as discussed above.

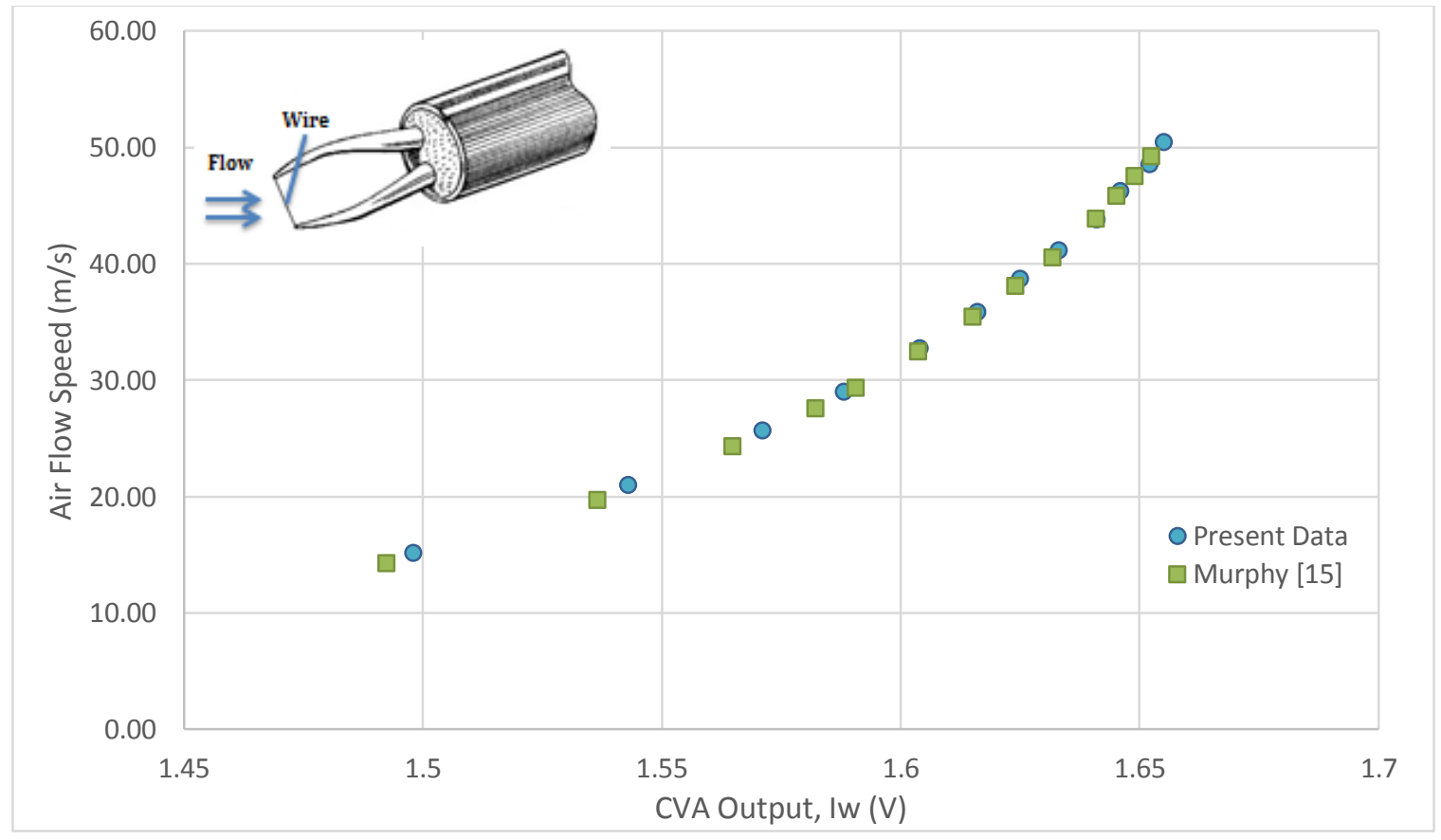

Figure 2.4 Initial CVA calibration compared with Ryan Murphy's calibration 


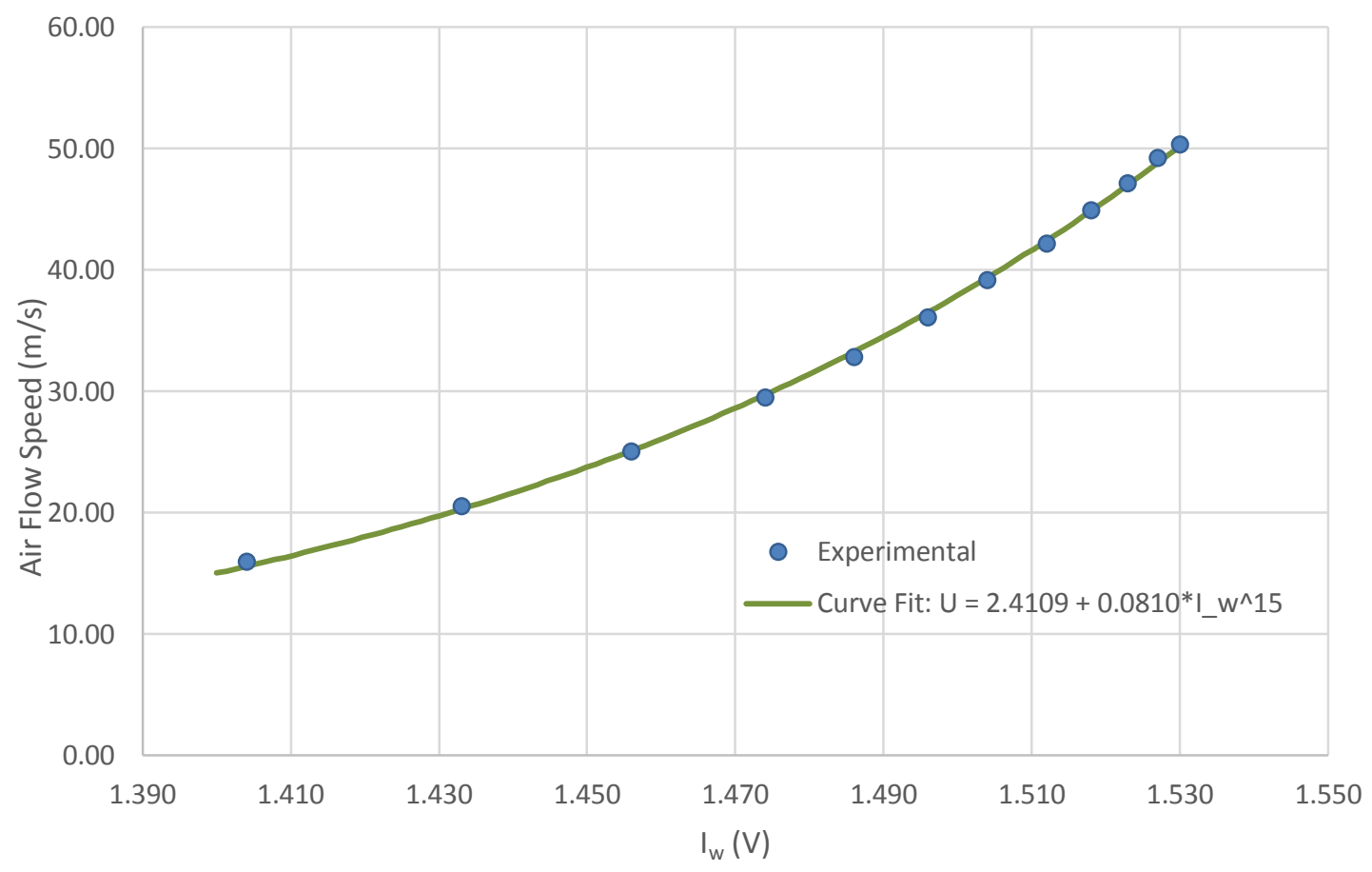

Figure 2.5 CVA II calibration for $\mathrm{V}_{\mathrm{w}}=0.59 \mathrm{~V}$

Neumeister, Li, and Murphy [1] [16] [15] showed that a power law curve fit works very well for CVA data because the heat transfer law that governs the hot-wire is in the form of a power law and the power law was seen as a good representation of the CVA calibrations in their work. The power-law curve fit is in the form,

$$
U=P+Q I_{w}{ }^{K}
$$

MATLAB's lsqcurvefit function was used to find each calibration curve. The power exponent, $k$, was selected and fixed based on a value that would result in a good visual fit for curves. Once a curve fit is obtained, it can be used to determine mean and fluctuating air flow velocities when measuring CVA outputs in an unknown air flow. 


\subsection{Turbulent Jet Measurements}

The next step was to take turbulence measurements on the centerline of the jet and compare those results with prior work to validate the test set-up and procedure. Knowing that downstream of the potential core at the nozzle jet outlet, there would be velocity fluctuations with a broadband frequency range, CVA I was initially used along the centerline of the turbulent jet above a $10 \mathrm{~mm}$ diameter nozzle of the calibration apparatus as shown in the diagram in Figure 2.6. This was an easy way to compare initial data to prior work under similar conditions, using Neumeister's data [1] for comparison, and it allowed for a simple way to make velocity fluctuation measurements before moving into a more complicated test set-up for measuring a boundary layer.

Data was recorded using National Instruments data acquisition device, NI USB6009 and a LabVIEW front panel that was created for these experiments to take in a large amount of data at each point in the centerline. To measure the distance downstream from the nozzle outlet at each point data was acquired, a scale was held up next to the wire. By taking a picture and zooming in, a measurement within one hundredth of an inch can be obtained. One of these pictures is shown in Figure 2.7. A screenshot of the LabVIEW front panel can be found in Appendix C. 


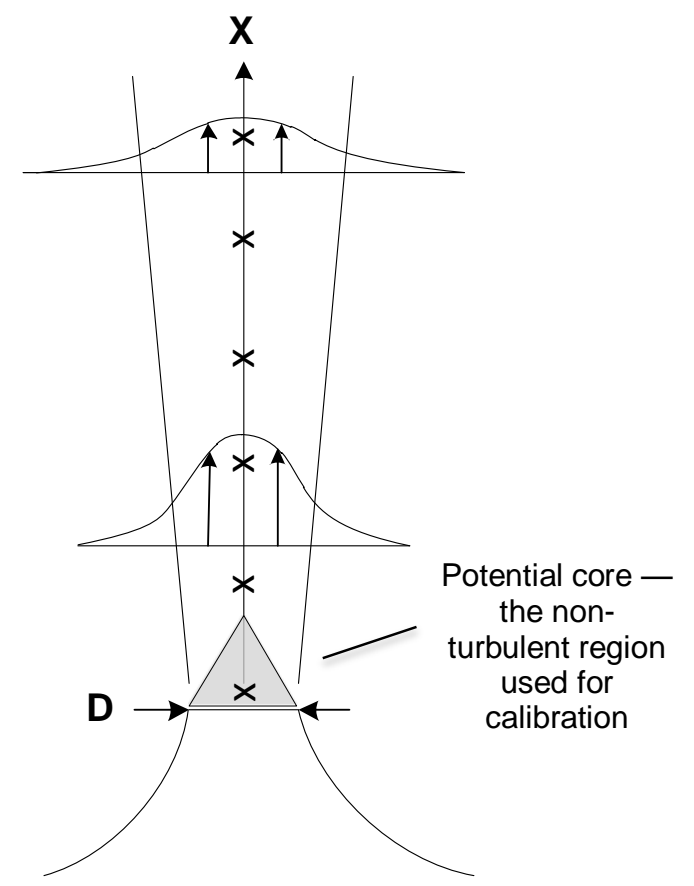

Figure 2.6 Diagram illustrating centerline turbulence measurements

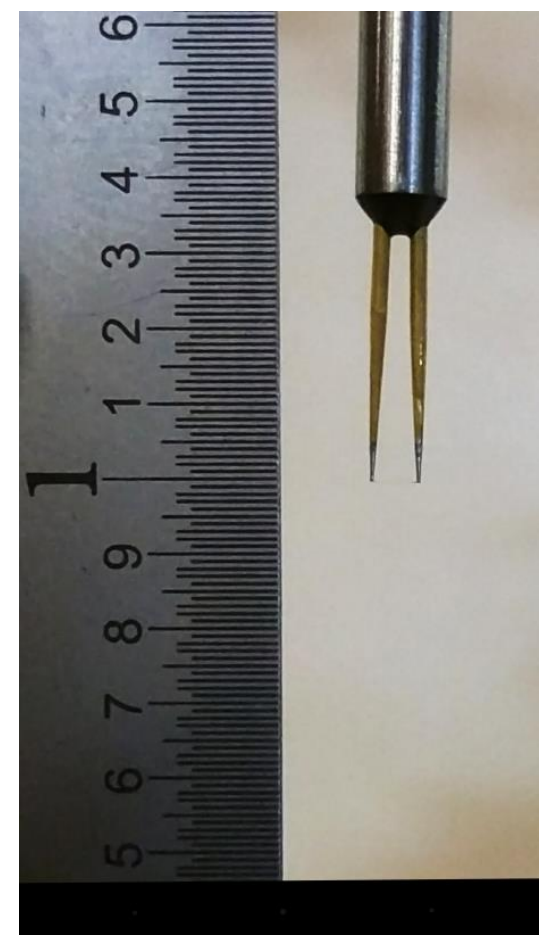

Figure 2.7 Image used to determine hot wire distance from nozzle outlet

The velocity fluctuations on the centerline of the jet were initially measured in the potential "core" and 5 more locations between 0 and 5 inches from the $10 \mathrm{~mm}$ diameter nozzle outlet 
$(x / D=0-12.7)$ with a jet exit velocity, $U$, of $50 \mathrm{~m} / \mathrm{s}$. The velocity fluctuations measured from the wire current output $I_{w}$ are quantified by the turbulence intensity and are compared to Neumeister's results in Figure 2.8. Turbulence intensity is the percent ratio of the RMS velocity component to the mean local velocity, giving a metric for the amount of fluctuation in the air flow. The results agree for $x / D$ greater than 10 , but not for $x / D$ less than 8 . The differences may be related to the use of a different jet apparatus, or the calibration of a different CVA output.

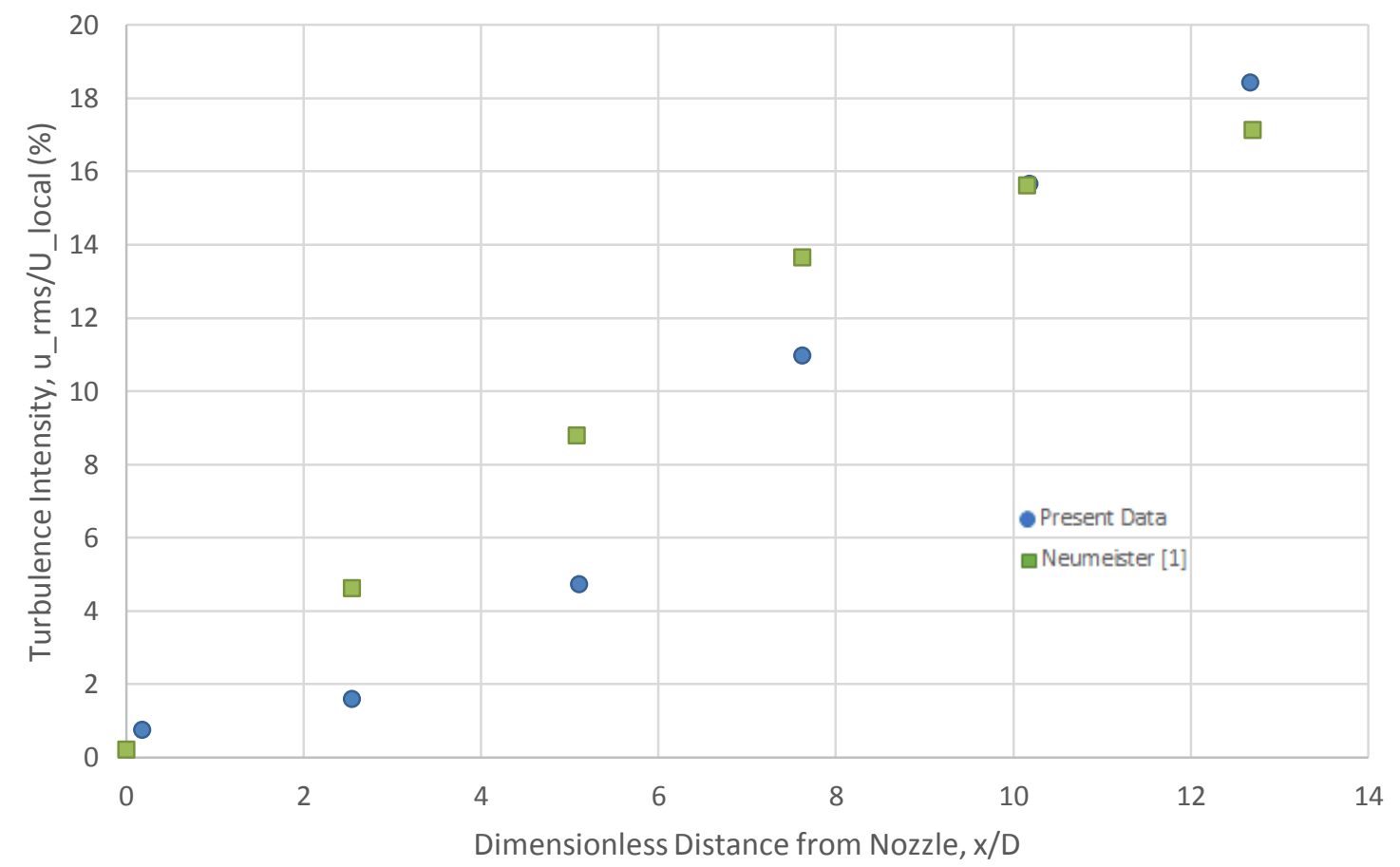

Figure 2.8 Comparison of turbulence intensity results measured on the centerline of the turbulent jet for similar operating conditions

It was necessary to also compare the mean centerline measurements to theory to ensure that the velocity along the centerline of the jet decreases inversely with distance from the source [17]. By plotting the mean data and fitting a curve, it can be seen in Figure 2.9 that the local velocity at the centerline appears to behave as expected. This was done 
using a $5 \mathrm{~mm}$ diameter nozzle to show that this relationship is valid for points farther away from the jet exit at larger $x / D$ ratios.

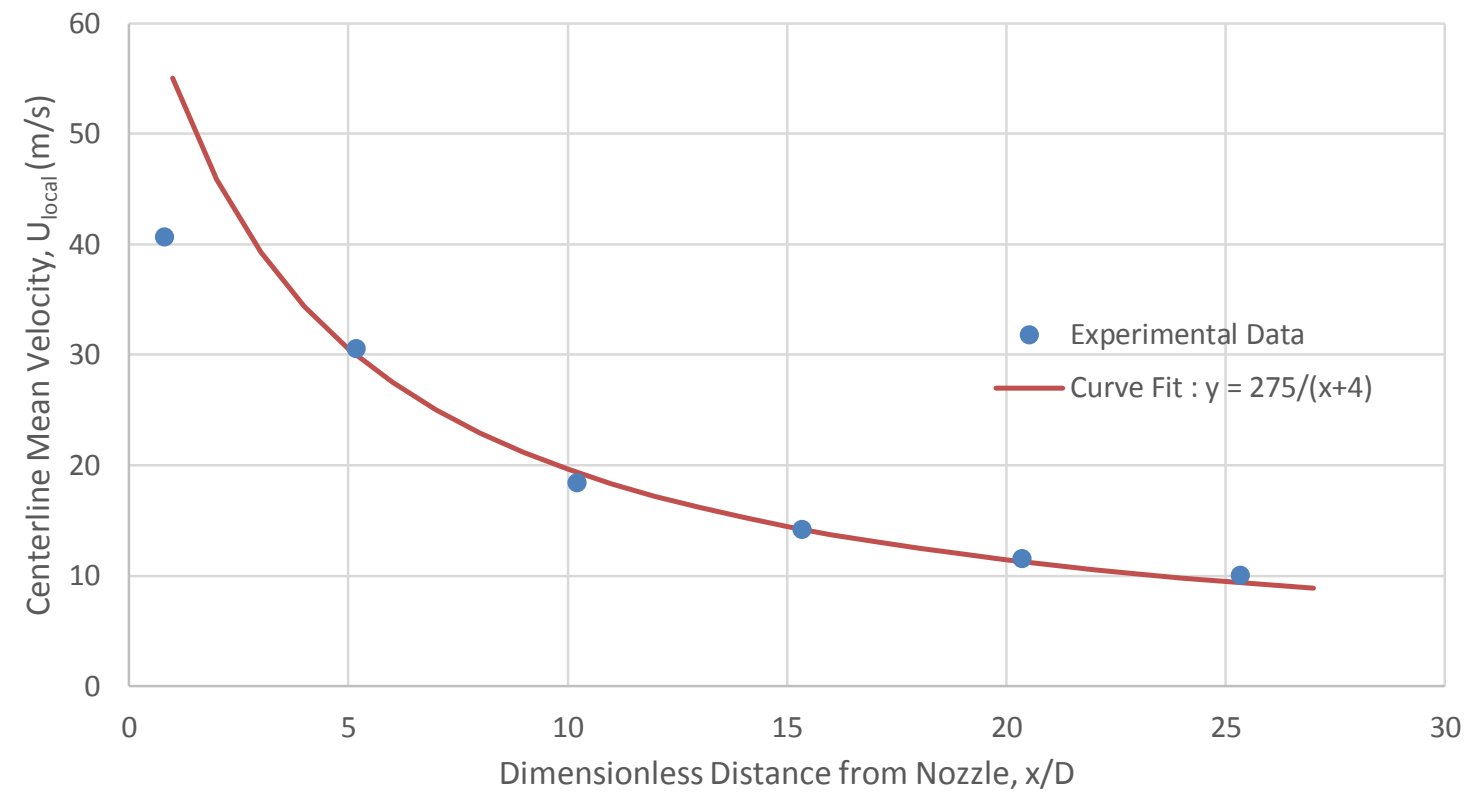

Figure 2.9 Mean local velocities at each point on the centerline of the turbulent jet with curve fit to show the drop off that behaves like the inverse of distance

Just as Neumeister showed in his work, the turbulence intensities reached about $17 \%$ in the jet centerline, 5 in. away from the $10 \mathrm{~mm}$ diameter nozzle outlet $(x / D=12.7)$. These intensities are comparable to the results from Wygnanski and Fiedler's turbulent jet experiment [18], displayed in Figure 2.10. Wygnanski and Fiedler measured 24\% turbulence intensity at the distance of $x / D=20$ along the jet centerline, $y / x=0$. Selfsimilarity for the turbulent jet does not occur until about $x / D=50$; this is when the turbulence intensity is expected to be the same any farther away from the source. Their measured turbulence level is $7 \%$ higher than that measured by the CVA, but they were 7.6 $x / D s$ farther away than the hot-wire probe connected to the CVA at 5 in. above the nozzle 
and the turbulence intensity would be expected to increase for larger $x / D$. Tests were later run for larger values of $x / D$ and these results are discussed in Chapter 3 .

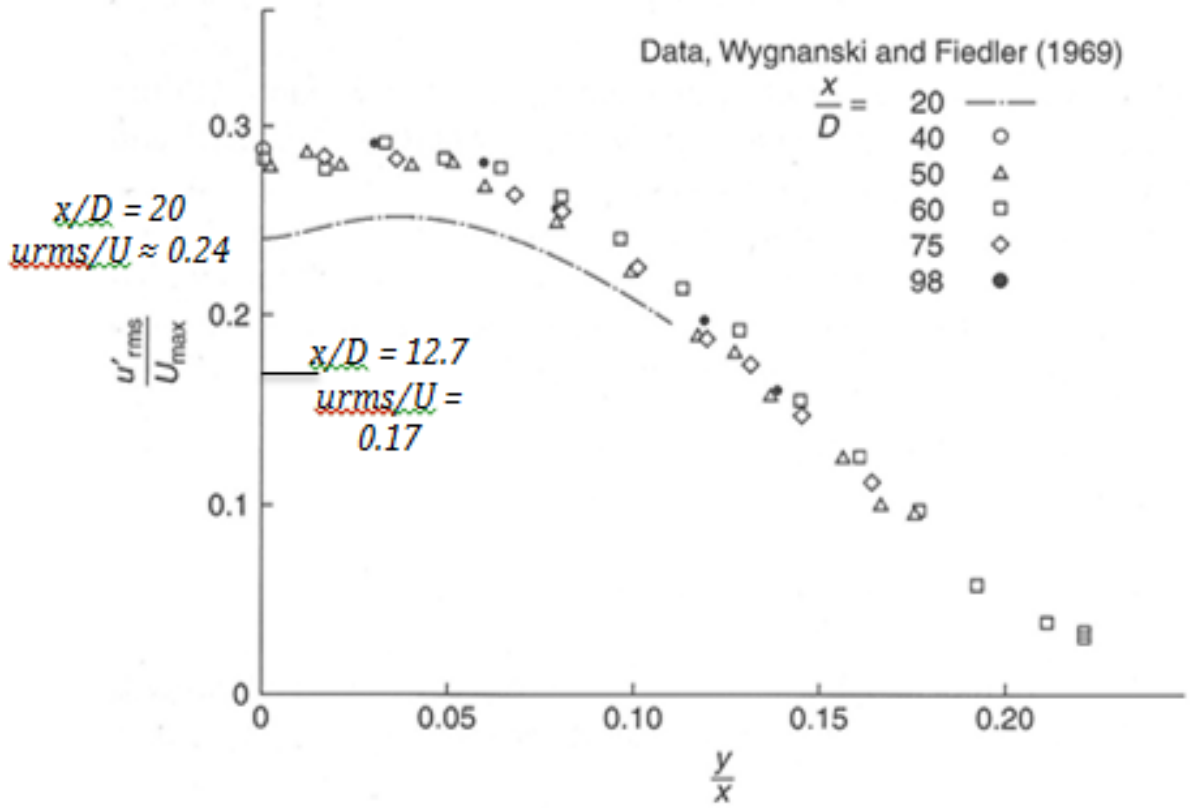

Figure 2.10 Turbulence intensities measured in a circular turbulent jet [18]

Further, the turbulent jet has velocity fluctuations with a broadband frequency range, so CVA could be suffering from attenuation of the higher frequencies, so that the CVA measured intensity would be lower than the actual turbulence intensity. In order to observe and quantify the fluctuations being seen by CVA, the output was hooked up to an analog spectrum analyzer. Shown in Figure 2.11, this confirms the energy that was expected; significant amplitude can be seen out to about $2.5 \mathrm{kHz}$, showing that there could be attenuation taking place due to the thermal lag of the wire. 


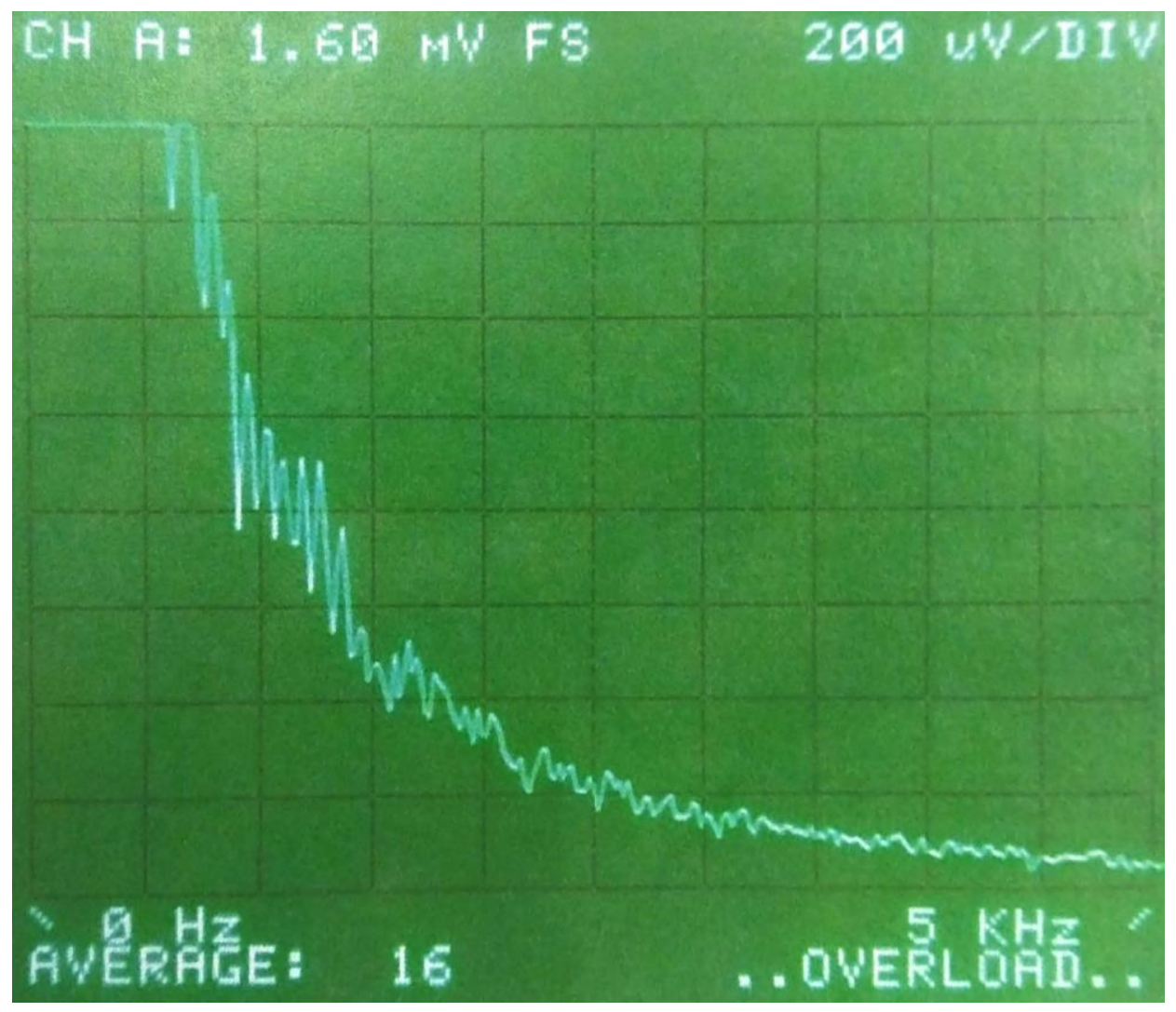

Figure 2.11 Analog spectrum analysis of CVA signal for sensor 5 inches away from $10 \mathrm{~mm}$ nozzle jet outlet with $50 \mathrm{~m} / \mathrm{s}$ exit velocity

The jet of the calibration apparatus was a convenient way to practice CVA operation and evaluate CVA measurements of velocity fluctuations. The next test was to measure the velocity fluctuations in a turbulent boundary layer.

\subsection{Boundary Layer Measurements}

In an effort to obtain more useful measurements for testing each approach aimed at improving the frequency response of CVA, turbulent boundary layer measurements were performed. Boundary layers are also an intended application of CVA with BLDS, so these were very useful measurements for each approach in this thesis. CVA II was used, with the CVA output read by a laptop computer through the same USB-connected National 
Instruments DAQ used for the centerline measurements. In order to obtain comparable results to prior work, a test setup similar to the work done in Hon Li's thesis was used [16]. The test was conducted in the 2-foot by 2-foot wind tunnel in the Mechanical Engineering Fluids Lab at Cal Poly. The wind tunnel can achieve a maximum velocity of $110 \mathrm{mph}$, or $50 \mathrm{~m} / \mathrm{s}$, but measurements for this research were done at $U_{\infty}=22 \mathrm{~m} / \mathrm{s}$. Data was taken using a flat plate with a slight favorable pressure gradient with a sharp leading edge and a small trip wire to ensure attached laminar flow at the leading edge and a turbulent boundary layer for measurements. To trip the flow, a 0.02 inch diameter trip wire spanning the width of the 3 foot long, 2 foot wide flat plate is secured 3 inches downstream of the leading edge. To ensure attached laminar flow at the leading edge, there are four washers on each of the rear supports to tilt the nose down at 0.58 degrees and a flap on the trailing edge to ensure a favorable pressure gradient. The hot-wire was located 28 inches downstream of the leading edge, and a Pitot-static probe located 6 inches from the ceiling of the test section with the static port lined up with the hot-wire sensor. The Pitot-static probe was used to measure freestream velocities and this differential pressure was measured with a Setra 239 pressure transducer. The test setup for the CVA can be seen in Figures 2.12 and 2.13. 


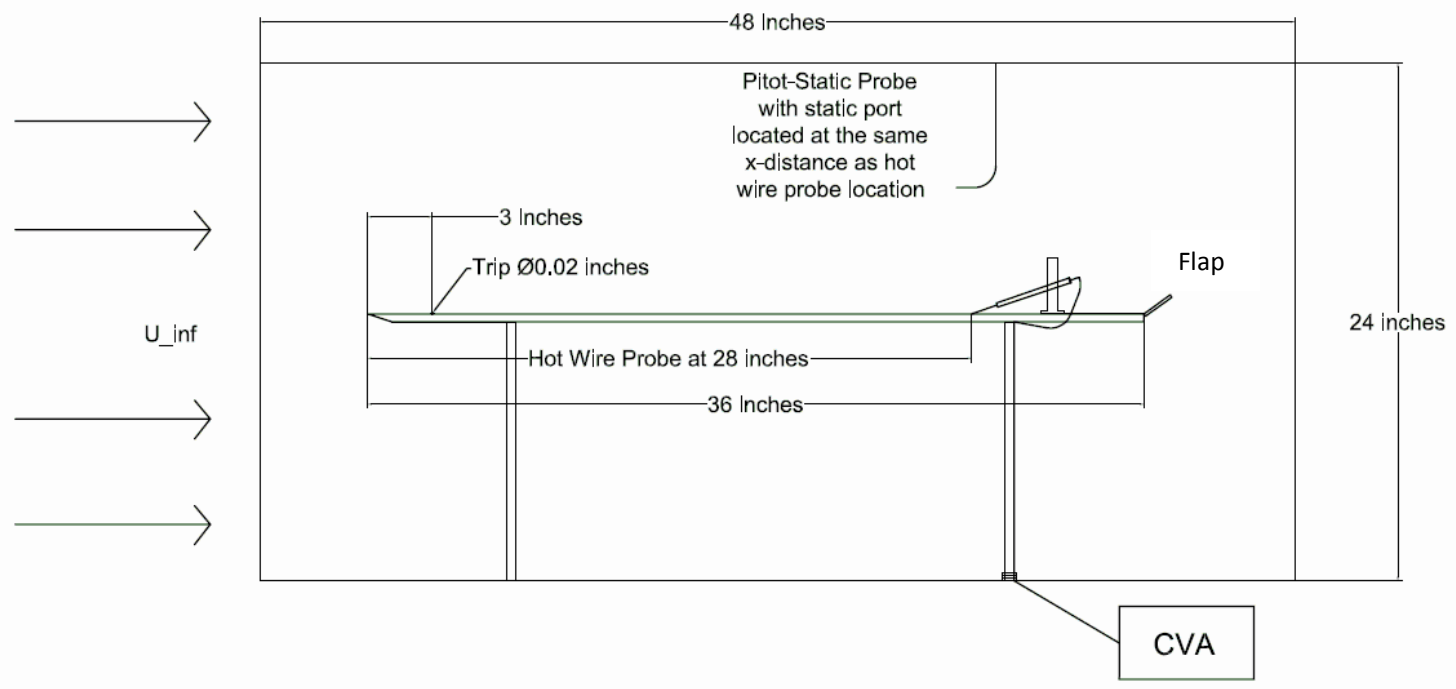

Figure 2.12 Line diagram of boundary layer measurement set up in Cal Poly Wind Tunnel [16]

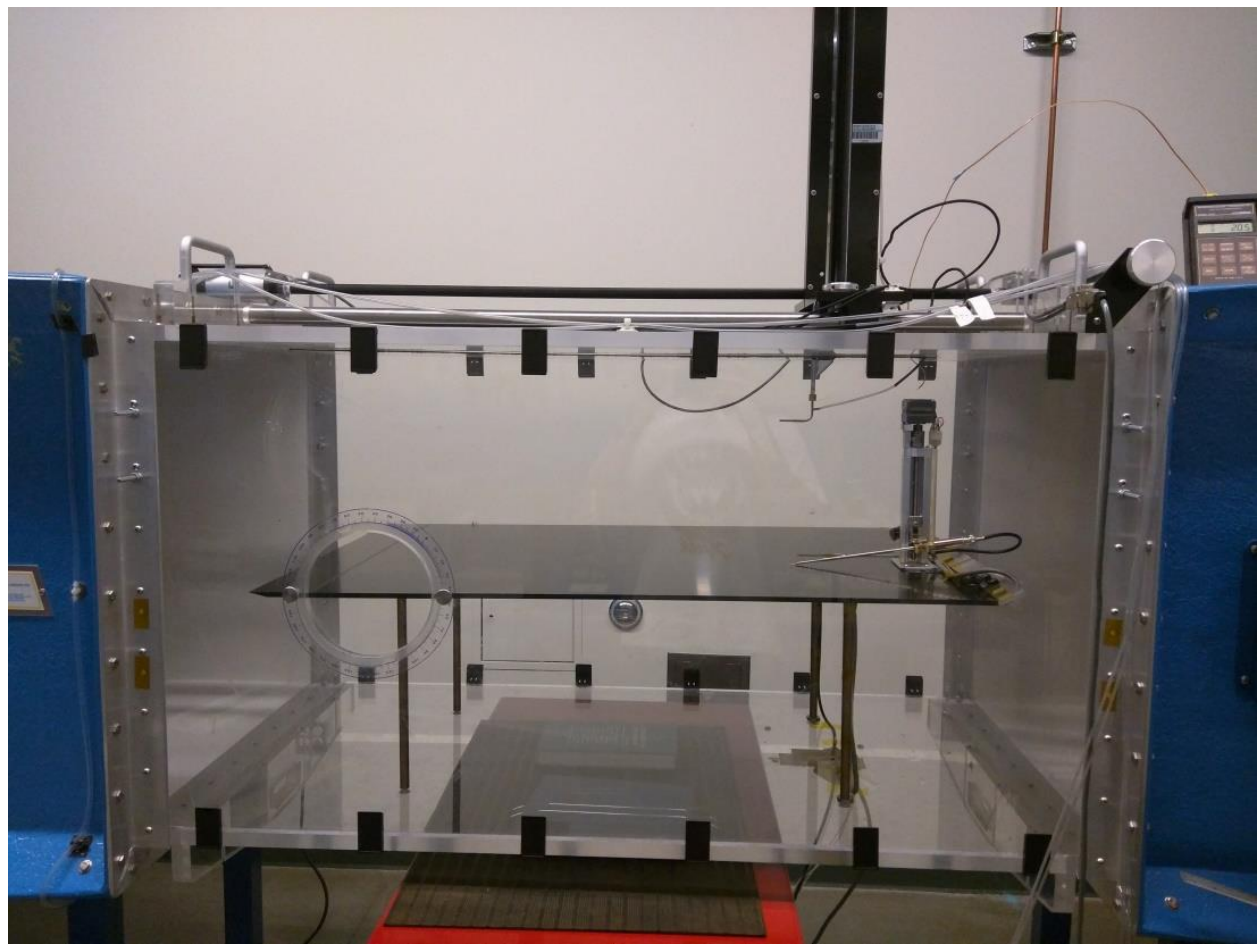

Figure 2.13 Layout of boundary layer measurement set up in Cal Poly Wind Tunnel 
Due to the fragile nature of the hot wire sensors, it becomes very difficult to locate the distance of the sensor from the surface of the flat plate (the origin) before the sweep begins. Locating the sensor as close as possible to the plate must be done delicately to avoid crashing the sensor into the plate, and then its location must be measured with precision. The placement of the sensor was done by using the stepper motor to lower the sensor to a spot visibly close to the surface and then using the digital microscope seen in Figure 2.14 to monitor the distance with more precision while further moving the probe one step at a time toward the surface. The digital microscope was monitored on the laptop computer being used to take data, and the pictures shown in Figure 2.15 were captured to quantify the distance. By using the scale of known thickness $0.038 \pm 0.0005$ inches in Figure 2.15 and noting the reflection on the plate in the image, the distance can be measured in pixels from the captured image between the sensor and its reflection and divided by two to get an accurate origin for each test. A confidence interval was obtained for these measurements by establishing uncertainties in counting pixels and converting the observed distance in the capture back to inches. A typical starting location is $0.028 \pm 0.0015$ inches. A calculation is shown in Appendix D. 


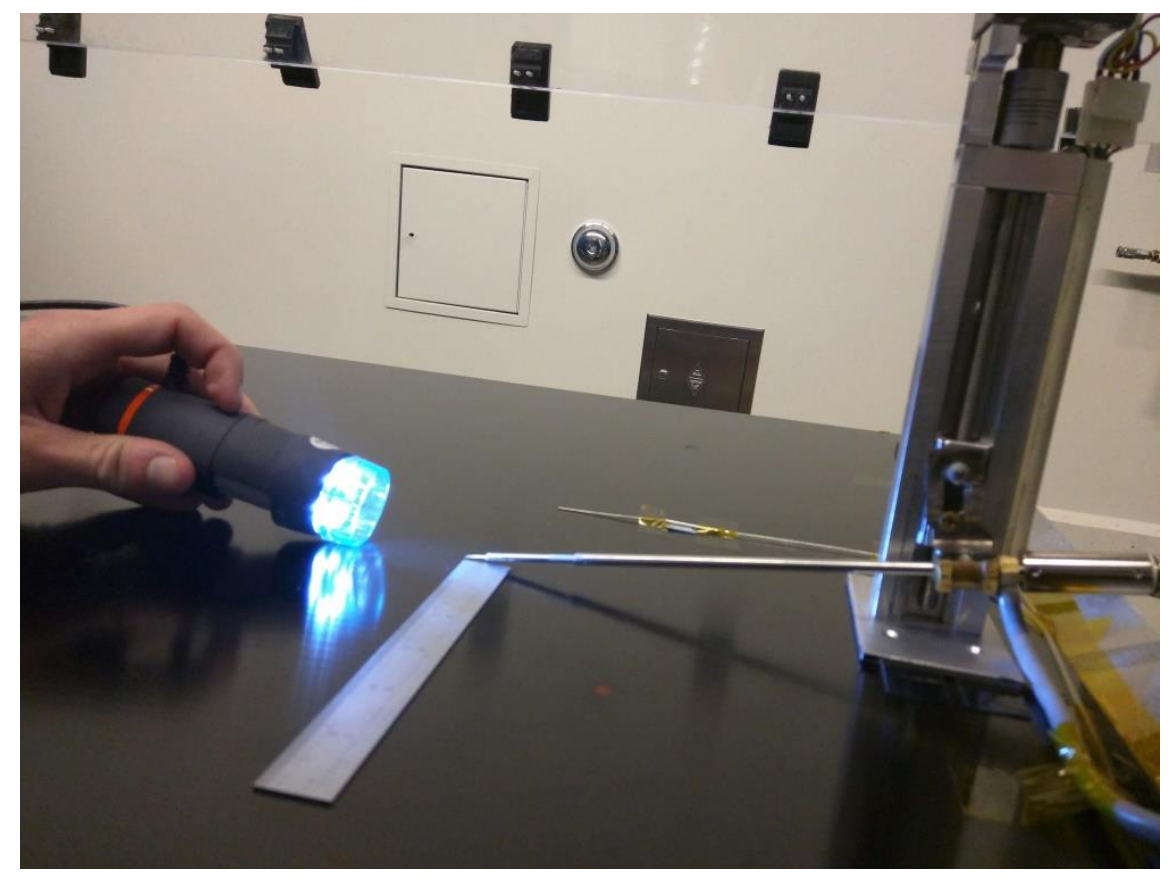

Figure 2.14 Digital microscope in position to capture sensor distance from plate
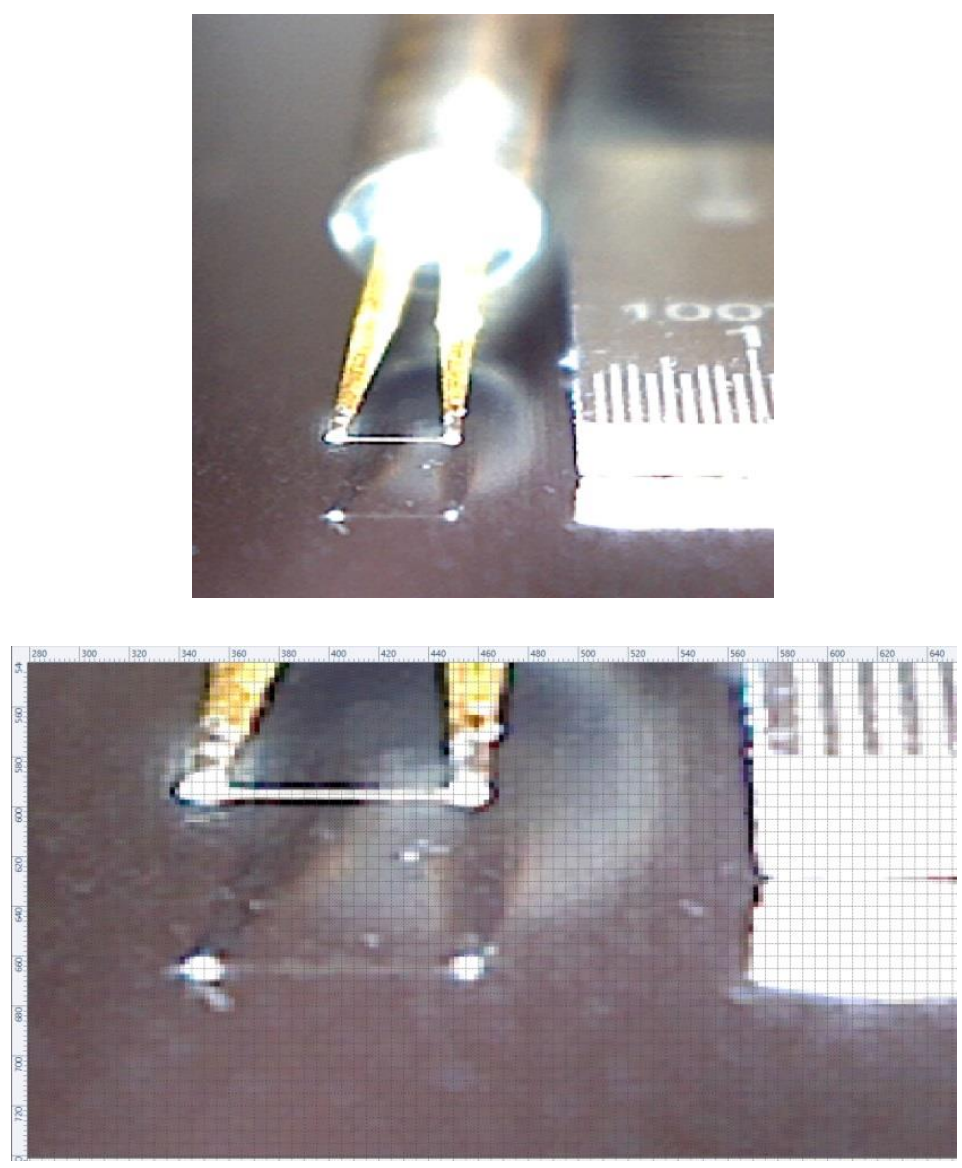

Figure 2.15 Images used to measure starting sensor distance from plate 
Initial boundary layer measurements were taken to compare with Hon Li's data and data published by Klebanoff [19] to verify the test set-up. A mean velocity profile can be found in Figure 2.16. Turbulence intensities of the present data compared to data from Klebanoff and Li are shown in Figure 2.17. The first thing to note is the high turbulence intensity observed out in the freestream. Theoretically, there should be very low turbulence in the freestream (less than about $0.5 \%$ ), but due to electrical noise in the system, these measurements show almost $2 \%$ turbulence intensity. A study was later completed on the noise present in the system and the ramifications it has in conjunction with CVA measurements; the findings are presented in Chapter 4. It was discovered through this comparison and other testing that the noise level for the $I_{w}$ output is noticeably higher than that of the $V_{s}$ output. In general, the initial measurements taken followed a very similar trend to both Klebanoff and Li's data, providing verification that the test set-up is valid and further testing can be completed. With the confirmation of testing procedures and initial data, the three main methods for improving frequency response were tested next. 


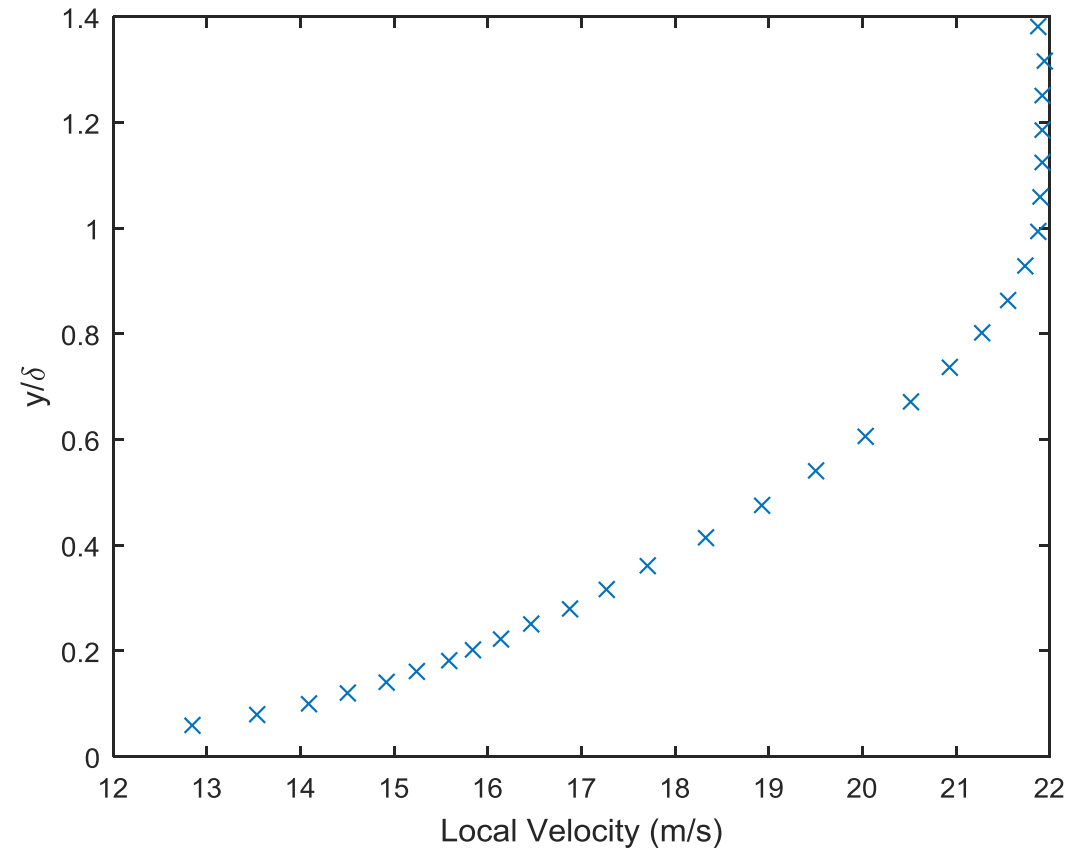

Figure 2.16 Sample mean velocity profile from initial boundary layer tests with CVA

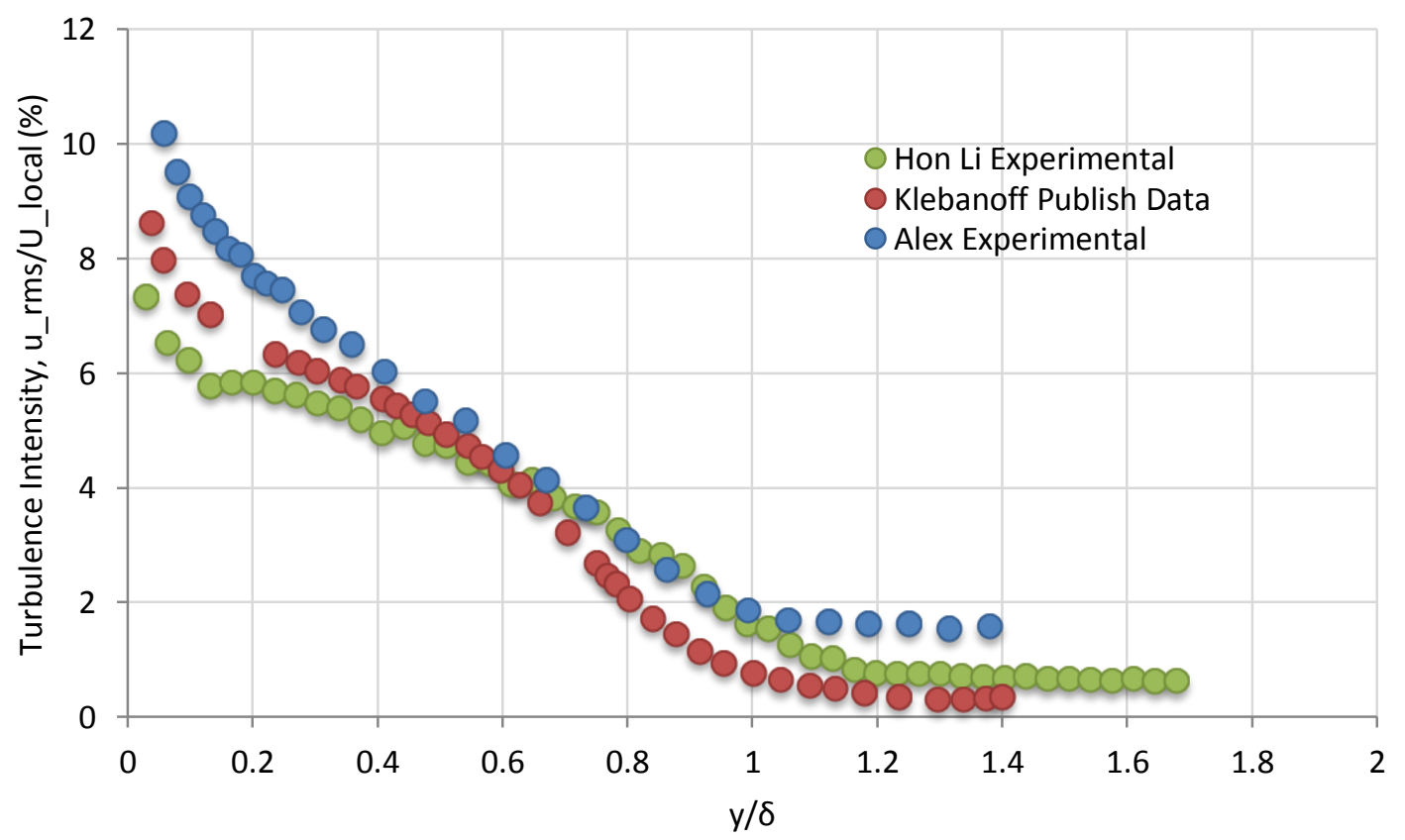

Figure 2.17 Initial boundary layer measurements compared with Li and Klebanoff data [19] [16] 


\section{Wire Voltage Operation}

The first method that was researched and tested to determine feasibility of application with CVA measurements on BLDS was wire voltage operation. Operating CVA at a higher voltage results in a higher temperature sensor, which consequently has a higher $O H R$. This chapter outlines the predictions about $V_{w}$ effect on CVA frequency response and makes experimental comparisons between different wire voltages in both the centerline of a turbulent jet and a turbulent boundary layer. Conclusions are then addressed about the effectiveness of using this technique to improve CVA frequency response while weighing the benefits in frequency response against the problems with wire survival.

\subsection{Theory}

The effect of $O H R$ was revealed by equations (1.3) and (1.4):

$$
\begin{gathered}
a_{w}=\frac{R_{w}-R_{\infty}}{R_{\infty}}=O H R-1 \\
M_{C V A}=\frac{1+a_{w}}{1+2 a_{w}} \frac{\rho_{w} c_{w} D^{2}}{4 k_{\infty}} \frac{1}{A^{\prime}+B^{\prime}\left(\frac{\rho_{\infty} U D}{\mu_{\infty}}\right)^{1 / 2}}
\end{gathered}
$$

To quantify this effect, the thermal electrical model developed by Neumeister [1] was used to plot overheat ratios and cut-off frequencies for the 3.8 micron TSI sensor operated at various wire voltages assuming STP conditions and at a local velocity, $U$, equal to $22 \mathrm{~m} / \mathrm{s}$. This plot was presented in Chapter 1 in Figure 1.4. It is immediately evident that the increase in frequency response is not very large. Over the range of $\mathrm{V}_{\mathrm{w}}=0.3 \mathrm{~V}$ to $0.7 \mathrm{~V}$, the theoretical cut-off frequency only increases from 1.6 to $2.2 \mathrm{kHz}$. Knowing that turbulent air flows can have $5.6 \mathrm{kHz}$ bandwidths as discussed in Chapter 1, CVA measurements of 
fluctuations at higher frequencies would be attenuated and CVA would act similarly to a low pass filter.

Additionally, increasing the wire voltage presents the risk of wire burnout. At a certain temperature (about $300^{\circ} \mathrm{C}$ for the TSI sensors), the wires have a high risk of breaking. This occurs at about $O H R=2.2$, so for the experimentation in this thesis using CVA II and the TSI sensors, it was ensured that the sensors never reached higher than OHR $=2$. My comparisons were done between $\mathrm{V}_{\mathrm{w}}=0.48 \mathrm{~V}$ and $0.58 \mathrm{~V}$ because increasing $\mathrm{V}_{\mathrm{w}}$ much higher than about $0.58 \mathrm{~V}$ in practice resulted in $\mathrm{OHR}$ greater than 2 with no air flow and much lower than $0.48 \mathrm{~V}$ results in very poor sensitivity, as described in Chapters 1 and 2.

It should now be noted that previously in Chapter 1 , the frequency response was only discussed in terms of its existence due to the thermal lag of the wire; however, ComteBellot demonstrated that the time constant is increased with lead resistance [7]. Explicit equations were formulated and testing was done [7] to show that the time constant can increase under certain conditions for the lead resistance, cold wire resistance, and wire overheat. For a ratio of lead resistance to cold resistance of 0.5 , and an $O H R=2$, the time constant was increased by as much as $15 \%$. These equations were taken into account and the thermal electrical model developed by Neumeister [1] was modified to get a better estimate for the time constants and subsequent cut-off frequencies. The updated code can be found in Appendix E. This code also includes radiation added into the heat transfer model; however, due to the high convection coefficient due to the forced convection, radiation heat transfer appears to be negligible in comparison. This was proved in 
simulations with the thermal electrical model as well as sample calculations. The updated model and a sample calculation can be found in Appendix F.

Looking back at Figure 1.2, the lead resistance is shown as $R_{L}$ in series with $R_{w}$. For the heat transfer model and EES prediction code, $R_{L}$ was ignored because it was thought to have an insignificant effect; however, Comte-Bellot showed that this is not the case [7]. When $R_{L}$ is not taken into account, instead of Ohm's law being presented as it is in equation (2.3), the equation becomes,

$$
V_{w}=I_{w} R_{w}
$$

When solved for the current in the wire while keeping the voltage constant, this model overestimates the wire current.

Taking the 3.8 micron TSI sensors operated at $V_{w}=0.58 \mathrm{~V}$ and a freestream velocity, $U=22 \mathrm{~m} / \mathrm{s}$ (resulting in $O H R=1.6$ ), Table 3.1 shows how the cutoff frequencies change as the lead resistance is varied. $L M$ is the correction factor developed in the article, $f_{C V A}$ is the theoretical half amplitude cut-off frequency with no correction, and $f_{C V A} l c$ is the corrected half amplitude cutoff frequency that accounts for the lead resistance.

Table 3.1 Variation in corrected half amplitude cut-off frequency for a TSI 3.8 micron sensor at freestream velocity of $22 \mathrm{~m} / \mathrm{s}$, resulting in OHR $=1.6$

\begin{tabular}{|c|c|c|c|}
\hline $\mathrm{R}_{\mathrm{L}}$ (ohms) & $\mathrm{LM}$ & $\mathrm{f}_{\mathrm{CVA}}(\mathrm{Hz})$ & $\mathrm{f}_{\mathrm{CVA} \_\mathrm{Ic}}(\mathrm{Hz})$ \\
\hline 0 & 1 & 2028 & 2028 \\
\hline 1 & 1.055 & 2028 & 1924 \\
\hline 2 & 1.106 & 2028 & 1837 \\
\hline 3 & 1.155 & 2028 & 1764 \\
\hline
\end{tabular}

The 3.8 micron TSI sensors likely have a lead resistance of less than an ohm which would decrease the half amplitude cut-off frequency by no more than $100 \mathrm{~Hz}$. While this is not much of a concern, sensors with a higher support resistance and lower cold resistance 
have the potential to have a noticeably lower half amplitude cut-off frequency. The 2.5 micron Dantec sensor used for experimentation in Chapter 5 has a higher lead resistance and lower cold resistance, so these effects needed to be discussed and kept in mind for those results.

To validate and demonstrate the implications of these predictions pertaining to operation of the wire voltage, the TSI sensors were first tested in the centerline of the turbulent jet, as described in Chapter 2 , at $V_{w}=0.48 \mathrm{~V}$ and $0.58 \mathrm{~V}$ using a $10 \mathrm{~mm}$ diameter nozzle.

\subsection{Turbulent Jet Measurements with $10 \mathrm{~mm}$ Nozzle}

The first tests completed were measurements taken at various streamline locations along the centerline of the turbulent jet issuing from a $10 \mathrm{~mm}$ diameter nozzle as shown in the diagram in Figure 2.6. Figure 3.2 shows the turbulence intensities at each point in the centerline plotted at each dimensionless distance from the nozzle exit for each of the two wire voltages. The data follows the pattern that is expected: about $1 \%$ turbulence intensity in the potential core that can be attributed to noise and about $17 \%$ and beginning to level out at 12.7 diameters away from the exit, but shows that there is very little difference in signal attenuation between the two voltages. The fact that the RMS results for both $V_{w}$ settings agree implies that either there is no attenuation taking place for either test, or that the half amplitude cut-off frequencies are not much different, as predicted above. Father out in the jet where there are higher frequency velocity fluctuations, the measurements for $V_{w}=0.58 \mathrm{~V}$ would be expected to be slightly higher because the cut-off frequency is theoretically slightly higher for $V_{w}=0.58 \mathrm{~V}\left(\sim 2 \mathrm{kHz}\right.$ compared to $\sim 1.9 \mathrm{kHz}$ for $\left.V_{w}=0.48 \mathrm{~V}\right)$; 
however, due to the small difference in cut-off frequency, the difference in measurements is negligible.

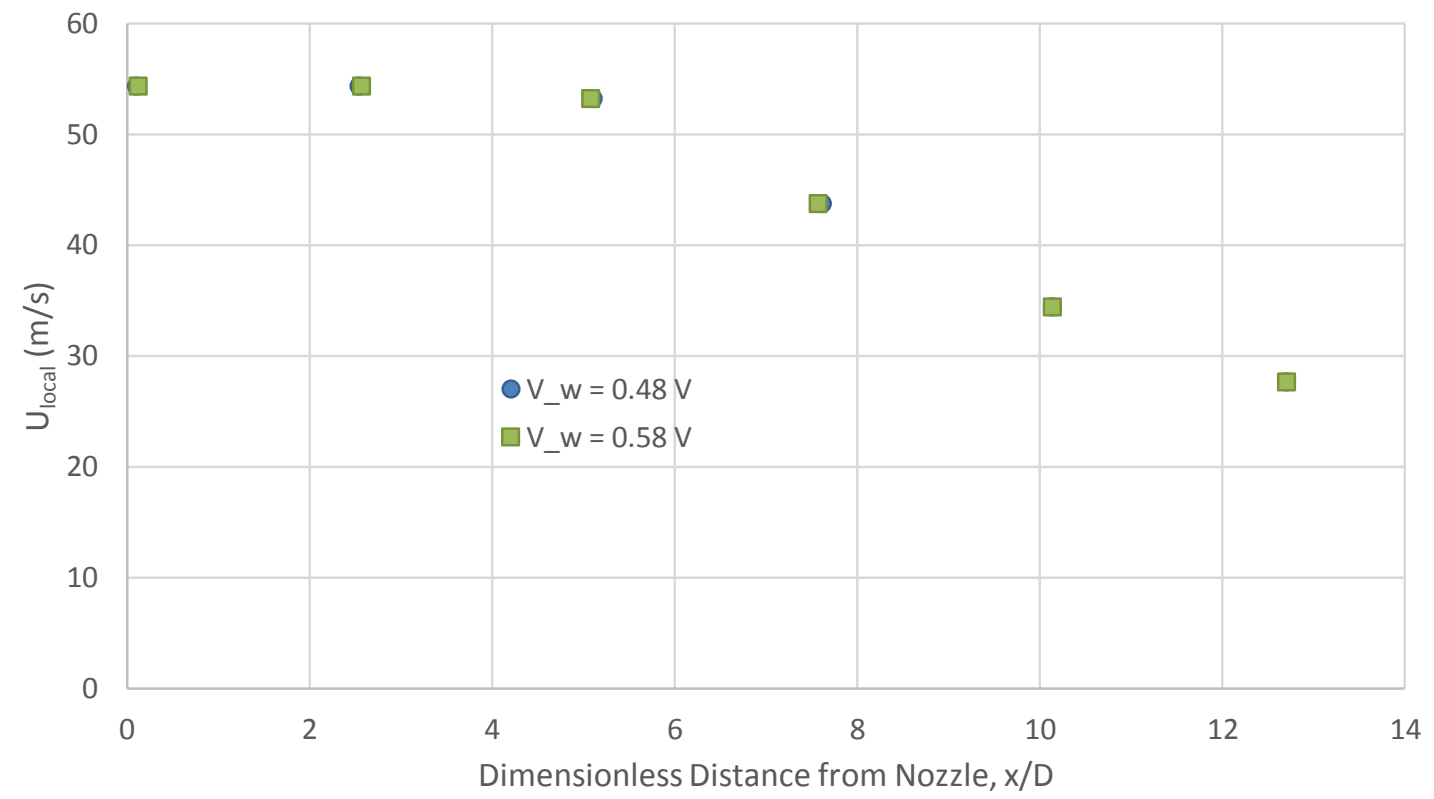

Figure 3.1 Comparison of mean local velocities at each point on the centerline of the turbulent jet with 10 $\mathrm{mm}$ diameter nozzle at $50 \mathrm{~m} / \mathrm{s}$ jet exit velocity

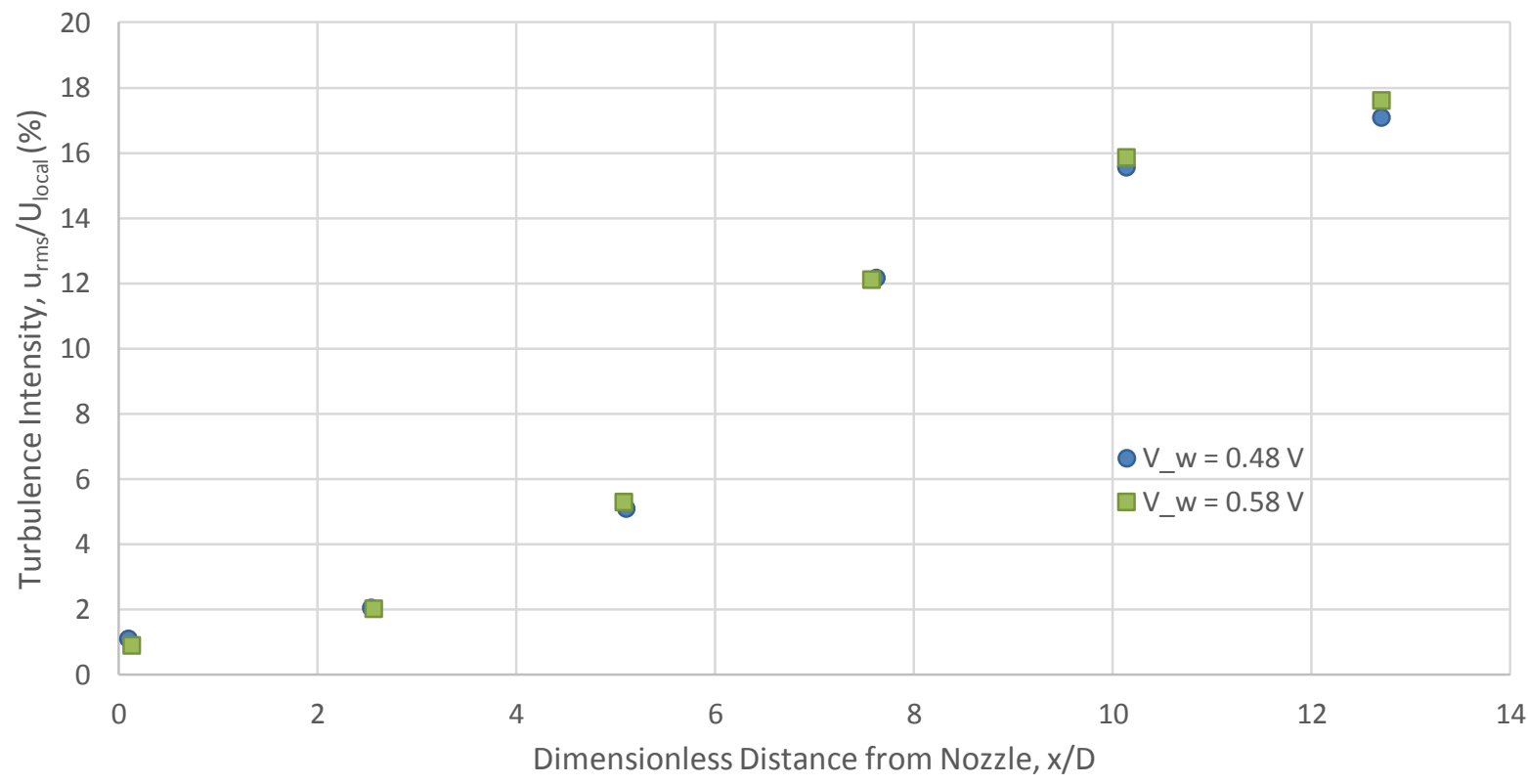

Figure 3.2 Comparison of turbulence intensities at each point on the centerline of the turbulent jet with 10 $\mathrm{mm}$ diameter nozzle at $50 \mathrm{~m} / \mathrm{s}$ jet exit velocity 


\subsection{Turbulent Jet Measurements with $5 \mathrm{~mm}$ Nozzle}

To see if the difference would be more significant farther away from the jet exit, measurements were taken under the same operating conditions for a $5 \mathrm{~mm}$ diameter nozzle. This allowed for measurements at $x / D=25.4$ where the flow should be closer to approaching self-similarity with more frequent fluctuations than those seen at $x / D=12.7$. Figure 3.4 shows the turbulence intensities at each point in the centerline plotted as a dimensionless distance from the nozzle exit for both wire voltages. These measurements showed a significant difference between the two wire voltages at each point outside of the core. Even at $x / D=5$ and 10 where there was no difference at all for the $10 \mathrm{~mm}$ nozzle tests, there are differences of about $2 \%$ and $5 \%$ turbulence intensity, respectively. This could quickly be attributed to the reduction in nozzle diameter scaling the high frequency turbulent velocity fluctuations enough to where the lower $O H R$ test attenuated a significantly higher amount of the signal than the higher $O H R$ test did; however, the results for the $10 \mathrm{~mm}$ and $5 \mathrm{~mm}$ nozzles should still agree at each dimensionless distance from the outlet. It should also be noted that the turbulence intensities appear to decrease for the last few measurements taken, which should not occur.

These suggest that there is other noise or inaccuracies present in the test. The core measurements should theoretically show no fluctuations but instead measured about $1 \%$ turbulence intensity. This can be attributed to electrical noise in the CVA II circuitry, but is not significant enough to be causing the error at hand. The electrical noise present would also be affecting both tests and would not cause the large shift observed. Due to the very small diameter of the nozzle, it is difficult to ensure that the sensor stays directly in the centerline of the jet. This is more prevalent farther away from the outlet which could 
explain the drop in intensities for the last three points. Wygnanski and Fiedler's data in Figure 2.10 supports this assertion as the intensities can be seen decreasing for lateral movement away from the centerline.

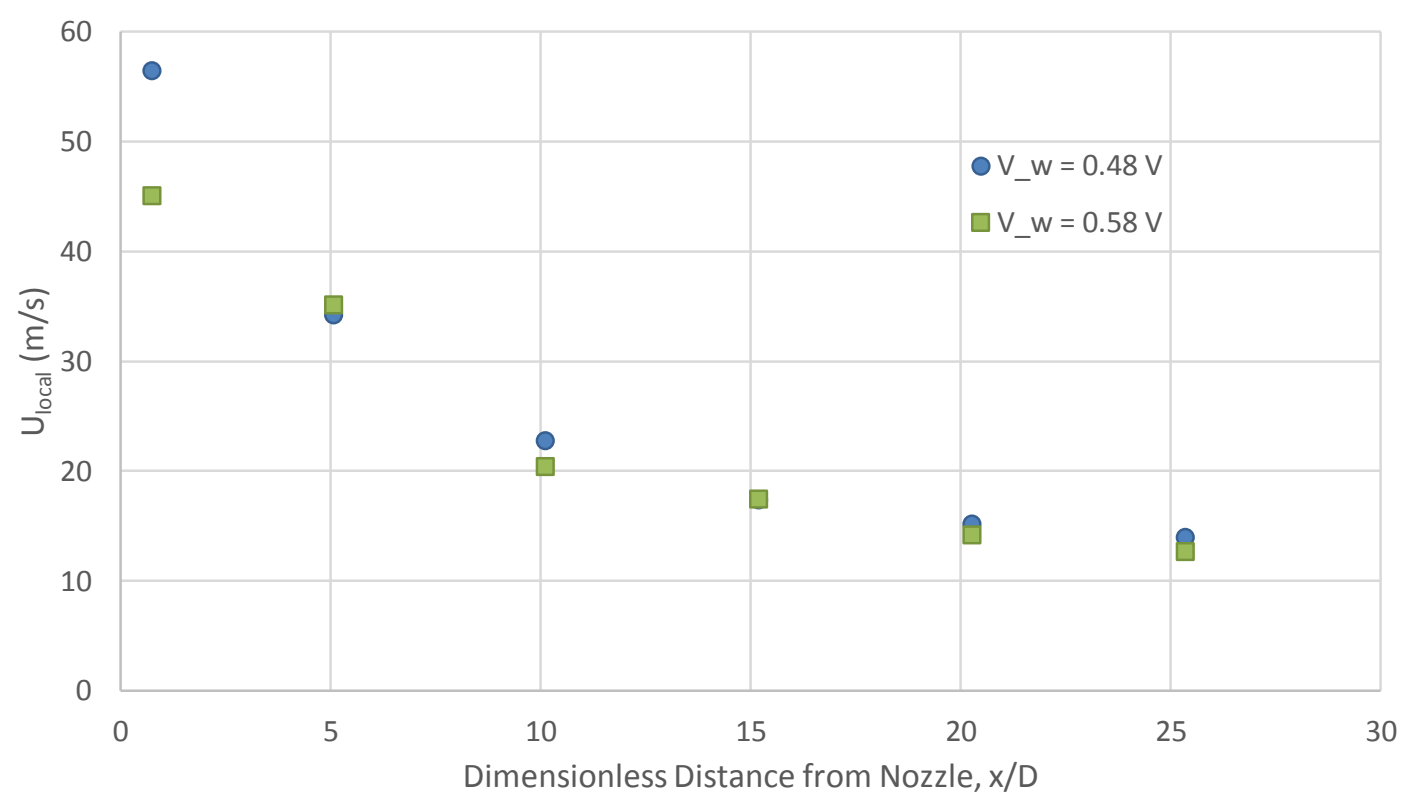

Figure 3.3 Comparison of local mean velocities at each point on the centerline of the turbulent jet with 5 $\mathrm{mm}$ diameter nozzle at $50 \mathrm{~m} / \mathrm{s}$ jet exit velocity 


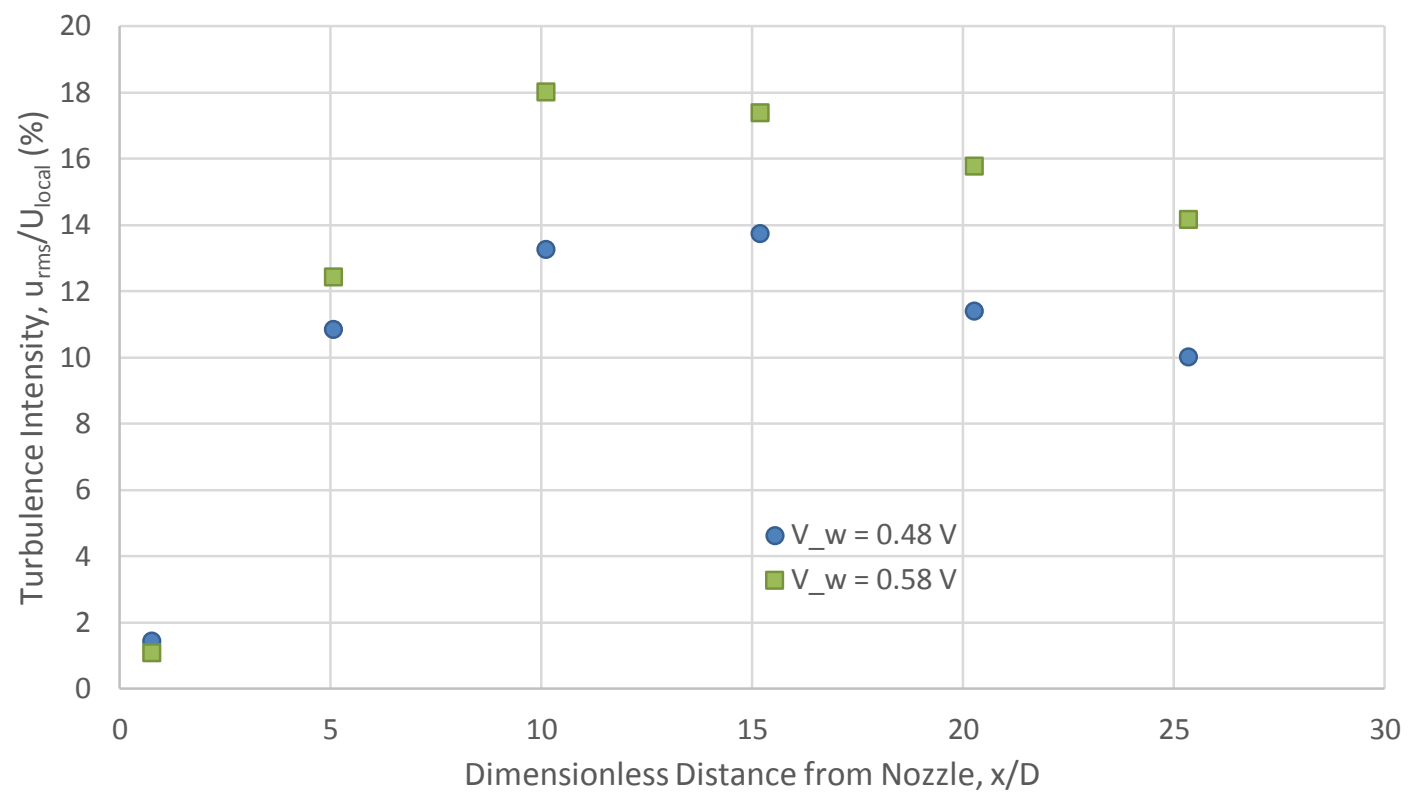

Figure 3.4 Comparison of turbulence intensities at each point on the centerline of the turbulent jet with 5 $\mathrm{mm}$ diameter nozzle at $50 \mathrm{~m} / \mathrm{s}$ jet exit velocity

To help diagnose the issues with the $5 \mathrm{~mm}$ nozzle tests, a test was completed using the $5 \mathrm{~mm}$ diameter nozzle at half of the jet exit speed $(U=25 \mathrm{~m} / \mathrm{s})$. In theory, the frequency of the turbulent velocity fluctuations would be back down in the same range as the previous test at $50 \mathrm{~m} / \mathrm{s}$ exit velocity and a $10 \mathrm{~mm}$ diameter nozzle if both the nozzle diameter and jet exit speed were halved ( $5 \mathrm{~mm}$ nozzle diameter and $25 \mathrm{~m} / \mathrm{s}$ jet exit velocity). So a test was done at these conditions to verify little difference between different $O H R$ values at each point in the jet centerline like with the $10 \mathrm{~mm}$ diameter test at $50 \mathrm{~m} / \mathrm{s}$ jet exit velocity. This test was limited because calibrations can only be done down to about $10 \mathrm{~m} / \mathrm{s}$ in air velocity with the calibration apparatus and the power supply being used and local mean velocity drops very quickly with the $5 \mathrm{~mm}$ nozzle. Using the calibration curve to find the fluctuations and local mean velocity was therefore inaccurate past about 10 diameters because the velocity dropped so low and the calibration was no longer good. The data from this test did show agreement at each point and plots of the data out to about 10 diameters are included for reference in Figures 3.5 and 3.6. 
Due to the low air speed and small nozzle diameter, the results were still unclear and the data does not agree perfectly. It is possible that the $5 \mathrm{~mm}$ nozzle test did scale the fluctuations enough to where the lower $O H R$ test had a significant amount of more attenuation, but the issues with the $5 \mathrm{~mm}$ nozzle test set-up make the results in Figure 3.4 inconclusive. The sensors were next tested in a turbulent boundary layer for a realistic scenario with a good range of fluctuations to make further conclusions about the effect of increasing wire voltage during operation.

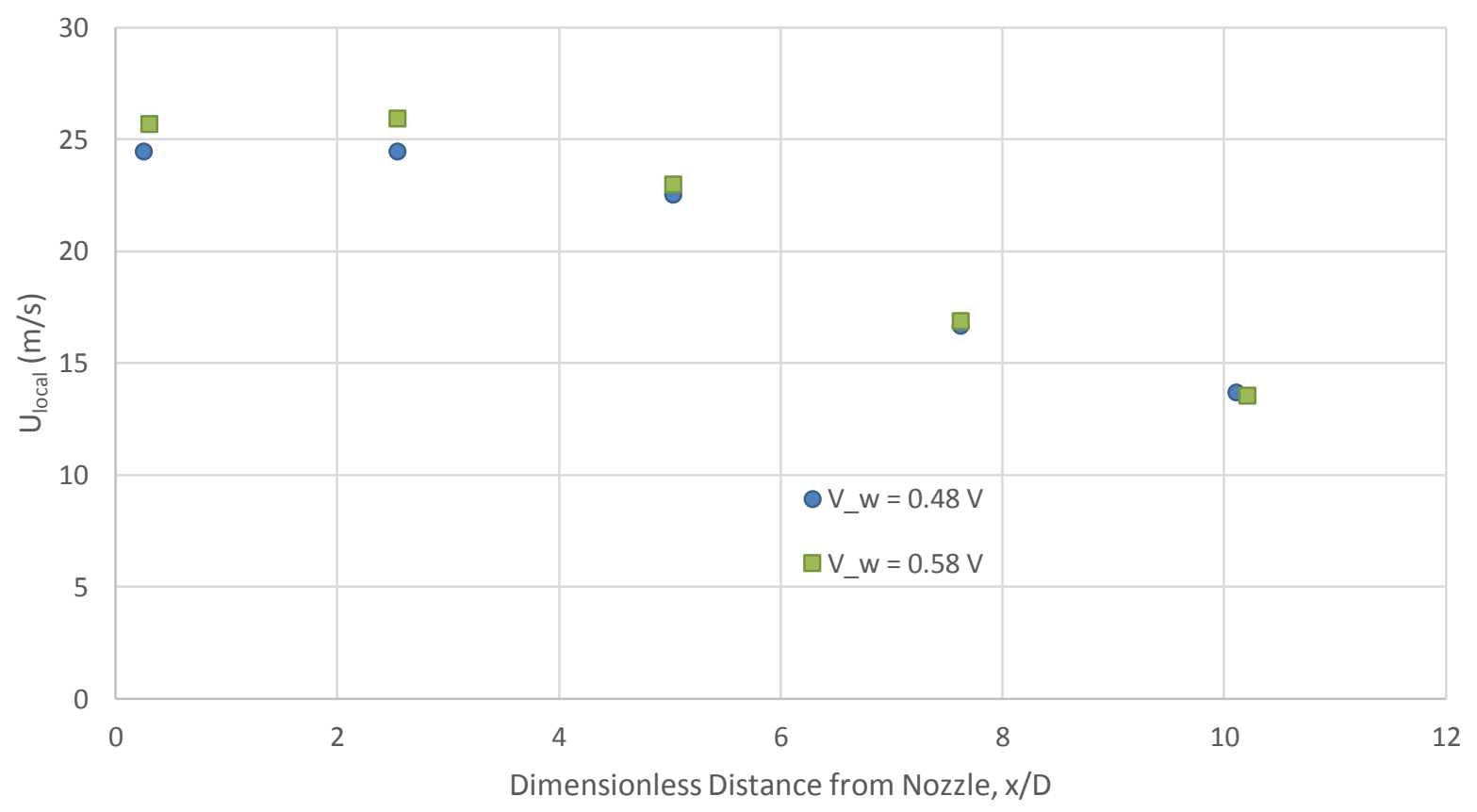

Figure 3.5 Comparison of local mean velocities at each point on the centerline of the turbulent jet with 5 $\mathrm{mm}$ diameter nozzle at $25 \mathrm{~m} / \mathrm{s}$ jet exit velocity 


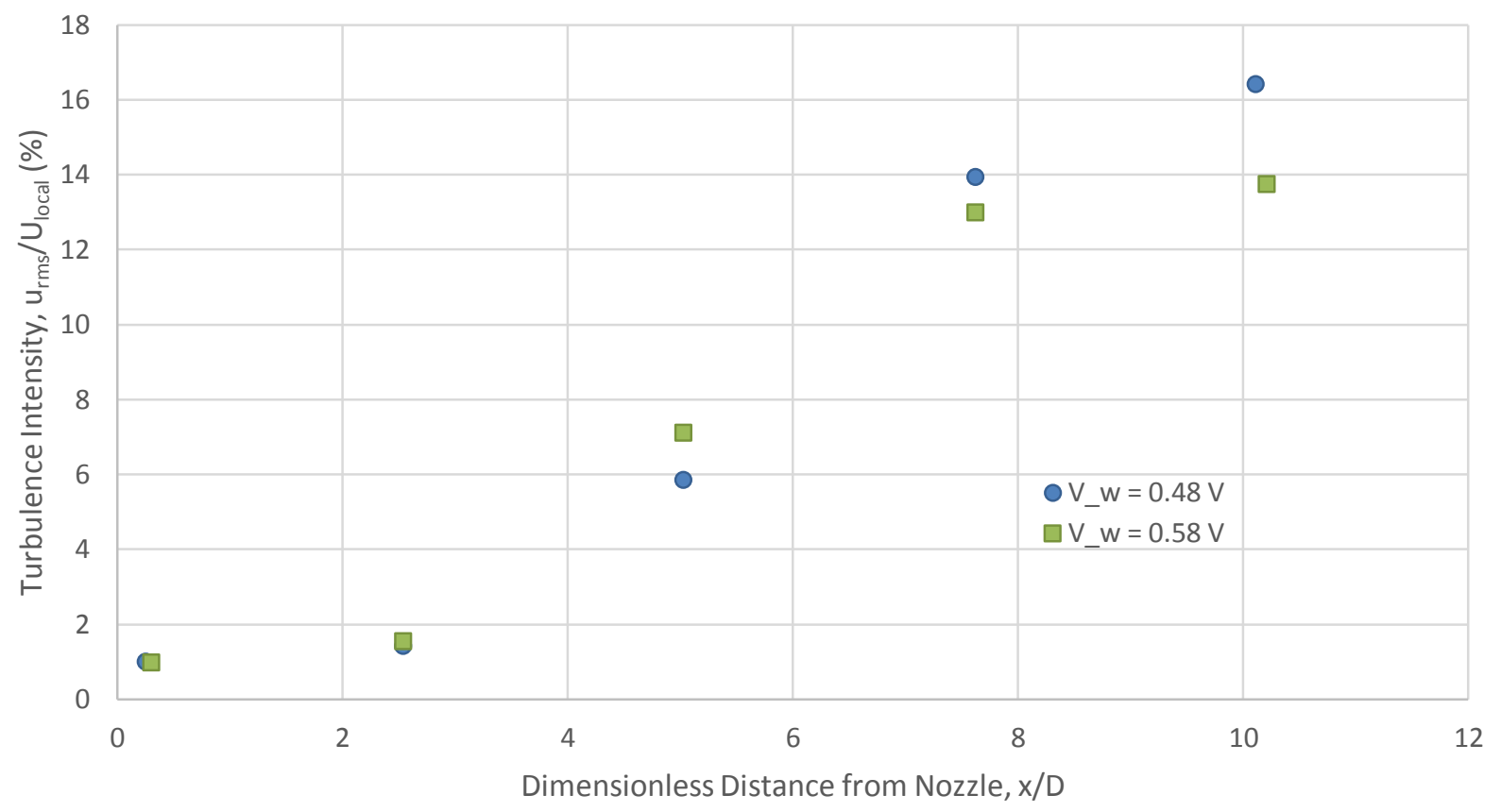

Figure 3.6 Comparison of turbulence intensities at each point on the centerline of the turbulent jet with 5 $\mathrm{mm}$ diameter nozzle at $25 \mathrm{~m} / \mathrm{s}$ jet exit velocity

\subsection{Boundary Layer Measurements}

Boundary layer measurements were taken as outlined in Chapter 2 for a more realistic test with a wider range of OHR's and frequencies. As mentioned at the end of Chapter 2 where the initial boundary layer measurements were compared to published data by Klebanoff [19] and Hon Li's [16] data, there is a very large amount of noise observed in the freestream where almost $2 \%$ turbulence intensity was measured. This is consistent with all tests, so was not a concern for comparing the differences between measurements with different values of $O H R$. Figure 3.10 reveals the minimal difference between the two cases tested. The possibility that the $V_{w}=0.48 \mathrm{~V}$ test would return slightly lower turbulence measurements due to attenuating more signal is clearly not the case because measurements throughout the whole profile appear consistent between each test. This is further confirmed 
when looking at the frequency spectra for various points in the boundary layer in Figures 3.11 to 3.13 where there appears to be no earlier roll off for the lower $V_{w}$ case or anything else to suggest that there might be more attenuation than in the $V_{w}=0.58 \mathrm{~V}$ case. Figure 3.9 shows the boundary layer profile where the dimensionless height in the boundary layer is plotted against the local velocities measured. These boundary layer measurements established confidence in the testing procedures with CVA II and agreement with the centerline measurements taken and theoretical cut off frequencies calculated, confirming that there is very little improvement in frequency response when increasing $V_{w}$ of the sensor to potentially dangerous levels. All data was taken using the $I_{w}$ output, and a wind tunnel calibration for each wire voltage can be found in Figures 3.7 and 3.8. These two calibrations reveal the effect of wire overheat on the sensitivity of the sensor. $I_{w}$ increases by $0.25 \mathrm{~V}$ for the entire velocity range in the $V_{w}=0.48 \mathrm{~V}$ case, whereas $I_{w}$ increases by $0.35 \mathrm{~V}$ over the same velocity range in the $V_{w}=0.58 \mathrm{~V}$ case. As discussed earlier, as the wire overheat is decreased, it becomes less of a velocity sensor and more of a temperature sensor. 


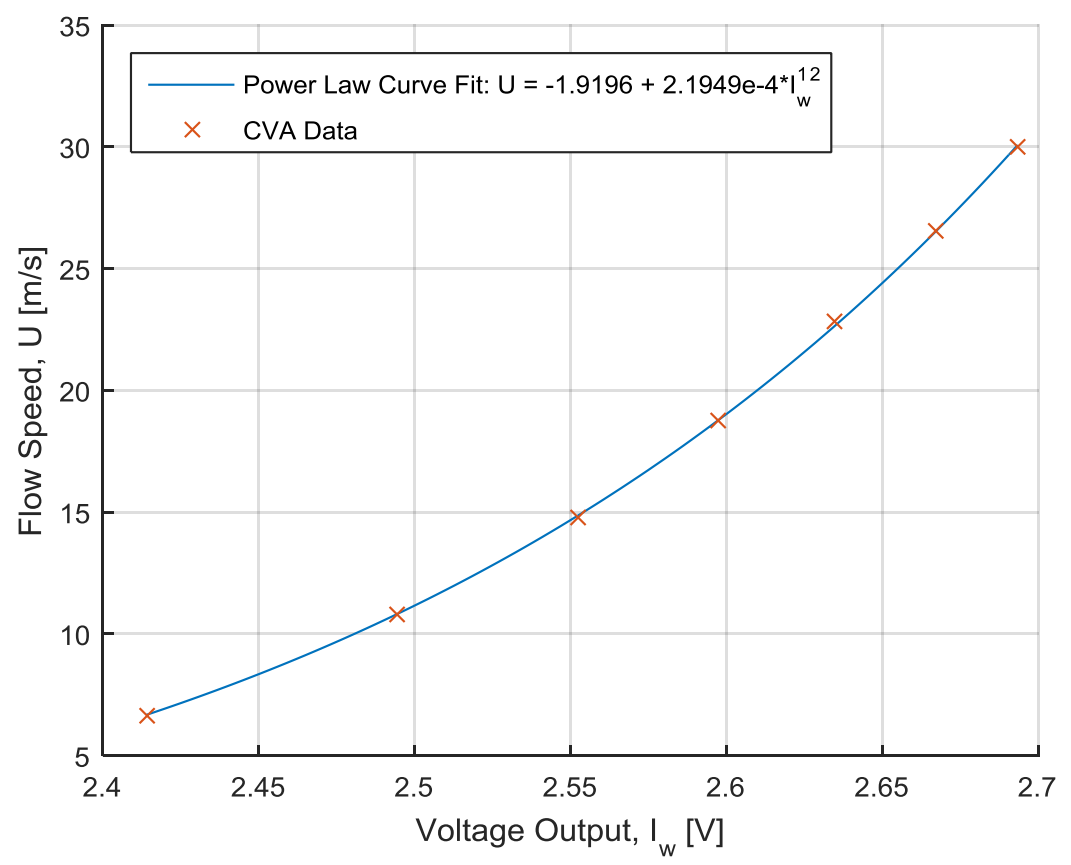

Figure 3.7 Sample $I_{w}$ calibration for $V_{w}=0.48 V$ used for boundary layer measurements at $U=23 \mathrm{~m} / \mathrm{s}$ and $\mathrm{f}_{\mathrm{s}}=2.5 \mathrm{kHz}$

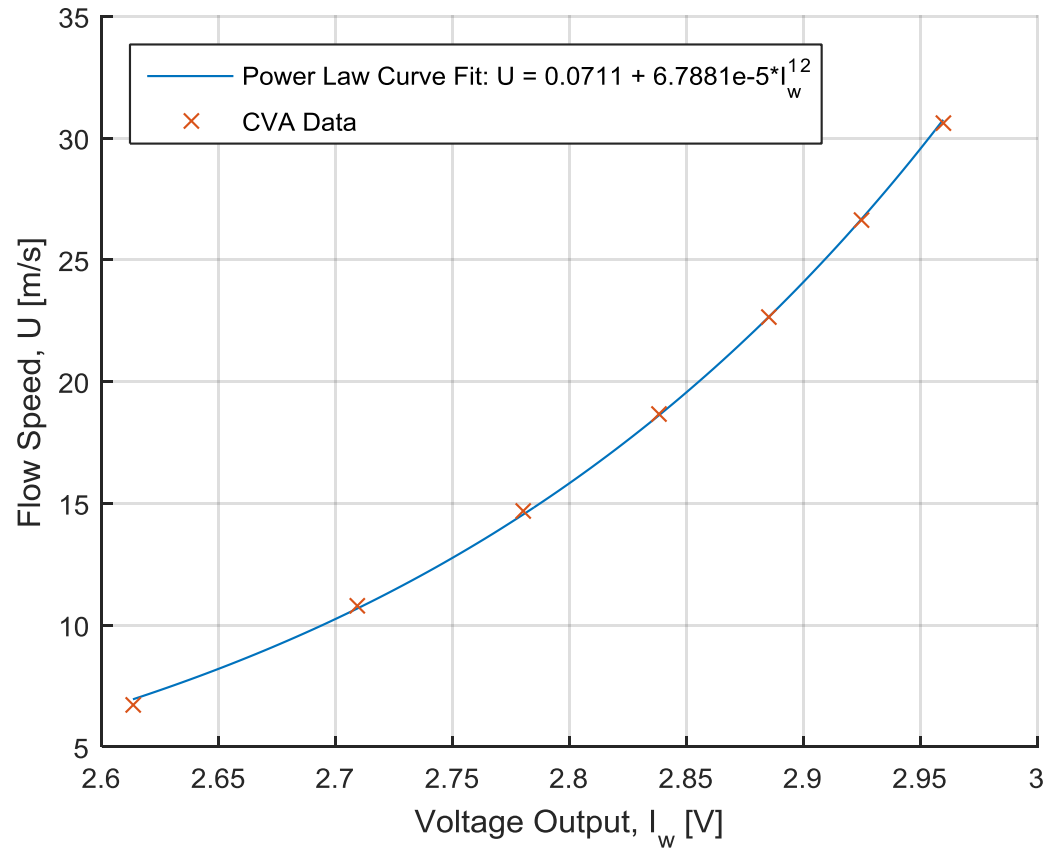

Figure 3.8 Sample $I_{w}$ calibration for $V_{w}=0.58 V$ used for boundary layer measurements at $U=23 \mathrm{~m} / \mathrm{s}$ and $\mathrm{f}_{\mathrm{s}}=2.5 \mathrm{kHz}$ 


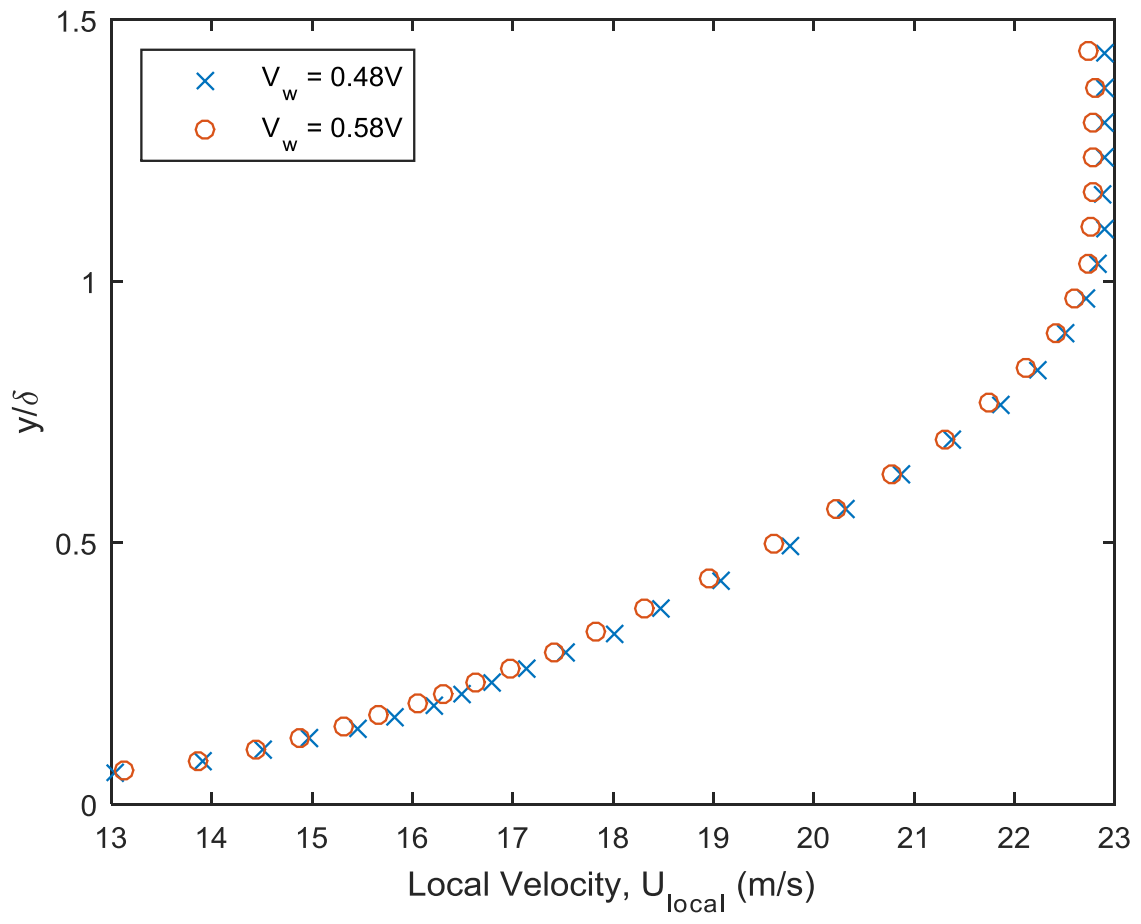

Figure 3.9 Mean velocities at each point for each $V_{w}$ test plotted for boundary layer measurements at $U=$ $23 \mathrm{~m} / \mathrm{s}$ and $\mathrm{f}_{\mathrm{s}}=2.5 \mathrm{kHz}$

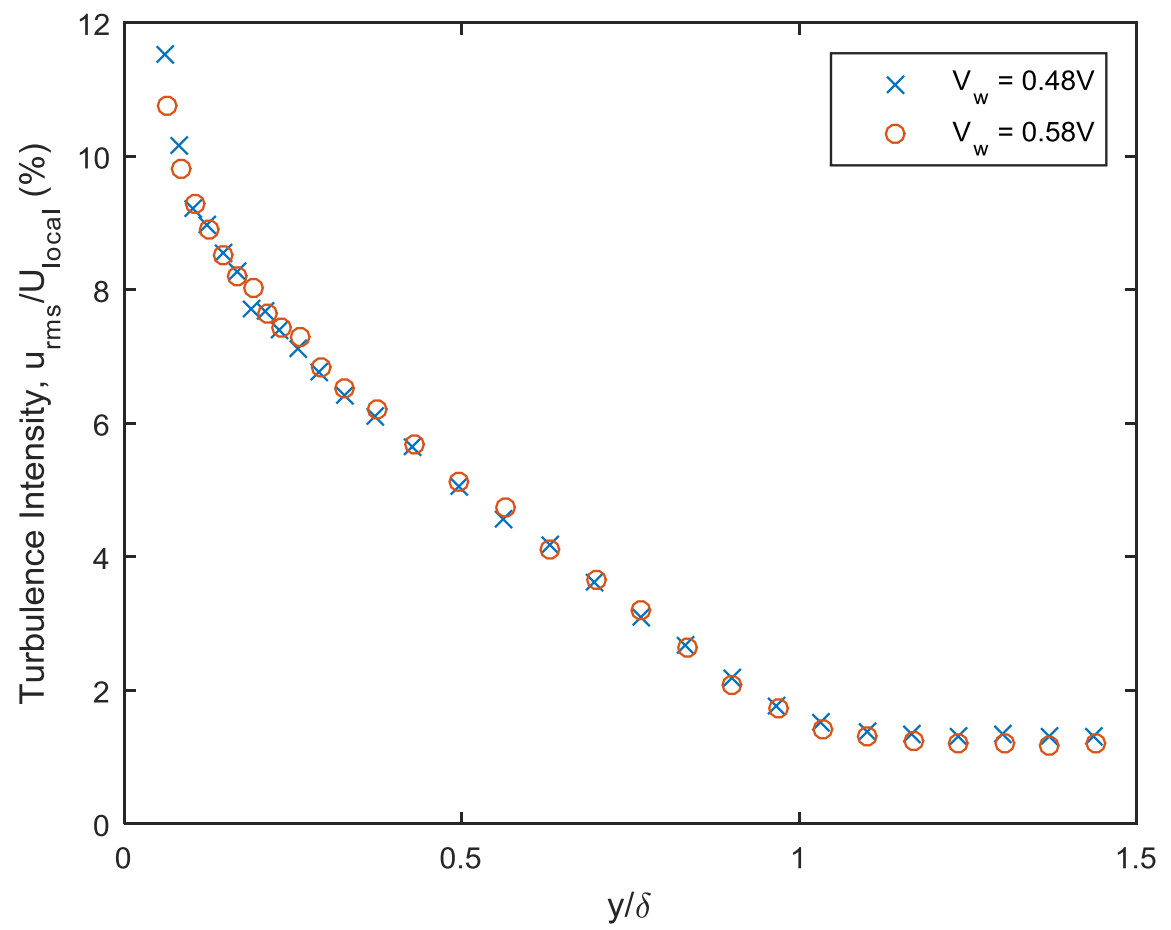

Figure 3.10 Turbulence intensities for each $V_{w}$ test for boundary layer measurements at $U=23 \mathrm{~m} / \mathrm{s}$ and $f_{s}$ $=2.5 \mathrm{kHz}$ 


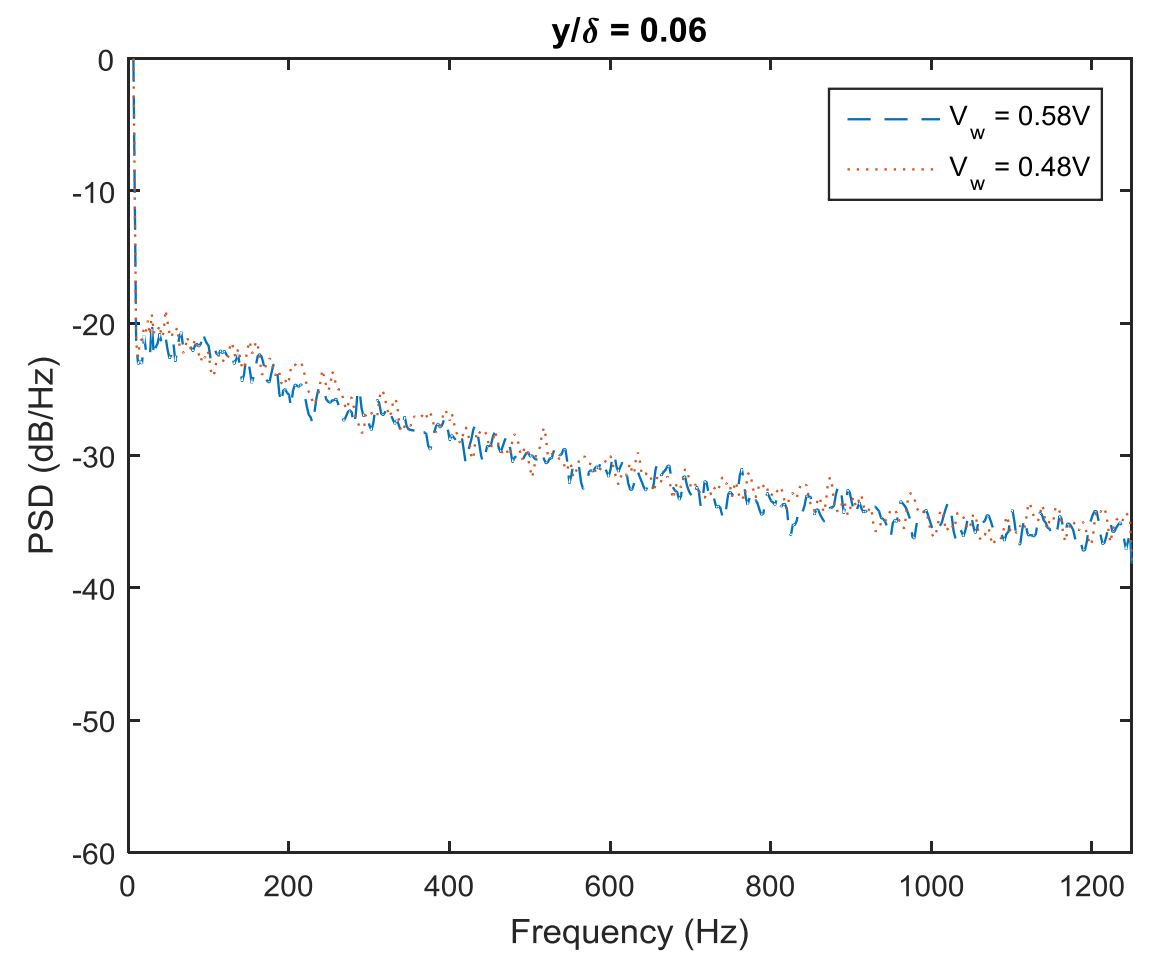

Figure 3.11 Frequency spectra for each $V_{w}$ test for the closest point to the wall at $U=23 \mathrm{~m} / \mathrm{s}$ and $\mathrm{f}_{\mathrm{s}}=2.5$ $\mathrm{kHz}$

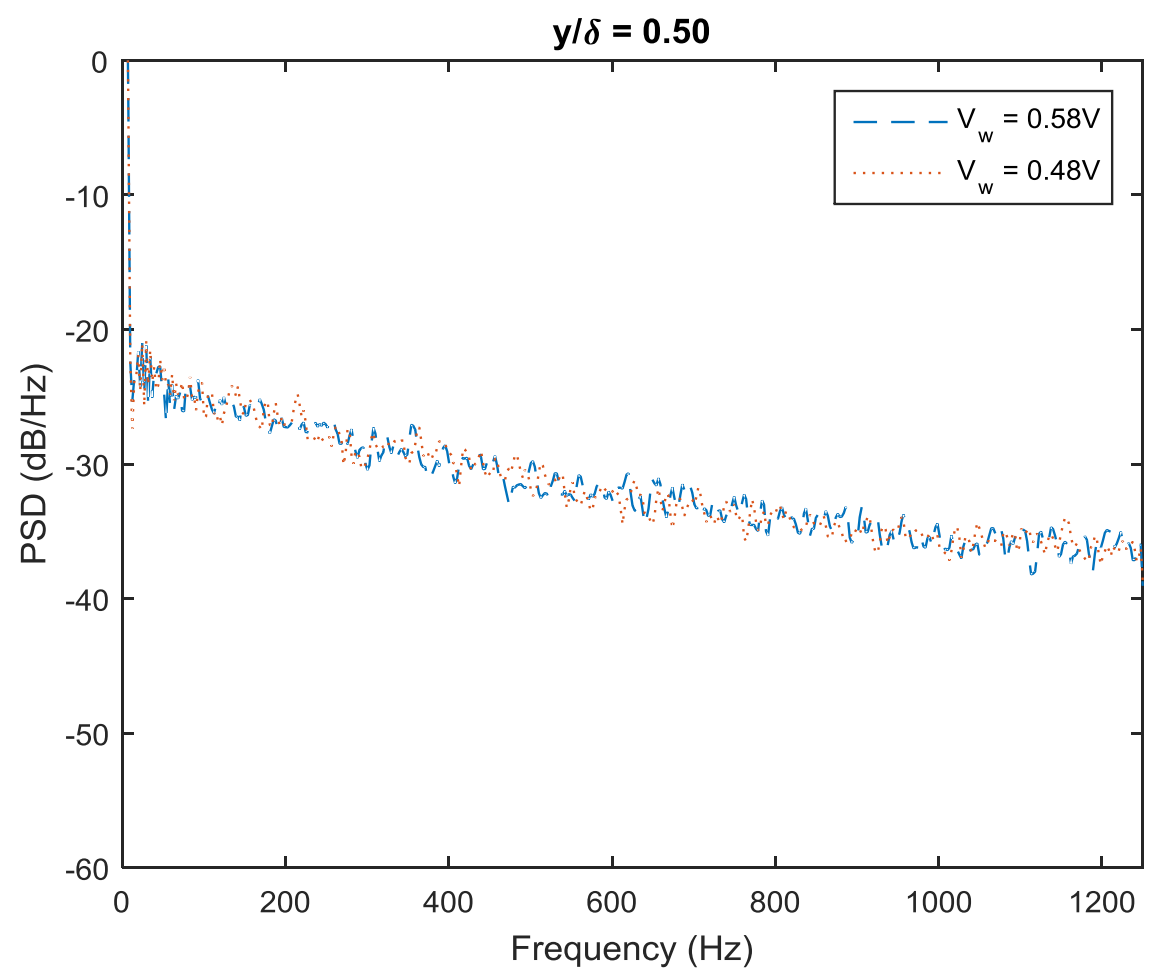

Figure 3.12 Frequency spectra for each $V_{w}$ test halfway through the boundary layer at $U=23 \mathrm{~m} / \mathrm{s}$ and $f_{s}=$ $2.5 \mathrm{kHz}$ 


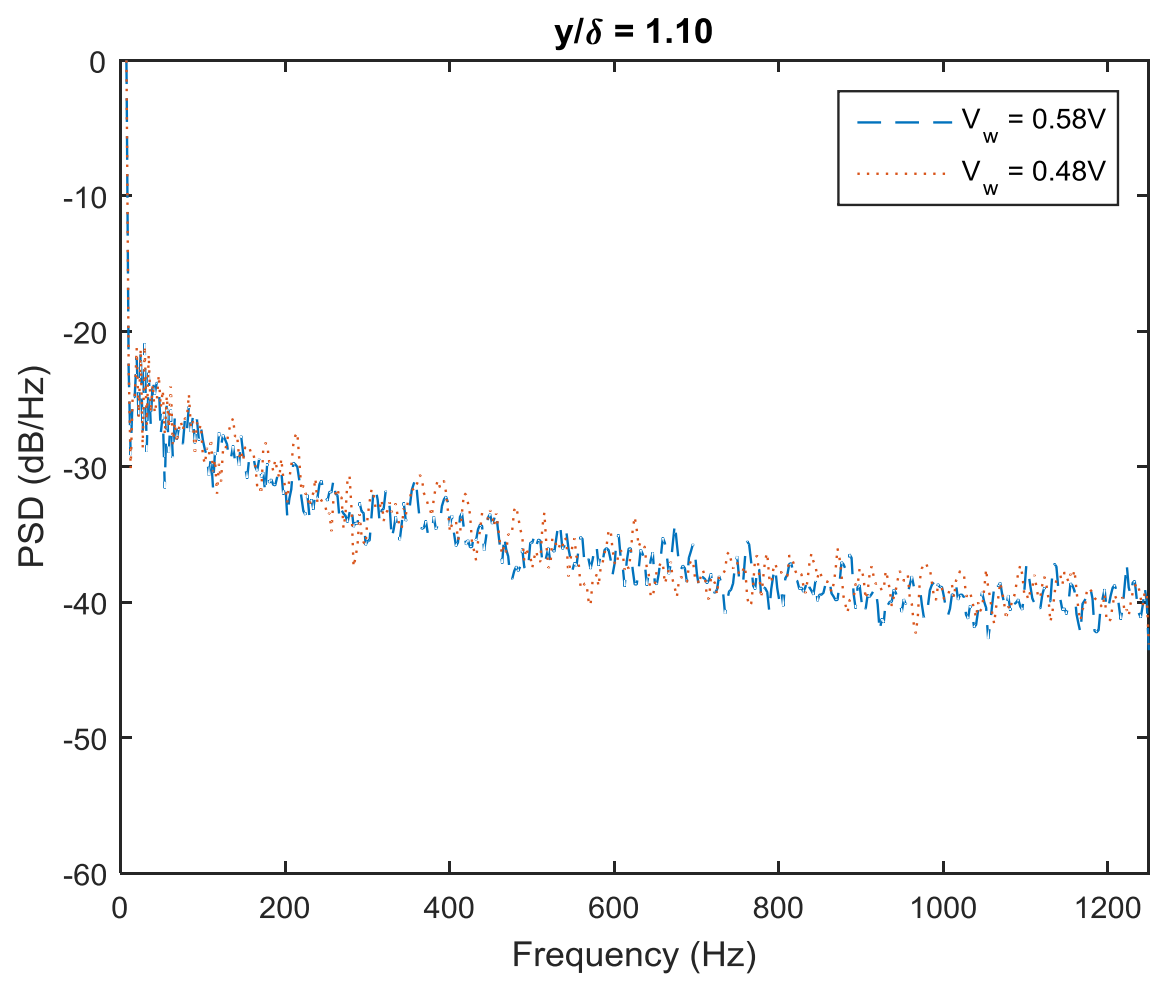

Figure 3.13 Frequency spectra for each $V_{w}$ test for a freestream point at $U=23 \mathrm{~m} / \mathrm{s}$ and $f_{s}=2.5 \mathrm{kHz}$

\subsection{Conclusions}

After observing tests for both the centerline of a turbulent jet and a turbulent boundary layer on a flat plate, it is apparent that the operation of CVA at higher $V_{w}$ (and therefore higher $\mathrm{OHR}$ ) does not result in a sizable improvement in frequency response that outweighs the danger of wire burnout. The theory and predicted values from calculations show that the improvement is only a few hundred hertz at best for the half amplitude cutoff frequency, and the tests appear to confirm the suspicion that this does not have a substantial effect on turbulence measurements. The limited range of wire voltages that the sensors can be tested for does not allow for enough adjustment to have any measureable effect on the centerline or boundary layer measurements. The upper limit of sensor temperature at which the danger of wire burnout is very high creates a limit for how sensitive the measurements 
are and how fast the wire can respond and limits the possible effectiveness of this method for improving frequency response.

Increasing the wire voltage does have a large effect on the sensitivity of CVA, which is why the sensors cannot be operated at too low of an OHR. At very low OHR, the sensors are not sensitive to velocity fluctuations; this is evidenced in calibrations like the one shown in Figure 2.5, where at higher velocity, the CVA outputs change far less for a given change in velocity. It is also well illustrated in the comparison of calibrations at different wire voltages like those in Figures 3.7 and 3.8. At lower overheats the sensors become far more sensitive to temperature. So although operating at higher overheats where the safety of the wire is more of a concern does not provide much of an improvement in frequency response, it is still good practice because the sensor is much more sensitive to fluctuations. 


\section{Compensation}

Compensation has been explored as a method for correcting for the wire thermal capacitance. Compensation can be thought of as a sort of "anti-filtering" in which the technique seeks to amplify the measurements that were attenuated because the sensor could not respond fast enough to the actual fluctuations. Two approaches have been explored: "hardware" compensation, and "software" compensation.

The Tao Systems technical note [14] outlines the hardware compensation network designed into the Tao CVA, where a variable compensation time constant can be set by the user for each specific sensor and flow condition. It can be operated by setting the variable time constant equal to the time constant of the sensor itself $\left(M_{C V A}\right)$, but because the time constant also varies with flow conditions as shown in (1.4), the time constant needs to be set at each point by way of an in-situ measurement using a square wave test. This requires user interaction during measurements which is not practical for application with the BLDS.

Hence, this chapter focuses on studying the effects of compensation done "downstream" of the measurements by way of time series post-processing. Comte-Bellot discusses a software compensation algorithm for the CVA signal, which has potential to alleviate signal attenuation while still maintaining the autonomous nature of BLDS [6]. By applying the algorithm shown in equation (4.1) to a large time series of data, the same concept of amplifying the attenuated measurements can be achieved.

$$
e_{c o r r}(i)=e_{\text {raw }}(i)+f_{S}\left[M_{C V A}\left(e_{r a w}(i)-e_{\text {raw }}(i-1)\right)\right]
$$

Here, $e_{\text {corr }}(i)$ is the software corrected CVA output sample at each time step in volts, $e_{\text {raw }}(i)$ is the raw CVA output sample at each time step in volts, $e_{\text {raw }}(i-1)$ is the raw CVA output sample at the previous time step in volts, $f_{s}$ is the sampling frequency in Hertz, 
and $M_{C V A}$ is the in situ measured time constant in seconds. Each sample is "corrected" by the addition of term on the right to its original value. For measurements with higher frequency fluctuations where not all of the fluctuations are captured due to attenuation, the data will not be as smooth, resulting in larger gaps between samples in the time series. These points will have a larger "correction" due to the difference between each sample and the one before it. This compensation algorithm is applied to data taken with CVA II in the centerline of a turbulent jet and a turbulent boundary layer on a flat plate for direct comparisons between compensated and uncompensated data. Results can be found in these following sections.

\subsection{Validation of Test Set-Up}

The test set-up outlined in Chapter 2 for collecting a large time series of data using the NI USB-6009 DAQ needed to be tested to confirm that there was no obvious difference between analog measurements taken with a Fluke and digital data taken with the data acquisition device and LabVIEW code. Time series $I_{w}$ data was acquired at 3 and 4 inches away from the $5 \mathrm{~mm}$ nozzle exit on the centerline of the turbulent jet, and the RMS voltage for $I_{w}$ was also measured with the Fluke. The results are tabulated in Table 4.1.

Table 4.1 Comparisons between mean and RMS data measured with a Fluke DVM and data calculated from a time series acquired with the NI DAQ

\begin{tabular}{|c|c|c|c|c|c|c|}
\cline { 2 - 7 } \multicolumn{1}{c|}{} & \multicolumn{3}{c|}{3 inches } & \multicolumn{3}{c|}{4 inches } \\
\cline { 2 - 7 } \multicolumn{1}{c|}{} & Fluke & DAQ & $\%$ Difference & Fluke & DAQ & \% Difference \\
\hline Mean (V) & 1.43 & 1.43 & 0.000 & 1.40 & 1.40 & 0.000 \\
\hline RMS $(\mathrm{mV})$ & 20.3 & 20.1 & 0.010 & 22.4 & 22.8 & -0.018 \\
\hline
\end{tabular}


Another check to ensure the test set-up was valid was to plot the time series data and compare it to an oscilloscope output of the same signal and confirm that the data was similar. These plots can be found in Figures 4.1 and 4.2.

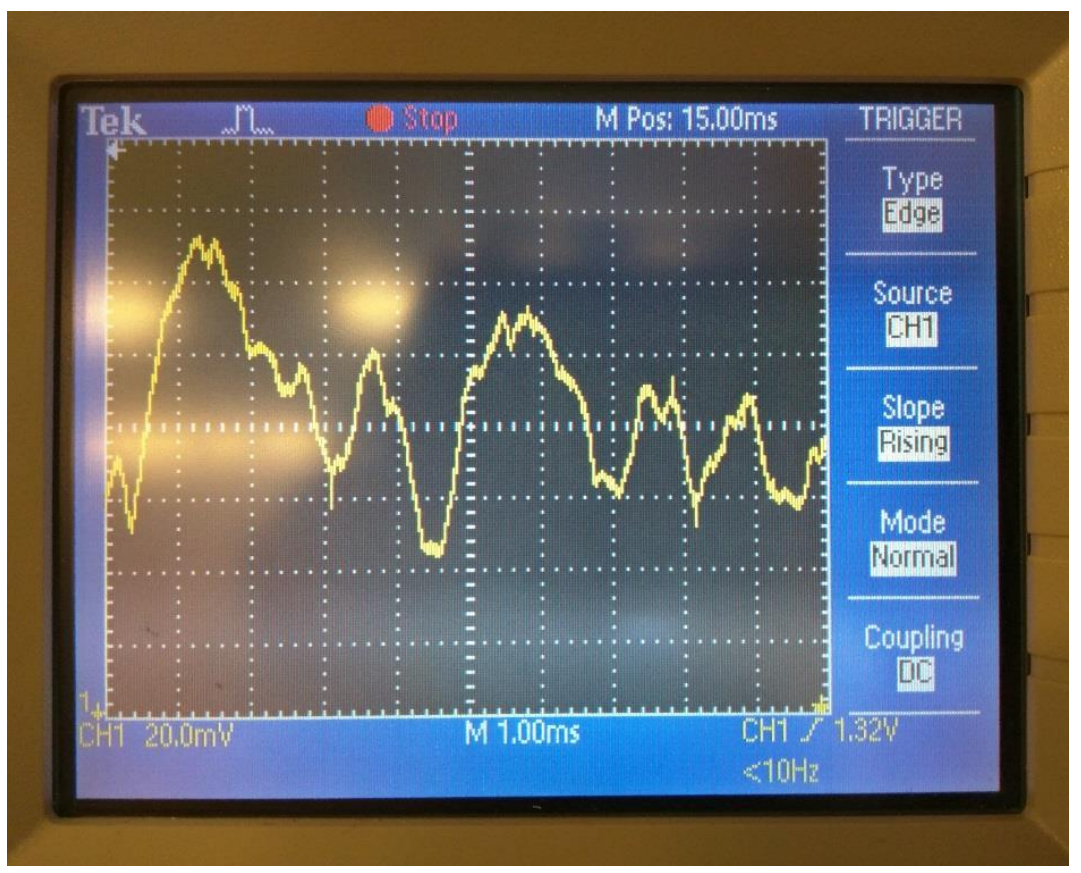

Figure 4.1 Oscilloscope output for $I_{w}$ signal in the centerline of a turbulent jet

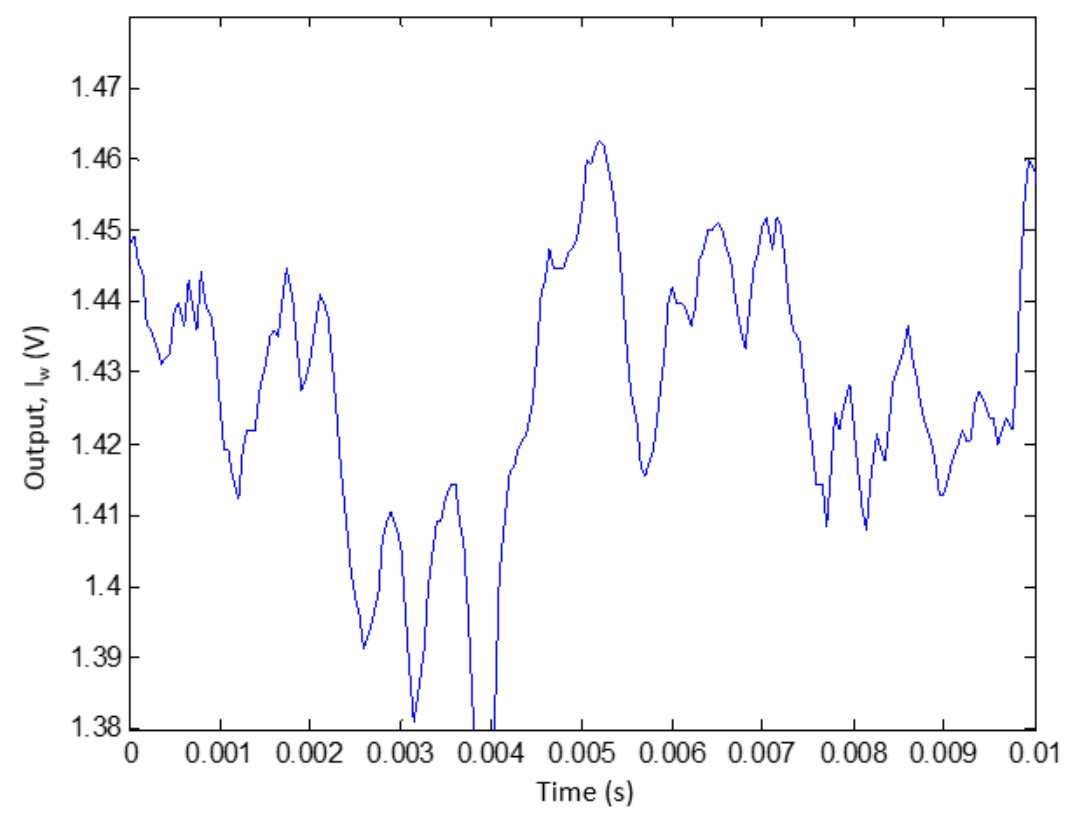

Figure 4.2 Plot of time series data for $I_{w}$ signal in the centerline of a turbulent jet taken with LabVIEW code and NI USB-6009 DAQ 
Noting in Figure 4.1 that each vertical axis grid line is $20 \mathrm{mV}$ apart, the total variation is about $\pm 40 \mathrm{mV}$ about a mean value which is very similar to the time series plot in Figure 4.2. The data is not exactly the same between the two figures because the tests could not be done at the exact same time; however, the similarity in magnitude and the agreement between Fluke and DAQ measurements in Table 4.1 is confidence enough to move forward with testing.

\subsection{Software Compensated Turbulent Jet Data}

For tests in this section, data was acquired at a sampling rate of $20 \mathrm{kHz}$ to ensure that all fluctuations could be captured and the frequency response could be observed well beyond the possible half amplitude cut-off frequency of the sensors. The time constant was calculated at each point on the centerline to be implemented in the time series correction. Calibrations for each nozzle test can be found in Figures 4.3 and 4.4. One thing to keep in mind for implementing compensation is that it should only affect the fluctuating data being measured. When observing the mean flow measurements, the compensated and uncompensated data should remain the same. This can be observed for centerline turbulence tests for each nozzle in Figures 4.5 and 4.6.

The fluctuations on the centerline of the jet should scale with distance away from the exit as shown in previous tests and theoretically there should be almost no fluctuations in the potential core of the jet. It would then follow that there would ideally be no measureable correction in the potential core, and more correction for the points farther downstream than for those closer to the jet exit; however, initial tests revealed that even the core measurement had a significant correction of the data after applying the compensation algorithm for both the $10 \mathrm{~mm}$ and $5 \mathrm{~mm}$ nozzle. The rest of the points appear 
to have a similar correction resulting in what appears to be a systematic shift in the data. This trend is revealed in the plots of turbulence intensity for the $10 \mathrm{~mm}$ and $5 \mathrm{~mm}$ nozzles in Figures 4.7 and 4.8, respectively.

Frequency spectra also help to visualize the data correction. The compensated and uncompensated spectra for the core measurement for the $10 \mathrm{~mm}$ and $5 \mathrm{~mm}$ nozzles are shown in Figures 4.9 and 4.10, respectively. The spectra for each nozzle look very similar, as expected. There should be no correction for the core measurement because there should be almost no fluctuations. The raw data shows very little energy after a few hundred hertz, and at low frequencies, the compensation has no effect on the spectra. However, from 1 $\mathrm{kHz}$ out to $10 \mathrm{kHz}$ where there should be virtually no energy as captured by the sensors for the raw data, the small amount of signal is still amplified a significant amount. This presence of energy from 1 to $10 \mathrm{kHz}$ is consistent with the high compensated value of turbulence intensity seen in both cases. The consistent spikes in the spectra appear to be 60 Hz noise.

The case appears to be the same for each point further downstream on the centerline as well. The compensation would be expected to scale the raw data in the $1-3 \mathrm{kHz}$ range where the CVA measurements are expected to roll off due to the time constant of the sensor. Due to the higher velocity fluctuations, there is more energy in the $1 \mathrm{kHz}$ range for points farther downstream as demonstrated in Figures 4.11 and 4.12 where spectra are shown for each case at a point 3 inches away from the jet exit (corresponding to $x / D=7.6$ and 15.1 for the $10 \mathrm{~mm}$ and $5 \mathrm{~mm}$ nozzles, respectively). Figures 4.13 and 4.14 show spectra 5 inches away from the nozzle exit for each test (corresponding to $x / D=12.7$ and 25.3 for the $10 \mathrm{~mm}$ and $5 \mathrm{~mm}$ nozzles, respectively). These plots again look as expected 
where there is more energy at lower frequencies for points that are more diameters away from the exit with a correction of data outside of about $1 \mathrm{kHz}$.

Noting that the raw fluctuation measurement for the potential core is not insignificant, electrical noise in the system becomes an immediate concern. The next section explores the potential sources of the electrical noise.

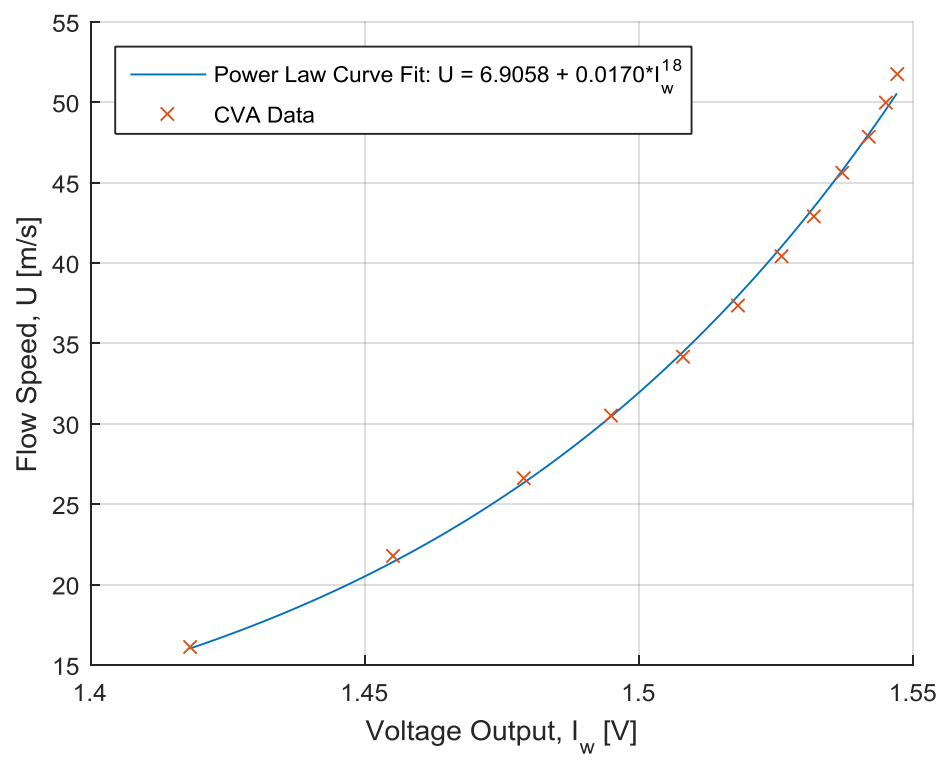

Figure 4.3 $\mathrm{I}_{\mathrm{w}}$ calibration used for $10 \mathrm{~mm}$ nozzle measurements 


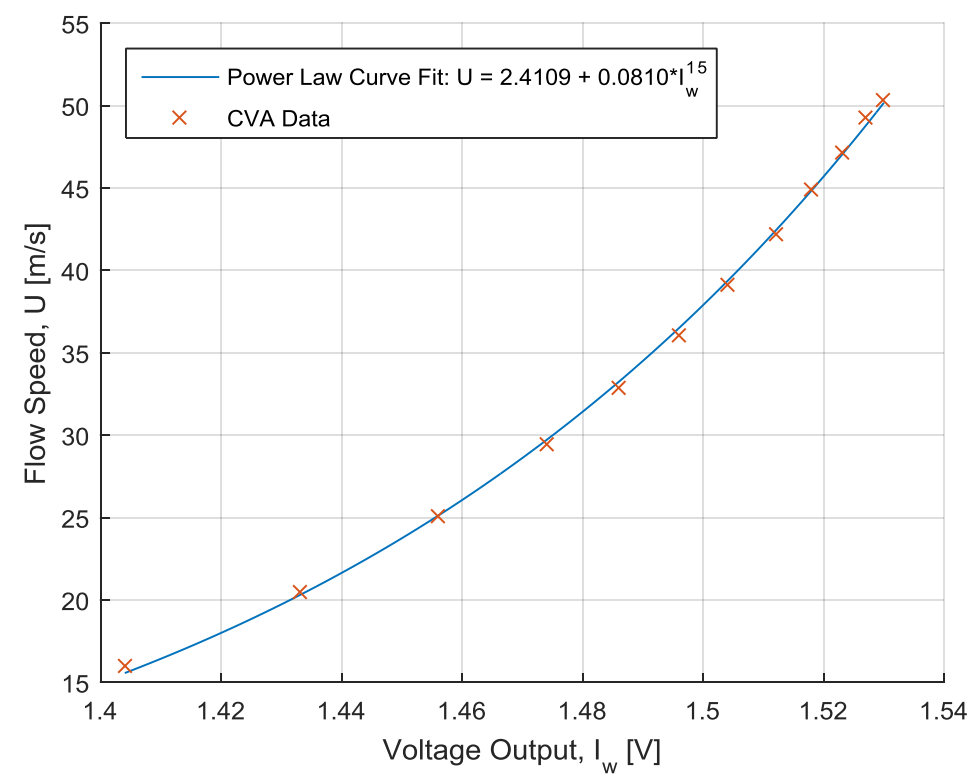

Figure 4.4 $\mathrm{I}_{\mathrm{w}}$ calibration used for $5 \mathrm{~mm}$ nozzle measurements

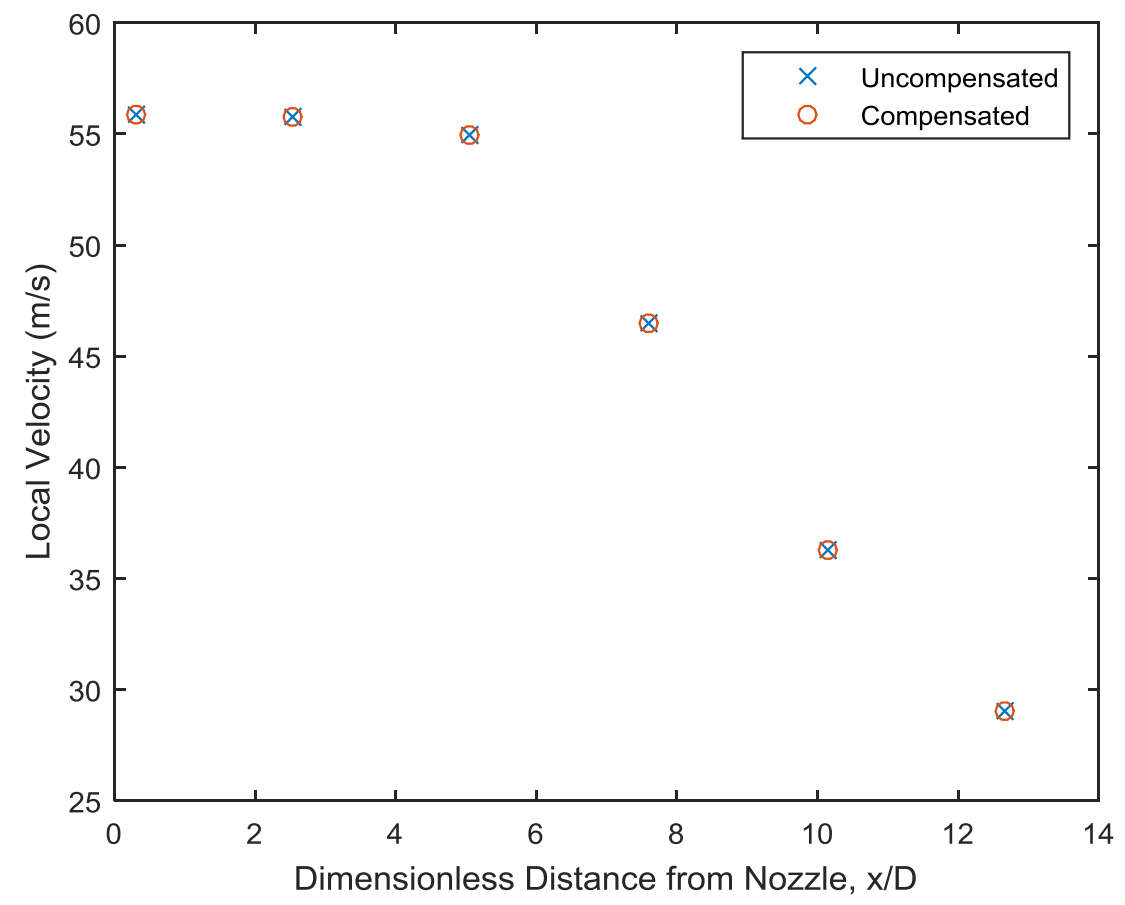

Figure 4.5 Comparison between mean local velocity measurements for $10 \mathrm{~mm}$ nozzle and $50 \mathrm{~m} / \mathrm{s}$ jet exit velocity for compensated and uncompensated data 


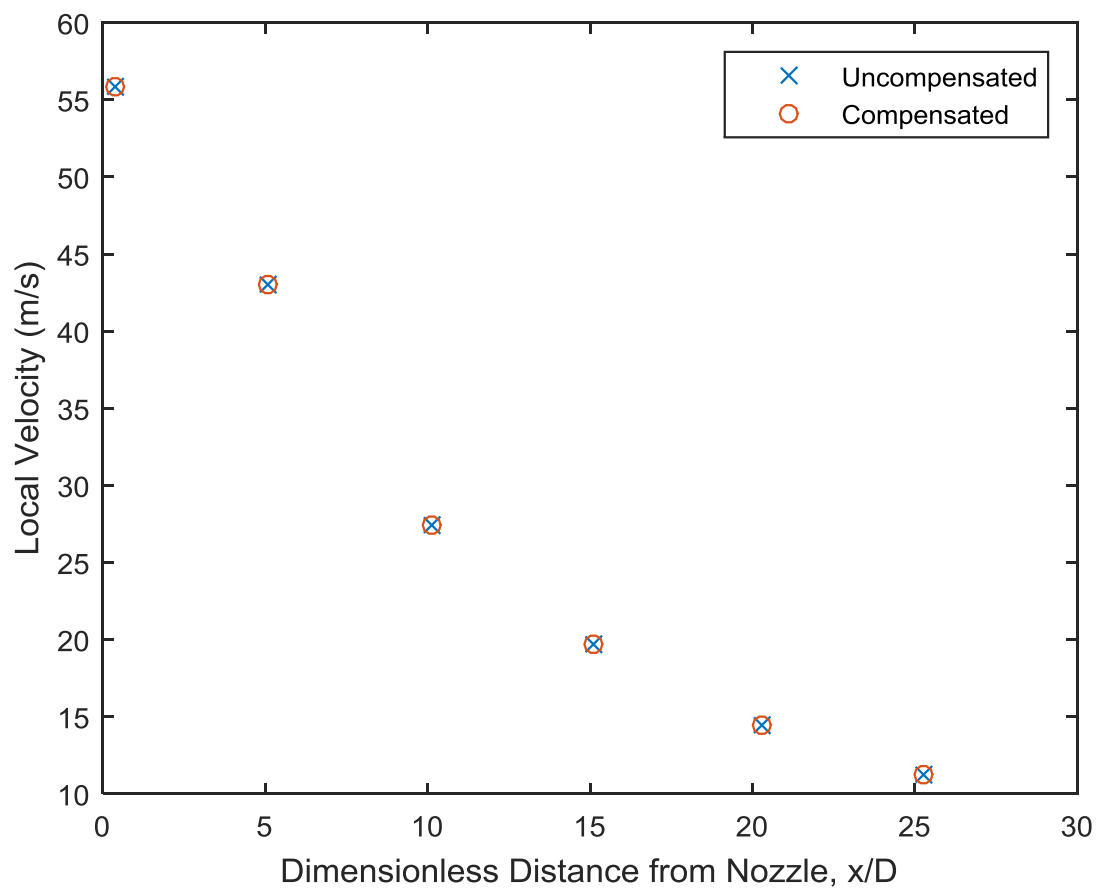

Figure 4.6 Comparison between mean local velocity measurements for $5 \mathrm{~mm}$ nozzle and $50 \mathrm{~m} / \mathrm{s}$ jet exit velocity for compensated and uncompensated data

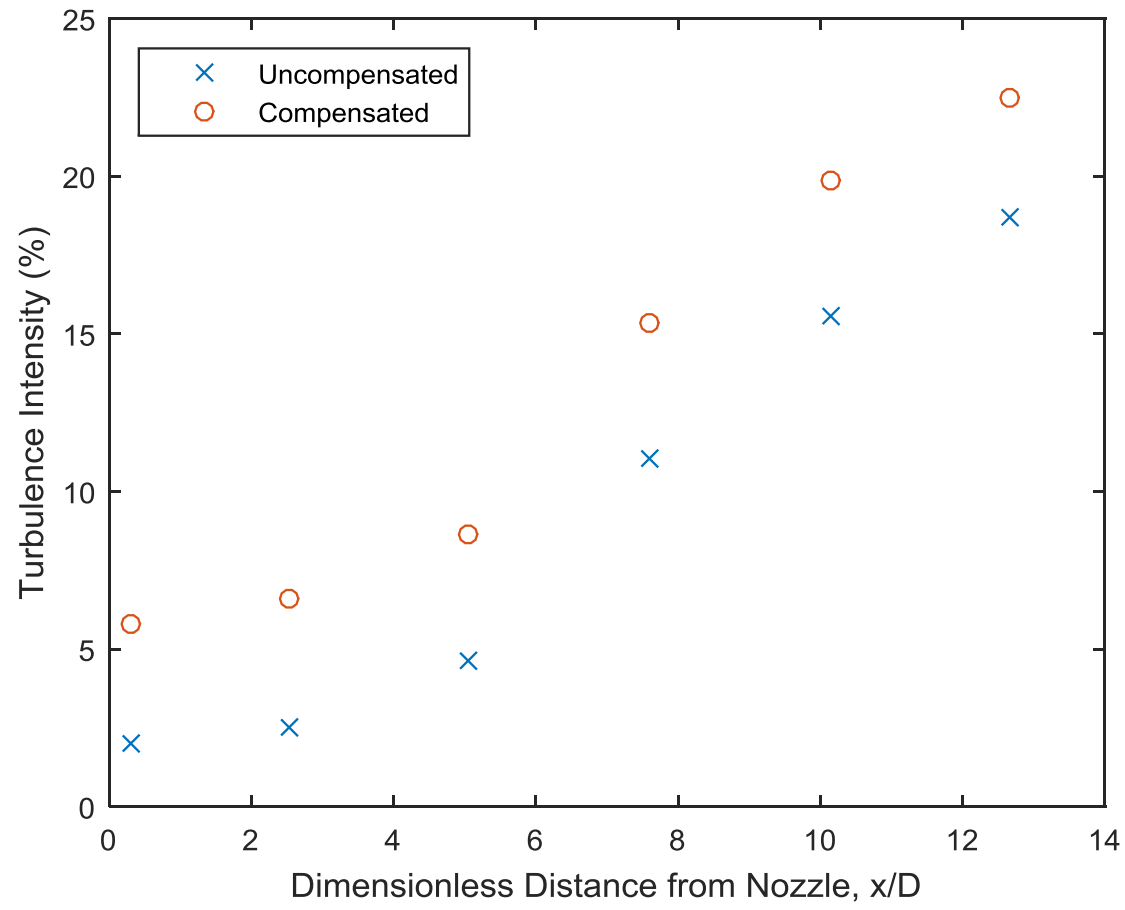

Figure 4.7 Comparison between turbulence intensity measurements for $10 \mathrm{~mm}$ nozzle and $50 \mathrm{~m} / \mathrm{s}$ jet exit velocity for compensated and uncompensated data 


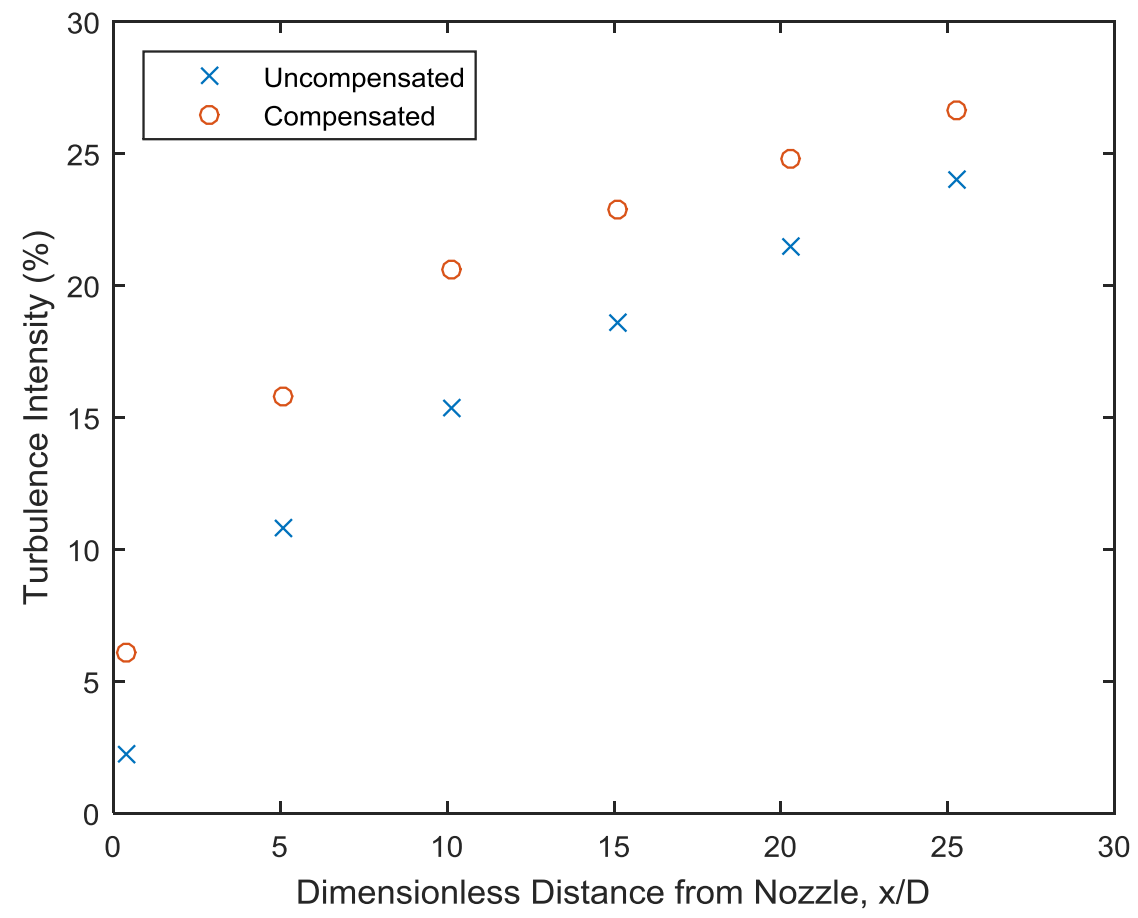

Figure 4.8 Comparison between turbulence intensity measurements for $5 \mathrm{~mm}$ nozzle and $50 \mathrm{~m} / \mathrm{s}$ jet exit velocity for compensated and uncompensated data

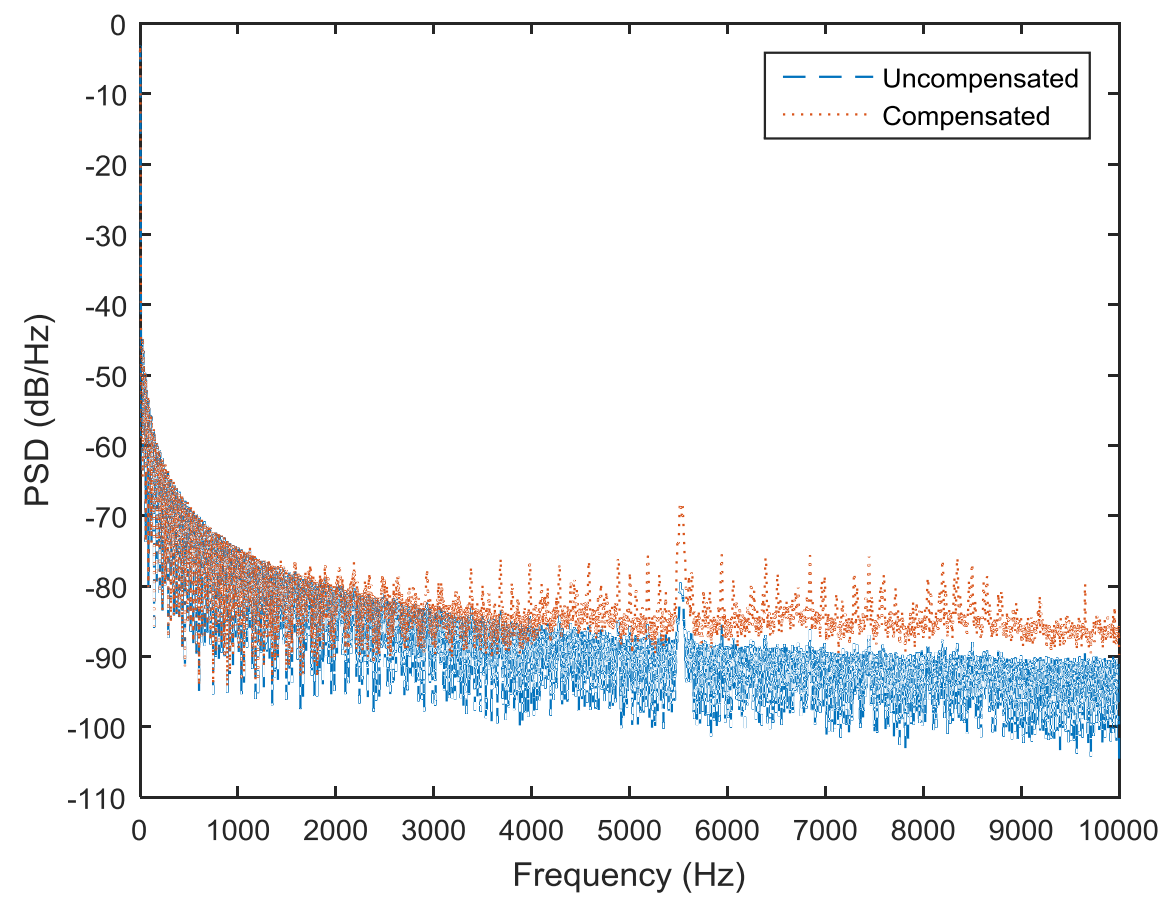

Figure 4.9 Comparison of compensated and uncompensated power spectral densities for $x / D=0.3$ on the centerline of the turbulent jet for $10 \mathrm{~mm}$ nozzle and $50 \mathrm{~m} / \mathrm{s}$ jet exit velocity 


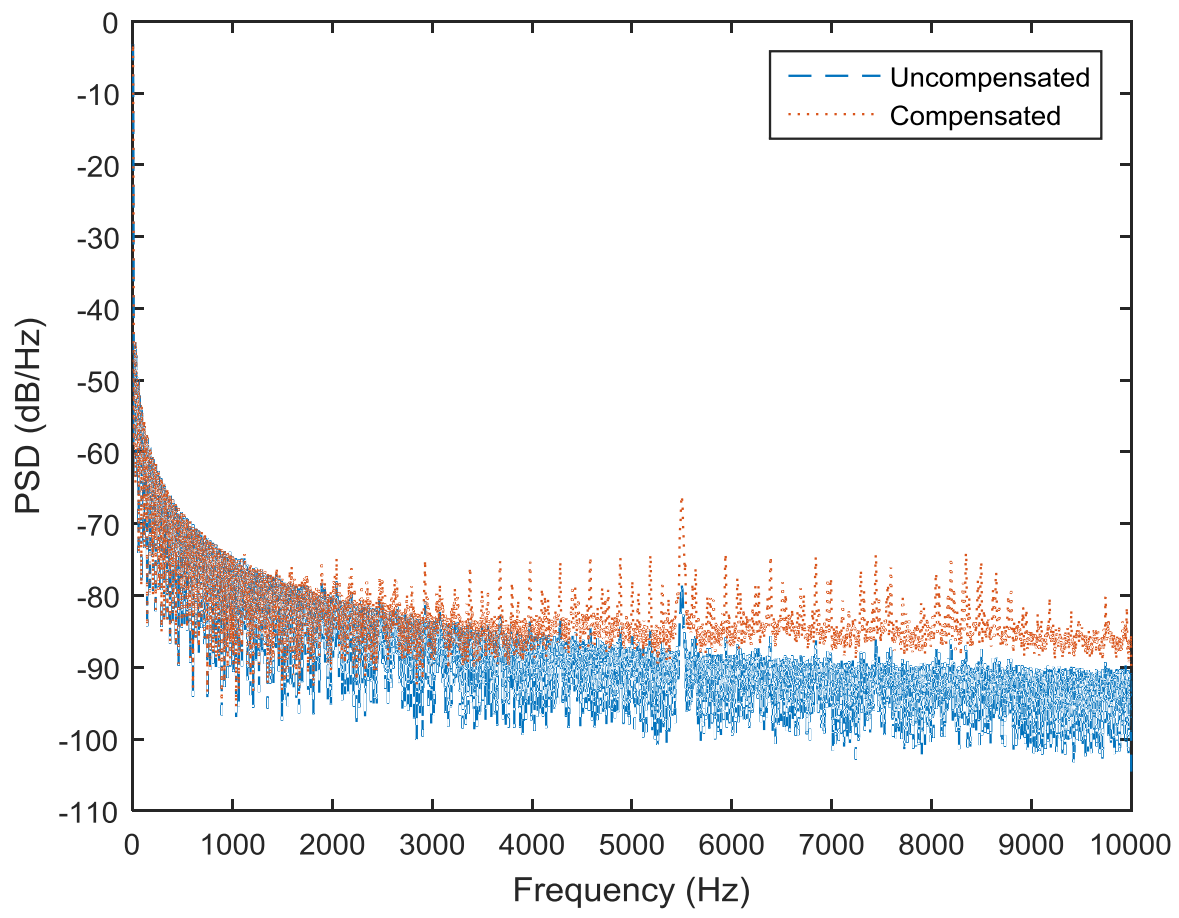

Figure 4.10 Comparison of compensated and uncompensated power spectral densities for $\mathrm{x} / \mathrm{D}=0.4$ on the centerline of the turbulent jet for $5 \mathrm{~mm}$ nozzle and $50 \mathrm{~m} / \mathrm{s}$ jet exit velocity

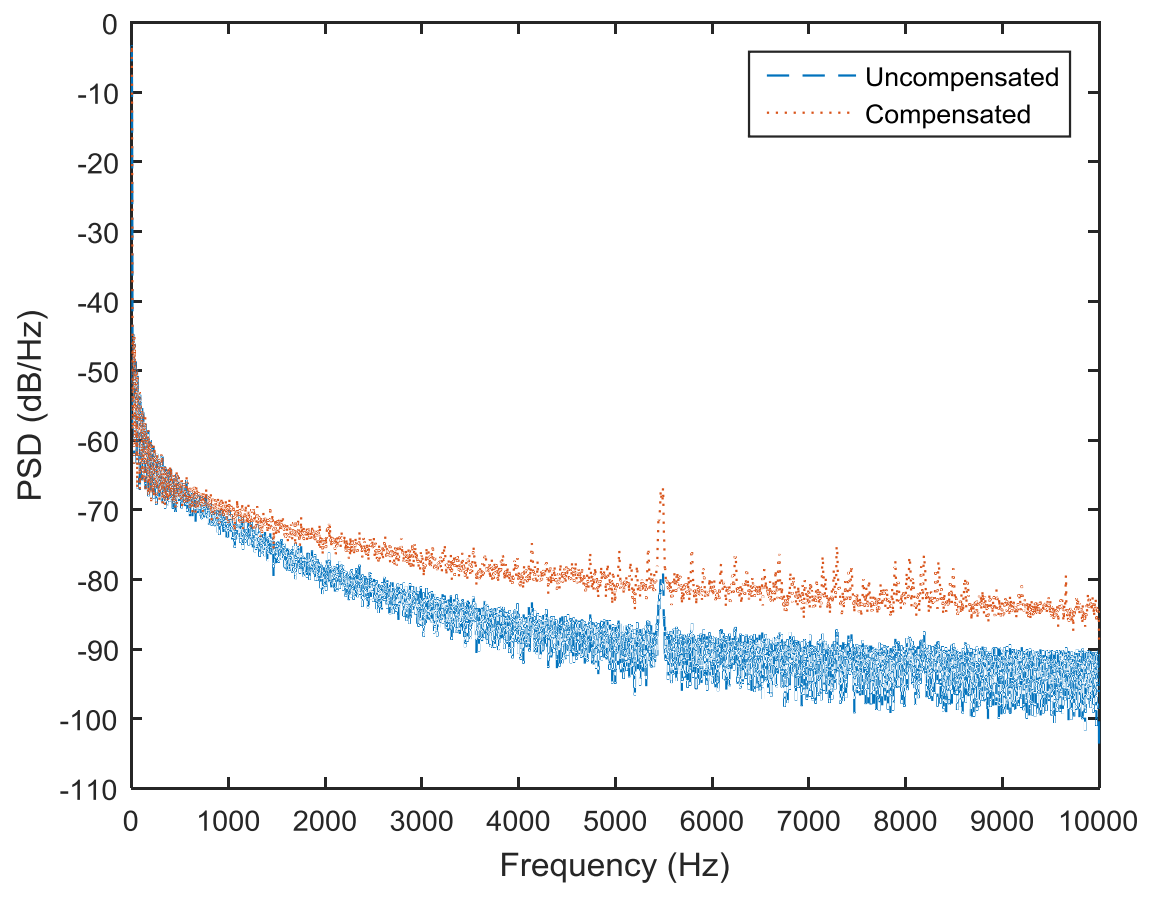

Figure 4.11 Comparison of compensated and uncompensated power spectral densities for $\mathrm{x} / \mathrm{D}=7.6$ on the centerline of the turbulent jet for $10 \mathrm{~mm}$ nozzle and $50 \mathrm{~m} / \mathrm{s}$ jet exit velocity 


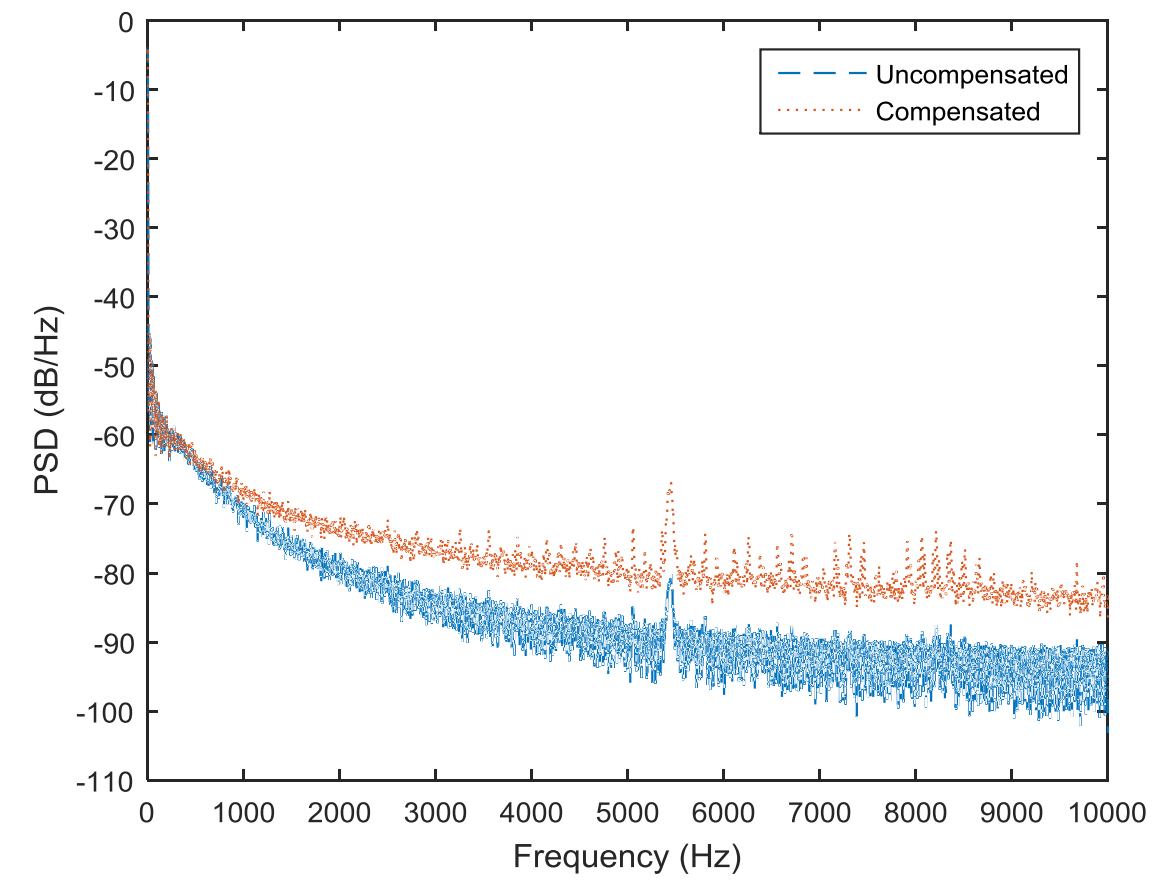

Figure 4.12 Comparison of compensated and uncompensated power spectral densities for $\mathrm{x} / \mathrm{D}=15.1$ on the centerline of the turbulent jet for $5 \mathrm{~mm}$ nozzle and $50 \mathrm{~m} / \mathrm{s}$ jet exit velocity

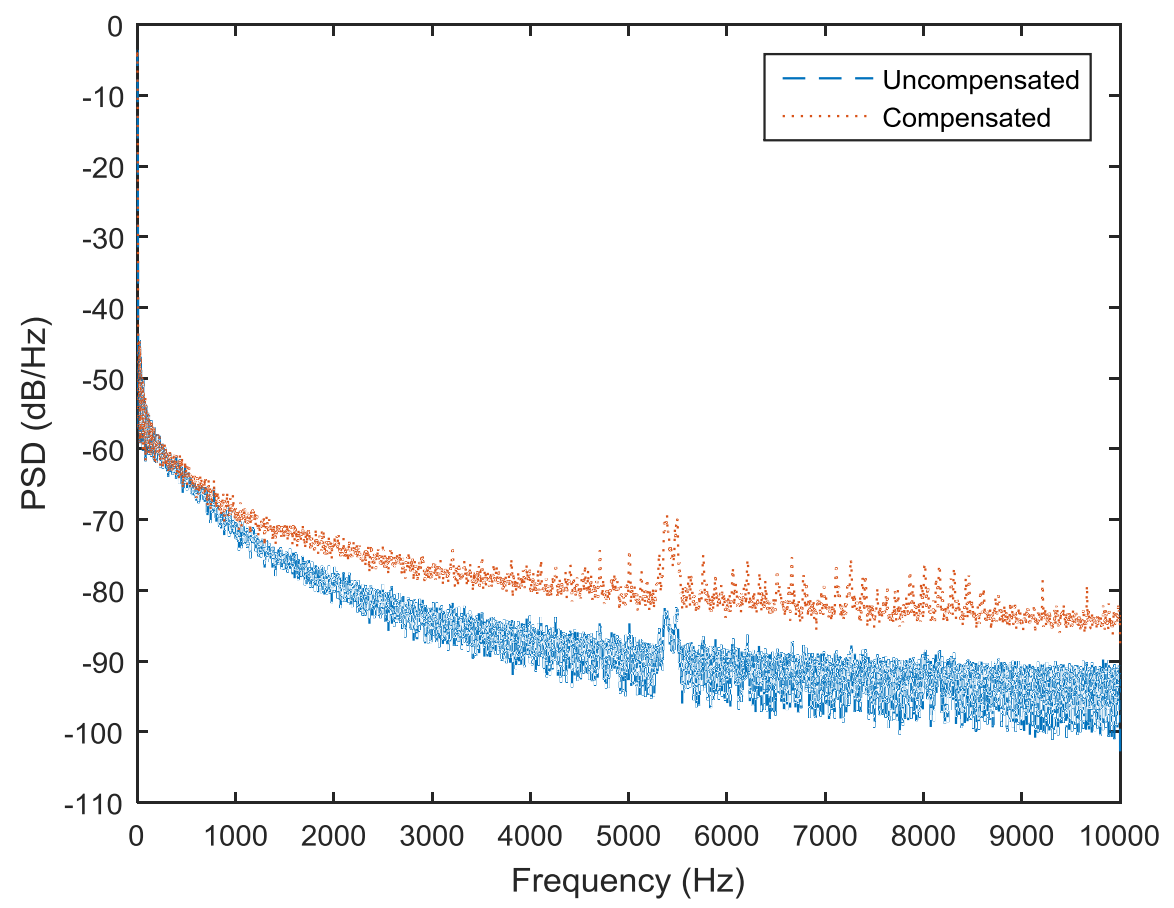

Figure 4.13 Comparison of compensated and uncompensated power spectral densities for $\mathrm{x} / \mathrm{D}=12.7$ on the centerline of the turbulent jet for $10 \mathrm{~mm}$ nozzle and $50 \mathrm{~m} / \mathrm{s}$ jet exit velocity 


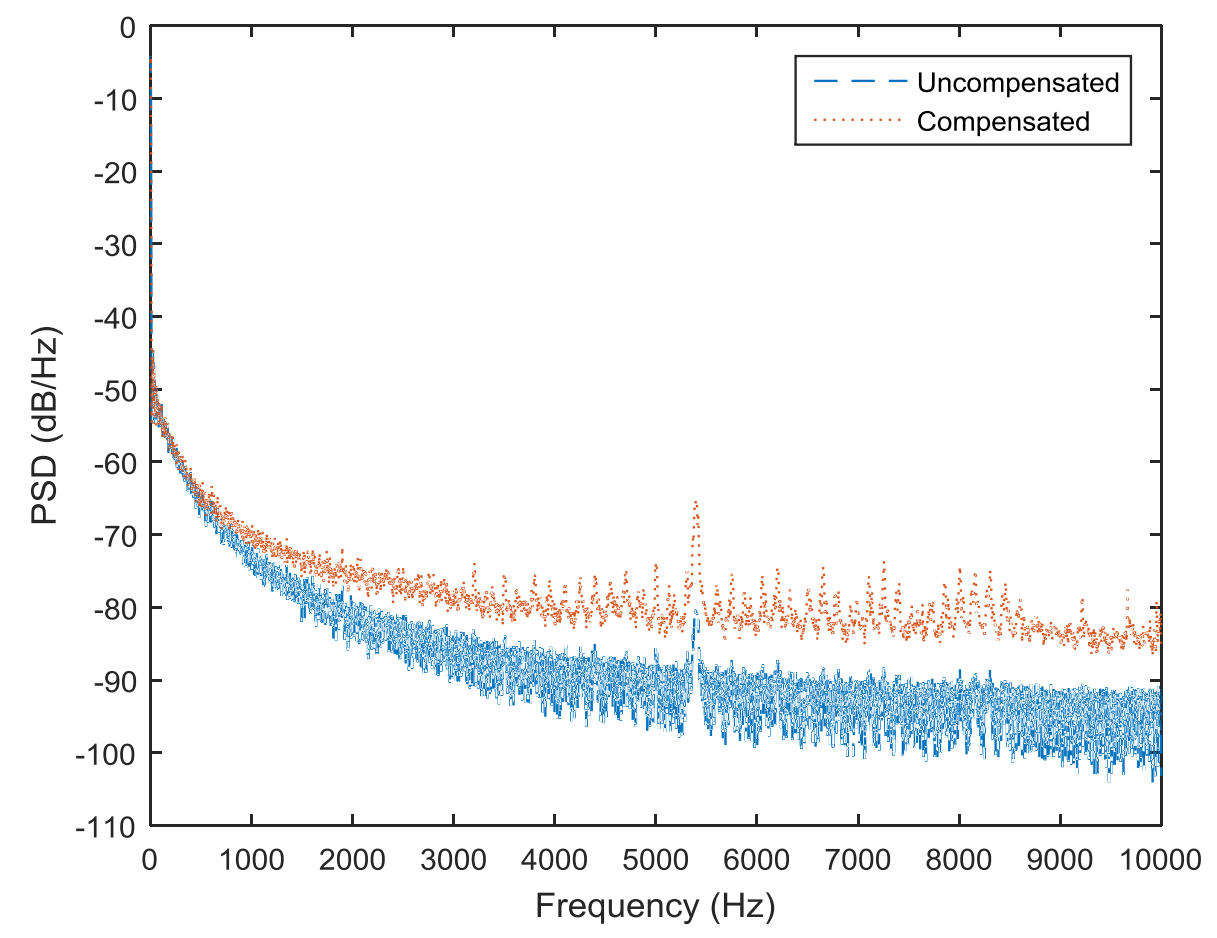

Figure 4.14 Comparison of compensated and uncompensated power spectral densities for $\mathrm{x} / \mathrm{D}=25.3$ on the centerline of the turbulent jet for $5 \mathrm{~mm}$ nozzle and $50 \mathrm{~m} / \mathrm{s}$ jet exit velocity

\subsection{Noise Study}

A significant downside to CVA is the lack of sensitivity. Figure 4.3, above, shows a typical calibration for the 3.8 micron sensor. The decrease in sensitivity as $O H R$ is decreased was discussed in Chapter 3 where a calibration for the sensor operated at $V_{w}=$ $0.48 \mathrm{~V}$ had a smaller change in the CVA $I_{w}$ output than for the sensor operated at $V_{w}=0.58$ V. It was also noted that lack of sensitivity was even more evident on the calibration curve at higher local velocities. In this case, we see that for the lowest velocities where the $O H R$ is maximum, there is a $37 \mathrm{mV}$ change in the $I_{w}$ output for a $5.7 \mathrm{~m} / \mathrm{s}$ change in local velocity $(0.15 \mathrm{~m} / \mathrm{s}$ per $\mathrm{mV})$, while for the highest velocities, there is a $2 \mathrm{mV}$ change in $I_{w}$ for a 1.7 $\mathrm{m} / \mathrm{s}$ change in local velocity $(0.85 \mathrm{~m} / \mathrm{s}$ per $\mathrm{mV})$. So even fractions of a millivolt can have a 
significant effect on the measurements. Considering that electromagnetic interference (EMI) can easily fluctuate in the one millivolt range, freestream fluctuation measurements become very unreliable. This is one very strong possibility for the uncharacteristic looking compensation results.

This study of limiting the noise began with a diagnosis of whether or not the noise from the laptop being used for data collection was having a significant effect on the measurements because of its connection to AC power. After this, a low pass filter and buck and gain were used to try to minimize the noise and make the compensation more effective.

Three comparisons were made for the diagnosis of the laptop plugged into AC power. The NI DAQ was first shorted to ensure that there was no difference between the RMS voltage reading when the laptop was plugged in or unplugged. A comparison was then made between the laptop plugged in and unplugged for a $2 \mathrm{~V}$ full differential input from a DC power supply (similar in magnitude to the CVA outputs) with a known RMS voltage of about half of a millivolt, confirmed by checking with an oscilloscope. Lastly the comparison was made between the laptop plugged in and unplugged for a turbulent jet core measurement using the TSI 3.8 micron diameter sensor. The results can be found below in Table 4.2.

Table 4.2 Comparison of RMS voltage measurements recorded with the laptop plugged in to AC power or unplugged

\begin{tabular}{|c|c|c|}
\cline { 2 - 3 } \multicolumn{1}{c|}{} & \multicolumn{2}{c|}{$\mathrm{u}_{\mathrm{rms}}(\mathrm{mV})$} \\
\cline { 2 - 3 } \multicolumn{1}{c|}{} & $\begin{array}{c}\text { Laptop } \\
\text { Plugged In }\end{array}$ & $\begin{array}{c}\text { Laptop } \\
\text { Unplugged }\end{array}$ \\
\hline DAQ input shorted & 0.92 & 0.92 \\
\hline 2V full differential input from DC power supply (known RMS about $0.5 \mathrm{mV})$ & 1.25 & 0.95 \\
\hline Core Measurements with 3.8 micron diameter wire $\mathrm{V}_{\mathrm{w}}=0.58 \mathrm{~V}$ & 2.29 & 1.75 \\
\hline
\end{tabular}


As expected, the measurement taken with the DAQ input shorted revealed no difference between the laptop plugged in and unplugged. This helps to provide reassurance that there are no strange things happening with the DAQ or laptop that could be affecting experimental measurements. The $2 \mathrm{~V}$ full differential input from the DC power supply revealed a $0.3 \mathrm{mV}$ increase in the measurement of $u_{r m s}$ when the laptop was plugged in. The RMS was nearly double what was expected for the laptop unplugged case, suggesting additional noise apart from the laptop plugged into AC power, although the measurement was only slightly higher than the case where the DAQ input was shorted. When taking a measurement in the core of the turbulent jet, for similar operating conditions from other testing with the 3.8 micron TSI sensor, there was a $0.54 \mathrm{mV}$ increase in the RMS measurement. Using typical sensitivity from CVA calibration, a $0.54 \mathrm{mV}$ increase in RMS would translate to a velocity fluctuation of about $0.25 \mathrm{~m} / \mathrm{s}$. These results suggest a sizable amount of electrical noise affecting the CVA output from the laptop plugged into AC power, but reveals the existence of additional noise from the DAQ that seems to be amplified when applying software compensation.

Applying gain and offset on the CVA output is also a reasonable way to try to minimize the electrical noise by first offsetting the signal as much as possible without creating a negative signal at the lowest velocity measurements and then applying a gain to ramp the signal back up again. The gain and offset would therefore scale the mean output as well as the fluctuations in the output, hopefully making the noise less significant. CVA I and II both have each of these capabilities, but CVA II can only implement a gain of up to 2 . For a more drastic effect, CVA I was used to apply a gain of 4 to a $1.24 \mathrm{~V}$ offset signal for centerline turbulence measurements using a $5 \mathrm{~mm}$ diameter nozzle. Comparing these 
turbulence intensities shown in Figure 4.15 to turbulence intensities measured using the 5 mm nozzle without buck or gain shown in Figure 4.8, the core measurement was reduced by only a small amount, but the compensation did decrease. While this is encouraging, there is still more RMS in the potential core than what would be desired.

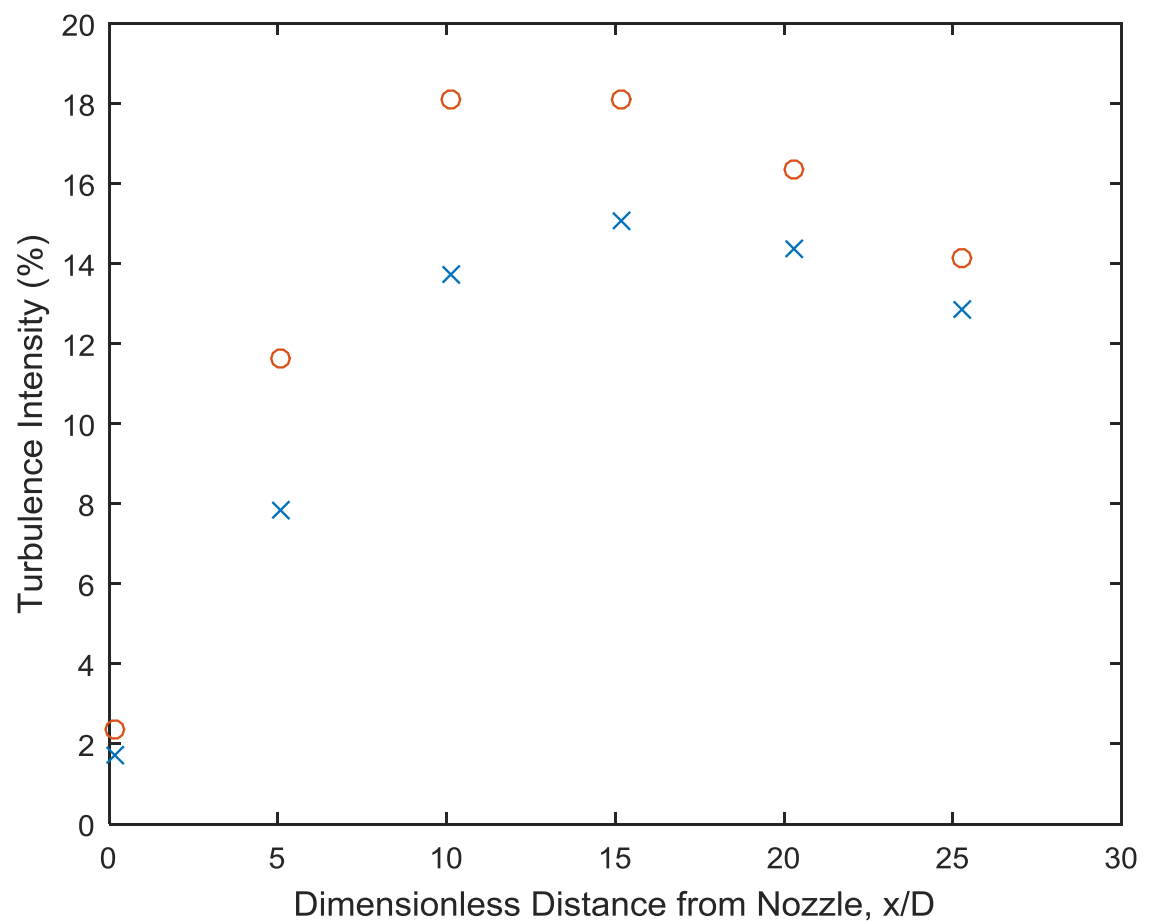

Figure 4.15 Centerline turbulence measurements using a gain of 4 on a $1.24 \mathrm{~V}$ offset signal for a $5 \mathrm{~mm}$ diameter nozzle and $\mathrm{U}=50 \mathrm{~m} / \mathrm{s}$

Applying a low pass filter to the measurements was also explored. By applying a Krohn-Hite Model 3100A band pass filter set as a low pass filter at $10 \mathrm{kHz}$ to the CVA output to act as an anti-aliasing filter, any high frequency noise from CVA should not be passed and picked up by the DAQ. Note that low pass filtering of the CVA output would not help with any noise coming from analog to digital conversion in the DAQ but would still allow all of the fluctuations in the flow to be measured since the CVA cannot respond to fluctuations much higher than $2 \mathrm{kHz}$. When taking centerline measurements for a $5 \mathrm{~mm}$ nozzle and the 3.8 micron TSI sensor, instead of seeing a decrease, the noise floor did not 
appear to diminish at all. The RMS value in the core was $3 \mathrm{mV}$ as compared to $2.3 \mathrm{mV}$ seen in previous tests without the filter. The filter electronics and extra cables used could have supplied additional noise at lower frequencies that affected the data taken.

The low sensitivity of CVA creates a definite need for noise reduction if software compensation is to be used. Filtering should be used on the CVA output for any measurements being taken regardless of post processing techniques, but there was not enough time to find a reliable filter to be used during the duration of this project.

\subsection{Boundary Layer Measurements}

Using the set-up discussed in Chapter 2 and used in Chapter 3, turbulent boundary layer measurements were made at $22 \mathrm{~m} / \mathrm{s}$ freestream velocity for the 3.8 micron TSI sensor operated at $V_{w}=0.58 \mathrm{~V}$ to observe the effect of software compensation. No offset, gain, or filtering was used for these tests and the laptop was left plugged in. Sampling was done at $20 \mathrm{kHz}$. The CVA output $V_{s}$ was used for these tests because it was found that this output is not as noisy as the $I_{w}$ output and freestream measurements are consistently about $1 \%$ turbulence intensity as compared to approximately $2 \%$ consistently measured when using the $I_{w}$ output. Figures 4.16 to 4.21 show results from these tests. For the local velocity and turbulence intensity plots in Figures 4.17 and 4.18, respectively, $y$ represents the vertical distance from the flat plate, and $\delta$ represents the thickness of the boundary layer and is equal to 0.5 inches. The correction in the freestream is still significant as it was in the centerline core measurements as evidenced by the measurements past $y / \delta=1$ in Figure 4.18 and the freestream spectra represented in Figure 4.21; however, the turbulence intensities still appear to have a steady shift in correction from close to the surface out to the freestream, which is not desirable. The spectra really demonstrate the compensation for 
the freestream where after about $1 \mathrm{kHz}$, the compensated data shows far more energy. A large difference in spectra can also be seen for the closest point to the wall shown in Figure 4.19 and a point midway through the boundary layer in Figure 4.20.

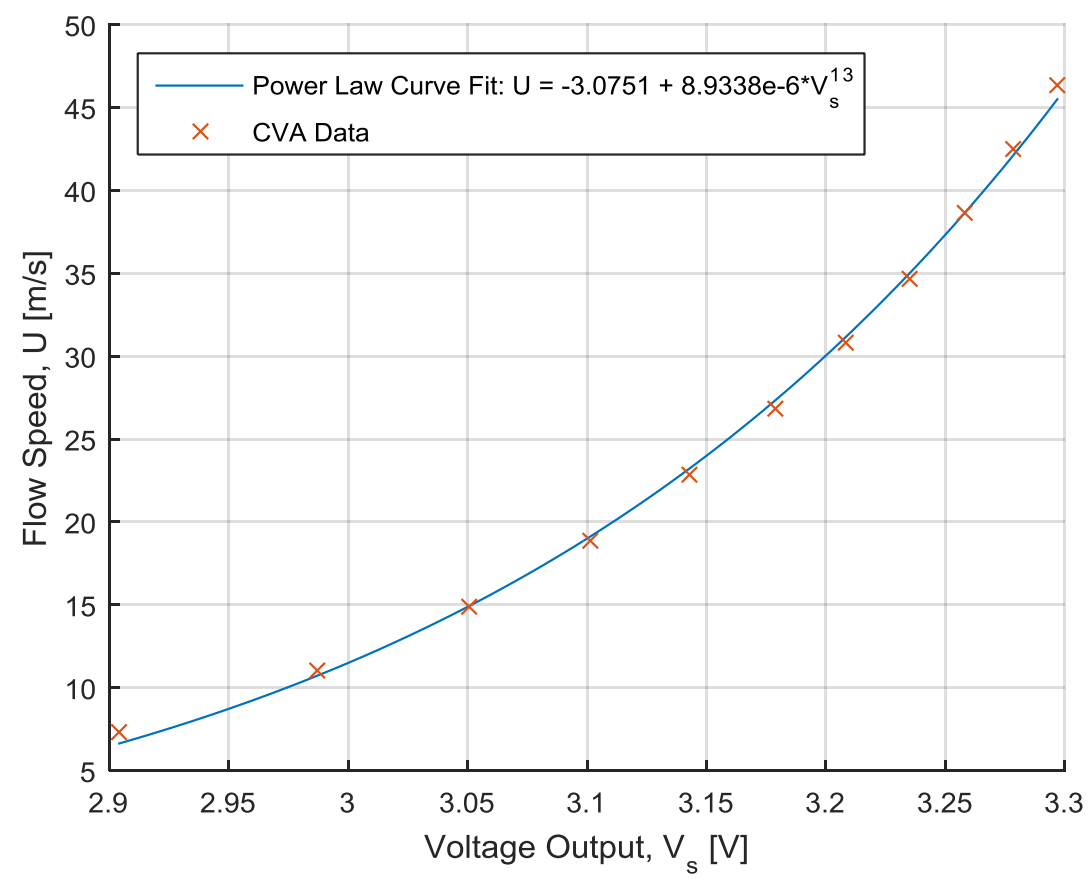

Figure 4.16 $\mathrm{V}_{\mathrm{s}}$ calibration for $\mathrm{V}_{\mathrm{w}}=0.58 \mathrm{~V}$ used for boundary layer measurements at $\mathrm{U}=23 \mathrm{~m} / \mathrm{s}$ and $\mathrm{f}_{\mathrm{s}}=$ $20 \mathrm{kHz}$ 


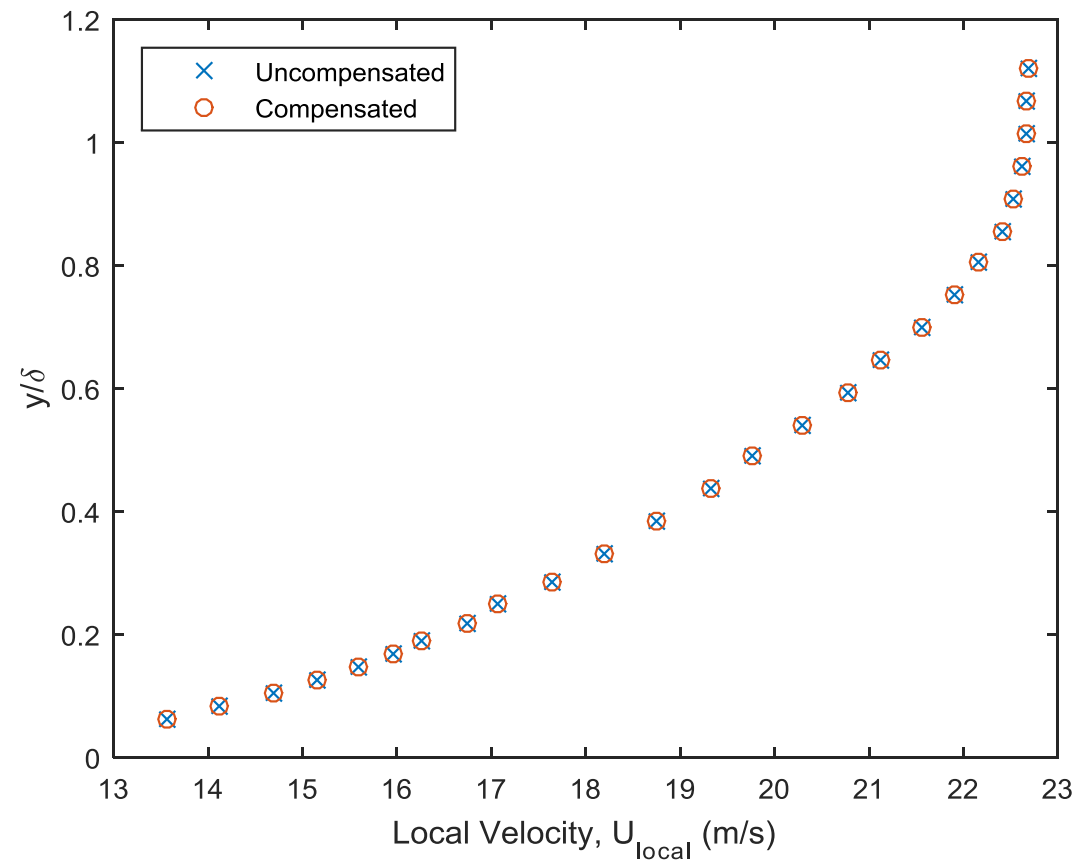

Figure 4.17 Mean velocity data at each point measured in the boundary layer for $U=22 \mathrm{~m} / \mathrm{s}, V_{w}=0.58 \mathrm{~V}$, and $\mathrm{f}_{\mathrm{s}}=20 \mathrm{kHz}$

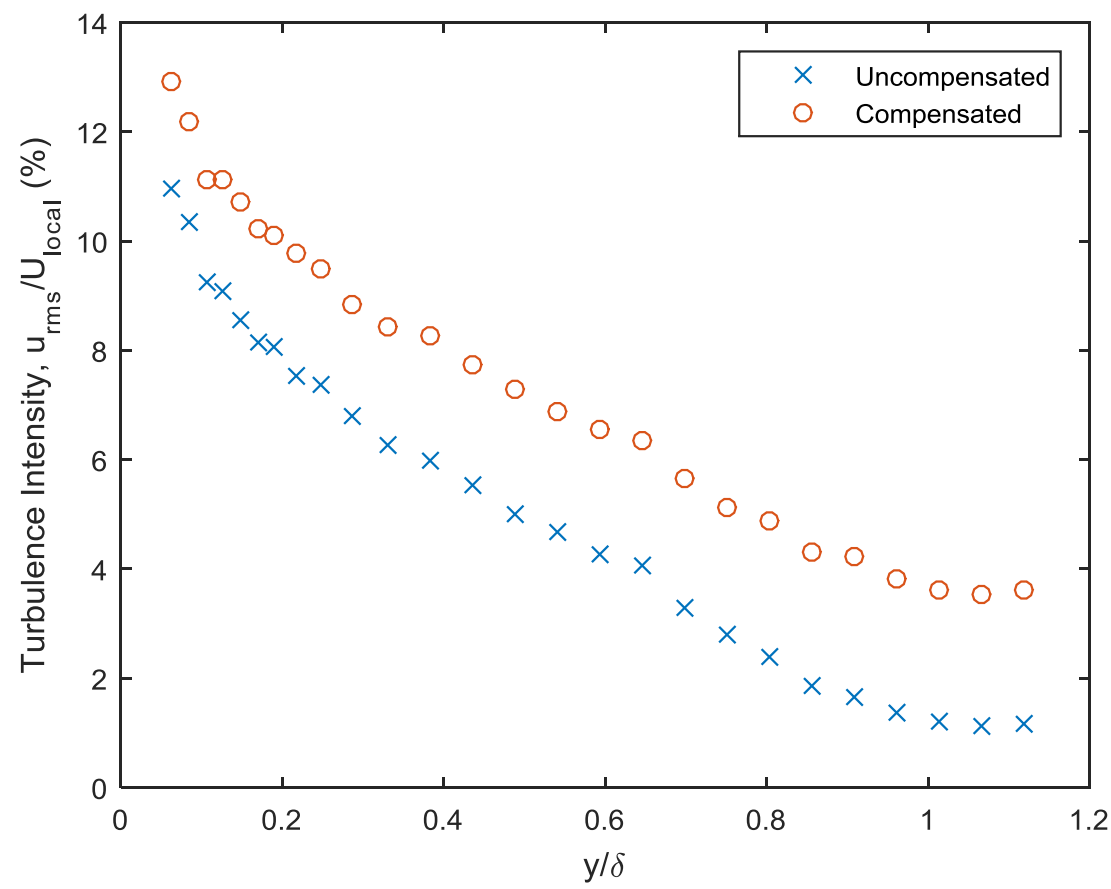

Figure 4.18 Turbulence intensities at each point measured in the boundary layer for $U=22 \mathrm{~m} / \mathrm{s}, \mathrm{V}_{\mathrm{w}}=0.58$ $\mathrm{V}$, and $\mathrm{f}_{\mathrm{s}}=20 \mathrm{kHz}$ 


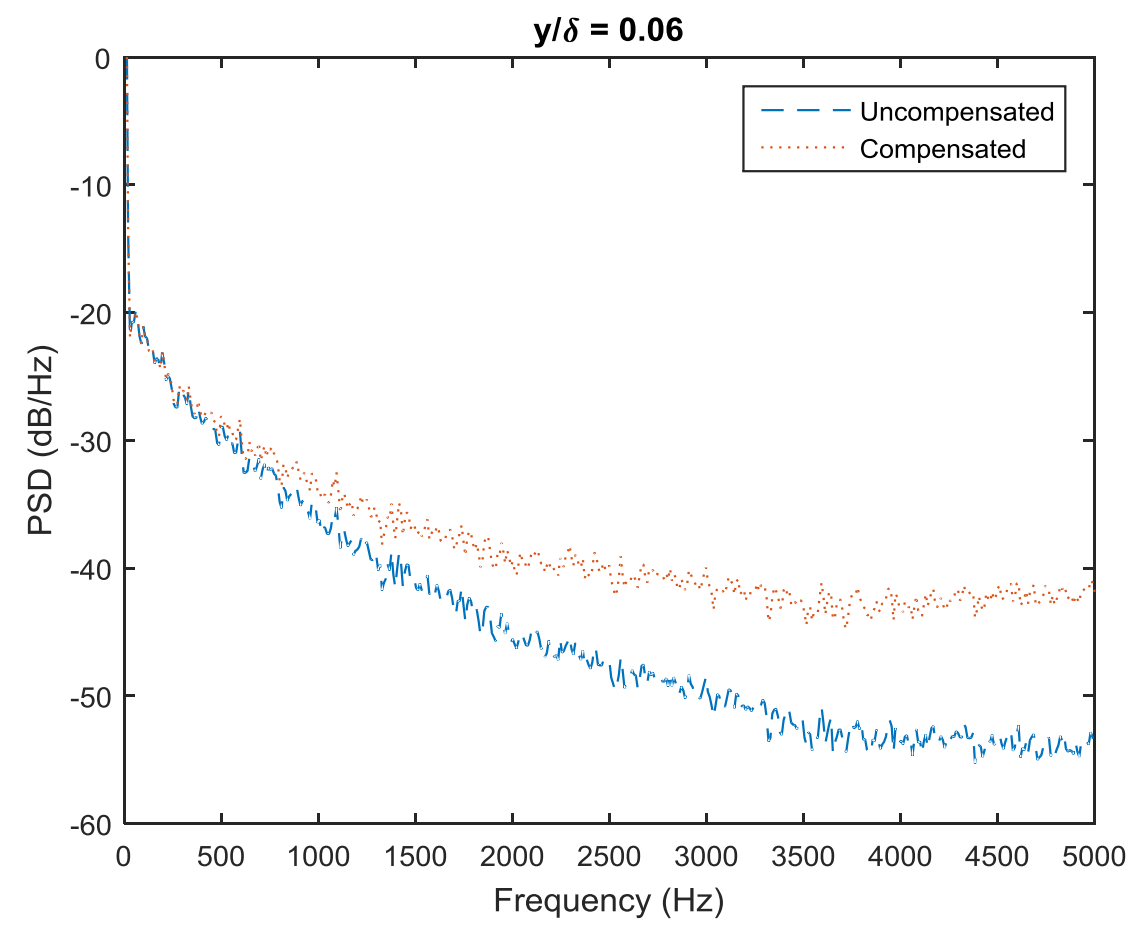

Figure 4.19 Compensated and uncompensated frequency spectra for a the closest point to the wall for $\mathrm{U}=$ $22 \mathrm{~m} / \mathrm{s}, \mathrm{V}_{\mathrm{w}}=0.58 \mathrm{~V}$, and $\mathrm{f}_{\mathrm{s}}=20 \mathrm{kHz}$

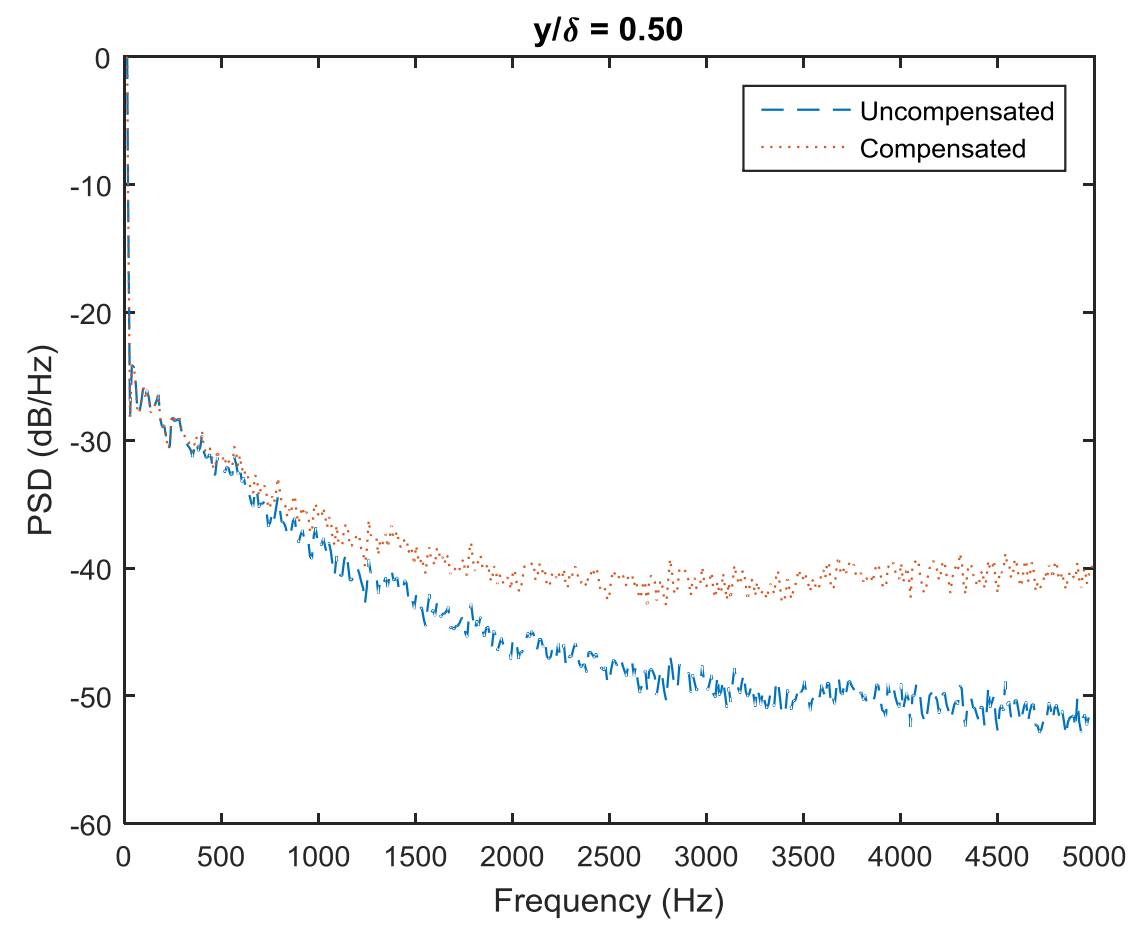

Figure 4.20 Compensated and uncompensated frequency spectra for a point midway through the boundary layer for $\mathrm{U}=22 \mathrm{~m} / \mathrm{s}, \mathrm{V}_{\mathrm{w}}=0.58 \mathrm{~V}$, and $\mathrm{f}_{\mathrm{s}}=20 \mathrm{kHz}$ 


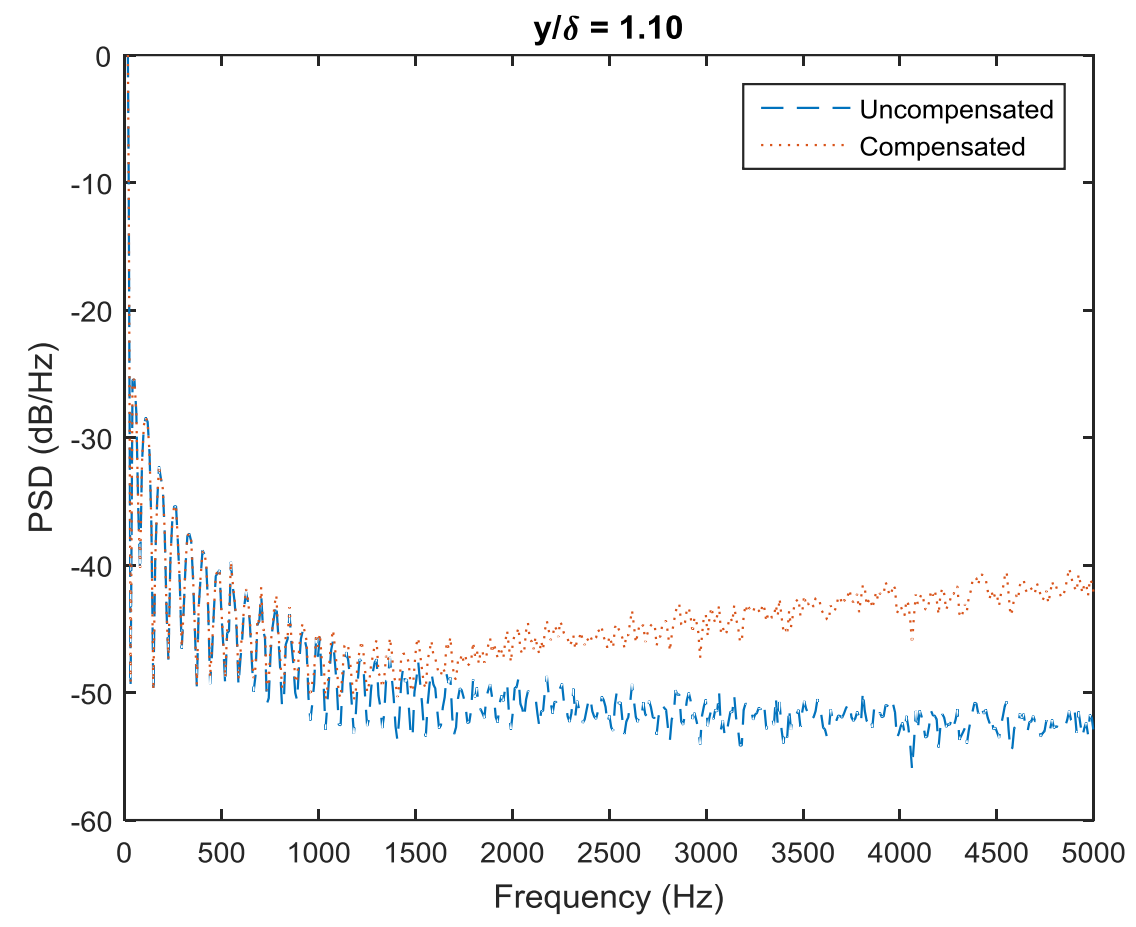

Figure 4.21 Compensated and uncompensated frequency spectra for a point in the free stream for $\mathrm{U}=22$ $\mathrm{m} / \mathrm{s}, \mathrm{V}_{\mathrm{w}}=0.58 \mathrm{~V}$, and $\mathrm{f}_{\mathrm{s}}=20 \mathrm{kHz}$

Looking back at equation (4.1), the sampling rate directly multiplies the term added on to the raw data. If the sampling frequency were to be lowered, the difference between individual samples would presumably increase, and so the compensation would not be much different than a case for which the sampling rate was higher unless there was noise at higher frequencies than the frequency of the lower sampling rate. To see if this might be the case, compensation was applied to the $22 \mathrm{~m} / \mathrm{s}$ freestream velocity boundary layer measurements made in Chapter 3 at $V_{w}=0.58 \mathrm{~V}$ which were taken at a sampling rate of $2.5 \mathrm{kHz}$. The calibration curve used for these measurements can be found in Figure 3.8. As expected, the local velocities show no difference between compensated and uncompensated data in Figure 4.22. The turbulence intensities are shown in Figure 4.23 and reveal that the compensation has a much smaller effect when using a lower sampling 
frequency. This is confirmed for the compensated frequency spectra in Figures 4.24 and 4.26 as well, where the compensated data is much closer to the uncompensated data than that for the $20 \mathrm{kHz}$ sampling test, above. This again points back to the conclusion that there may be higher frequency electrical noise that has a large effect on the implementation of software compensation, especially for freestream measurements.

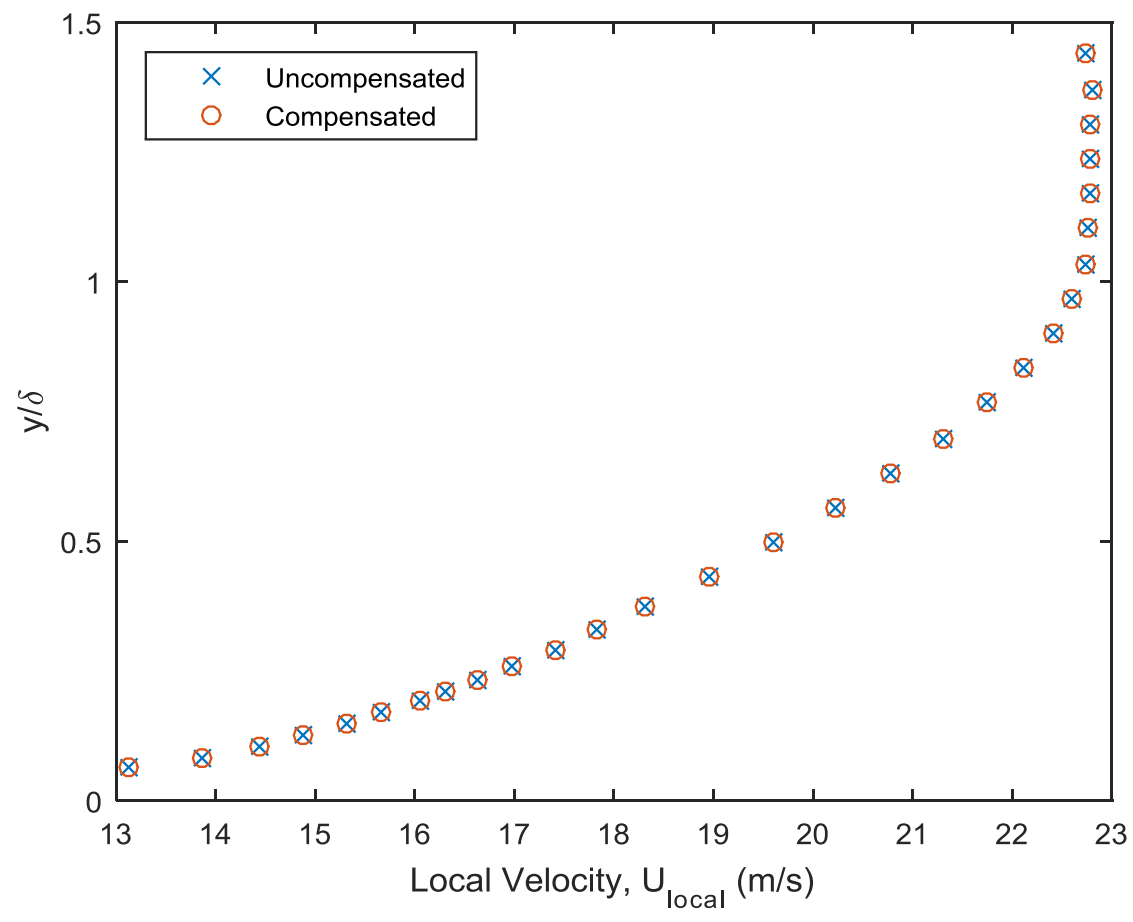

Figure 4.22 Mean velocity data at each point measured in the boundary layer for $U=22 \mathrm{~m} / \mathrm{s}, \mathrm{V}_{\mathrm{w}}=0.58 \mathrm{~V}$, and $\mathrm{f}_{\mathrm{s}}=2.5 \mathrm{kHz}$ 


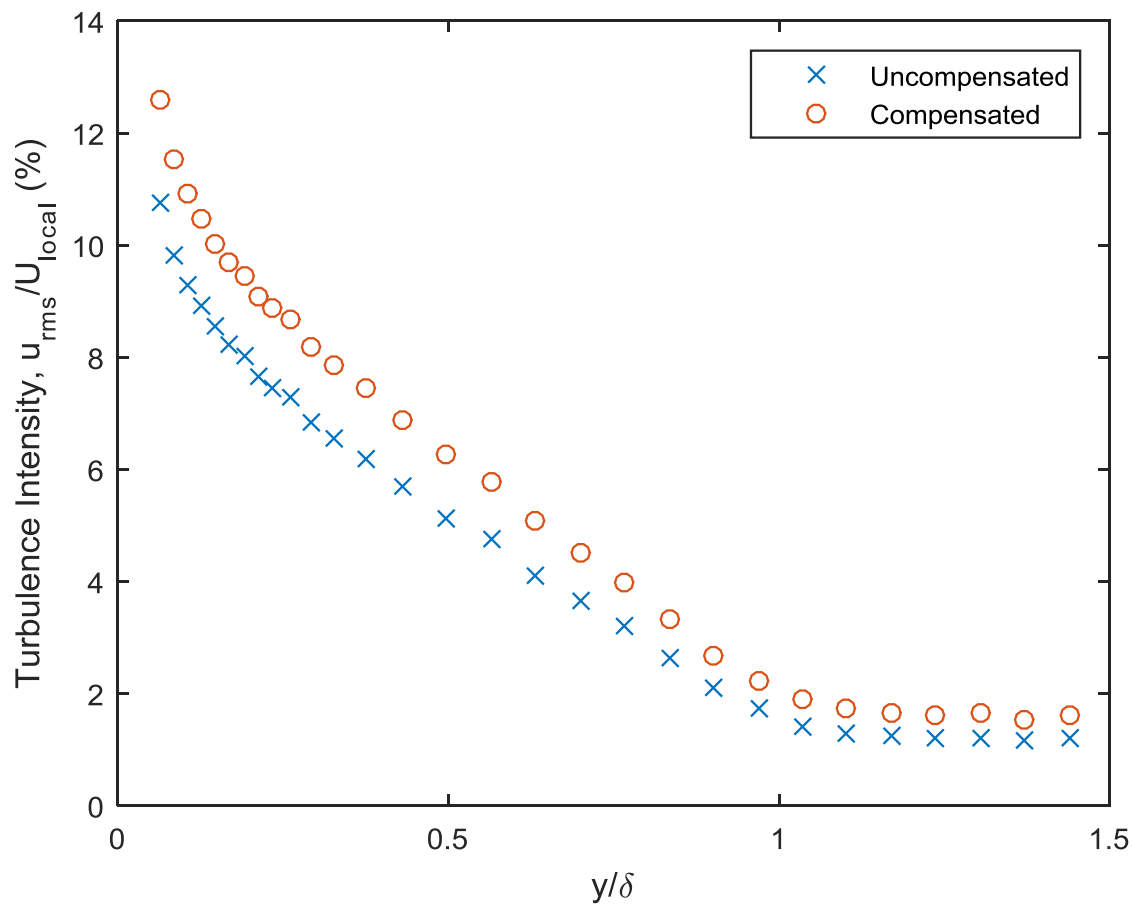

Figure 4.23 Turbulence intensities at each point measured in the boundary layer for $U=22 \mathrm{~m} / \mathrm{s}, V_{w}=0.58$ $\mathrm{V}$, and $\mathrm{f}_{\mathrm{s}}=2.5 \mathrm{kHz}$

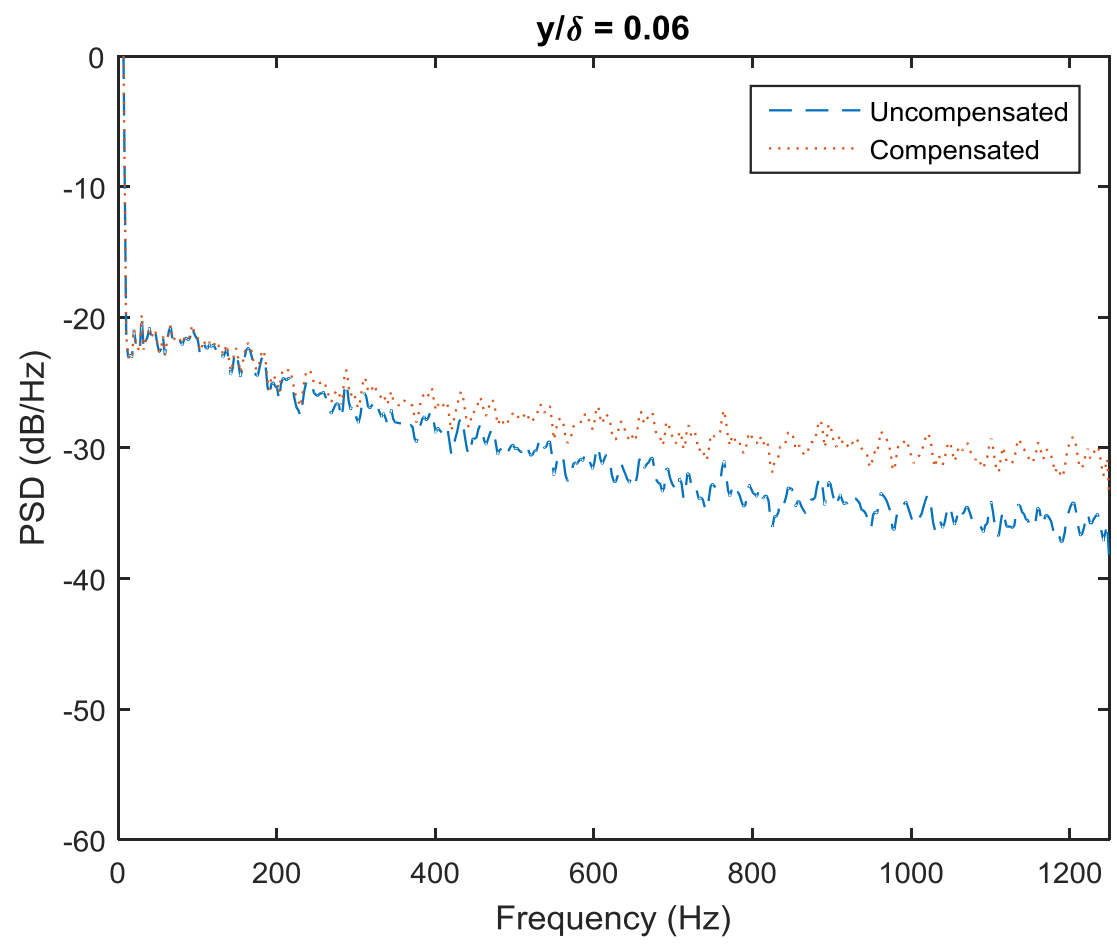

Figure 4.24 Compensated and uncompensated frequency spectra for a the closest point to the wall for $\mathrm{U}=$ $22 \mathrm{~m} / \mathrm{s}, \mathrm{V}_{\mathrm{w}}=0.58 \mathrm{~V}$, and $\mathrm{f}_{\mathrm{s}}=2.5 \mathrm{kHz}$ 


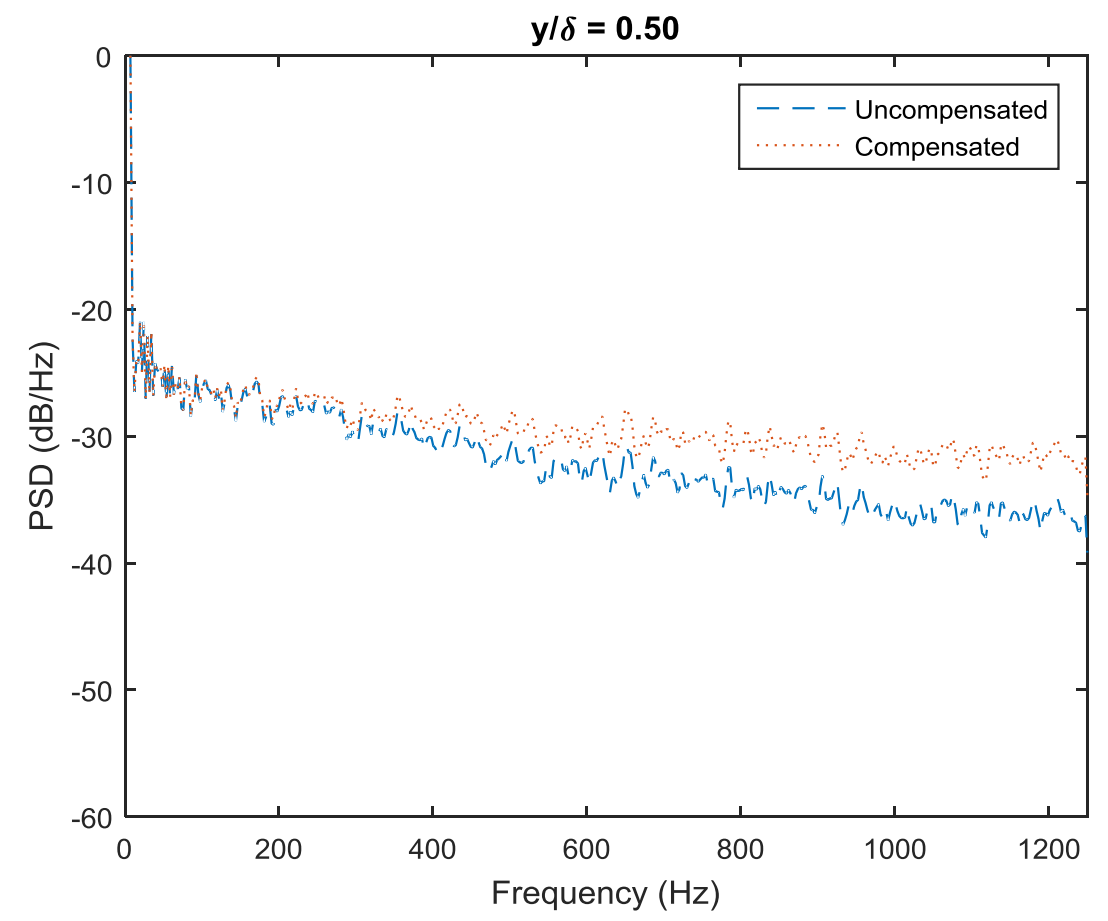

Figure 4.25 Compensated and uncompensated frequency spectra for a point midway through the boundary layer for $\mathrm{U}=22 \mathrm{~m} / \mathrm{s}, \mathrm{V}_{\mathrm{w}}=0.58 \mathrm{~V}$, and $\mathrm{f}_{\mathrm{s}}=2.5 \mathrm{kHz}$

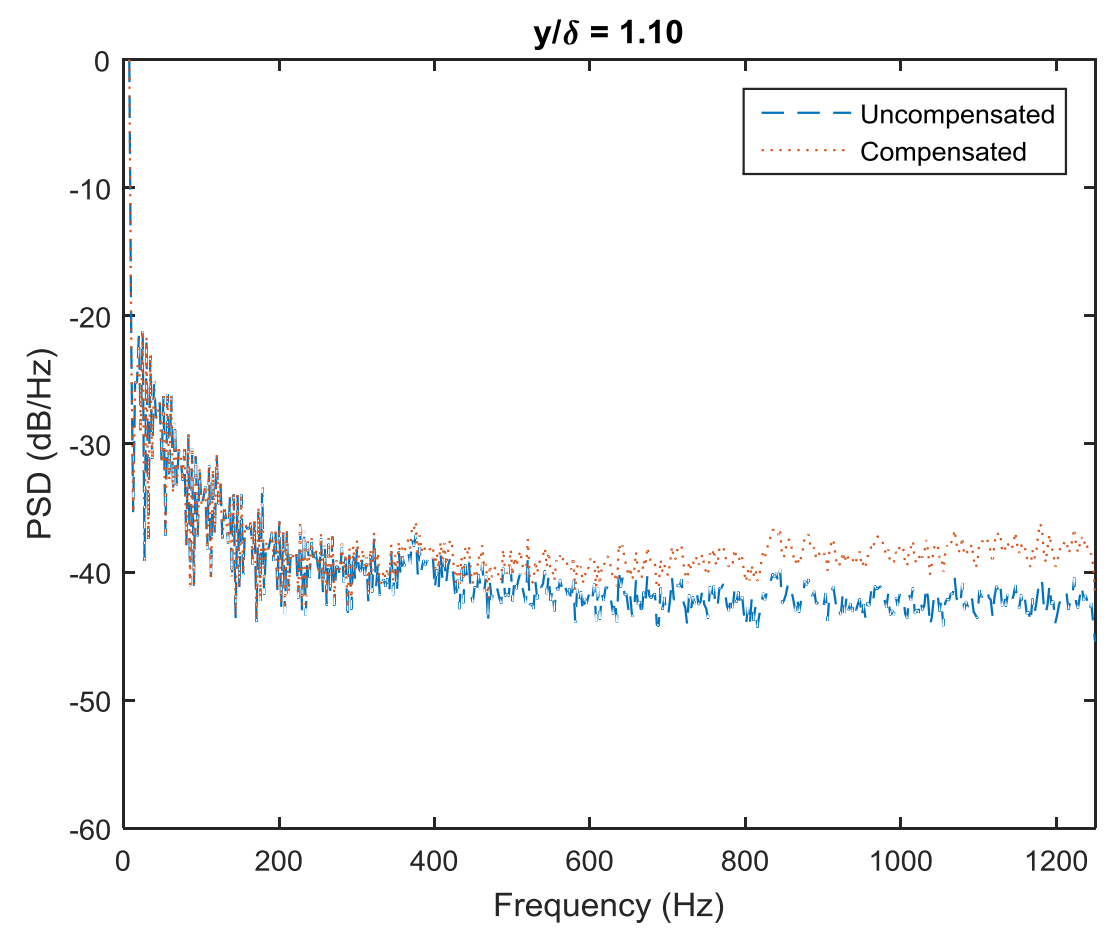

Figure 4.26 Compensated and uncompensated frequency spectra for a point in the free stream for $\mathrm{U}=22$ $\mathrm{m} / \mathrm{s}, \mathrm{V}_{\mathrm{w}}=0.58 \mathrm{~V}$, and $\mathrm{f}_{\mathrm{s}}=2.5 \mathrm{kHz}$ 


\subsection{Conclusions}

While software compensation appeared as if it could be a useful technique to improve frequency response with CVA measurements, it is evident that the electrical noise present in the system is amplified by the correction algorithm, resulting in measurements that are not representative of the fluctuations being measured. Implementation of this technique with CVA on BLDS is therefore not very attractive. If there was a way to minimize the noise in a measurement system using CVA, then software compensation could possibly be used to help get back some of the signal that was attenuated due to thermal lag of the sensor used. 


\section{Wire Size}

\subsection{Theory}

Equation (1.4) reveals that one of the most influential parameters on the thermal time constant of a hot wire sensor operated with CVA is the wire diameter, $D$. In theory, decreasing the diameter of the sensor can drastically improve the frequency response for measurements because $M_{C V A}$ varies by roughly $D^{3 / 2}$. To quantify this effect, the EES heat transfer model was run for various diameters. The results in Figure 5.1 demonstrate just how effective a smaller sensor can be. While the 3.8 micron TSI sensors have a half amplitude cut off frequency $\left(f_{C V A}\right)$ of about $2 \mathrm{kHz}, f_{C V A}$ for a custom made 2.5 micron sensor increases to about $4 \mathrm{kHz}$. This could translate to a significantly smaller amount of attenuation compared to the larger sensor.

A 2.5 micron type 55 sensor was purchased from Dantec Dynamics; Figure 5.2 shows a picture of the sensor. This sensor was tested on the centerline of a turbulent jet and in the turbulent boundary layer over a flat plate for direct comparisons with measurements made with the 3.8 micron TSI sensor.

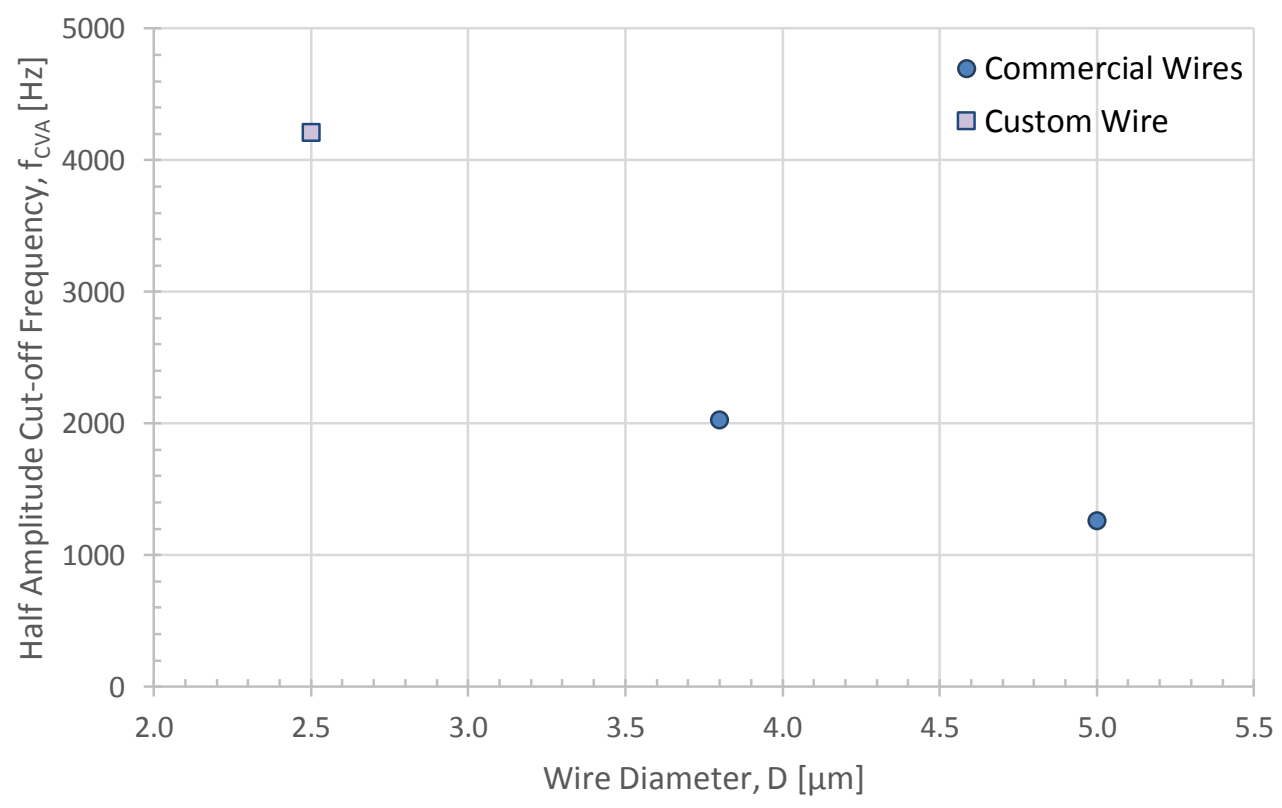

Figure 5.1 Theoretical half amplitude cutoff frequency, $f_{C V A}$, for various sensor diameters 


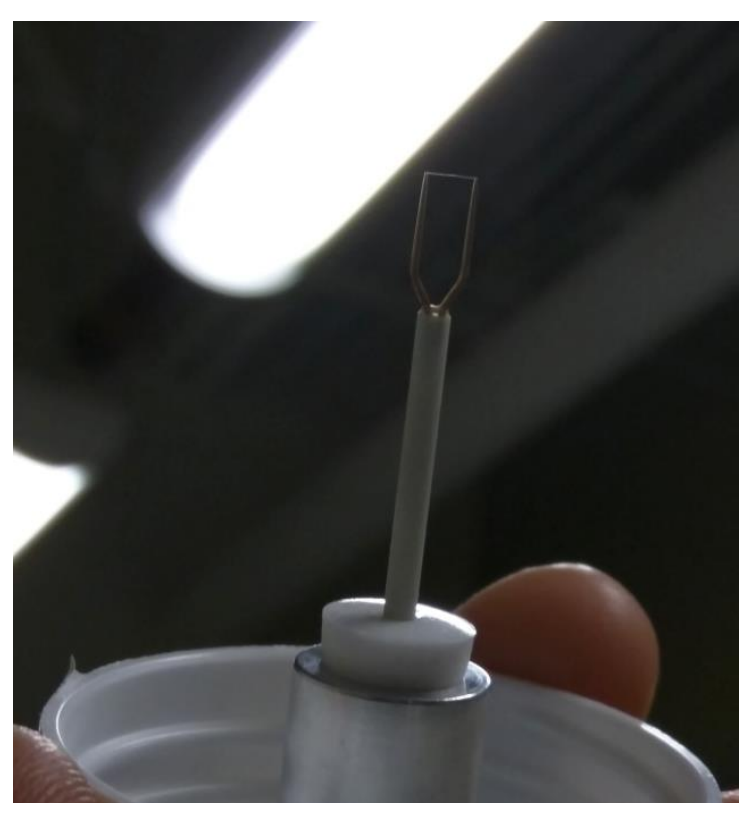

Figure 5.2 Custom 2.5 micron diameter probe type 55 Dantec Dynamics 15497 hot wire sensor

\subsection{Turbulent Jet Measurements}

The same jet and set-up discussed in Chapter 2 and used in Chapters 3 and 4 was to be used. However, the existence of particulates in the air flow that could damage the sensors became a concern due to the fragility and more expensive price of the 2.5 micron Dantec sensors. The previous test set-up for calibration and centerline measurements did not include a filter to prevent particulate damage. If a sensor were to break, there would be no way to determine if it was due to particulate damage or some other cause, so to ensure that particulate damage would not be a concern, a filter box was fabricated and the jet calibration apparatus from previous tests was secured to the top. Filter specifications can be found in Appendix B and a picture of the new test set-up can be found in Figure 5.3. 


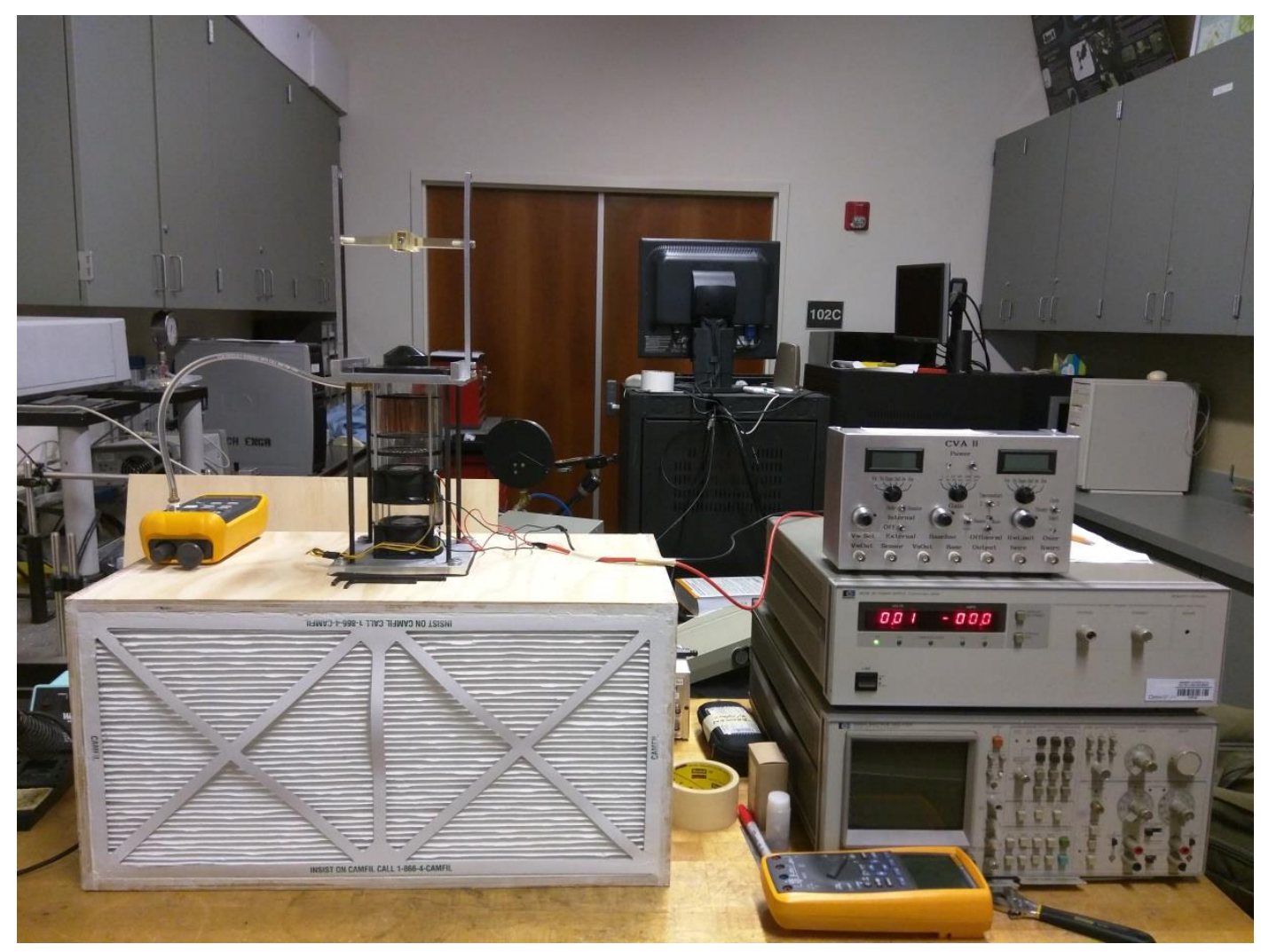

Figure 5.3 Test set-up for calibration and centerline measurements with filter box

The 2.5 micron Dantec sensor was calibrated and tested on the centerline of the turbulent jet with a $10 \mathrm{~mm}$ diameter nozzle at similar OHR's to make direct comparisons with the 3.8 micron TSI sensor from previous tests in this thesis. A sample calibration, mean velocities at each point in the jet, and turbulence intensities at each point in the jet can be found in Figures 5.4 to 5.6. 


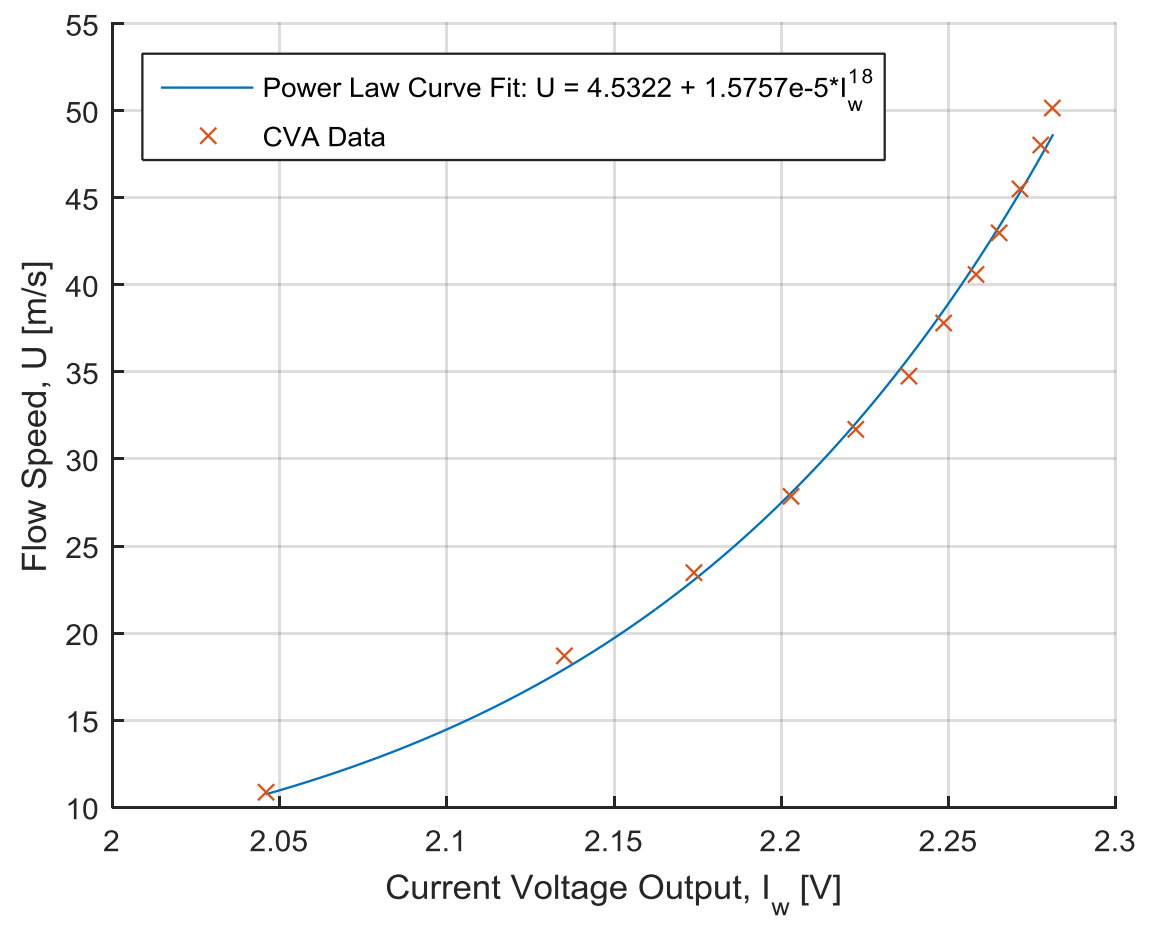

Figure 5.4 Sample $I_{w}$ calibration for 2.5 micron Dantec sensor operated at $V_{w}=0.52 \mathrm{~V}$

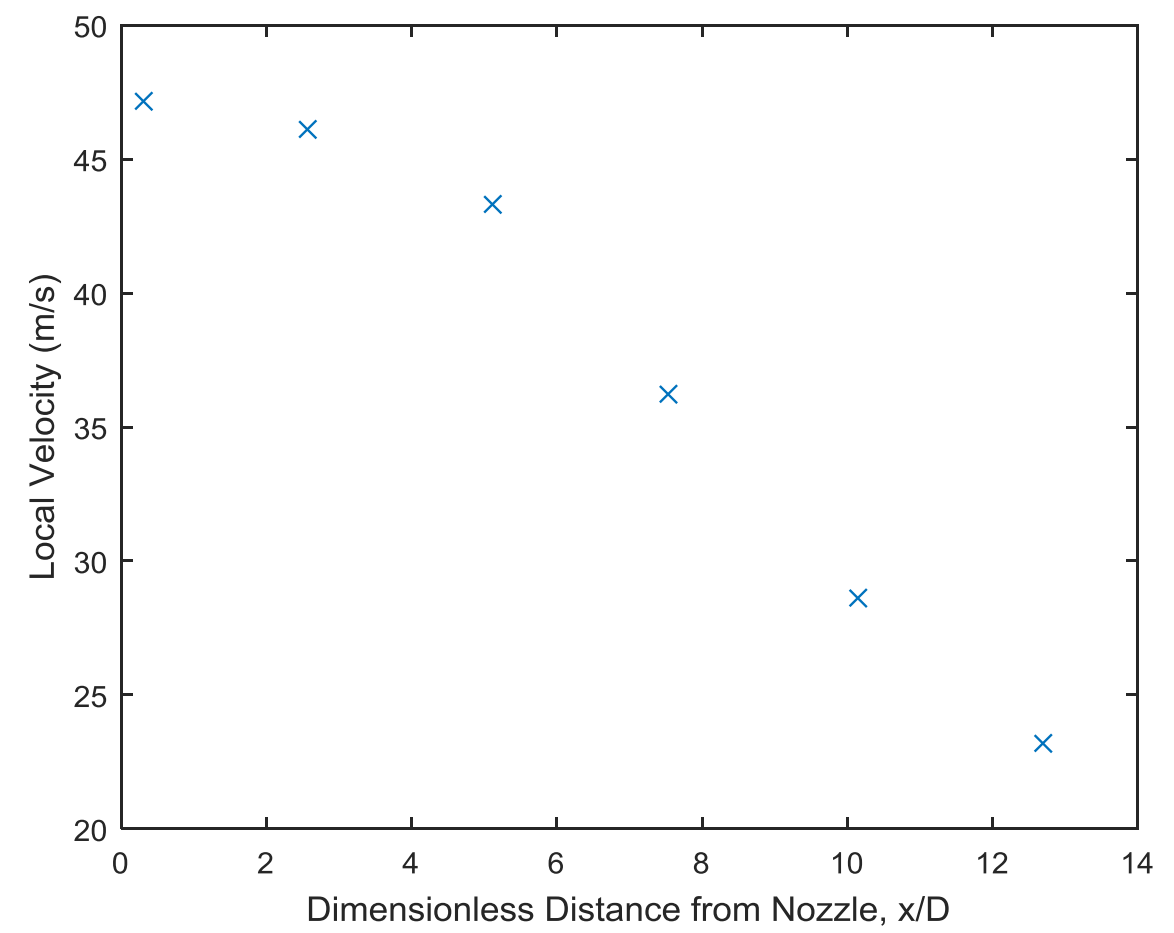

Figure 5.5 Mean local velocities at each point on the centerline of the turbulent jet for $10 \mathrm{~mm}$ nozzle and $50 \mathrm{~m} / \mathrm{s}$ jet exit velocity 


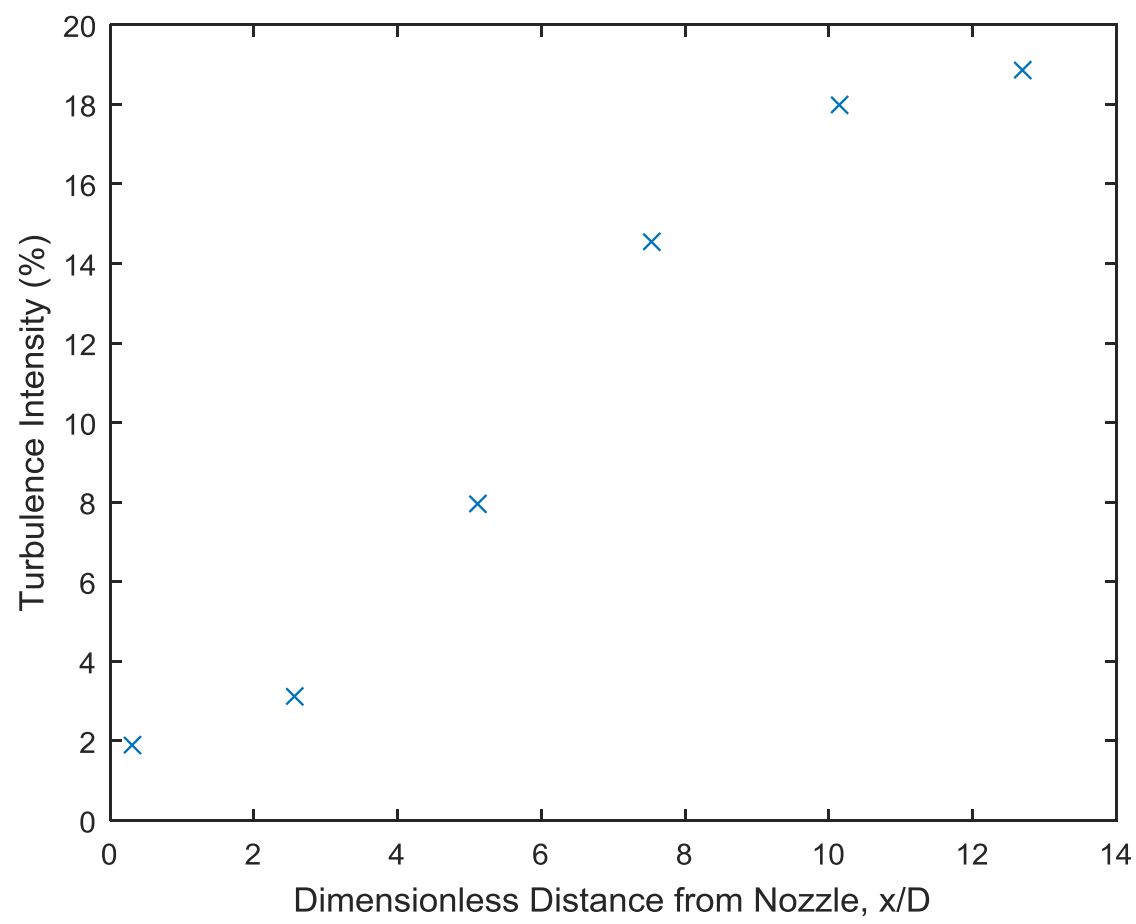

Figure 5.6 Turbulence intensities at each point on the centerline of the turbulent jet for $10 \mathrm{~mm}$ nozzle and $50 \mathrm{~m} / \mathrm{s}$ jet exit velocity

Figure 5.6 shows that the electrical noise seen in previous tests has stayed consistent with about $2 \%$ turbulence intensity in the core measurement. Refer to Figure 5.7 for a comparison of turbulence intensities measured for the two different sensors. As expected, the 2.5 micron sensor measured more turbulence intensity than the 3.8 micron sensor on the centerline away from the potential core. The core measurement looks very consistent between the two sensors, and there appears to be a maximum difference at $x / D=7.5$ with a closer agreement at $x / D=12.7$. After this point, the measurements look similar again, likely because as the jet grows and turbulence length scales increase, the lower frequency fluctuations (less than about $1 \mathrm{kHz}$ ) are larger in amplitude. 


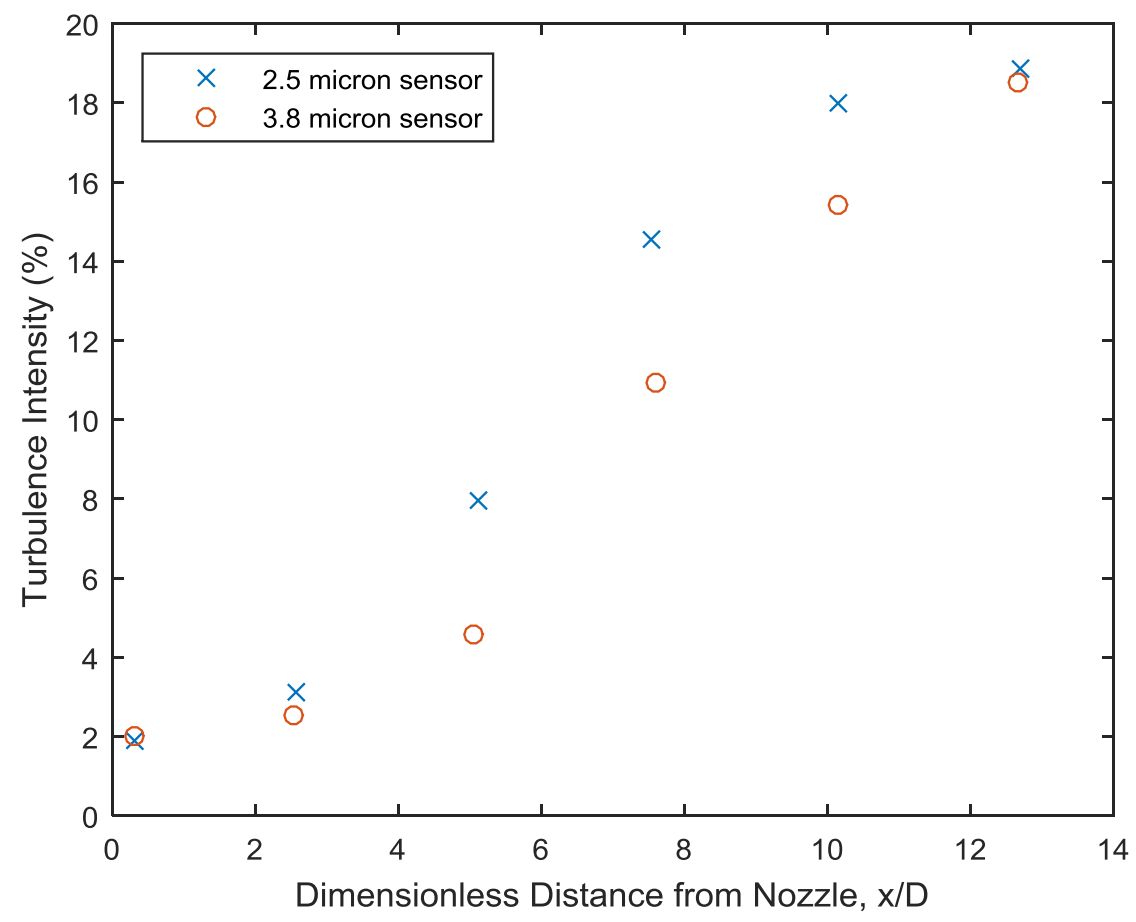

Figure 5.7 Turbulence intensity measurements for each sensor for a $10 \mathrm{~mm}$ diameter nozzle and $50 \mathrm{~m} / \mathrm{s}$ jet exit velocity

To better observe these results, the frequency spectra are plotted together for $x / D=$ 7.5 and $x / D=12.7$ in Figures 5.8 and 5.9, respectively. These plots reveal that there is indeed more energy in the lower frequency range at $x / D=12.7$ with a quicker roll off to the higher frequencies. It also confirms that for the $x / D=7.5$ case, the 3.8 micron data rolls off faster in the 1 to $3 \mathrm{kHz}$ range where we would expect more attenuation for the larger sensor due to its larger time constant. 


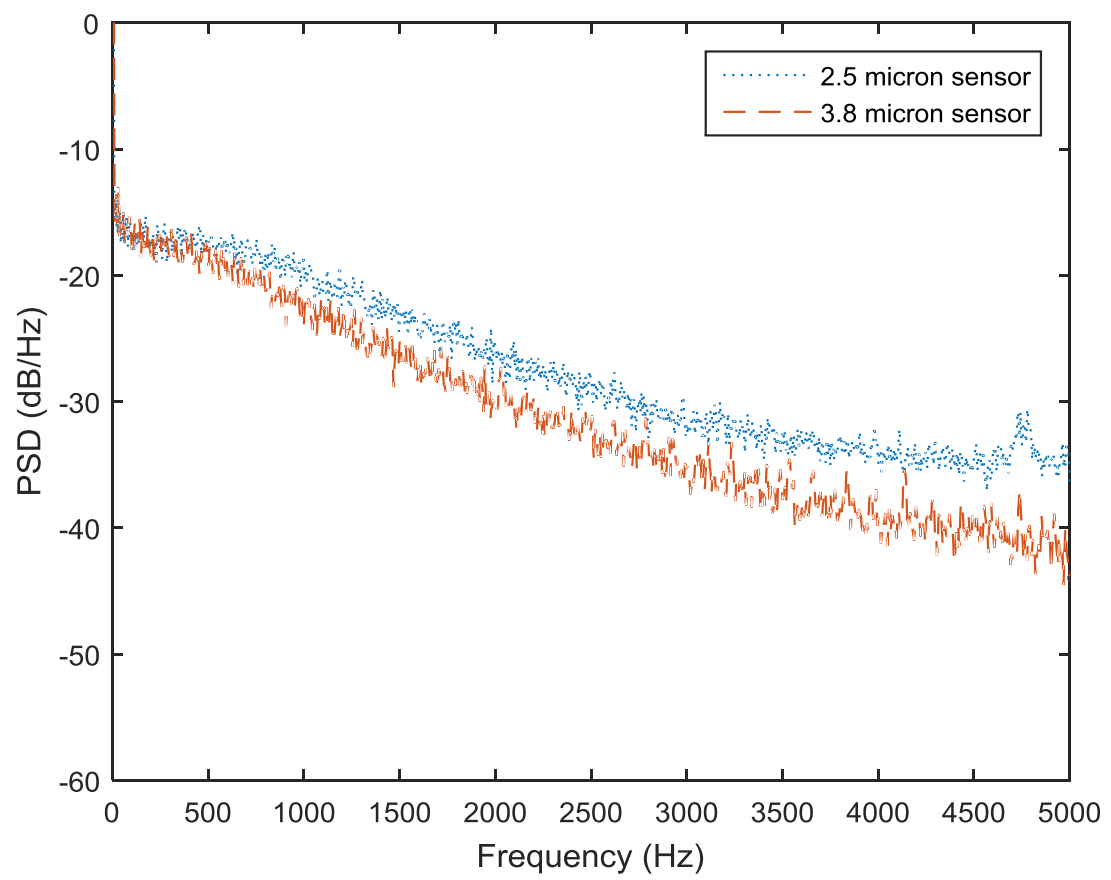

Figure 5.8 Power spectral densities plotted for each sensor at $x / D=7.5$ for a $10 \mathrm{~mm}$ diameter nozzle and $50 \mathrm{~m} / \mathrm{s}$ jet exit velocity

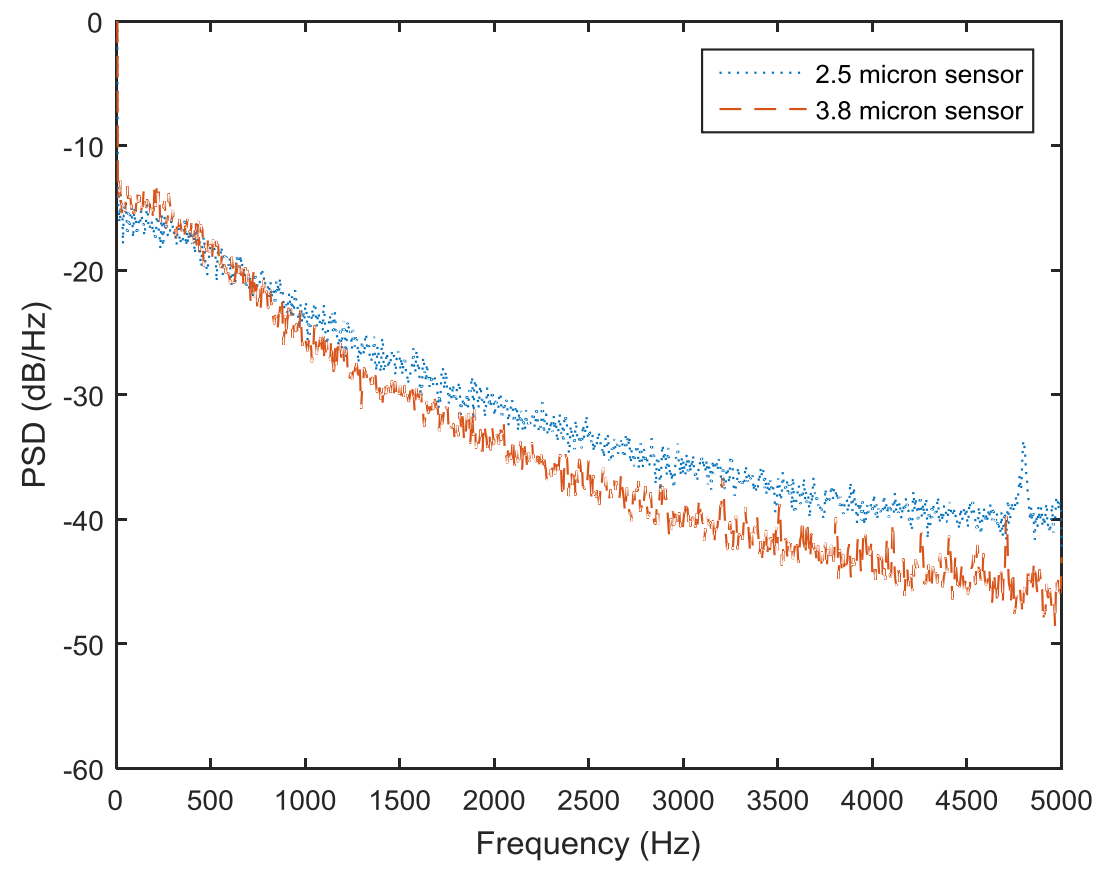

Figure 5.9 Power spectral densities plotted for each sensor at $x / D=12.7$ for a $10 \mathrm{~mm}$ diameter nozzle and $50 \mathrm{~m} / \mathrm{s}$ jet exit velocity 
To see if the software compensation would work as expected with the smaller sensor, a plot of corrected and uncorrected turbulence intensities is shown in Figure 5.10. Because of the improvement in frequency response, there is less compensation for all of the points in the centerline with a relatively constant correction at each point outside of the core. The amount of compensation is similar to that for the previous tests with the 3.8 micron sensor, and the nearly constant shift in the compensated results is most likely due to the amplification of noise. It would be expected that the compensation for the 3.8 micron sensor would give roughly the same end result signal "post correction" as the 2.5 micron sensor after compensation, but this is not the case for all points on the centerline. Referencing Figure 4.7, it is clear that the signal was compensated a similar amount, but for points at $x / D=5.1,7.6$, and 10.2, the raw measurements were not the same for the two tests, as shown in Figure 5.7 and discussed above. Where the raw measurements were the same at $x / D=12.7$, the compensated values also agree. There is a small difference between the compensated data for each sensor for the measurements in and near the potential core. Compensation has a larger effect on the core measurement where the measured turbulence intensity is assumed to be mostly noise, and less of an effect for the points farther downstream where the noise is a much smaller percentage of the measured turbulence intensity. The reason for this difference can be understood by looking back to equation (4.1). The time constant is directly multiplying the difference between each point in the time series. For the smaller time constant of the 2.5 micron sensor, the correction added on to each point is smaller than that for the 3.8 micron sensor with the larger time constant. The decrease in time constant appears to decrease the effect of noise on software compensation, but not enough to completely alleviate the concerns with its implementation. 


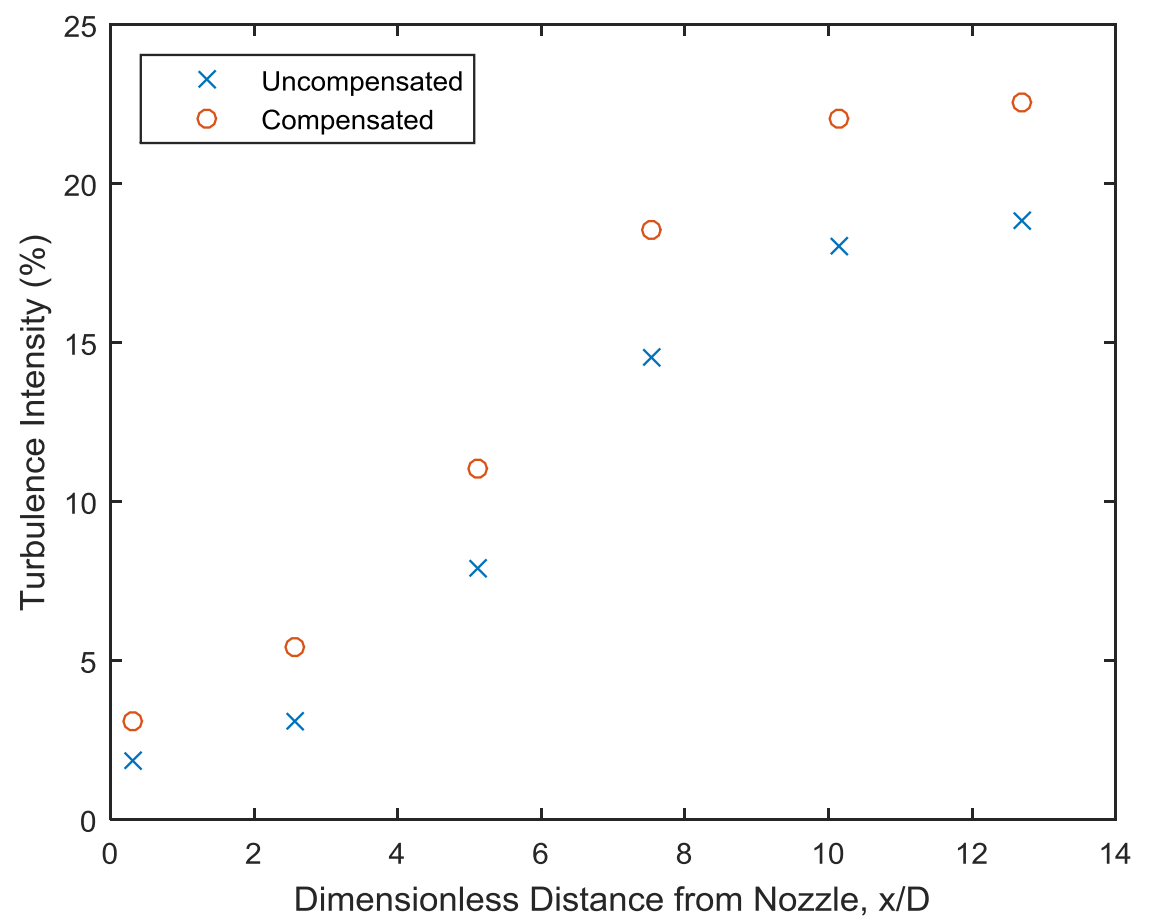

Figure 5.10 Compensated and uncompensated turbulence intensity measurements for a $10 \mathrm{~mm}$ diameter nozzle and $50 \mathrm{~m} / \mathrm{s}$ jet exit velocity for the 2.5 micron diameter wire

\subsection{Boundary Layer Measurements}

To analyze measurements more like those targeted for CVA with BLDS, data was again taken in a tripped turbulent boundary layer on a flat plate using the same procedure outlined in Chapter 2 and used in Chapters 3 and 4. To make these comparisons, both sensors were operated at similar overheats to ensure that the difference in the time constant for each sensor was due mainly to the difference in diameter. For all work discussed previously, $I_{w}$, the CVA voltage output proportional to wire current, was used as the CVA output. However, these boundary layer comparisons were made using the CVA voltage output, $V_{s}$, because it was found to have less electrical noise than the $I_{w}$ output.

Calibrations for each sensor are shown in Figures 5.11 and 5.12. Comparing the two calibrations, the 2.5 micron sensor has reduced sensitivity compared to the 3.8 micron 
sensor. For the span of about 11 to $46 \mathrm{~m} / \mathrm{s}$, the 3.8 micron $V_{s}$ output increases by about 330 $\mathrm{mV}$, while the 2.5 micron $V_{s}$ output only changes by about $200 \mathrm{mV}$. Looking at the local sensitivity around the freestream points in the calibration $(34 \mathrm{~m} / \mathrm{s}$ and $45 \mathrm{~m} / \mathrm{s})$, there is an even bigger difference. The 3.8 micron sensor has a local sensitivity of roughly $0.2 \mathrm{~m} / \mathrm{s}$ per millivolt while the 2.5 micron sensor is about $0.4 \mathrm{~m} / \mathrm{s}$ per millivolt. Assuming the freestream noise were the same for each case in $\mathrm{mV}$ RMS, the measured turbulence intensity would be about $50 \%$ higher in the freestream for the 2.5 micron sensor. Indeed, the comparisons in Figures 5.15 and 5.16 provide confirmation, where the freestream turbulence intensity is about $1 \%$ for the 3.8 micron sensor and about $1.5 \%$ for the 2.5 micron sensor for both freestream velocity cases.

Data was taken at two different free stream velocities, the first at $34 \mathrm{~m} / \mathrm{s}$ and the second at $45 \mathrm{~m} / \mathrm{s}$. Due to the high frequency turbulent velocity fluctuations close to the wall where velocity fluctuations are maximum, there should be the largest difference in spectra and measured turbulence intensity at the closest point to the wall with less of a difference in the points closer to the freestream.

Figures 5.13 and 5.14 show the mean local velocities for each test at every point in the boundary layer. These agree closely, as expected, because the difference in time constant between the two sensors should have no effect on the mean measurements. The apparent shift to lower mean velocities for the 2.5 micron test is because the sensor started at a closer point to the wall, but the measurements still appear to line up very well, providing a boundary layer profile that looks accurate.

Figures 5.15 and 5.16 show turbulence intensities for the $34 \mathrm{~m} / \mathrm{s}$ and $45 \mathrm{~m} / \mathrm{s}$ freestream velocity cases, respectively. The freestream velocity fluctuations are expected 
to be well below $0.5 \%$ turbulence intensity, so the measured values in the freestream are mostly evidence of noise as discussed throughout Chapter 4, and are consistent with both tests. The difference in measurement between the two sensors in the freestream is most likely due to the difference in sensitivity as discussed above. The largest difference in turbulence intensity measurement occurs at the points closest to the wall, as expected, with a decreasing difference at points moving up toward the freestream from there, and the smallest difference in the freestream. The turbulence intensities in Figure 5.16 are lesser for all points in the boundary layer because the freestream velocity was higher for this case.

The frequency spectra also appear consistent with expectations. A comparison of the point closest to the wall for both tests is shown in Figures 5.17 and 5.18 where the energy is consistent at the lowest frequencies, and then the 3.8 micron sensor data rolls off faster than the 2.5 micron sensor data. The $45 \mathrm{~m} / \mathrm{s}$ freestream velocity case shows the This roll off is less severe for the point midway through the boundary layer shown in Figures 5.19 and 5.20, because the fluctuations have less amplitude at higher frequencies. The earlier roll off for the 3.8 micron sensor case is direct evidence of the additional attenuation taking place as compared to the 2.5 micron sensor case due to the larger time constant of the wire. The energy shown at frequencies much more than about $500 \mathrm{~Hz}$ are visibly less than those for the 2.5 micron case. The slight increase in magnitude at low frequencies for the $45 \mathrm{~m} / \mathrm{s}$ freestream velocity case in both Figure 5.18 and Figure 5.20 is expected due to the extra energy from the higher velocities. Finally for a point in the freestream shown in Figures 5.21 and 5.22, the data agrees very well for each sensor because there are no high frequency velocity fluctuations, and presumably neither sensor is attenuating any signal. 
The apparent harmonics in the freestream spectra appear to be $60 \mathrm{~Hz}$ noise and are consistent for each test.

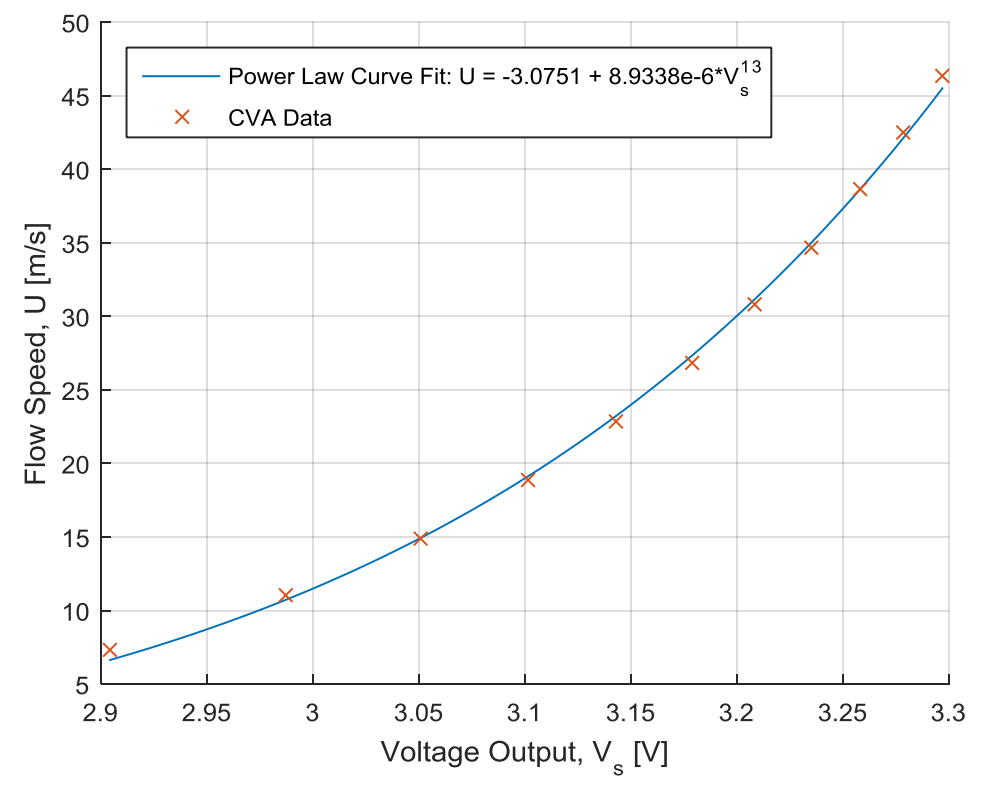

Figure 5.11 Wind tunnel $V_{s}$ calibration used for the 3.8 micron TSI sensor measurements operated at $\mathrm{V}_{\mathrm{w}}=$ $0.58 \mathrm{~V}$

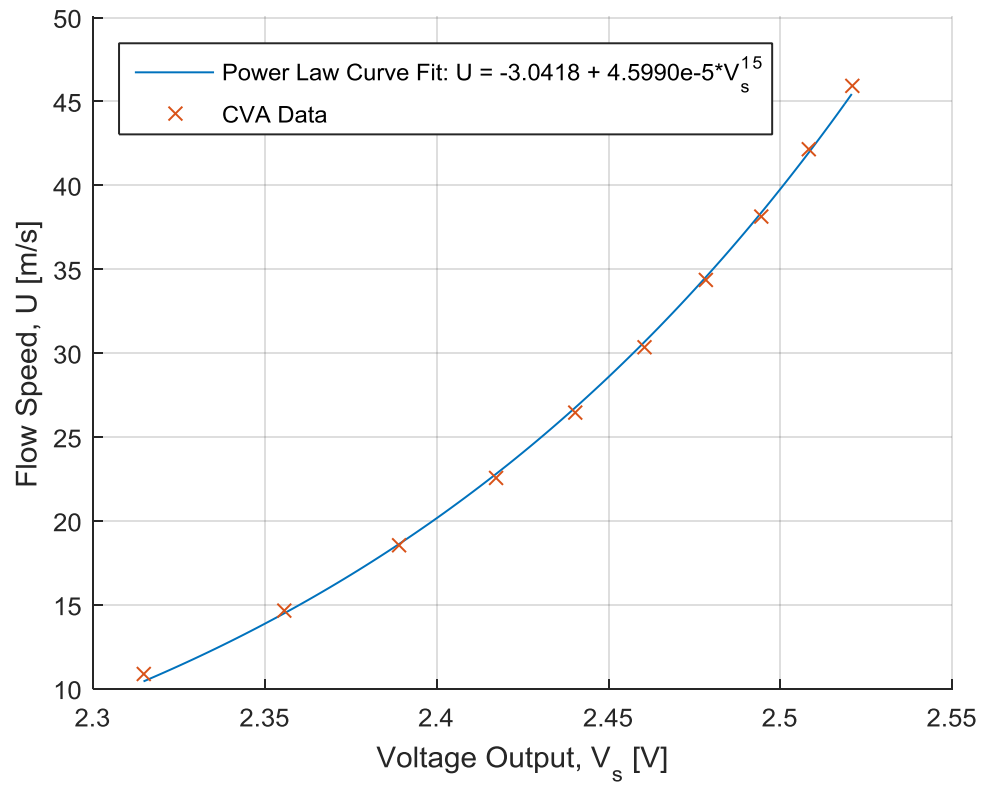

Figure 5.12 Wind tunnel $V_{s}$ calibration used for the 2.5 micron Dantec sensor measurements operated at $\mathrm{V}_{\mathrm{w}}=0.52 \mathrm{~V}$ 


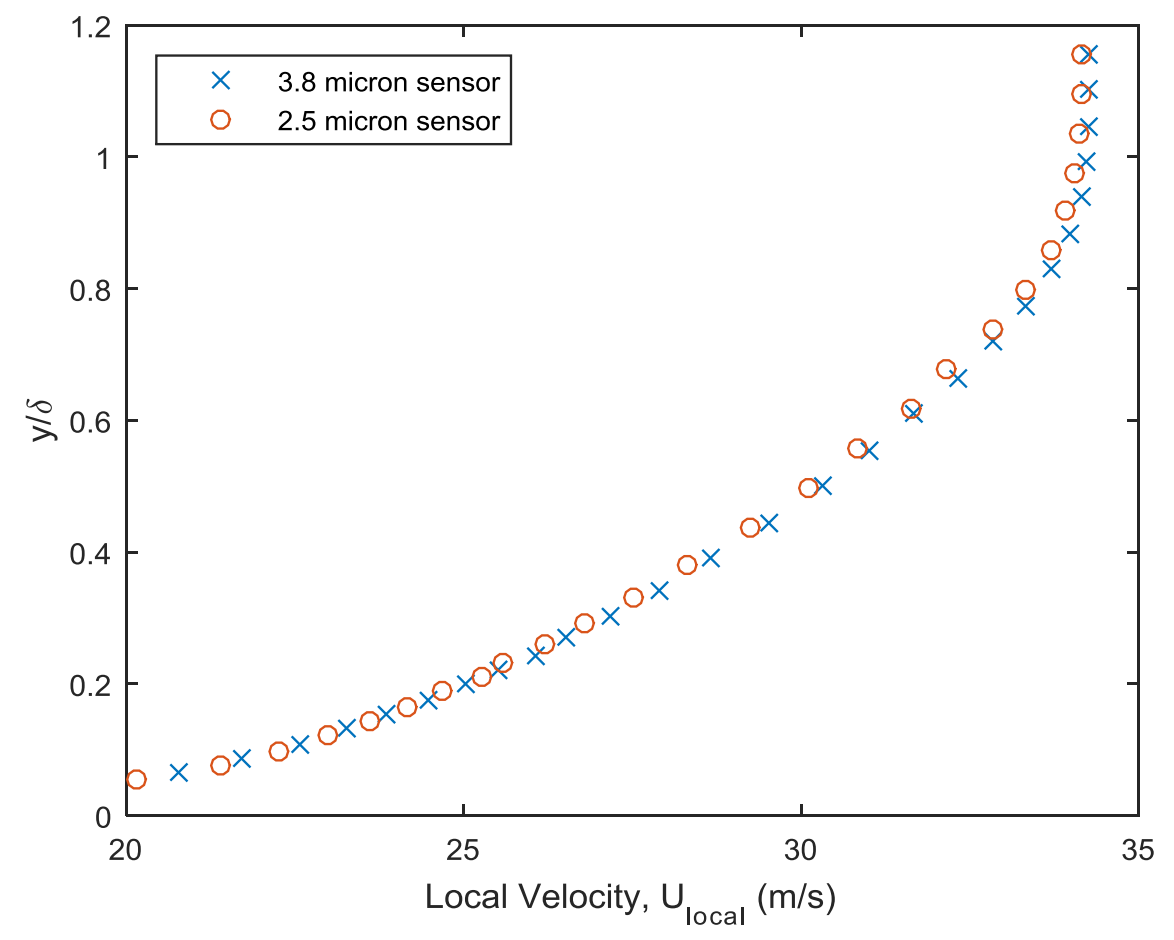

Figure 5.13 Mean velocity data for each sensor measured in the boundary layer at each point for $\mathrm{U}=34$ $\mathrm{m} / \mathrm{s}$

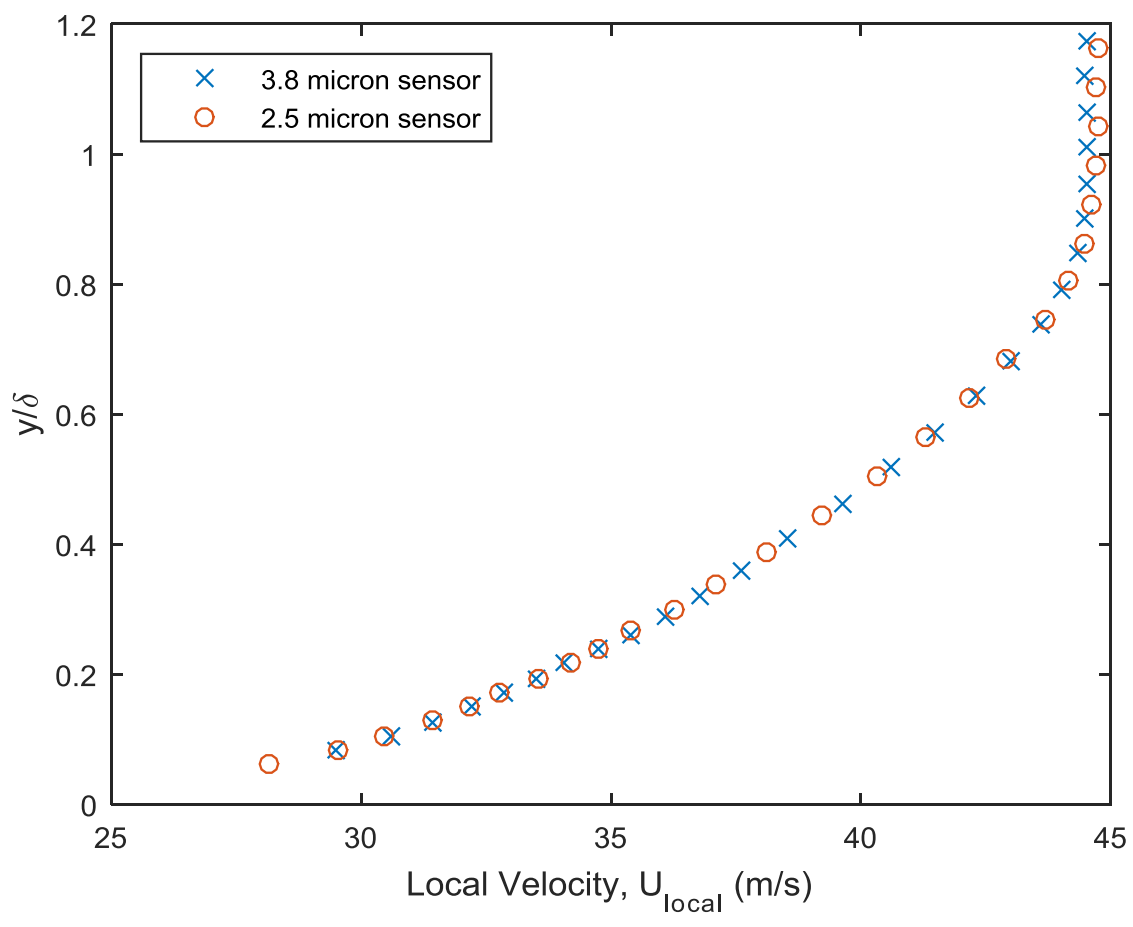

Figure 5.14 Mean velocity data for each sensor measured in the boundary layer at each point for $\mathrm{U}=45$ $\mathrm{m} / \mathrm{s}$ 


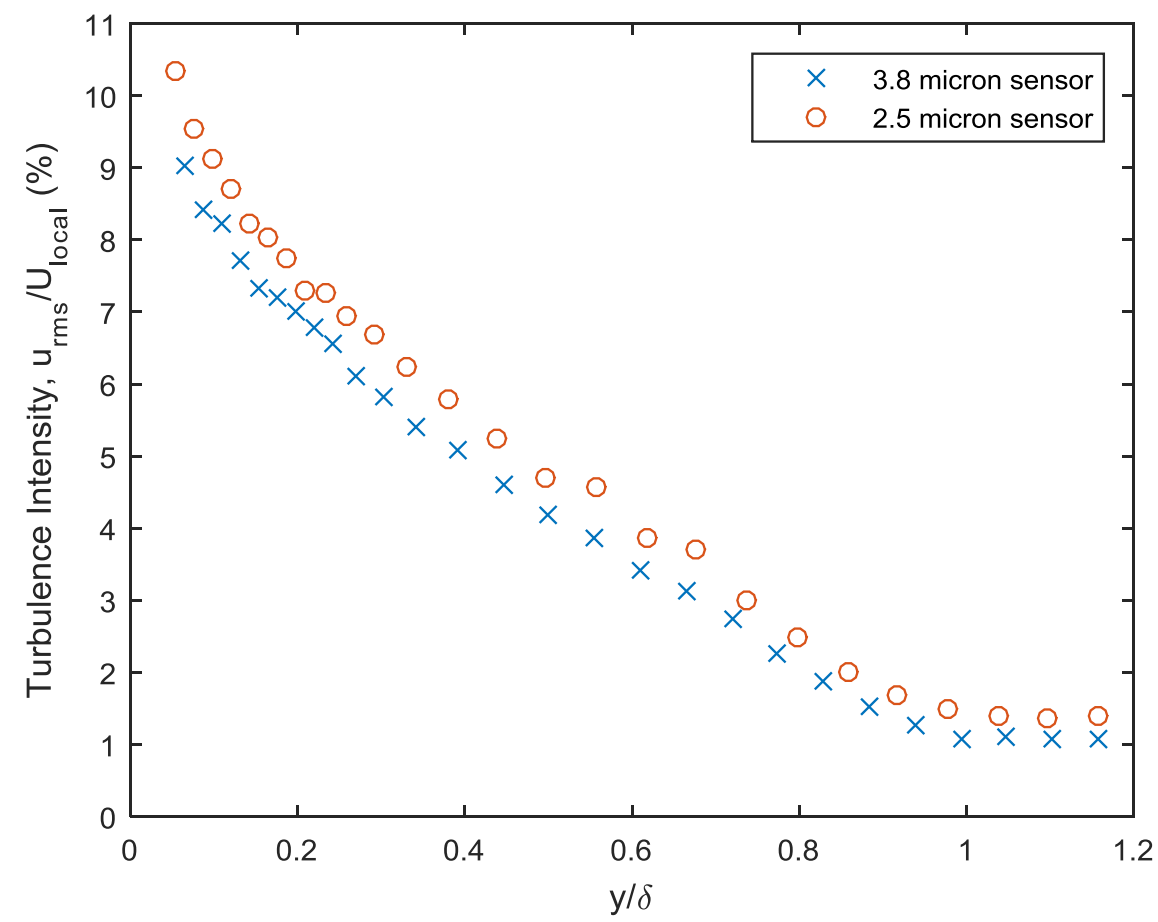

Figure 5.15 Turbulence intensities for each sensor measured in the boundary layer at each point for $\mathrm{U}=34$ $\mathrm{m} / \mathrm{s}$

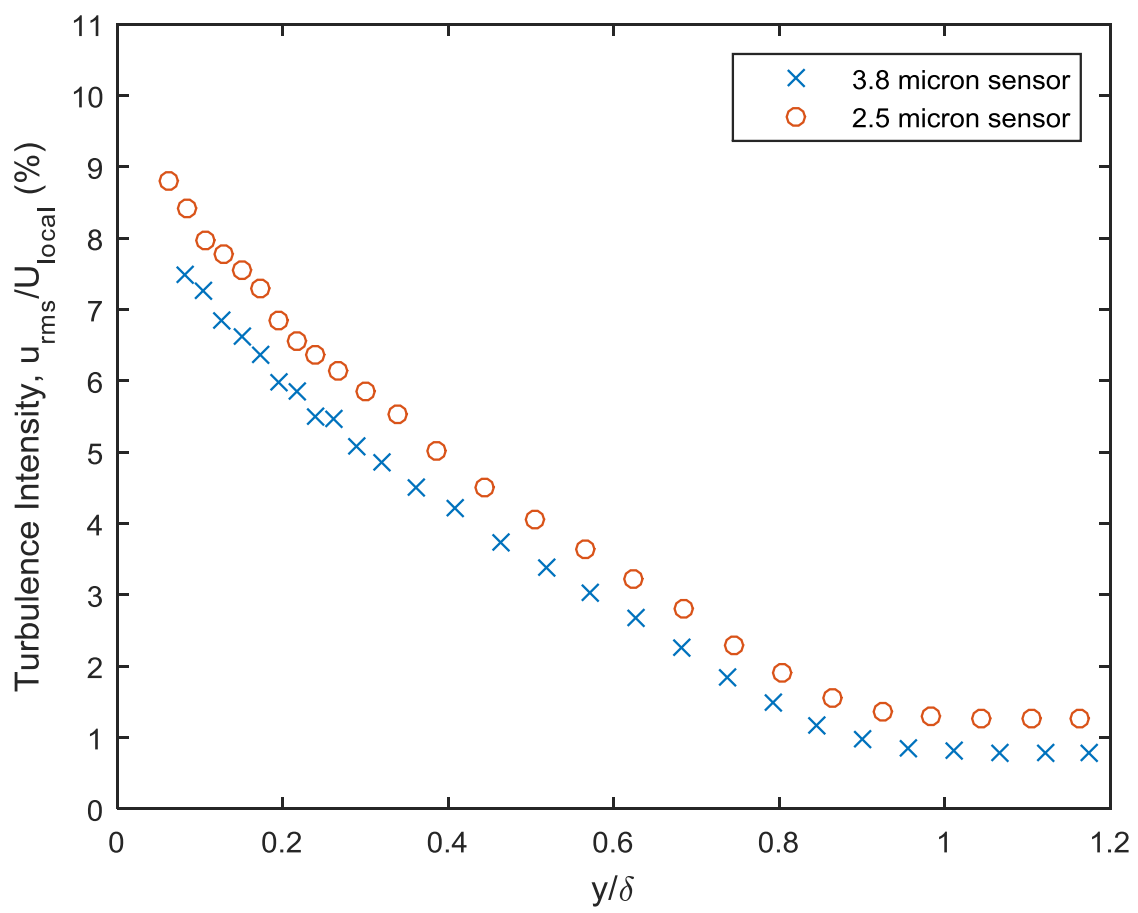

Figure 5.16 Turbulence intensities for each sensor measured in the boundary layer at each point for $\mathrm{U}=45$ $\mathrm{m} / \mathrm{s}$ 


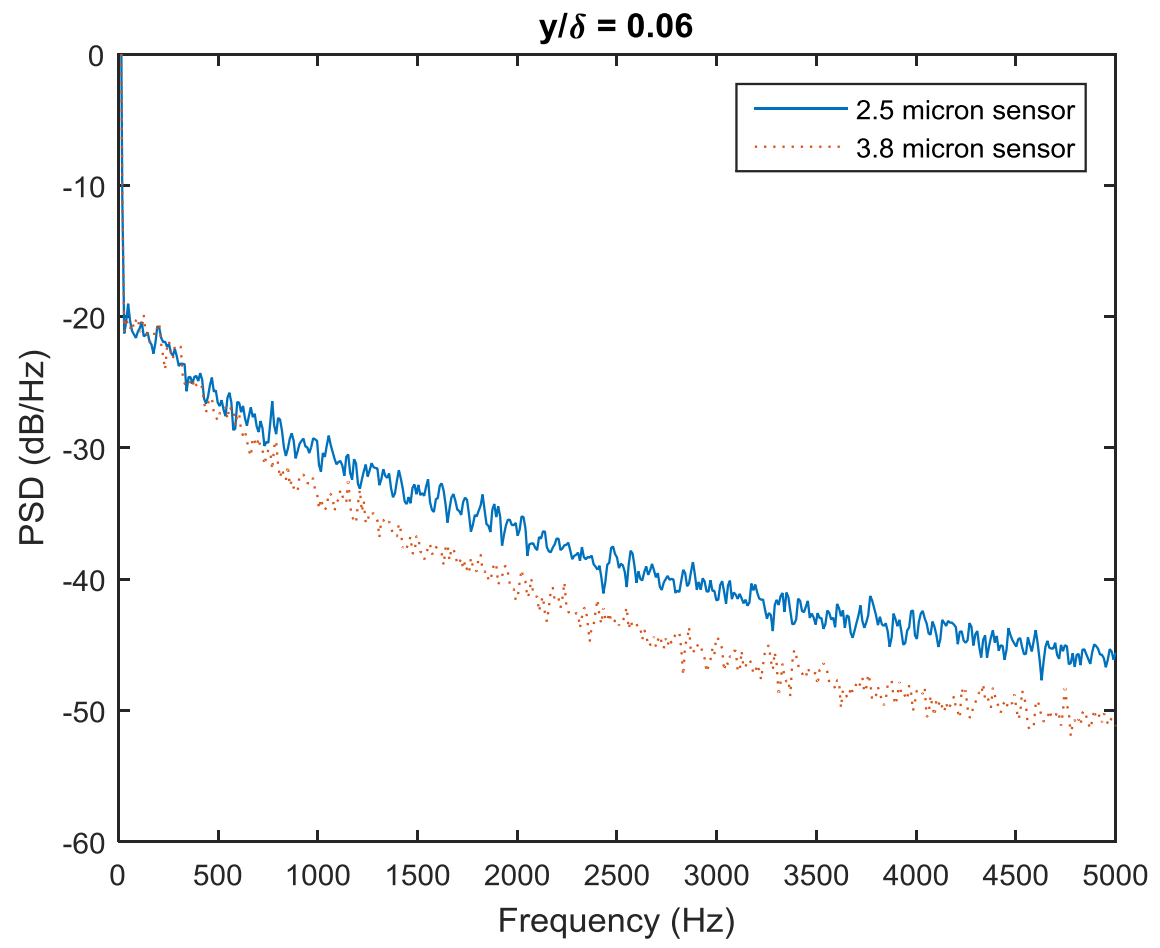

Figure 5.17 Power spectra for each sensor for $34 \mathrm{~m} / \mathrm{s}$ freestream velocity test at closest point to the wall

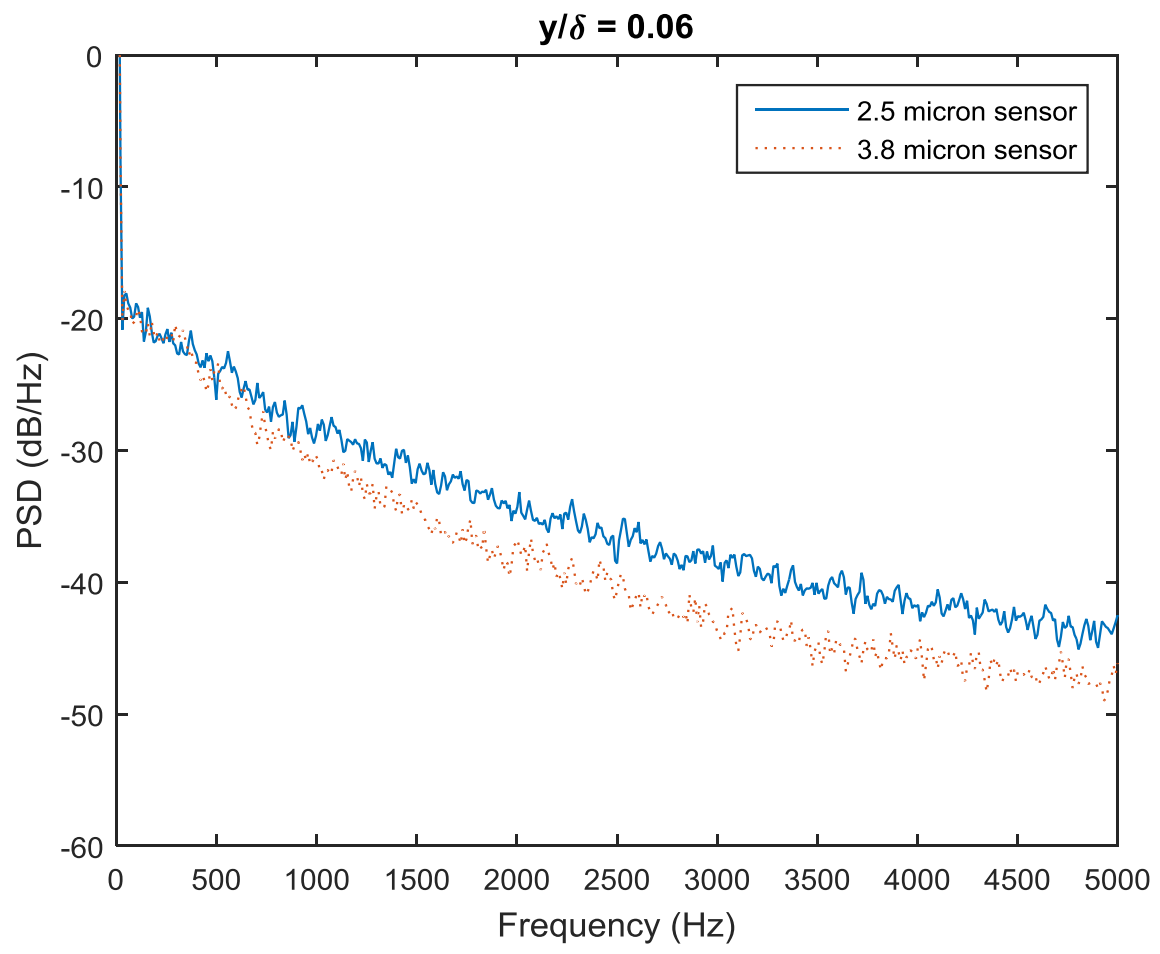

Figure 5.18 Power spectra for each sensor for $45 \mathrm{~m} / \mathrm{s}$ freestream velocity test at closest point to the wall 


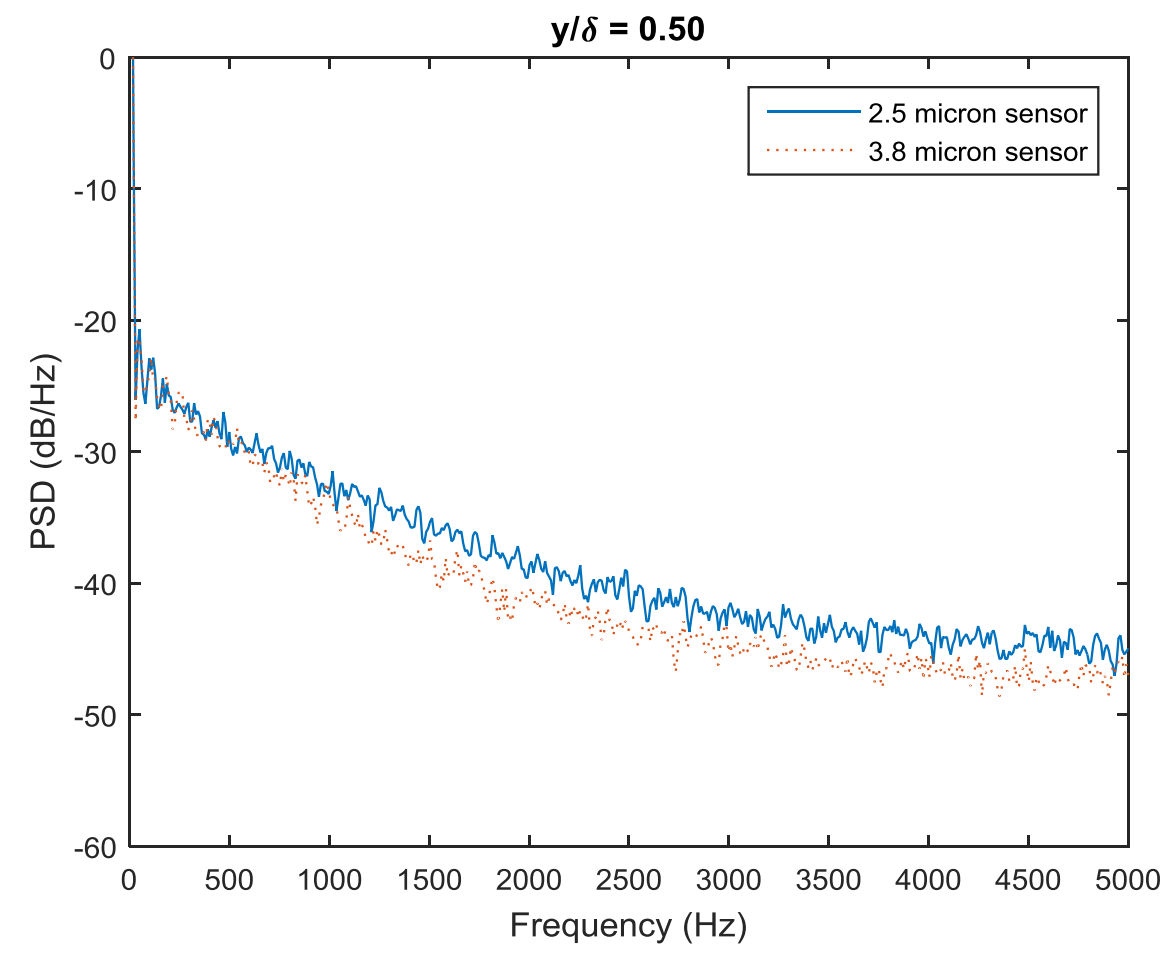

Figure 5.19 Power spectra for each sensor for $34 \mathrm{~m} / \mathrm{s}$ freestream velocity test at point midway through the boundary layer

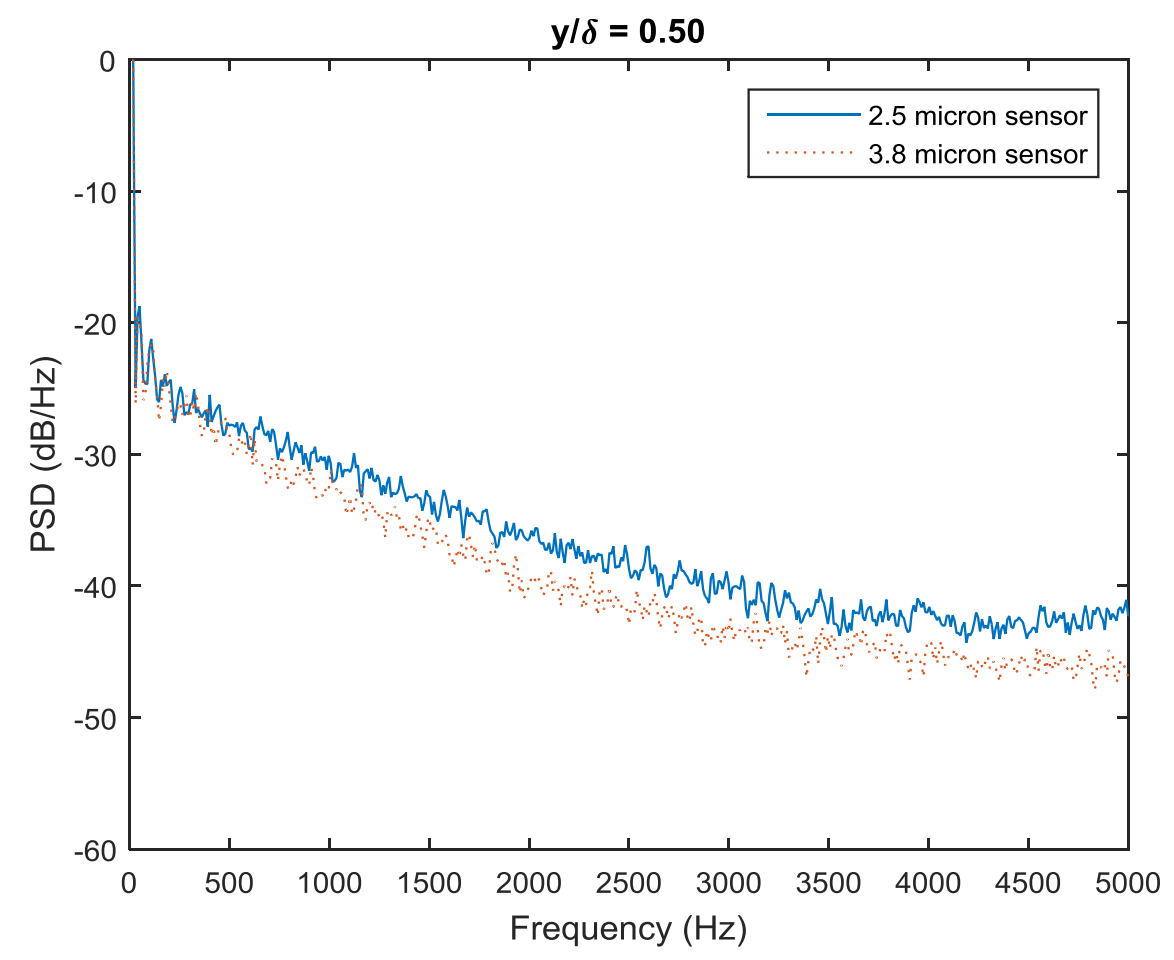

Figure 5.20 Power spectra for each sensor for $45 \mathrm{~m} / \mathrm{s}$ freestream velocity test at point midway through the boundary layer 


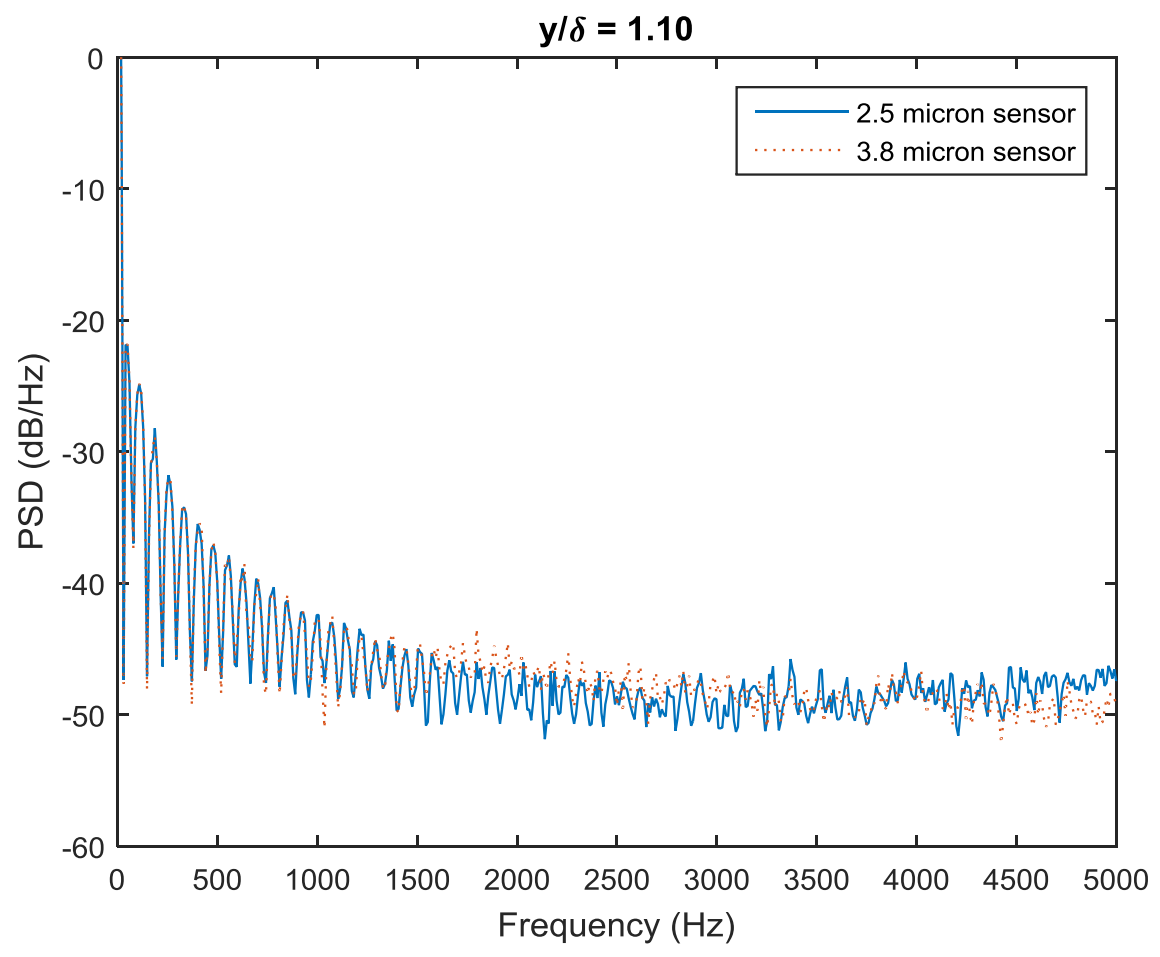

Figure 5.21 Power spectra for each sensor for $34 \mathrm{~m} / \mathrm{s}$ freestream velocity test at freestream point

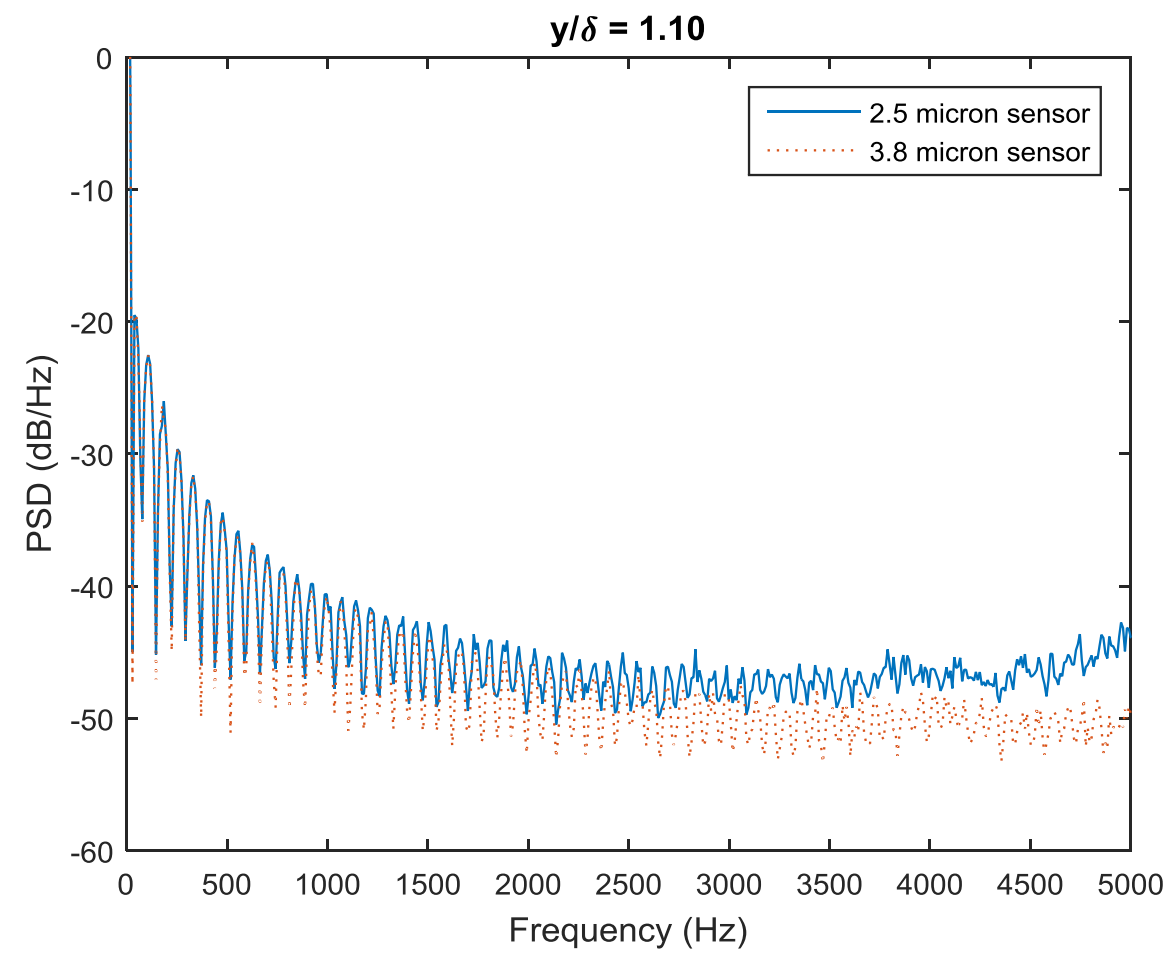

Figure 5.22 Power spectra for each sensor for $45 \mathrm{~m} / \mathrm{s}$ freestream velocity test at freestream point 


\subsection{Conclusions}

The observation that decreasing sensor diameter leads to a significant decrease of the time constant, $M_{C V A}$ (equation (1.4)) and therefore improved frequency response (increase of $f_{C V A}$ (equation (1.1))) has been confirmed with centerline measurements in a turbulent jet and measurements in a turbulent boundary layer on a flat plate. Under similar operating conditions, the 2.5 micron diameter Dantec Dynamics sensor measured higher turbulence intensities and showed less roll off in the frequency spectra than the 3.8 micron TSI sensor for both the turbulent jet test and boundary layer tests. While electrical noise in the system remains a concern, the effect of sensor diameter on the frequency response of a sensor operated with CVA has been confirmed. The fragility of the smaller sensor was a concern at first, but no sensors were broken due to particulate damage or sensor burnout. When operated carefully, it appears that the increase in frequency response can be well worth the trade-off with fragility; however, as revealed by the calibration curves and freestream measurements, the lower sensitivity of a smaller sensor is also a concern.

The other concern with smaller sensors was that they might be much more expensive because they need to be custom made like the 2.5 micron Dantec Dynamics sensor was; however, the price increase is only marginal. It was also found that Dantec Dynamics also makes a standard 1 micron sensor for similar prices to other standard sized sensors like the 3.8 and 5 micron sensors. This 1 micron Dantec sensor is usually used for temperature measurements, but if it is safe to operate up to $T_{w}=250^{\circ} \mathrm{C}$ like the 3.8 and 2.5 micron sensors and the decrease in sensitivity is not too drastic, this sensor could allow for an even more dramatic increase in $f_{C V A}$ due to the $D^{3 / 2}$ relationship in the calculation of $M_{C V A}$. When running this sensor in the EES thermal-electrical simulation code for $U=30$ 
$\mathrm{m} / \mathrm{s}$ and $O H R=1.8$, it was found that this sensor would have a predicted half-amplitude cut off frequency, $f_{C V A}$ of $16.5 \mathrm{kHz}$ when taking into account the quoted cold resistance of $50 \mathrm{ohms}$ and active length of $0.4 \mathrm{~mm}$. This would make its frequency response comparable to CTA. If the sensor is robust enough for practical measurements, this could be a viable solution for CVA signal attenuation when improved frequency response is required. 


\section{Conclusions and Recommendations}

The development of the constant voltage anemometer (CVA) for the boundary layer data system (BLDS) has been motivated by a need for the explicit autonomous measurement of velocity fluctuations in the boundary layer. Previous work showed that CVA has proven to be a possible solution for the autonomous measurement of velocity fluctuations on aircraft, but shows significant signal attenuation due to the thermal lag of the sensor operated in constant voltage mode. The thermal lag of the sensor is quantified by a time constant, $M_{C V A}$, shown in equation (1.4). When the time constant is decreased, the half amplitude cut off frequency, $f_{C V A}$, is increased, thereby decreasing the amount of attenuation during measurements. In this thesis, three main approaches have been outlined in theory and tested experimentally to determine the feasibility and effectiveness of implementing them with CVA to limit attenuation: operation at higher $V_{w}$, implementation of software compensation, and utilization of smaller diameter sensors.

\subsection{Conclusions}

1. Operation of CVA at higher voltage (directly resulting in higher $O H R$ 's) does not result in a sizable improvement in frequency response that outweighs the increased danger of wire burnout. The theory and predicted values from calculations show that the improvement is only about $150 \mathrm{~Hz}$ ( $8 \%$ increase) at best for the half amplitude cutoff frequency, and the tests appear to confirm the suspicion that this does not have a substantial effect on turbulence measurements. The maximum temperature that a sensor can be operated without wire burnout creates a limit for the effect of $V_{w}$ on frequency response. Operating up to or near this limit does have 
a large effect on the sensitivity of CVA measurements, but does not provide much of an increase in frequency response compared to lower $V_{w}$ 's.

2. Software compensation of the CVA output does not appear to be useful for measurements with BLDS. The electrical noise present in the CVA measurement system is amplified by the correction algorithm and creates measurements that are not representative of the fluctuations being measured. Implementation of this technique with CVA on BLDS is therefore not very attractive. If there was a way to minimize the noise in a measurement system using CVA, then software compensation could possibly be used to help get back some of the signal that was attenuated due to thermal lag of the sensor used.

3. Decreasing sensor diameter leads to a significant decrease of $M_{C V A}$ (equation (1.4)) and therefore increase of $f_{C V A}$ (equation (1.1)). Under similar operating conditions, the 2.5 micron diameter Dantec Dynamics sensor showed less roll off in the frequency spectra (measured higher turbulence intensities) than the 3.8 micron TSI sensor for both the turbulent jet test and boundary layer tests. Smaller sensors are more fragile and seem to have a decrease in sensitivity as compared to larger sensors; however, for some applications, the increase in frequency response may be worth the trade-off with fragility and sensitivity.

\subsection{Recommendations}

1. CVA should be operated at high overheats to ensure maximum sensitivity to velocity fluctuations and minimum sensitivity to temperature fluctuations, but the increase in frequency response is only marginal. 
2. Further investigation into limiting electrical noise during CVA measurements should be explored; the addition of low pass filtering of the CVA output as discussed in Chapter 4 could be very helpful. Until the electrical noise is reduced, software compensation should not be implemented with CVA measurements.

3. CVA operation with smaller sensors is highly beneficial to frequency response. Additional testing with even smaller sensors such as the 1 micron Dantec sensor and testing compared to CTA measurements would be a very effective diagnosis of CVA frequency response. 


\section{REFERENCES}

[1] W. Neumeister, "Hot-Wire Anemometer for the Boundary Layer Data System," MS Thesis. California Polytechnic State University, San Luis Obispo, 2012.

[2] K. Pettersson and A. Rizzi, "Aerodynamic Scaling to Free Flight Conditions: Past and Present," Progress in Aerospace Sciences, vol. 44, no. 4, pp. 295-313, 2008.

[3] R. V. Westphal, M. Bleazard, A. Drake, A. M. Bender, D. Frame and S. R. Jordan, "A Compact, Self-Containing System for Boundary Layer Measurement in-Flight," in AIAA2006-3828, AIAA Meeting Papers on Disc [CD-ROM], Reston, VA, 2006. No.10-13.

[4] L. Fingerson, "Thermal Anemometry, Current State and Future Directions," Review of Scientific Instruments, vol. 65, no. 2, pp. 285-300, 1994.

[5] J. Hinze, Turbulence, New York: McGraw-Hill, 1975.

[6] G. Comte-Bellot and G. Sarma, "Constant voltage anemometer practice in supersonic flows," AlAA Journal, vol. 29, no. 2, pp. 261-270, 2001.

[7] G. Comte-Bellot, J. Weiss and J. C. Béra, "Lead-resistance effects in a constant voltage anemometer," Rev. Sci. Instrum., vol. 75, no. 5, pp. 1290-1296, 2004.

[8] D. Collis and M. Williams, "Two-Dimensional Convection from Heated Wires at Low Reynolds Numbers," Journal of Fluid Mechanics, vol. 6, no. 3, pp. 357-384, 1959.

[9] A. Wazzan, "Spatial and Temporal Stability Charts for the Falkner-Skan Boundary-Layer Profiles," Clearinghouse, Springfield, VA, 1968.

[10] G. Sarma, "Flow Rate Measuring Apparatus". United States Patent 5074147, December 1991.

[11] G. S. Sarma, "Analysis of a Constant Voltage Anemometer Circuit," in Instrument Measurement and Technology Conference, Irvine, 1993.

[12] G. R. Sarma, "Transfer function analysis of the constant voltage anemometer," Review of Scientific Instruments, vol. 69, no. 6, pp. 2385-2391, 1998.

[13] M. A. Kegerise and E. F. Spina, "A comparative study of constant-voltage and constanttemperature hot-wire anemometers Part I: The static response," Experiments in Fluids, vol. 29, no. 2, pp. 154-164, 2000. 
[14] Tao of Systems Integration, Inc., "Technical Note: Constant Voltage Anemometer," 2005.

[15] R. Murphy, "Development of an Autonomous Single-Point Calibration for a Constant Voltage Hot-Wire Anemometer," MS Thesis. California Polytechnic State University, San Luis Obispo, 2015.

[16] H. Li, "Constant Voltage Hot-Wire Anemometry for the Boundary Layer Data System," MS Thesis, California Polytechnic State University, San Luis Obispo, 2013.

[17] E. J. List, "Turbulent Jets and Plumes," Annual Review of Fluid Mechanics, vol. 14, pp. 189212, 1982.

[18] I. Wygnanski and H. Fiedler, "Some Measurements in the Self-Preserving Jet," J. Fluid Mech., vol. 38, no. 3, pp. 577-612, 1969.

[19] P. Klebanoff, "Characteristics of Turbulence in a Boundary Layer with Zero Pressure Gradient," NACA, vol. 1247, 1955.

[20] F. M. White, Viscous Fluid Flow, New York: McGraw-Hill, 2006.

[21] L. King, "On the Convection of Heat from Small Cylinders in a Stream of Fluid: Determination of the Convection Constants of Small Platinum Wires, with Applications to Hot-Wire Anemometry," in Proceedings of the Royal Society of London. Series A, Containing Papers of a Mathematical and Physical Character, London, September 1914.

[22] H. H. Brunn, Hot-Wire Anemometry, New York: Oxford University Press, 1995.

[23] G. Comte-Bellot, "Ch. 34," in The Handbook of Fluid Dynamics, CRC Press, 1998.

[24] "EES," F-Chart Software, 2015. [Online]. Available: http://www.fchart.com/ees/.

[25] T. Incorporated, Thermal Anemometry Probes, Shoreview, MN, 2008. 


\section{APPENDICES}

\section{APPENDIX A. CVA OPERATING PROCEDURE}

\section{CVA Quick Reference Guide}

\section{Required Equipment}

CVA System

3 BNC cables

2 Digital Volt Meters (DVM)

Hot-wire probe support

Probe support shorting plug

Hot-wire probe

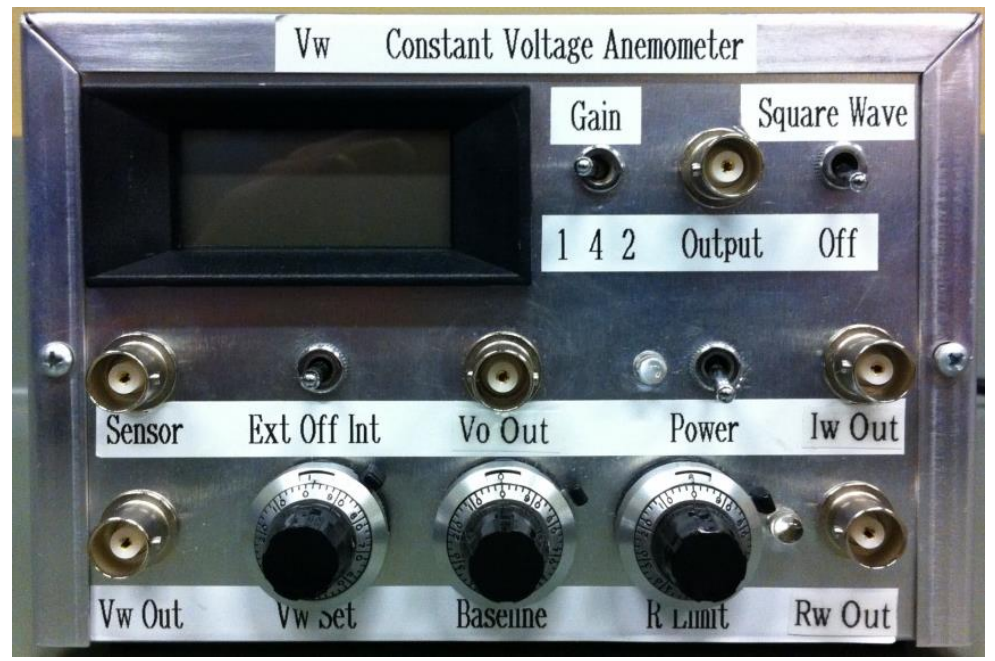

\section{Nomenclature}

$V_{w}(\mathrm{~V})=$ Constant voltage value across hot-wire probe

$R_{w}(\Omega)=$ Wire resistance at operating temperature (hot)

$R_{\infty}(\Omega)=$ Wire resistance at room temperature (cold)

$I_{w}(\mathrm{~mA})=$ Current through wire

$R_{\text {lim }}(\Omega)=$ Threshold at which wire voltage will decrease by $0.1 \mathrm{~V}$

\section{Output Conversions}

\begin{tabular}{cl}
$\begin{array}{c}\text { System } \\
\text { Parameter }\end{array}$ & $\begin{array}{l}\text { Calculation Using CVA } \\
\text { Output }\end{array}$ \\
\hline$V_{w}(\mathrm{~V})=$ & $\boldsymbol{V}_{\boldsymbol{w}}$-Out $=\boldsymbol{V}_{\boldsymbol{w}}$-Set \\
$I_{w}(\mathrm{~mA})=$ & $(40 \mathrm{~mA} / \mathrm{V}) \times \boldsymbol{I}_{\boldsymbol{w}}$-Out $(\mathrm{V})$ \\
$R_{w}(\mathrm{ohms})=$ & $(5 \Omega / \mathrm{V}) \times \boldsymbol{R}_{\boldsymbol{w}}$-Out $(\mathrm{V})-$ box $(0.1 \Omega)-$ BNC cable res. \\
& $(\Omega)-$ probe support res. $(\Omega)-$ internal probe res. $(\Omega)$ \\
$R_{\infty}($ ohms $)=$ & DVM reading $(\Omega)-$ BNC cable res. $(\Omega)-$ probe \\
& support res. $(\Omega)-$ internal DVM res. $(\Omega)-$ internal \\
& probe res. $(\Omega)$ \\
$R_{\text {lim }}($ ohms $)=$ & $(2.5 \Omega /$ revs $) \times$ R-Limit $(\#$ revs $)$
\end{tabular}




\section{Operation Procedure}

1. Ensure the Ext., Off, and Int. selector switch is set to the middle $\boldsymbol{O}$ ff position.

2. Flip Power switch up to turn CVA system on. Power LED should light green and the $\boldsymbol{R}$ Limit indicator should light red.

3. Set wire voltage $\left(V_{w}\right)$ to $0.1 \mathrm{~V}$ using $\boldsymbol{V}_{\boldsymbol{w}}$-Set knob dial.

Note: Measuring $\boldsymbol{V}_{\boldsymbol{w}}$-Out on a DVM without Ext. mode active will not show the true $V_{w}$; use numbers on knob dial.

4. Connect the probe support to one end of a BNC cable and the opposite BNC cable end to a DVM that outputs a low short circuit current $(\leq 1 \mathrm{~mA})$. Install probe support shorting plug. Measure and record combined resistance of the BNC cable, probe support, and internal DVM resistance. Turn off DVM.

5. Remove shorting plug from probe support and carefully install hot-wire probe. Record probe serial \#.

6. Now measure combined hot-wire probe resistance with DVM and subtract off total resistance from step \#4, as well as manufacturer specified internal probe resistance. The remaining value in ohms is the cold wire resistance $\left(R_{\infty}\right)$.

7. Remove BNC cable end connected to DVM and connect to the Sensor output on CVA system.

8. Set the resistance limit $\left(R_{\text {lim }}\right)$ threshold to a couple ohms above $R_{\infty}$ found in step \#6 using the $\boldsymbol{R}$-Limit knob dial. There are 2.5 ohms per revolution of the $\boldsymbol{R}$-Limit knob dial. Warning: If probe resistance exceeds the $\boldsymbol{R}$-Limit setting in ohms $\left(R_{\text {lim }}\right)$, as indicated by red $\boldsymbol{R}$-Limit LED illumination, $V_{w}$ will drop 0.1 volts for burnout protection. $V_{w}$ will raise back up $0.1 \mathrm{~V}$ when probe resistance is cooled below $R_{\text {lim, }}$, indicated by the $\boldsymbol{R}$-Limit LED colored green.

9. Connect one DVM to the $\boldsymbol{V}_{\boldsymbol{w}}$-Out BNC jack and another DVM to the $\boldsymbol{R}_{\boldsymbol{w}}$-Out BNC jack.

10. Move the selector switch left to $\boldsymbol{E x t}$. from the center $\boldsymbol{O}$ ff position. The $\boldsymbol{R}$-Limit LED should turn green as a result of step \#8 and $\boldsymbol{V}_{\boldsymbol{w}}$-Out should read $0.1 \mathrm{~V}$ on DVM.

11. Measure the cold probe resistance $\left(R_{\infty}\right)$ with the CVA by gradually lowering the $\boldsymbol{V}_{\boldsymbol{w}}$-Set knob dial over the $0.04 \mathrm{~V}-0.05 \mathrm{~V}$ range while monitoring $\boldsymbol{R}_{\boldsymbol{w}}$-Out using the connected DVM with $5 \Omega / \mathrm{V}$. Record the lowest observed resistance and verify that it is similar to the combined resistance $(<0.5 \Omega$ difference) from step \#6.

12. Increase $V_{w}$ back to $0.1 \mathrm{~V}$ and move selector switch to the $\boldsymbol{O} f \boldsymbol{f}$ position. 
13. Position the hot-wire sensor within a nozzle diameter of the Cal-Jet nozzle outlet or setup probe in wind-tunnel.

14. Set $\boldsymbol{R}$-Limit to a couple ohms above the expected probe's hot operating resistance $\left(R_{w}\right)$ using

$$
R \operatorname{Limit}(\# \text { revs })=\frac{O H R \times R_{\infty}(\Omega)}{2.5 \Omega / r e v} \text { and } O H R=\frac{R_{w}}{R_{\infty}} .
$$

15. Turn AIRFLOW ON and adjust to velocity at first measurement point.

16. Move the selector switch left to $\boldsymbol{E x t}$. from the center $\boldsymbol{O}$ ff position. $\boldsymbol{V}_{\boldsymbol{w}}$-Out should read 0.1 V on DVM.

17. Increase $V_{w}$ to desired set-point within 0-1 V range (The RESET button on the top of the instrument panel will need to be pushed at this time. Otherwise the set-point voltage $\boldsymbol{V}_{\boldsymbol{w}}$ will continue in safe mode.) while monitoring $\boldsymbol{R}_{\boldsymbol{w}}$-Out with connected DVM. Calculate necessary value for $\boldsymbol{R}_{\boldsymbol{w}}$-Out from OHR with respect to flow speed using

$$
R_{w} \operatorname{Out}(V)=\frac{O H R x R_{\infty}(\Omega)+\text { res. offsets incl. } 0.1 \Omega \text { for CVA box }}{5\left(\frac{\Omega}{V}\right)} .
$$

Never exceed an OHR $>$ 2.0. Lock $\boldsymbol{V}_{\boldsymbol{w}}$-Set knob dial before measurements.

18. Once $V_{w}$ is properly set, use one of the DVMs for measuring the op-amp output voltage, $\boldsymbol{V}_{\boldsymbol{o}}$-Out, or the wire current output, $\boldsymbol{I}_{\boldsymbol{w}}$-Out, for mean and RMS data. Use the other DVM for monitoring the mean $\boldsymbol{R}_{\boldsymbol{w}}$-Out or $\boldsymbol{V}_{\boldsymbol{w}}$-Out.

Note: Set DVM to Volt range for mean data and $\mathrm{mV}$ range for RMS data, in order to avoid accuracy problems.

19. The $\boldsymbol{R}$-Limit LED should remain solid green during operation. If $\boldsymbol{R}$-Limit LED illuminates solid red, immediately flip selector switch to $\boldsymbol{O} f \boldsymbol{f}$ from $\boldsymbol{E x t}$. in an effort to protect the probe. Recheck $R_{\text {lim }}, R_{\infty}$, and the $V_{w}$ set-point.

20. If the $\boldsymbol{R}$-Limit LED blinks red (possibly during large turbulent fluctuations), check that the mean value of $\boldsymbol{R}_{\boldsymbol{w}}$-Out will not cause OHR $>2.0$. If safe, try increasing $R_{\text {lim }}$ by turning the $\boldsymbol{R}$-Limit knob dial $1 / 2$ a revolution, equal to $1.25 \mathrm{ohms}$, in order to stabilize the green R-Limit LED.

\section{Once measurements are complete, DO NOT reduce airflow below first} measurement point.

22. Move selector switch to $\boldsymbol{O}$ ff from the $\boldsymbol{E x t}$. position. The $\boldsymbol{R}$-Limit LED should turn red. 23. Flip Power switch down to power off CVA. All LED lights should become dark. 
24. Decrease $V_{w}$ back down to $0.1 \mathrm{~V}$ using $\boldsymbol{V}_{\boldsymbol{w}}$-Set knob dial.

25. Turn off airflow and DVMs.

26. Carefully remove hot-wire probe from probe support and return probe to original case. 


\section{APPENDIX B. UPDATED JET APPARATUS}

Filters used were model number 855148-022 with the following specifications:
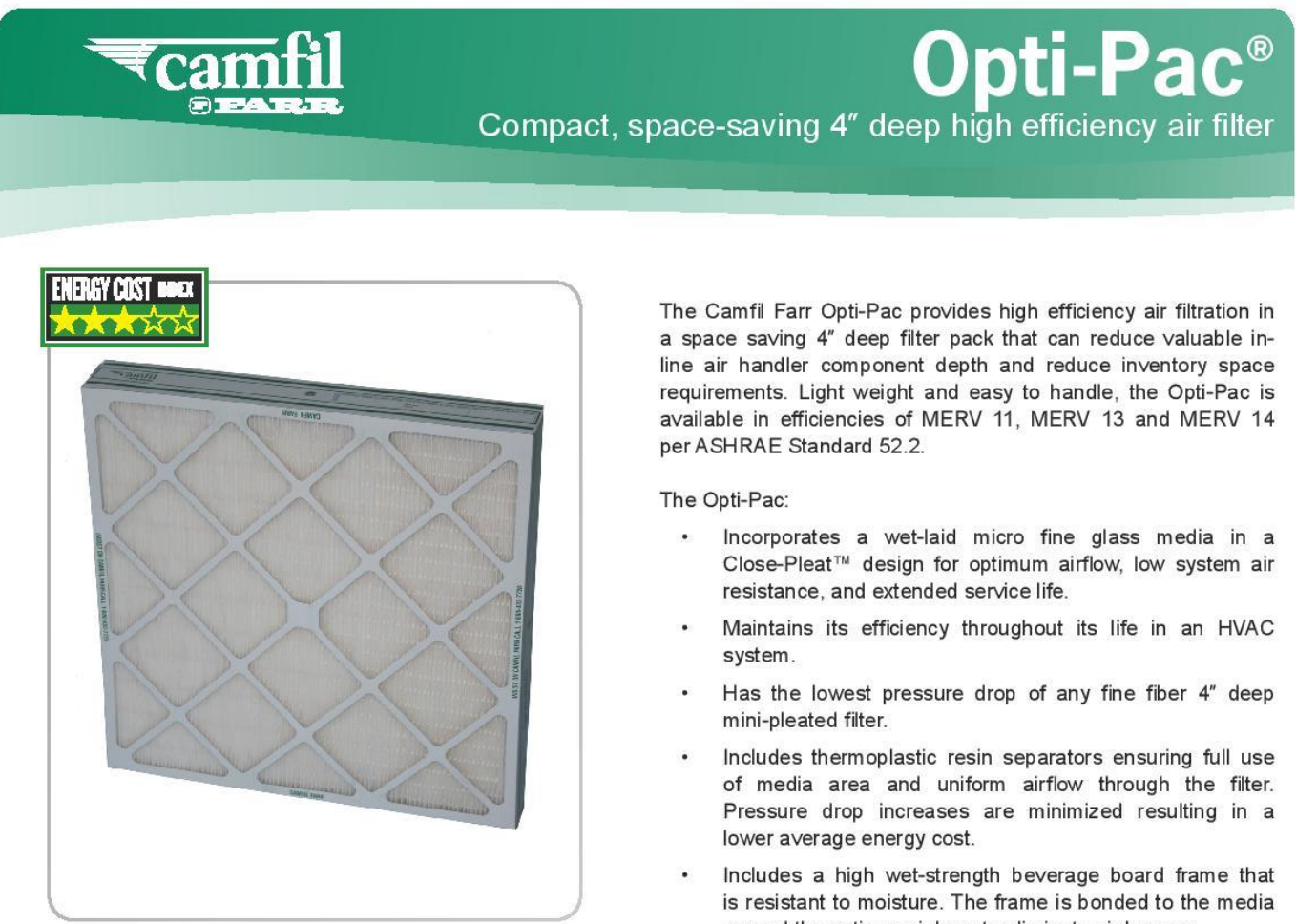
a space saving 4 " deep filter pack that can reduce valuable inline air handler component depth and reduce inventory space requirements. Light weight and easy to handle, the Opti-Pac is available in efficiencies of MERV 11, MERV 13 and MERV 14 per ASHRAE Standard 52.2

The Opti-Pac:

- Incorporates a wet-laid micro fine glass media in a Close-Pleat ${ }^{\mathrm{TM}}$ design for optimum airflow, low system air resistance, and extended service life.

- Maintains its efficiency throughout its life in an HVAC system.

- Has the lowest pressure drop of any fine fiber 4" deep mini-pleated filter.

- Includes thermoplastic resin separators ensuring full use of media area and uniform airflow through the filter. Pressure drop increases are minimized resulting in a lower average energy cost.

- Includes a high wet-strength beverage board frame that is resistant to moisture. The frame is bonded to the media around the entire periphery to eliminate air bypass.

- Has diagonal support members on the air-entering and air-exiting sides ensuring filter pack rigidity. The diagonal support members are bonded to the apex of each media pleat to ensure pleat and media stability and assist in providing a strong and durable filter enclosure.

- Is guaranteed against media pack failure to 5.0 " w.g. Expensive filter blowouts are eliminated and system cleanliness and integrity are maintained.

- Is available in a variety of sizes for virtually any application.

The Opti-Pac is excellent for VAV systems, or any commercial, medical or industrial application where space is a premium. Its compact depth reduces the in line space in air handlers allowing the application of additional components or reducing the overal space footprint of the air handling system. Disposal costs are also minimized as the Opti-Pac reduces waste by consuming up to $2 / 3$ less dumpster volume; reducing disposal costs and the facility's carbon footprint.

The Energy Cost Index (ECI) is a system that rates a filter's energy usage and its ability to maintain

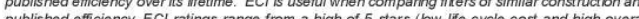

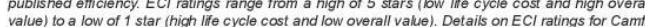
Farr and competitor's products are avallable from your Camfil Farr sales outlet and on the web al www.camfilfarr.com.

www.camfilfarr.com 


\section{$\overline{\text { Tamfil }}$}

\section{Opti-Pac ${ }^{\circledR}$}

Compact, space-saving $4^{\prime \prime}$ deep high efficiency air filters

Performance Data

\begin{tabular}{|c|c|c|c|c|c|c|c|c|}
\hline $\begin{array}{l}\text { ASHRAE } \\
\text { Efficiency }\end{array}$ & PartNumber & $\begin{array}{l}\text { Nominal Depth } \\
\text { (inches) }\end{array}$ & $\begin{array}{l}\text { Nominal Size } \\
\text { (inches, } \mathrm{HxW} \text { ) }\end{array}$ & $\begin{array}{l}\text { Actual Depth } \\
\text { (inches) }\end{array}$ & $\begin{array}{l}\text { Actual Dimensions } \\
\text { ( } H \times W \text { W } \\
\text { (inches) }\end{array}$ & $\begin{array}{l}\text { Initial Resistance } \\
\text { (inches w.g.) }\end{array}$ & $\begin{array}{l}\text { Airflow Capacity } \\
\text { (cm) }\end{array}$ & $\begin{array}{l}\text { Media Area } \\
\text { (sq. A.) }\end{array}$ \\
\hline \multirow{8}{*}{ MERV 11} & 855148-001 & \multirow{8}{*}{4} & $20 \times 20$ & \multirow{8}{*}{3.75} & $19.38 \times 19.38$ & \multirow{8}{*}{0.33} & 1390 & 80 \\
\hline & $855148-002$ & & $24 \times 12$ & & $23.38 \times 11.38$ & & 1000 & 53 \\
\hline & $855148-003$ & & $24 \times 20$ & & $23.38 \times 19.38$ & & 1670 & 97 \\
\hline & $855148-004$ & & $24 \times 24$ & & $23.38 \times 23.38$ & & 2000 & 113 \\
\hline & $855148-005$ & & $25 \times 16$ & & $24.38 \times 15.38$ & & 1390 & 80 \\
\hline & $855148-006$ & & $20 \times 16$ & & $19.38 \times 15.38$ & & 1100 & 64 \\
\hline & $855148-007$ & & $24 \times 18$ & & $23.38 \times 17.38$ & & 1500 & 87 \\
\hline & $855148-008$ & & $25 \times 20$ & & $24.38 \times 19.38$ & & 1740 & 101 \\
\hline \multirow{8}{*}{ MERV 13} & $855148-011$ & \multirow{8}{*}{4} & $20 \times 20$ & \multirow{8}{*}{3.75} & $19.38 \times 19.38$ & \multirow{8}{*}{0.47} & 1390 & 80 \\
\hline & $855148-012$ & & $24 \times 12$ & & $23.38 \times 11.38$ & & 1000 & 53 \\
\hline & $855148-013$ & & $24 \times 20$ & & $23.38 \times 19.38$ & & 1670 & 97 \\
\hline & $855148-014$ & & $24 \times 24$ & & $23.38 \times 23.38$ & & 2000 & 113 \\
\hline & $855148-015$ & & $25 \times 16$ & & $24.38 \times 15.38$ & & 1390 & 80 \\
\hline & $855148-016$ & & $20 \times 16$ & & $19.38 \times 15.38$ & & 1100 & 64 \\
\hline & $855148-017$ & & $24 \times 18$ & & $23.38 \times 17.38$ & & 1500 & 87 \\
\hline & $855148-018$ & & $25 \times 20$ & & $24.38 \times 19.38$ & & 1740 & 101 \\
\hline \multirow{8}{*}{ MERV 14} & $855148-021$ & \multirow{8}{*}{4} & $20 \times 20$ & \multirow{8}{*}{3.75} & $19.38 \times 19.38$ & \multirow{8}{*}{0.60} & 1390 & 80 \\
\hline & $855148-022$ & & $24 \times 12$ & & $23.38 \times 11.38$ & & 1000 & 53 \\
\hline & $855148-023$ & & $24 \times 20$ & & $23.38 \times 19.38$ & & 1670 & 97 \\
\hline & $855148-024$ & & $24 \times 24$ & & $23.38 \times 23.38$ & & 2000 & 113 \\
\hline & $855148-025$ & & $25 \times 16$ & & $24.38 \times 15.38$ & & 1390 & 80 \\
\hline & $855148-026$ & & $20 \times 16$ & & $19.38 \times 15.38$ & & 1100 & 64 \\
\hline & $855148-027$ & & $24 \times 18$ & & $23.38 \times 17.38$ & & 1500 & 87 \\
\hline & $855148-028$ & & $25 \times 20$ & & $24.38 \times 19.38$ & & 1740 & 101 \\
\hline
\end{tabular}

DATA NOTES

Fither should be scheduled for change when intitial pressure drop has doubled. Final pressure drop should not exceed $1.0^{\circ} \mathrm{w}$.

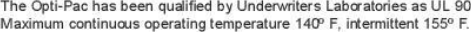

Specifications

1.0 General

1.1. Air filters shall be 4" deep high efficiency ASHRAE box style filters consisting of mini-pleated wet laid fine fiber media, thermoplastic resin separators, frame to media adhesive and high wet strength beverage board

1.2. Sizes shall be as noted on drawings or other suppor ting materials. 2.0 Construction

2.1. Filter media shall be of one continuous sheet of micro fine wet-laid glass mat filter media formed into uniformly spaced pleats and formed into a minipleat pack configuration.

2.2. Thermoplastic pleat separators shall provide uniform media separation to promote uniform airflow throughout the media.

2.3. The enclosing frame shall be of high wet strength beverage board which shall be bonded to the entire periphery of the media pack to prevent air bypass.

2.4. The frame shall include integral diagonal support members to ensure

shall be bridge-engineered to prevent filter racking and ensure filter configuration integrity.

2.5. Filter shall be bidirectional with regard to airflow.

3.0 Performance

3.1. The filter shall have a Minimum Efficiency Reporting Value of MERV $(11,13$, 14)" When evaluated under the guidelines of ASHRAE Standard 52.2. It shall have a MERV.A of $(11,13,14)^{*}$ when tested under Appendix $J$ of that standarc. 3.2 - Initial resistance to airflow shall be $\left(0.33^{\prime \prime}, 0.47^{\prime \prime}, 0.60 "\right)$ " w.g at an airflow of $500 \mathrm{fpm}$

3.3. Filter shall be listed by Underwriters Laboratories as UL 900 .

3.4. Manufacturer shall provide evidence of facility certification to ISO $9001: 2000$

3.5. The filter shall be capable of withstanding 5.0" w.g. without failure of the media pack.

Supporting Data - Provide ASHRAE product test report per ASHRAE Standard 52.2,

Product shall be Camfil Farr Opti-Pac or approved equal. Items in parentheses () require selection.

For detailed specifications please consult your local Camfil Farr Distributor or Representative or uww.camfilfarr.con.

Camfil Farr has a policy of uninterrupted research, development and product improvement. We reserve the right to change designs and specifications without notice.

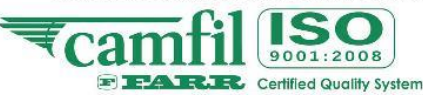




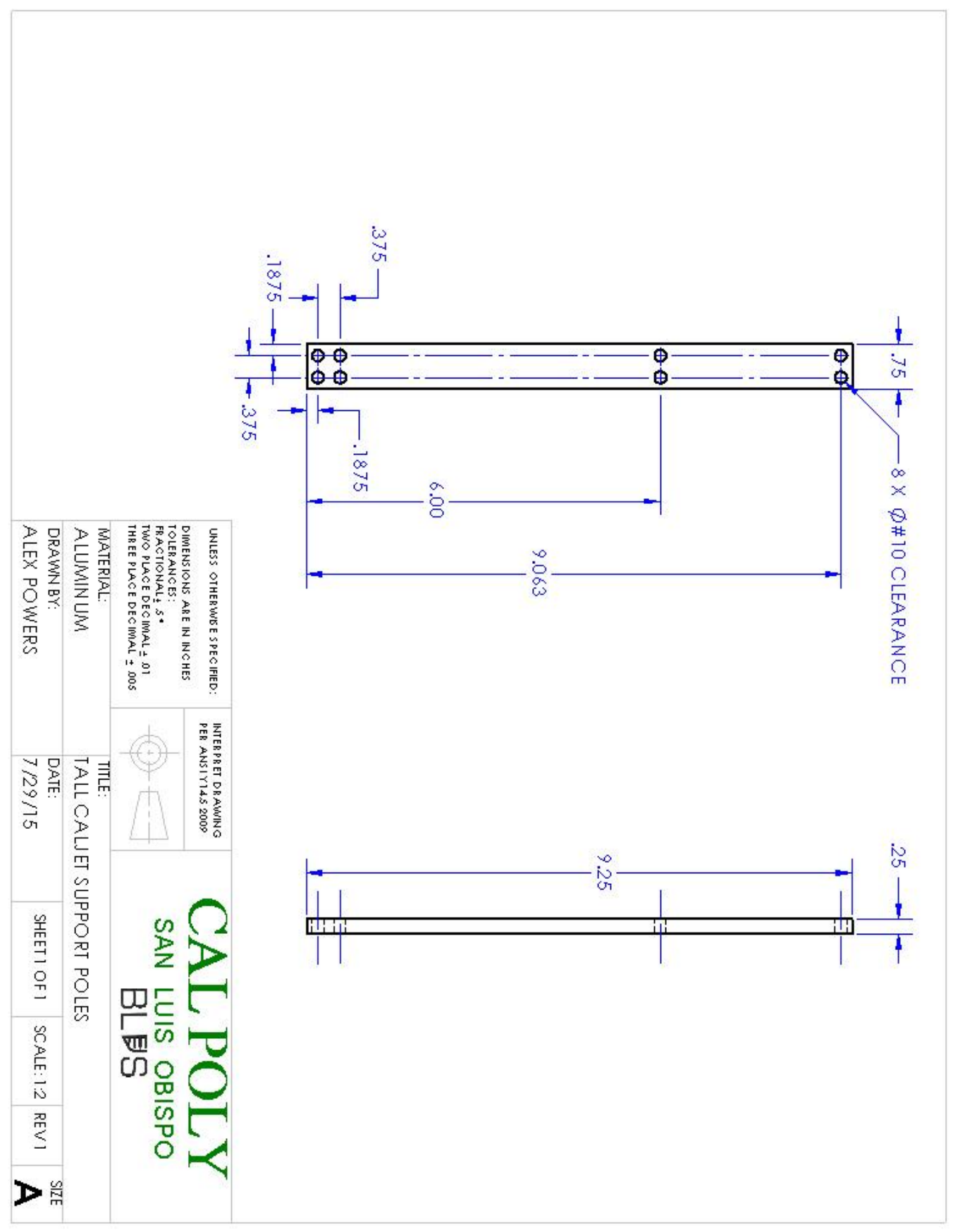




\section{APPENDIX C. LABVIEW FRONT PANELS}

Front panel used for boundary layer measurements:

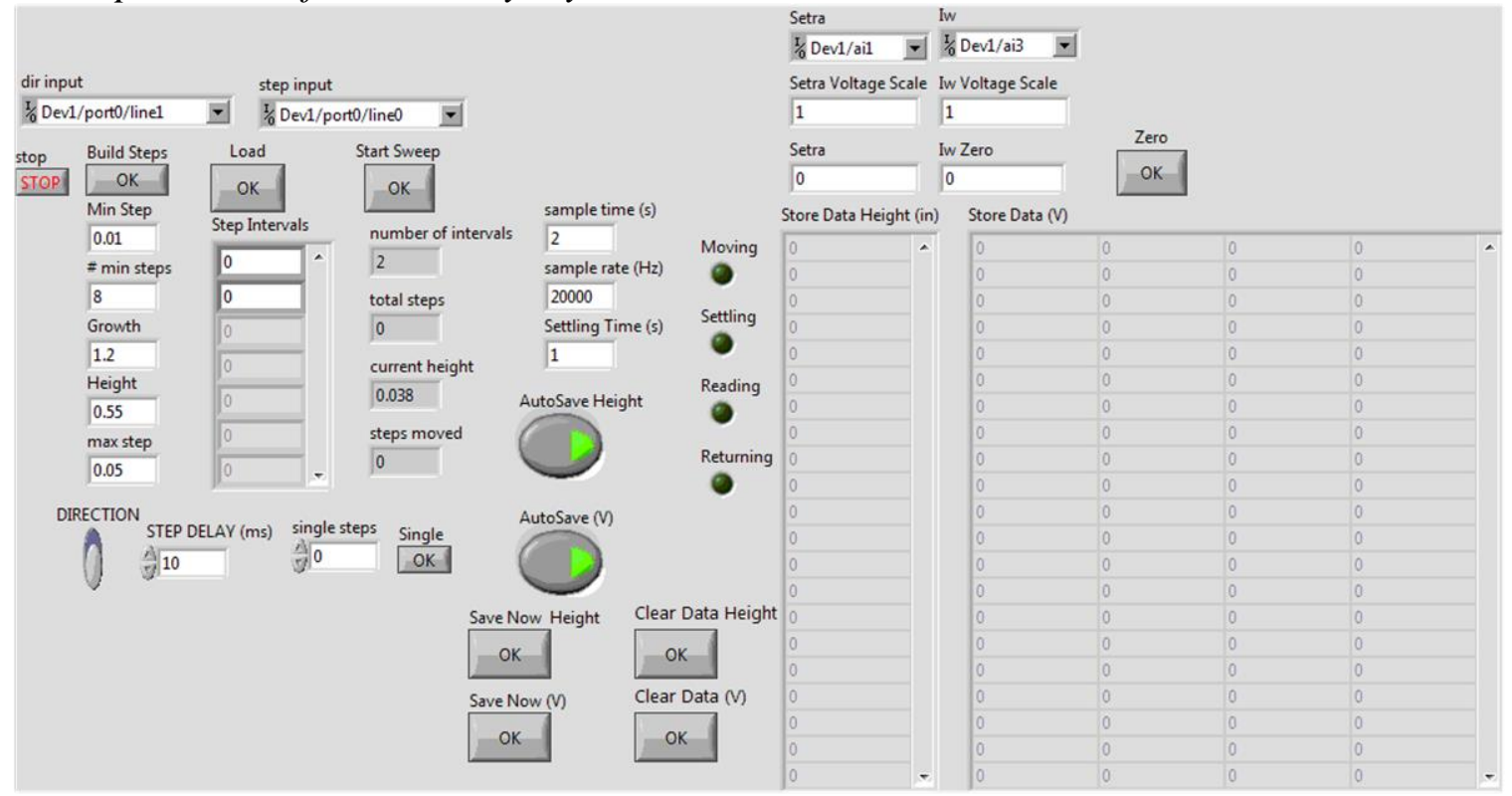

Front panel used for jet centerline measurements:

\begin{tabular}{|c|c|c|c|c|c|c|c|c|c|}
\hline Iw & \multirow{3}{*}{$\begin{array}{l}\text { Zero } \\
\text { OK }\end{array}$} & \multirow{3}{*}{$\begin{array}{l}\text { Read } \\
\text { OK }\end{array}$} & \multicolumn{7}{|c|}{ Store Data(V) } \\
\hline \multirow[t]{2}{*}{ I/0 Dev1/ai3 $=$} & & & 0 & 0 & 0 & 0 & 0 & 0 & A \\
\hline & & & 0 & 0 & 0 & 0 & 0 & 0 & \\
\hline \multirow[b]{2}{*}{ Iw Voltage Scale } & \multirow{2}{*}{\multicolumn{2}{|c|}{ sample rate $(\mathrm{Hz})$}} & 0 & 0 & 0 & 0 & 0 & 0 & \\
\hline & & & 0 & 0 & 0 & 0 & 0 & 0 & \\
\hline 1 & \multicolumn{2}{|c|}{20000} & 0 & 0 & 0 & 0 & 0 & 0 & \\
\hline Iw Zero & \multicolumn{2}{|c|}{ sample time (s) } & 0 & 0 & 0 & 0 & 0 & 0 & \\
\hline \multirow[t]{16}{*}{0} & \multirow[t]{3}{*}{5} & & 0 & 0 & 0 & 0 & 0 & 0 & \\
\hline & & & 0 & 0 & 0 & 0 & 0 & 0 & \\
\hline & & & 0 & 0 & 0 & 0 & 0 & 0 & \\
\hline & \multicolumn{2}{|c|}{ Save Now } & 0 & 0 & 0 & 0 & 0 & 0 & \\
\hline & \multirow{2}{*}{ OK } & & 0 & 0 & 0 & 0 & 0 & 0 & \\
\hline & & & 0 & 0 & 0 & 0 & 0 & 0 & $\equiv$ \\
\hline & \multirow{2}{*}{\multicolumn{2}{|c|}{ Clear Data }} & 0 & 0 & 0 & 0 & 0 & 0 & \\
\hline & & & 0 & 0 & 0 & 0 & 0 & 0 & \\
\hline & \multirow[t]{3}{*}{ OK } & & 0 & 0 & 0 & 0 & 0 & 0 & \\
\hline & & & 0 & 0 & 0 & 0 & 0 & 0 & \\
\hline & & & 0 & 0 & 0 & 0 & 0 & 0 & \\
\hline & \multirow{5}{*}{ STOF } & & 0 & 0 & 0 & 0 & 0 & 0 & \\
\hline & & & 0 & 0 & 0 & 0 & 0 & 0 & \\
\hline & & & 0 & 0 & 0 & 0 & 0 & 0 & \\
\hline & & & 0 & 0 & 0 & 0 & 0 & 0 & \\
\hline & & & 0 & 0 & 0 & 0 & 0 & 0 & 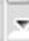 \\
\hline
\end{tabular}


Front panel used for calibrations:

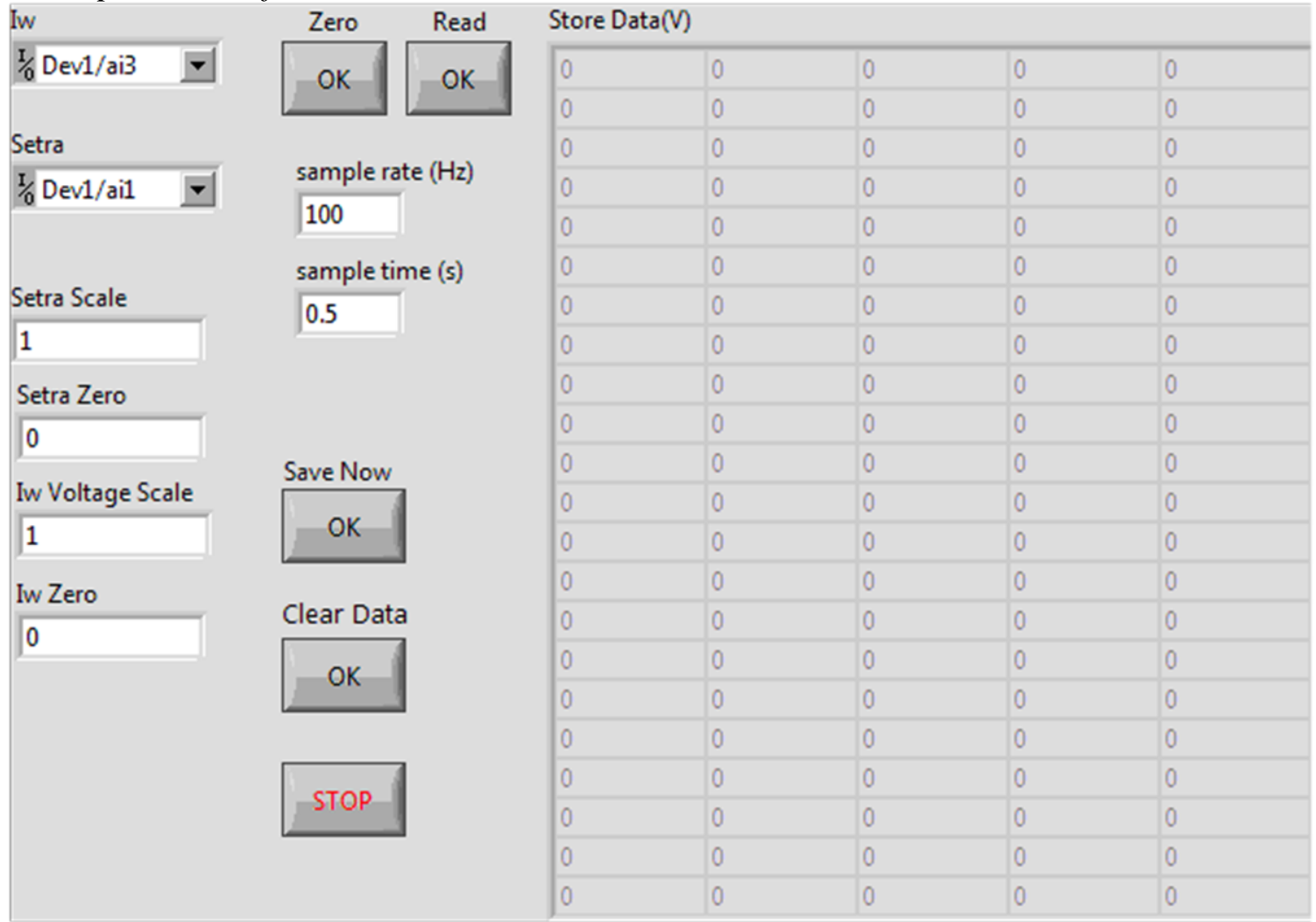




\section{APPENDIX D. UNCERTAINTY ANALYSIS FOR BOUNDARY LAYER ORIGIN}

This appendix shows uncertainty analysis and a sample calculation corresponding to the determination of the starting height of a sensor being used to make measurements in a boundary layer over a flat plate. By using an optical microscope to get a picture of the sensor and a scale of known thickness $0.038 \pm 0.0005$ inches, the distance of the sensor from the plate can be calculated with an approximate confidence interval by comparing the number of pixels between the sensor and its reflection to the number of pixels between the top of the scale and the bottom of its reflection (a known distance) and dividing by two. An uncertainty in counting pixels was established as \pm 2.5 pixels at each edge due to blurriness.

The following equations were used to determine the uncertainty in entirety:

- Sensitivities calculated as: $S_{x_{i}}=C\left(x_{i}+u_{x_{i}}\right)-C\left(x_{i}\right) \approx \frac{\partial C}{\partial x_{i}} u_{x_{i}}$

- Total uncertainty calculated as: $u_{c}=\sqrt{\sum S_{i}^{2}}$

- If the number of pixels per inch is $x=\frac{\text { inches }}{\text { pixel }}=\frac{i}{p}$, then the uncertainty in $x$ can be calculated as $U_{x}=\left[\left(\frac{d x}{d i} U_{i}\right)^{2}+\left(\frac{d x}{d p} U_{p}\right)^{2}\right]^{\frac{1}{2}}=\left[\left(\frac{1}{p} U_{i}\right)^{2}+\left(\frac{-i}{p^{2}} U_{p}\right)^{2}\right]^{\frac{1}{2}}$

The known reference distance (twice the scale thickness) is always $0.076 \pm 0.001$ inches and for a sample measurement, the counted number of pixels was $95 \pm 5$ pixels. Therefore, $i=0.076, p=95, U_{i}=0.001$, and $U_{p}=5$, and $x=0.0008 \pm 0.000043 \frac{\text { inches }}{\text { pixel }}$. There were 70 pixels counted between the sensor and its reflection, so this results in $0.056 \pm 0.003$ inches. Dividing by two to get the distance from the plate, we arrive at $\mathbf{0 . 0 2 8} \pm \mathbf{0 . 0 0 1 5}$ inches for the starting location. 


\section{APPENDIX E. UPDATED THERMAL ELECTRICAL MODEL (EES} CODE)

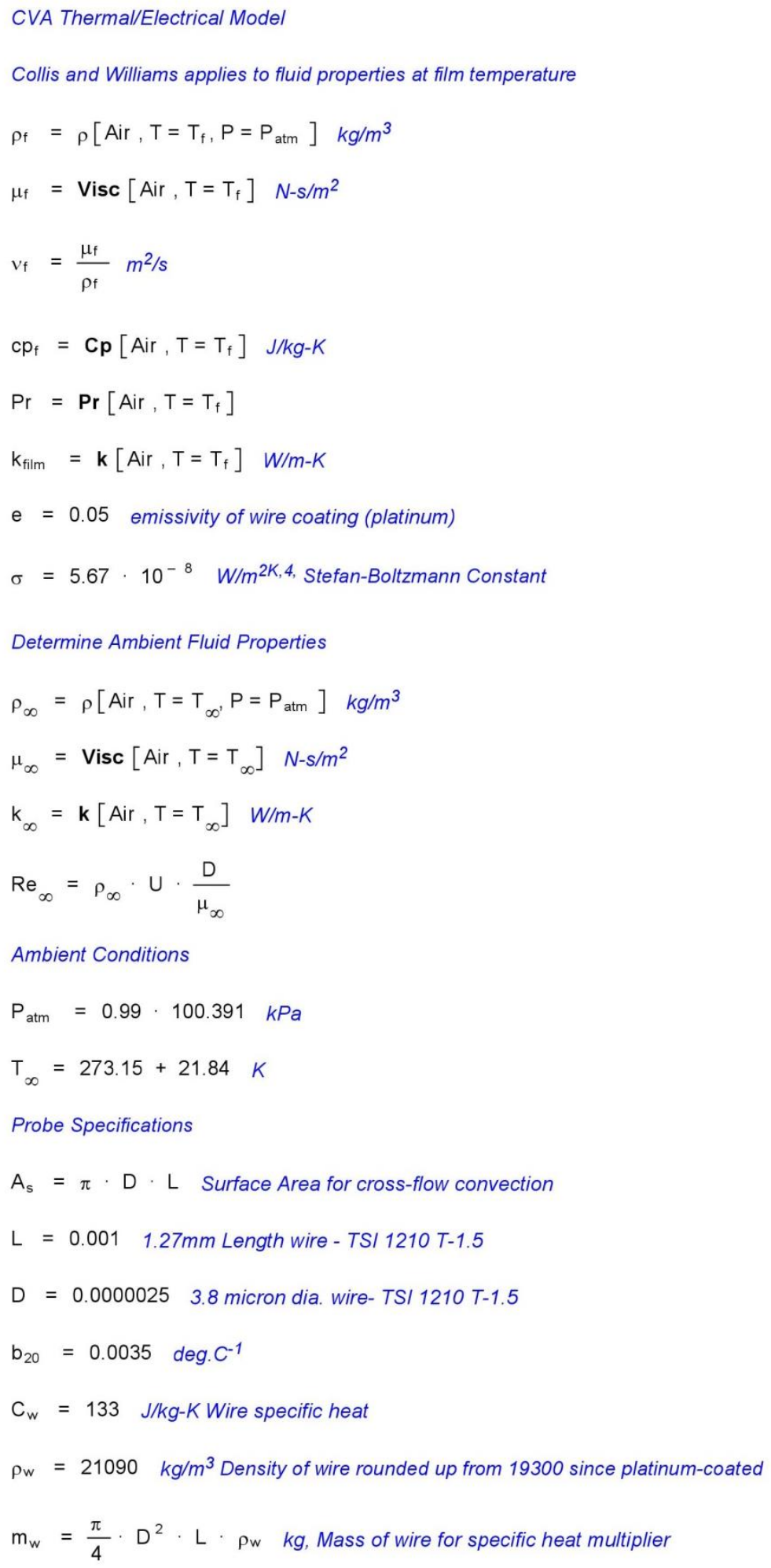


$T_{f}=\frac{T_{w}+T_{\infty}}{2} K$

$T_{\text {weel }}=T_{w}-273.15[\mathrm{~K}]$ Temperature output in Celsius for display purposes

$U=22 \mathrm{~m} / \mathrm{s}$, Flow Velocity

Thermal Equilibrium

$\mathrm{V}_{\mathrm{w}}=\mathrm{I}_{\mathrm{w}} \cdot \mathrm{R}_{\mathrm{w}} \mathrm{V}$

$P_{w}=I_{w} \cdot V_{w} \quad W$

$\mathrm{P}_{\mathrm{w}, \text { conv }}=\mathrm{h} \cdot \mathrm{A}_{\mathrm{s}} \cdot\left[\mathrm{T}_{\mathrm{w}}-\mathrm{T}_{\infty}\right] \mathrm{W}$, Cylinder in cross-flow convection

$\mathrm{P}_{\mathrm{w}, \mathrm{rad}}=\mathrm{e} \cdot \sigma \cdot \mathrm{A}_{\mathrm{s}} \cdot\left[\mathrm{T}_{\mathrm{w}}{ }^{4}-\mathrm{T}_{\infty}{ }^{4}\right] \mathrm{W}$, Cylinder grey body radiation

$\mathrm{P}_{\mathrm{w}}=\mathrm{P}_{\mathrm{w}, \text { conv }}+\mathrm{P}_{\mathrm{w}, \mathrm{rad}}$ W, Cylinder heat transfer

Circuit Properties

$\mathrm{R}_{2}=50 \mathrm{Ohms}$

$\mathrm{R}_{\mathrm{F}}=1000$ Ohms

$\mathrm{R}_{\mathrm{P}}=0.16$ Ohms, Internal Probe Resistance

$\mathrm{R}_{\mathrm{C}}=0.34 \quad 0.11+0.02 \quad$ Ohms, Cable and ProbeSupport Resistance

$\mathrm{R}_{\mathrm{L}}=2$ Ohms, Cable Lead Resistance

$\mathrm{V}_{\text {wotal }}=0.54 \mathrm{~V}$, Total Set-Point Across Cable Containing Probe

Resistance Relations

$R_{w}=R_{\infty} \cdot\left[1+b_{20} \cdot\left(T_{w}-T_{\infty}\right)\right]$ Probe Resistance Assuming Linear Temperature Dependent

$\mathrm{R}_{\infty}=4.98$ Ohms, Measured Cold Resistance At 20 deg. C

$\mathrm{OHR}=\frac{\mathrm{R}_{\mathrm{w}}}{\mathrm{R}_{\infty}}$

$a_{w}=\frac{R_{w}-R_{\infty}}{R_{\infty}}$

Nusselt Number from Collis Williams Correlation

Scaling Factor used to adjust the heat transfer. Collis and Williams underpredicts this Nu particular hot-wire by $30 \%$

$\mathrm{SF}=1$

Nus $=S F \cdot\left[A+B \cdot R e_{\text {film }}{ }^{n}\right] \cdot\left[\frac{T_{f}}{T_{\infty}}\right]^{0.17}$

$A=0.48$ 
$B=0.68$
$n=0.45$

Nus $=h \cdot \frac{D}{k_{\text {film }}}$

$\mathrm{Re}_{\text {film }}=\rho_{\mathrm{f}} \cdot U \cdot \frac{\mathrm{D}}{\mu_{\mathrm{f}}}$ Collis Williams Coefficients Valid for $0.02<R e<44$

Output Parameters

$V_{\circ}=\left[1+\frac{R_{2}}{R_{F}}+\frac{R_{2}}{R_{\text {wotal }}}\right] \cdot \frac{V_{\text {wotal }}}{2} V$

$\mathrm{R}_{\text {wotal }}=\mathrm{R}_{\mathrm{w}}+\mathrm{R}_{\mathrm{C}}+\mathrm{R}_{\mathrm{P}}$ Ohms

$V_{\text {wotal }}=I_{w} \cdot R_{\text {wotal }} V$

$\mathrm{I}_{\mathrm{wmA}}=\mathrm{I}_{\mathrm{w}} \cdot 1000[\operatorname{dim} / \mathrm{A}] \mathrm{mA}$

$\mathrm{I}_{\text {wolts }}=\frac{\mathrm{I}_{\mathrm{wmA}}}{40[\operatorname{dim} / \mathrm{N}]} \mathrm{V}$, Actual CVA outputs Voltage with $40 \mathrm{~mA} / \mathrm{Volt}$

PDR $=\frac{\mathrm{P}_{\mathrm{w}}}{\mathrm{R}_{\mathrm{w}}-\mathrm{R}_{\infty}}$ W/ohm, Temperature Corrected Calibration Quantity

Calculated Time Constant and Frequency Response

$M_{c c a}=C_{w} \cdot m_{w} \cdot\left[\frac{R_{w}-R_{\infty}}{b_{20} \cdot I_{w}{ }^{2} \cdot R_{\infty}{ }^{2}}\right]$ sec

$M_{c v a}=\frac{M_{c c a}}{1+2 \cdot a_{w}} \sec$

$\mathrm{M}_{\mathrm{cvams}}=\mathrm{M}_{\mathrm{cva}} \cdot 1000[\mathrm{~ms} / \mathrm{s}] \mathrm{ms}$

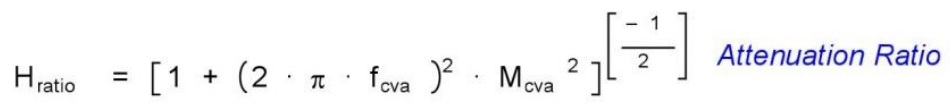

$\mathrm{H}_{\text {ratio }}=0.5$ Calculate Frequency at Half Amplitude

Corrected Time Constant and Frequency Response for Lead Resistance Effects from Comte-Bellot Article

$L M=\frac{1+\frac{R_{L}}{R_{\infty} \cdot\left[1+a_{w}\right]}}{1+\frac{R_{L}}{R_{\infty} \cdot\left[1+a_{w}\right] \cdot\left[1+2 \cdot a_{w}\right]}}$ Time constant correction factor for lead resistance effects

$M_{\mathrm{cva}, \mathrm{lc}}=\mathrm{LM} \cdot \mathrm{M}_{\mathrm{cva}} \quad \mathrm{sec}$, Corrected time constant for lead resistance effects from Comte article

$\mathrm{M}_{\mathrm{cva}, \mathrm{lc}, \mathrm{ms}}=\mathrm{M}_{\mathrm{cva}, \mathrm{lc}} \cdot 1000[\mathrm{~ms} / \mathrm{s}] \mathrm{ms}$ 


$$
\begin{aligned}
& H_{\text {ratio,lc }}=\left[1+\left(2 \cdot \pi \cdot f_{\text {cva,lc }}\right)^{2} \cdot M_{\text {cva,lc }}{ }^{2}\right]^{\left[\frac{-1}{2}\right] \text { Corrected Attenuation Ratio }} \\
& H_{\text {ratio, } l c}=0.5 \text { Calculate Corrected Frequency at Half Amplitude }
\end{aligned}
$$




\section{APPENDIX F. RADIATION HEAT TRANSFER MODEL AND CALCULATIONS}

To confirm that radiation heat transfer is negligible compared to the forced convection, the heat transfer model and EES thermal electrical model were updated. A sample calculation was completed to explicitly show that radiation contributes a negligible portion of the heat transfer. The model and sample calculation are shown in this appendix.

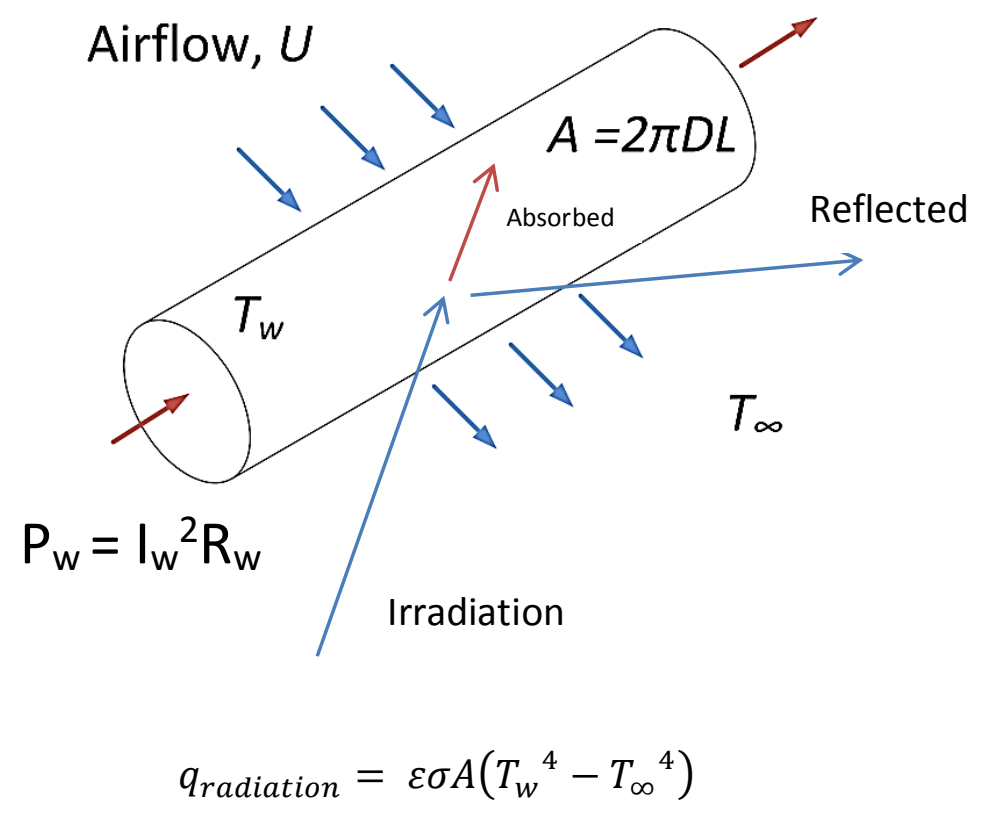

Thermal equation without radiation:

$$
\begin{gathered}
V_{w}=I_{w} R_{w} \\
P_{w}=I_{w} V_{w}=I_{w}{ }^{2} R_{w} \\
q_{\text {convection }}=h A\left(T_{w}-T_{\infty}\right) \\
I_{w}{ }^{2} R_{w}=h A\left(T_{w}-T_{\infty}\right)
\end{gathered}
$$

Thermal equation with radiation:

$$
I_{w}{ }^{2} R_{w}=h A\left(T_{w}-T_{\infty}\right)+\varepsilon \sigma A\left(T_{w}{ }^{4}-T_{\infty}{ }^{4}\right)
$$


So, assuming atmospheric conditions $\left(T_{\infty}=20^{\circ} \mathrm{C}\right.$ and $\left.P_{\infty}=101.325 \mathrm{kPa}\right)$, a conservatively high value for emissivity $(\varepsilon=0.9)$, a conservative value for the sensor temperature (assume operated at $O H R=2$ ) with cold resistance $\mathrm{R}_{\infty}=6 \mathrm{ohms}$, and using $D=3.8 \mu \mathrm{m}, L=1.27$ $\mathrm{mm}, \sigma=5.67 \mathrm{e}-8 \frac{\mathrm{W}}{\mathrm{m}^{2} \mathrm{~K}^{4}}, \alpha=0.0042{ }^{\circ} \mathrm{C}^{-1}$, and film properties $\rho_{f}=0.865 \frac{\mathrm{kg}}{\mathrm{m}^{3}}, \mu_{f}=2.341 \mathrm{e}-5$ $\frac{\mathrm{kg}}{\mathrm{ms}}$, and $k_{f}=0.0322 \frac{\mathrm{W}}{\mathrm{m}^{2} \mathrm{~K}}$, the following equations can be used to calculate the heat transfer due to convection and the heat transfer due to radiation:

Linear temperature dependence:

$$
\frac{R_{w}}{R_{\infty}}=1+\propto\left(T_{w}-T_{\infty}\right)
$$

Nusselt Number with Collis and Williams Correlation:

$$
\begin{gathered}
N_{u}=\left(0.24+0.56 \operatorname{Re}_{f}^{0.45}\right)\left(\frac{T_{f}}{T_{\infty}}\right)^{0.17} \\
R e_{f}=\frac{\rho_{f} U D}{\mu_{f}}
\end{gathered}
$$

Heat Transfer Coefficient:

$$
h=\frac{N_{u} k_{f}}{D}
$$

Using the equations above for the heat transfer, we arrive at $q_{\text {radiation }}=0.0000558 \mathrm{~W}$, $q_{\text {convection }}=0.0288 \mathrm{~W}$, and the total heat transfer dissipated, $I_{w}{ }^{2} R_{w}=0.0288558 \mathrm{~W}$. So the heat transfer due to radiation is a mere $\mathbf{0 . 2 \%}$ of the total heat transfer. Radiation heat transfer was added to the thermal electrical model in the EES code as seen in Appendix E; however, it has now been proven to have a negligible effect on the model predictions. 